\title{
Ação educativa na Atenção Básica à Saúde de pessoas com diabetes mellitus e hipertensão arterial: avaliação e qualificação de estratégias com ênfase na educação nutricional.
}

Ana Maria Bartels Rezende

Tese apresentada ao Programa de PósGraduação em Nutrição em Saúde Pública para obtenção do título de Doutor em Nutrição em Saúde Pública.

Área de Concentração: Nutrição em Saúde Pública.

Orientadora: Profa. Dra. Ana Maria Cervato-Mancuso

São Paulo 
É expressamente proibida a comercialização desse documento, tanto na sua forma impressa como eletrônica. Sua reprodução total ou parcial é permitida exclusivamente para fins acadêmicos e científicos, desde que na reprodução figure a identificação do autor, título, instituição e ano da tese. 
"Conhecer é tarefa de sujeitos, não de objetos. E é como sujeito e somente enquanto sujeito, que o homem pode realmente conhecer." 
Ao marido e companheiro Oscar, pela inesgotável paciência e sabedoria que redimem e orientam a minha vida,

Dedico esta tese e o meu amor! 


\section{AGRADECIMENTOS}

\section{A Deus,}

Por me colocar diante de tantas oportunidades, conceder-me saúde e a graça da família e dos amigos.

\section{À Ana Maria Cervato-Mancuso,}

Pela a orientação sensível, compromissada, dialógica e competente. Não haveria outra, diante de tantas “Anas”, com tamanha dedicação e persistência.

\section{À Elaine Cristina Viana, Mariuza Arlete Gagno, Angela Camila Ghizi, June Ferreira Maia, Rosana Vargas de Oliveira e Susete Dresch, \\ Pela amizade, apoio e convivência harmoniosa, sem os quais talvez não fosse possível concretizar o projeto do doutorado.}

\section{À minha filha Barbara,}

Pela ajuda na transcrição dos discursos e, principalmente, pela compreensão e colaboração no percurso final do preparo da tese.

\section{Ao professor Marcelo Sipione e às alunas Barbara Monteiro, Christina Helal e Jislaine Barbosa, \\ Pela colaboração na coleta de dados dos grupos focais e estímulo para a conclusão do estudo.}

\section{Ao Centro Universitário Vila Velha - UVV,}

Pela compreensão nos momentos de ausência das atividades de trabalho.

À coordenação, aos profissionais de saúde da unidade de Maruípe e aos sujeitos-pacientes participantes da pesquisa,

Pela colaboração fundamental. 


\section{APRESENTAÇÃO}

Esta tese encontra-se estruturada em três seções. A primeira inclui os seguintes elementos: Introdução na qual se contextualiza o objeto de investigação; apresentam-se as definições, conceitos e bases teóricas utilizadas no desenvolvimento do estudo e como subsidio para análise dos resultados e justifica-se a sua realização. Objetivos gerais e específicos. Métodos que inclui a tipologia, a caracterização do cenário e da população do estudo; o delineamento da coleta de dados com descrição das técnicas e instrumentos utilizados nas três etapas da pesquisa; o método de processamento e análise dos resultados.

A segunda seção refere-se aos Resultados e Discussão da pesquisa. Os resultados da primeira e da segunda etapa são apresentados em três manuscritos, no formato prévio para submissão à publicação. Os resultados da terceira etapa são apresentados em formato tradicional.

A terceira seção trás as Conclusões sobre o conjunto da obra e as considerações finais e contribuições do estudo para a área da Saúde Pública.

As Referências para as citações de cada manuscrito são apresentadas ao final deles e as das demais seções ao final da Obra.

Ao final encontram-se os anexos e a primeira página do Currículo Lattes da autora e sua orientadora. 


\section{RESUMO}

\section{Rezende A.M.B. Ação educativa na atenção básica à saúde de pessoas com} diabetes mellitus e hipertensão arterial: avaliação e qualificação de estratégias com ênfase na educação nutricional. [Tese de Doutorado]. São Paulo: Faculdade de Saúde Pública. Universidade de São Paulo, 2011.

Introdução: As ações educativas são práticas inerentes ao projeto assistencial de saúde em todos os níveis de atenção, na perspectiva de empoderamento e emancipação das pessoas para atuar nos aspectos fundamentais de sua vida, como a alimentação. O diabetes mellitus e a hipertensão arterial estão entre os fatores de risco modificáveis para as doenças cardiovasculares, cujo controle associado a mudanças de estilo de vida pode ser estimulado no âmbito da Atenção Básica à Saúde, minimizando a morbimortalidade por essas doenças e o seu impacto na saúde pública. Objetivo: Analisar o processo educativo com ênfase na educação alimentar e nutricional para pessoas com diabetes mellitus e hipertensão arterial no âmbito da Atenção Básica à Saúde. Métodos: Estudo analítico-descritivo de natureza qualitativa, realizado entre profissionais de saúde e pessoas com diabetes mellitus e/ou hipertensão arterial acompanhadas em Unidade de Estratégia de Saúde da Família do município de Vitória- ES. Procedeu-se a coleta de depoimentos por meio de entrevistas semiestruturadas. Aplicou-se a técnica do Discurso do Sujeito Coletivo para a análise das percepções sobre os espaços, os sujeitos, os resultados e os desafios das ações educativas na promoção de práticas de vida e alimentares adequadas. As ideias centrais destacadas no material discursivo foram utilizadas como substrato para a qualificação dessas ações, num processo compartilhado com os profissionais de saúde, em que se empregou a técnica dos grupos focais. Resultados: Foram entrevistados 27 profissionais, entre médicos, enfermeiros, orientador físico, auxiliares de enfermagem e agentes comunitários de saúde, bem como 22 usuários-pacientes. Na percepção dos profissionais de saúde, os grupos constituem o espaço mais eficaz para a prática 
educativa. Porém, a preferência do usuário é pela ação individualizada e medicocentrada que ocorre nas consultas. A visão mais frequente sobre os resultados das ações educativas foi que estas contribuem para mudanças apenas para parte das pessoas assistidas, sendo a rebeldia do paciente e os fatores de insegurança alimentar e nutricional relacionados ao acesso aos alimentos, à baixa escolaridade e ao envelhecimento dependente da população, destacados como dificuldades concretas para mudança das práticas alimentares. Quanto aos desafios atribuídos à estrutura e aos resultados do processo educativo, a percepção foi que este não está suficientemente sedimentado entre os profissionais de saúde, que persistem com práticas normativo-prescritivas em suas condutas, o que dificulta o seguimento do plano terapêutico. No discurso dos usuários, evidenciaram-se, como maior dificuldade para a adesão ao tratamento e à mudança de hábitos alimentares, as prescrições restritivas ou proibitivas. $\mathrm{O}$ processo de qualificação das práticas educativas apontou a necessidade de fortalecimento das ações educativas na prática assistencial; instituição de mecanismos de avaliação dos seus impactos; centralidade do sujeito no planejamento das ações e na definição do plano terapêutico; garantia da interdisciplinaridade e integralidade das ações; valorização do planejamento e da organização do trabalho educativo; capacitação permanente da equipe de saúde. Conclusões: Ações educativas para capacitação das pessoas com diabetes mellitus e hipertensão arterial, no âmbito da Atenção Básica à Sáude, estão ainda estruturadas no modelo assistencial hegemônico, de abordagem predominantemente higienista, que culpabiliza as pessoas por seus problemas de saúde e que desconsidera a participação da comunidade nos processos educativos a ela dirigidos. A Estratégia de Saúde da Família se coloca como campo potencialmente fértil para a qualificação e reorientação das práticas educativas em saúde, o que se recomenda seja feito à luz das diretrizes das Políticas Públicas de Atenção Básica e de Promoção da Saúde.

Descritores: Educação em Saúde; Educação Alimentar e Nutricional; Atenção Primária à Saúde; Diabetes Mellitus; Hipertensão; Pesquisa Qualitativa. 


\begin{abstract}
Rezende A.M.B. Educational action in basic health care of people with diabetes mellitus and hypertension: evaluation and qualification of strategies emphasizing nutrition education. [Doctoral Thesis] São Paulo: Public Health School. University of São Paulo, 2011.
\end{abstract}

Introduction: Educational action is a type of practice that is inherent to all levels of health care from the perspective of empowering and emancipating people to act in fundamental aspects of their lives, such as eating. Diabetes mellitus and hypertension are among the modifiable risk factors of cardiovascular diseases whose control, associated to lifestyle changes, can be stimulated in the Basic Health Care sphere, minimizing morbidity and mortality caused by these diseases, as well as their impact on public health. Objective: Analyze the education process focusing on eating and nutrition education for people with diabetes mellitus and hypertension in the Basic Health Care sphere. Methods: It is an analytical, descriptive, and qualitative study carried out among health care professionals and people with diabetes mellitus and/or hypertension cared for at a family health strategy unit in the city of Vitória, ES, Brazil. Their testimony was collected through semistructured interviews. The Collective Subject Discourse technique was employed for analyzing their perception of space, subjects, results and challenges of the educational actions in promoting appropriate life and eating practices. The central ideas standing out in their discourse were used as substrate for qualifying these actions in a process shared with health care professionals, in which the focus group technique was adopted. Results: Twenty-seven (27) professionals (doctors, nurses, physical activity advisor, auxiliary nurses, and community health care agents) were interviewed, as well as 22 patient-users. In these health care professionals' perception, the groups represent the most effective space for educational practice. However, the user prefers the individualized, doctor-centered practice taking place during consultations. The most frequent 
view about the results of educational actions was that they contribute to changing just part of the assisted people. Patients' resistance to changes and the nutrition and food insecurity related to access to food; poor educational background; and population's dependent aging are highlighted as concrete difficulties in changing eating practices. Regarding the challenges attributed to structure and to the results of the educational process, the study found that they are not sufficiently spread among health care professionals, that the normative-prescriptive practices still guide their conduct, which hinders the subsequent therapies. From the users' discourse, we identified the restrictive and prohibitive prescriptions as the greatest difficulty in complying with treatment and changing eating habits. The process of qualification of educational practices pointed out the need of strengthening educational actions in health care practice; instituting mechanisms to assess its impact; centralizing action planning and therapy on the subject; ensuring interdisciplinarity and integrality of actions; valuing planning and organization of educational work; and permanently qualifying the health care team. Conclusions: Educational actions for recovering individuals with diabetes mellitus and hypertension in the Basic Health Care sphere are structured within a hegemonic health care model, with a predominantly hygienist approach, which blames individuals for their health problems; which disregards the participation of the community in the educational processes addressing them. The family health strategy is shown as a potentially fertile field for qualifying and reorienting educational health care practices, which should ideally be done in compliance with the guidelines of basic health care and health promotion public policies.

Keywords: Health Care Education; Eating and Nutrition Education; Primary Health Care; Diabetes Mellitus, Hypertension; Qualitative Research. 


\section{INDICE}

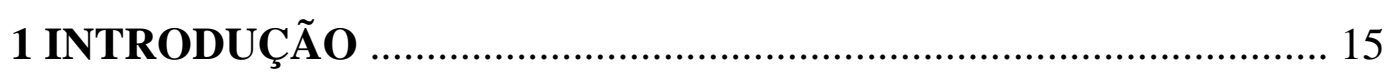

1.2 EDUCAÇÃO EM SAÚDE E EDUCAÇÃO NUTRICIONAL: DEFINIÇÕES E PERSPECTIVAS TEÓRICAS .......................... 24

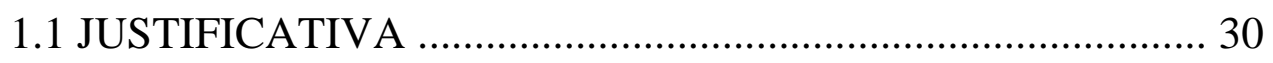

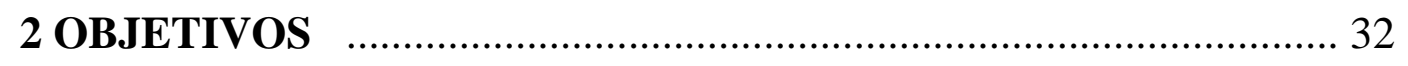

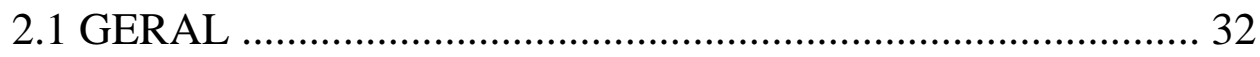

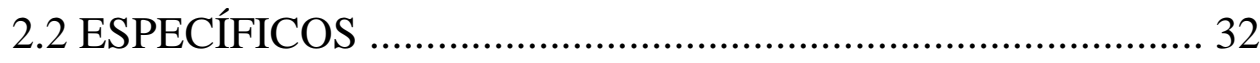

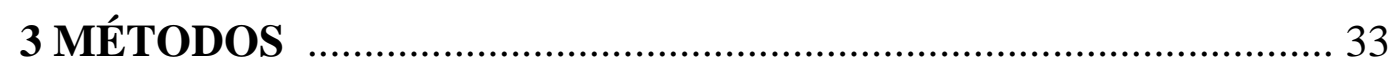

3.1 CARACTERIZAÇÃO DA PESQUISA …………………….... 33

3.2 O CENÁRIO DO ESTUDO ................................................... 33

3.2.1 A Escolha da UBS do Estudo ........................................ 36

3.2.1.1 A USF do território de Maruípe …………………….... 37

3.3 A POPULAÇÃO E OS SUJEITOS ………………………….... 39

3.3.1 A Escolha dos Sujeitos ………………………............... 40

3.4 AS ETAPAS DE CAMPO E A COLETA DOS DEPOIMENTOS 41

3.4.1 Primeira Etapa: Identificação das estratégias de intervenção educativa, implementadas no âmbito da ESF, para pessoas com DM e HA, na percepção dos profissionais de saúde. 41

3.4.2 Segunda Etapa: Identificação das estratégias de intervenção educativa, implementadas no âmbito da ESF, para pessoas com DM e HA, na percepção dos usuários. 42

3.4.3 Terceira Etapa: Qualificação das estratégias de intervenção nutricional educativa. 
3.5 A ORGANIZAÇÃO DOS DADOS E O PROCESSAMENTO 44 3.5.1 Os Dados das Entrevistas com Profissionais e Usuários 44 3.5.2 Os Depoimentos nos Grupos Focais ................................ 46

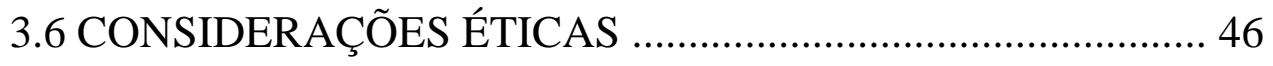

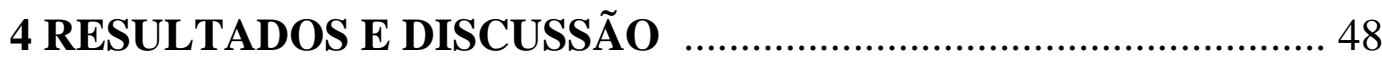

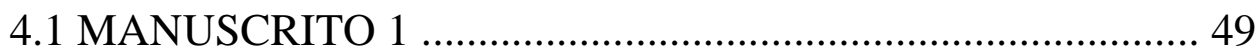

- Ação educativa para pessoas com diabetes mellitus e hipertensão arterial: reflexões sobre a educação em saúde na Estratégia de Saúde da Família.

4.2 MANUSCRITO 2 95

- Dificuldades e desafios da ação educativa com foco na educação nutricional de pessoas com diabetes mellitus e hipertensão arterial: a visão dos profissionais da Estratégia de Saúde da Família.

4.3 MANUSCRITO 3 138

- Ação educativa na Atenção Básica à Saúde para pessoas com diabetes mellitus e hipertensão arterial: escutando os sujeitospacientes.

4.4 RESULTADOS E DISCUSSÃO DA TERCEIRA ETAPA ... 172

- Caminhos para a qualificação do processo educativo

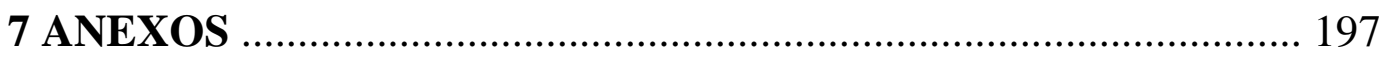

Anexo 1 Termo de Consentimento Livre e Esclarecido ........................ 198

Anexo 2 Discurso do Sujeito Coletivo- Manuscrito 1 ......................... 201

Anexo 3 Discurso do Sujeito Coletivo- Manuscrito 2 ……………..... 212

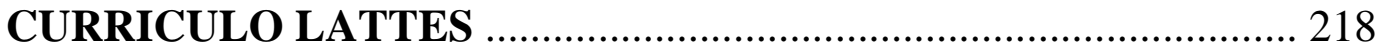




\section{LISTA DE SIGLAS}

Agentes comunitários de saúde (ACS)

Atenção Primária à Saúde (APS)

Centros de Referência de Assistência Social (CRAS)

Centros Municipais de Ensino Infantil (CEMEI's),

Comissão Intergestores Tripartite (CIT)

Comissões Intergestores Bipartite (CIBs)

Conhecimento-atitude-prática (CAP)

Diabetes mellitus (DM)

Direito Humano à Alimentação Adequada (DHAA).

Discurso do Sujeito Coletivo (DSC)

Doenças crônicas não transmissíveis (DCNT)

Doenças do aparelho circulatório (DAC)

Escolas Municipais de Ensino Fundamental (EMEF's)

Estratégia de Saúde da Família (ESF)

Expressões-chave (ECH)

Gerência de Educação em Saúde (GES)

Grupo de Apoio Terapêutico ao Tabagismo (GATT)

Health Belief Model (HBM)

Hipertensão arterial (HA)

Ideia central (IC)

Índice de Massa Corpora (IMC)

Instituto Brasileiro de Geografia e Estatística (IBGE)

Ministério da Saúde (MS)

Núcleo de Apoio à Saúde da Família (NASF)

Organização Mundial de Saúde (OMS)

Política Nacional de Alimentação e Nutrição (PNAN)

Política Nacional de Atenção à Saúde (PNAS)

Política Nacional de Atenção Básica (PNAB)

Política Nacional de Promoção à Saúde (PNPS) 
Programa de Agentes Comunitários de Saúde (PACS)

Programa de Saúde da Família (PSF)

Projetos Caminhando Juntos (CAJUN).

Secretaria de Atenção à Saúde (SAS)

Secretaria de Vigilância em Saúde (SVS)

Segurança Alimentar e Nutricional (SAN)

Serviço de Orientação ao Exercício (SOE)

Serviço Social da Indústria (SESI)

Sistema de Cadastro e Acompanhamento de Hipertensos e Diabéticos (Hiperdia/ SISHiperdia)

Sistema de Informação da Atenção Básica (SIAB)

Sistema de Segurança Alimentar e Nutricional (SISAN)

Sistema Único de Saúde (SUS)

Unidade de Saúde (US)

Unidade de Saúde da Família (USF)

Unidades básicas de saúde (UBS)

Universidade Federal do Espírito Santo (UFES) 


\section{INTRODUÇÃO}

Em menos de 40 anos, o Brasil passou de um perfil típico de mortalidade de uma população jovem para um quadro caracterizado por enfermidades complexas e onerosas, próprias das faixas etárias mais avançadas (GORDILHO et al., 2000), representadas principalmente pelas Doenças Crônicas não Transmissíveis (DCNT).

Entre as DCNT, as doenças do aparelho circulatório (DAC), em especial as coronarianas e o conjunto de morbidades geralmente associadas: dislipidemias, hipertensão arterial (HA), obesidade e diabetes mellitus (DM), constituem importante problema de saúde pública em todo o mundo (TURNER, 1980; ZIMMET et al., 1986; MARTINS et al., 1993; LESSA, 2004) e, nas últimas décadas, segundo registros oficiais, a primeira causa de morte no país (CHOR et al., 1995; BRASIL, 2005).

A HA, o DM e as dislipidemias são as principais condições de risco para essas doenças e encontram-se entre as dez primeiras causas de morte em vários países (YACH et al., 2004). Suas complicações mais frequentes - o infarto agudo do miocárdio, o acidente vascular cerebral, a insuficiência renal crônica, a insuficiência cardíaca, as amputações de membros inferiores e a cegueira definitiva - elevam o custo médico-social e atingem diretamente o Sistema Único de Saúde (SUS), em que são responsáveis por mais de um milhão de internações/ano, com um custo aproximado de 475 milhões de reais, sem considerar os gastos com procedimentos de alta complexidade (FLACK et al., 2002; MION et al., 2002; GARANTINI et al., 2004; BRASIL, 2005).

As modificações no estilo de vida e o controle de fatores de risco modificáveis, ou seja, aqueles sobre os quais podem atuar o paciente e a equipe de saúde, como dislipidemias, obesidade, HA, DM, tabagismo, sedentarismo, entre outros (Cunningham, apud COLOMBO e AGUILAR, 1997, p. 69), são considerados a base do tratamento e controle das doenças cardiovasculares (TURNER, 1980; GOLDMAN e COOK, 1984; ZIMMET et al.,1986; KRUMMEL, 1998; MINISTÉRIO DA SAÚDE, 2001) e demandam ações 
multidisciplinares em todos os níveis de atenção à saúde, prioritariamente na Atenção Básica.

Está bastante estabelecido que o comportamento alimentar, um dos principais elementos do estilo de vida, relaciona-se com alguns dos fatores de risco modificáveis já citados, principalmente com a obesidade - determinante importante da alta incidência de DAC em nosso meio. Estudos sobre a epidemia global de obesidade têm-se concentrado na identificação de fatores ambientais que a determinam (GORTMAKER et al., 1993; HILL e PETERS, 1998; EPSTEIN et al., 2000), indicando, nas últimas décadas, a predominância de um “ambiente obesogênico" nos países ocidentais ou com hábitos de vida ocidentalizados, em que práticas alimentares inadequadas, resultantes de maior acesso a alimentos de menor custo, palatáveis, práticos, mas de alta concentração energética, aliado a um modo de vida predominantemente sedentário, característico do estilo de vida moderno e urbano, favorecem a obesidade crescente (HILL et al., 2003; OLIVEIRA et al., 2003).

Especialmente em relação ao papel da dieta na prevenção e no controle das doenças, vários estudos têm enfatizado características dietéticas associadas com a redução e com o controle dos fatores de risco para as DAC. Podem ser citados o estudo de DANSINGER et al. (2005), que comparou os efeitos de quatro dietas populares na perda de peso e nos fatores de risco cardiovascular, encontrando resultados medianos, porém positivos; o estudo Dietary Approaches to Stop Hypertension (DASH), cujos resultados demonstraram que uma dieta rica em grãos integrais, oleaginosas, frutas e hortaliças e com baixo teor de lipídios saturados e totais reduziu significativamente a pressão arterial sistólica e a pressão arterial diastólica em hipertensos (APPEL et al., 1997), e o III National Health and Nutritional Examination Survey (NHANES III), que demonstrou que, nos Estados Unidos, variações regionais na pressão arterial estão associadas aos hábitos alimentares da população (HAJJAR e KOTCHEN, 2003).

Estudos em diferentes países têm demonstrado a importância de programas educativos para promover maior adesão ao tratamento, resultando em melhor controle da HA e/ou DM (AMBROSIO et al., 1988; GRUESSER et al., 1997; GONZALES et al., 1997; ARAUZ et al., 2001; CABRERA-PIVARAL et al., 
2001). Também no Brasil, embora em menor número de publicações e estudos com acompanhamento de curto prazo, têm-se demonstrado resultados favoráveis.

Na Costa Rica, na região de saúde de El Guarco, ARAUZ et al. (2001) empreenderam um programa de intervenção educativa comunitária sobre o DM tipo 2, direcionado para o nível primário de atenção. O programa foi elaborado com base num estudo qualitativo dos conhecimentos e práticas dos pacientes e dos profissionais de saúde quanto à prevenção e ao tratamento do diabetes e num levantamento sobre a disponibilidade de alimentos na comunidade. Foram desenvolvidos dois manuais, um para os profissionais de saúde e outro para os pacientes, além de estratégias comunitárias para dar sustentabilidade ao processo educativo. Após a capacitação dos profissionais de saúde, que capacitaram a comunidade, observou-se que os pacientes apresentaram queda na glicemia, de $189 \pm 79 \mathrm{mg} / \mathrm{dl}$ para $157 \pm 48 \mathrm{mg} / \mathrm{dl}(\mathrm{p}=0,03)$, e na hemoglobina glicosilada, de

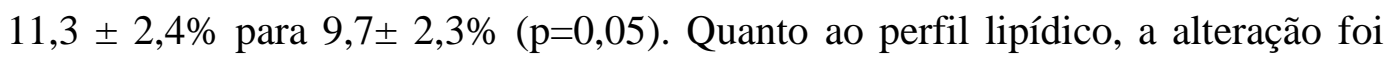
significativa para a diminuição de triglicerídeos $(\mathrm{p}=0,04)$ e não houve alteração significativa do peso corporal. O nível primário de atenção à saúde foi considerado ideal para a execução de programas educativos para tratamento, prevenção e detecção precoce de DM (ARAUZ et al., 2001).

MILLER et al. (2002), para avaliarem uma intervenção para melhorar o conhecimento sobre alimentação e as competências na gestão do DM, realizaram, na Pensilvânia, um estudo randomizado, controlado, envolvendo 98 idosos com DM tipo 2 (48 no grupo experimental e 50 no grupo controle) que participaram de dez sessões semanais em grupos conduzidos por um nutricionista. Concluíram que essa população se beneficiou da educação nutricional para melhorar os conhecimentos e as competências necessárias para a gestão do DM.

$\mathrm{Na}$ Escócia, um estudo recentemente realizado com 24 pacientes obesos avaliou a percepção sobre o tratamento dietético. Os resultados revelaram que esses pacientes consideraram importante o aconselhamento de um dietista para apoiá-los no controle do peso, pela necessidade de se sentirem responsáveis perante alguém e valorizar as informações prestadas quanto à alimentação, à atividade física, às estratégias de comportamento e à obesidade. $\mathrm{O}$ estudo ainda observou alterações no estilo de vida e saúde nos pacientes que aderiram ao 
tratamento. Eles relataram obstáculos às mudanças referentes à sensação de frustração, sobrecarga em relação às mudanças necessárias, entre outras (JONES et al., 2007).

Estudo realizado em São José do Rio Preto-SP, para avaliar os impactos do aconselhamento nutricional na mudança do estilo de vida e de indicadores antropométricos, bioquímicos e dietéticos preditores de DM, entre 104 adultos com excesso de peso (IMC entre 24 e $35 \mathrm{~m} / \mathrm{Kg}^{-2}$ ) cadastrados em uma unidade de saúde (US), observou mudanças significativamente positivas no grupo que passou por três sessões de aconselhamento nutricional em relação ao grupo-controle, indicando a viabilidade da intervenção nutricional na prevenção do diabetes tipo 2, na Atenção Básica, com realce para a viabilidade econômica dessa intervenção (SARTORELLI et al., 2004).

Em São Paulo-SP, numa Unidade Básica de Saúde de Vila Romana, foi proposta uma intervenção com 191 pacientes por meio da formação de grupos de hipertensos e de diabéticos hipertensos para ação educativa, seguimento regular, fornecimento de medicação, controles periódicos e atendimento de intercorrências. A intervenção durou 30 meses: nos três primeiros, ocorreram encontros seguidos de consultas periódicas e controle de doenças; nos demais, dispensação de medicamentos. Após a intervenção, observou-se redução relativa de $42 \%$ e absoluta de $26 \%$ no número de pacientes com HA moderada e grave. Quanto aos diabéticos, houve redução de $22 \%$ naqueles com glicemia superior a $200 \mathrm{mg} / \mathrm{dl}$ e aumento de $33 \%$ para aqueles com níveis inferiores a 125mg/dl. Embora o estudo não tivesse feito o controle de todos os determinantes da adesão e o controle das doenças, a intervenção foi considerada eficiente (SILVA et al., 2006).

Ainda em São Paulo, ALMEIDA-PITITTO (2009), em estudo de plausibilidade, avaliou os efeitos de um programa de dois anos de intervenção no estilo de vida sobre o perfil cardiometabólico de população nipo-brasileira de alto risco. Aderiram ao programa, em 2005, 728 indivíduos, dos quais 650 foram reavaliados em 2006 e 500, em 2007. Os resultados permitiram concluir que a intervenção trouxe benefícios ao perfil cardiometabólico deles após o primeiro e segundo anos do programa, independentemente do grau de tolerância a glicose no 
início do estudo. As mudanças nos fatores de risco cardiovascular foram proporcionais ao alcance das metas do programa. A maioria dos indivíduos sem DM manteve ou melhorou a tolerância a glicose após os dois anos de intervenção.

A despeito do reconhecimento científico sobre a importância de adotar práticas de vida e alimentares adequadas para a prevenção e o controle dos fatores de risco cardiovascular, especialmente do DM, HA e obesidade, para alcançar a adesão do paciente às orientações dos profissionais de saúde e a fidelidade às recomendações, permanece como grande desafio na abordagem pelo Sistema de Saúde a baixa adesão ou continuação ao tratamento de diabéticos e/ou hipertensos relatada em alguns estudos, em que pese à diversidade de métodos e critérios empregados.

HERNANDEZ-RONQUILLO et al. (2003), num estudo realizado no México, verificaram um nível de não adesão às recomendações dietéticas de $62 \%$ entre pacientes diabéticos tipo $2,85 \%$ para não adesão à atividade física, $17 \%$, à medicação oral e 13\%, à aplicação da insulina.

Relativamente aos fatores citados na literatura médica que dificultam a adesão ao tratamento por parte de pacientes diabéticos, estão o baixo nível socioeconômico, que resulta na menor adesão devido ao custo dos medicamentos (BOTELHO e DUDRAK, 1992) e dos alimentos (SHERMAN et al., 2000), a baixa escolaridade (ANDERSON e KIRK, 1982; MOREIRA et al., 2003) e fatores circunstanciais, como comer fora de casa em restaurantes e a oferta de alimentos inadequados por outras pessoas (ARY et al.,1986).

LESSA e FONSECA (1997), em estudo sobre raça, aderência ao tratamento e/ou consulta e controle da HA, obtiveram, entre outros resultados, um índice de adesão ao tratamento de $41,5 \%$, entre 200 pacientes entrevistados. Essa frequência foi considerada pelas autoras como mais elevada ou similar às observadas na literatura. Orientação dietética por escrito foi distribuída entre os $57,5 \%$ dos participantes do estudo, dos quais 49,5\% eram dos grupos que aderiram ao tratamento e/ou às consultas.

Em Pelotas-RS, ARAÚJO et al. (1999), ao estudarem a situação do cuidado dos pacientes diabéticos assistidos em uma unidade de atenção primária, constataram: apenas $28,4 \%$ que relataram fazer uso de dieta hipocalórica (tomada 
no estudo como critério para seguimento de dieta adequada ao diabético); 53,7\%, incluindo os que não faziam uso de dieta, relataram o uso sistemático de adoçantes; somente 20,9\% faziam algum tipo de atividade física como forma de tratamento.

Estudo com objetivos similares, abrangendo 378 pacientes diabéticos assistidos na Atenção Primária à Saúde (APS) de Pelotas-RS, encontrou resultados que também apontam a baixa adesão à dieta e à atividade física: dos $284(75 \%)$ participantes que receberam a prescrição de dieta, 53\% relataram tê-la feito nos 15 dias posteriores à consulta, $10 \%$ não estavam seguindo nenhum tipo de tratamento e $26 \%$ disseram usar apenas medicamentos no tratamento da doença. Concomitantemente, apenas $6,3 \%$ e $10,9 \%$ dos pacientes do estudo apresentaram controle aceitável do índice de massa corporal, glicemia e PA (ASSUNÇÃO et al., 2001).

Em Vitória-ES, para avaliar a adesão e o impacto do aconselhamento nutricional no tratamento da HA, foi realizado estudo longitudinal com 192 indivíduos hipertensos, distribuídos em um grupo (82 indivíduos) que recebeu orientação nutricional em quatro consultas trimestrais durante 12 meses e um grupo controle (110 indivíduos). Compararam-se medidas antropométricas e bioquímicas, o aumento do consumo de alimentos protetores e a diminuição de consumo de alimentos pouco adequados nos dois grupos, além da frequência às consultas. Observou-se melhora apenas nos parâmetros antropométricos: redução da circunferência da cintura e do IMC em relação ao grupo orientado, porém com diferenças não significativas. De outra forma, as mudanças nos parâmetros dietéticos foram mais positivas: substituição de carnes gordas por magras, aumento no consumo de hortaliças, redução do consumo de alimentos como carne salgada, carnes gordas, tempero pronto e vísceras. Todavia, adesão dos pacientes ao aconselhamento dietético foi considerada baixa (SILVA, 2005).

PAIVA et al. (2006), ao descreverem o perfil de população diabética e hipertensa, acompanhada pelo PSF do município de Francisco Morato, SP, e avaliarem a assistência prestada a essa população, verificaram que apenas 32,8\% da população estudada relatou uma dieta considerada adequada, segundo 
parâmetros da pesquisa. Em contrapartida, $75 \%$ relataram não ter o hábito de praticar atividade física.

O impacto da morbimortalidade cardiovascular na população brasileira que tem o DM e a HA como importantes fatores de risco traz um desafio para o Sistema Público de Saúde: a garantia do acompanhamento sistemático dos indivíduos identificados como portadores desses agravos e o desenvolvimento de ações de promoção da saúde e prevenção de DCNT. Estudiosos do tema consideram que o grande desafio do Sistema Único de Saúde (SUS) na abordagem do atual padrão de saúde e doença no país está na reorientação de novas práticas de saúde (MONTEIRO, 1995; BOOG, 1997).

Nesse sentido, intervenções com o objetivo de reduzir as cargas das DCNT são propostas, há alguns anos, pelo Ministério da Saúde (MS). Tradicionalmente essas ações são coordenadas, no âmbito nacional, pelas áreas técnicas assistenciais da Secretaria de Vigilância em Saúde (SVS) e Secretaria de Atenção à Saúde (SAS), de forma que a articulação entre elas aproxime as ações de vigilância epidemiológica às de assistência e promoção da saúde. A promoção constitui o eixo integrador e articulador das agendas dos serviços e a formulação de políticas públicas saudáveis.

Em 2000, a fim de estabelecer diretrizes e metas para a reorganização da assistência do portador de HA e de DM no SUS, o MS implantou o Plano de Reorientação da Atenção à Hipertensão Arterial e ao Diabetes Mellitus, em parceria com as Sociedades Brasileiras de Cardiologia, Nefrologia, Hipertensão e Diabetes, Secretarias Estaduais e Municipais de Saúde, Conselhos Nacionais de Secretários Estaduais e Municipais de Saúde, Federação Nacional de Portadores de Hipertensão e de Diabetes. Entre os objetivos desse plano, estão: orientar a implementação, nos estados e municípios, das ações de capacitação dos profissionais da Atenção Básica; pactuar normas e metas entre as três esferas de gestão da saúde; prestar assistência farmacêutica e dispensação de medicamentos de uso contínuo; promover atividades educativas para minimizar os impactos da HA e do DM sobre a saúde pública. Criou também o Sistema de Cadastro e Acompanhamento de Hipertensos e Diabéticos (Hiperdia, recentemente SISHiperdia) que possibilita a descrição do perfil epidemiológico das pessoas com 
HA e DM cadastradas e acompanhadas na rede básica de saúde (BRASIL, 2001; BOING e BOING, 2007).

A Coordenação Geral das Doenças e Agravos Não Transmissíveis da SVS, em 2005, assumiu a coordenação da Política Nacional de Promoção à Saúde (PNPS), constituindo um grupo de trabalho responsável por elaborar o documento preliminar dessa política. O objetivo da PNPS é contribuir para mudar o modelo de atenção do Sistema, de maneira a ampliar e qualificar ações de promoção de saúde e construir uma agenda estratégica integrada por meio do envolvimento de diversas instâncias gestoras no SUS e do fortalecimento de suas diretrizes (BRASIL, 2005).

Seguindo a orientação da Organização Mundial de Saúde (OMS), o Brasil está engajado no movimento da Estratégia Global para a Alimentação Saudável e Atividade Física. Entre as prioridades da PNPS, está a implantação do projeto "Pratique Saúde", em que a promoção da saúde está centrada no compromisso ético de enfrentar as desigualdades de acesso aos modos de viver e aos ambientes saudáveis por meio da construção de graus crescentes de autonomia dos indivíduos, das famílias e coletividades, no autocuidado, no cuidado com o meio ambiente e na produção da saúde (BRASIL, 2005).

Esse compromisso é convergente para uma das mais importantes circunstâncias que envolvem a instituição de práticas alimentares saudáveis, mais especificamente a adesão a condutas dietéticas especiais para o controle da HA e do DM: a (In) Segurança Alimentar e Nutricional (SAN). Diversos fatores de insegurança alimentar e nutricional, como baixo nível socioeconômico, exclusão social, dificuldades relacionadas ao acesso e preparo dos alimentos, nível de entendimento do paciente sobre a conduta dietética, resistência à mudança de hábitos alimentares e outros comportamentos pouco saudáveis, constituem obstáculos à promoção de práticas de vida saudáveis. No Brasil, adota-se, como conceito de SAN,

(...) a garantia do direito de todos ao acesso regular e permanente a alimentos de qualidade, em quantidade suficiente, sem comprometer o acesso a outras necessidades essenciais, tendo como base práticas alimentares promotoras de saúde que respeitem a diversidade cultural e 
que sejam ambiental, cultural, econômica e socialmente sustentáveis. (BRASIL, 2006a).

A Política Nacional de Alimentação e Nutrição (PNAN) implementada pela Coordenação Geral da Política de Alimentação e Nutrição (CGPAN) da SAS/MS, ao mesmo tempo que integra a Política Nacional de Saúde, insere-se no contexto da SAN, compondo o conjunto de políticas governamentais voltadas a concretizar o Direito Humano à Alimentação Adequada (DHAA).

Implementada em 1999 pelo Ministério da Saúde, a PNAN precede a PNPS e a Política Nacional de Atenção Básica (PNAB). Sua adoção configura um marco importante uma vez que a alimentação e a nutrição constituem requisitos básicos para a promoção e proteção da saúde. Já em sua primeira edição, traz o contexto brasileiro de convivência com a dupla carga de doenças nutricionais: as carenciais, ainda com prevalência significativa, e os altos e crescentes índices de obesidade. A PNAN inova ainda ao introduzir no texto de uma política pública a questão da SAN e sua vinculação com a promoção de práticas alimentares saudáveis, a prevenção e controle dos distúrbios nutricionais e a necessidade da abordagem intersetorial nas ações que propiciam o acesso universal à alimentação e nutrição (SECRETARIA..., 2000).

A PNAN tem por uma de suas diretrizes programáticas a promoção de práticas alimentares e estilos de vida saudáveis, com ênfase na alimentação para prevenção e controle das DCNT e na revisão de métodos, técnicas e estratégias para a educação nutricional:

Deverá (...) ser concedida ênfase particular à orientação quanto à prevenção de doenças crônicas não transmissíveis, tais como as cardiovasculares e a diabete melito e a adoção de hábitos alimentares apropriados (...) como forma de evitar o agravamento destas patologias (BRASIL, 2008, p. 22).

No entanto, para SANTOS, 2005, O documento que institui a PNAN carece de uma concepção clara de educação alimentar e nutricional, e da indicação de diretrizes para a sua prática.

Nos instrumentos normativos que encaminham diretrizes e ações de cada uma das políticas públicas citadas, estão explícitas a necessidade e a importância 
das práticas de educação em saúde e educação nutricional. Principalmente na Atenção Básica, a educação em saúde, em particular a educação nutricional, temse constituído como instrumento de transformação das práticas inadequadas de saúde (LIMA et al., 2000).

Ante o fortalecimento dessas políticas, o SUS enfrenta ainda o desafio de reorientar o modelo de atenção, de forma a garantir à população o acesso universal, equânime e integral a uma rede de serviços resolutivos. Como uma alternativa de enfrentamento a esse desafio, desde 1994 o Ministério da Saúde propôs o Programa de Saúde da Família (PSF) que, por ser considerado como estratégia estruturante dos sistemas municipais de saúde, passou a ser chamado de Estratégia de Saúde da Família (ESF) (ALVES, 2005; SCHERER, 2005; BARRETO e CARMO, 2007).

\subsection{EDUCAÇÃO EM SAÚDE E EDUCAÇÃO NUTRICIONAL - DEFINIÇÕES E PERSCPECTIVAS TEÓRICAS.}

Entendida como um processo a educação em saúde visa a capacitar as pessoas e os grupos sociais para ação consciente em prol da saúde e para o enfrentamento de problemas fundamentais da vida, tais como a nutrição. Campo de prática e conhecimento na saúde pública, ela constitui possibilidade para o desenvolvimento de vínculos entre os serviços de saúde e a população e, por isso, é considerada inerente a todas as práticas desenvolvidas no âmbito do SUS. (LIMA, 2000; VASCONCELOS, 2004).

Para STOTZ (2007) a educação em saúde, como concebida pelo modelo tradicional e dominante da saúde, é uma área de saber técnico que organiza conhecimentos das ciências sociais e da saúde com a finalidade de “instrumentalizar" os serviços para o controle dos pacientes e as pessoas para a prevenção das doenças, num processo em que os educadores profissionais e técnicos em saúde se apropriam do conhecimento técnico-científico da biomedicina para repassá-los como normas de conduta para as pessoas. Nessa visão, respaldada nas evidências da medicina preventivista e adotada como enfoque educativo predominante nos serviços de saúde há décadas, os problemas 
de saúde geralmente se reduzem a dimensão biopsicológica, o que traz a possibilidade de culpabilizar os indivíduos por seu adoecimento, principalmente para aquelas doenças que têm por causa os denominados comportamentos individuais de risco: sedentarismo, alimentação inadequada, consumo de álcool e tabaco, entre outros.

$\mathrm{O}$ autor questiona essa concepção do ponto de vista da percepção das pessoas sobre a doença, o adoecimento e a saúde, percepção essa que é influenciada pela posição social e pela cultura do grupo social de referência dos indivíduos e que precisa ser considerada ao se tentar entender as dificuldades que as pessoas têm em cuidar da sua própria vida e de enfrentar o adoecimento (STOTZ, 2007).

Na última década, com a perspectiva de reorientação do modelo de atenção à saúde no Brasil, a abordagem preventivista deixou de ser exclusiva e a educação em saúde passou a incorporar um novo enfoque: o da escolha informada, que enfatiza o indivíduo, sua privacidade e dignidade em poder decidir sobre sua vida, auxiliado pela informação técnica qualificada (LEFÈVRE e LEFÈVRE, 2004; STOTZ, 2007).

Esse enfoque propõe o deslocamento do uso do conceito de educação para o da informação. Educar, do latim educere, significa conduzir e, para LEFÈVRE e LEFÈVRE (2004), é isso que vem sendo feito no campo da saúde: condução, de forma explícita ou disfarçada, justificado por uma "boa causa", como o combate à doença. Esses autores consideram que a proposta educativa do tipo conducente na promoção de saúde deva ser substituída por proposta informativa, pois as pessoas não devem, e muitas não querem ser "educadas", conduzidas, mas sim conduzir suas vidas "com a ajuda e dialogando com informações técnicas devidamente decodificadas" (LEFÈVRE e LEFÈVRE, 2004, p. 60).

A proposta está embasada nas ideias de teóricos como Fortes, Labonte e Freire. O primeiro desenvolve a concepção de processamento não normatizador da informação, expressão que retrata uma condição de difusão de informação não autoritária, para a qual não seria apropriado para a promoção de saúde "educar", mas sim "informar" e "dialogar" com vistas à tomada de decisão pela sociedade, grupos ou indivíduos (FORTES, 1998). 
O segundo, numa dimensão socializadora da promoção de saúde, considera que o empowerment (empoderamento) das populações implica municiálas de informações significativas que sejam vistas, sentidas e utilizadas como insumos para a tomada autônoma de decisão (LABONTE, 1998).

No terceiro, encontram-se elementos para enfatizar a importância de uma pedagogia não normativa e dialogal (FREIRE, 1972). Esta, ao propiciar oportunidades de encontro e de troca entre o campo sanitário e o do senso comum e o fortalecimento deste, fortalece coletividades e indivíduos para que possam responder mais adequadamente aos determinantes do processo saúde-doença (LEFÈVRE e LEFÈVRE, 2004).

A perspectiva conceitual do empoderamento está associada à proposta de promoção de saúde, pela qual a educação toma uma dimensão socializadora, ou seja, ao municiar as pessoas com informações significativas para elas, que possam ser sentidas, vivenciadas e utilizadas por elas, as decisões serão tomadas com mais autonomia (LABONTE, 1998).

A visão da educação como meio para alcançar a promoção da saúde é comum entre autores do campo da saúde pública. ALVES, 2005, por exemplo, acata o conceito de Costa e Lopes, segundo os quais ela constitui um conjunto de saberes e práticas orientados para a prevenção de doenças e a promoção da saúde (Costa e Lopes, apud ALVES, 2005, p.43), e completa: "trata-se de um recurso por meio do qual o conhecimento cientificamente produzido (...) intermediado pelos profissionais de saúde, atinge a vida das pessoas (...) para adoção de novos hábitos e condutas de saúde" (ALVES, 2005, p.43).

WEARE (2002) parte da visão da Organização Mundial de Saúde sobre os princípios fundamentais da promoção da saúde, ou seja, a democracia, a equidade e a autonomia, para situar a educação em saúde como elemento essencial para a realização dos mesmos. Como princípios ou valores, eles não são elementos técnicos, operacionais, não são alcançáveis por si sós; então, a educação em saúde é esse elemento por que os princípios e objetivos da promoção da saúde se realizam.

No entanto, para CANDEIAS (1997), a qualidade das discussões técnicas sobre intervenções sociais em saúde podem ser afetadas por confusões conceituais 
entre educação e promoção em saúde. Ela assume as definições de Green e Kreuter: educação em saúde diz respeito a quaisquer combinações de experiências de aprendizagem delineadas com vistas a facilitar ações que conduzem à saúde; promoção de saúde é definida como combinação de apoios educacionais e ambientais que visam a atingir ações e condições de vida conducentes à saúde (Green, Kreuter, apud CANDEIAS, 1997, p. 210). Ao significar alguns elementos de ambas as definições, Candeias localiza uma maior complexidade e abrangência no conceito de promoção de saúde e considera que, embora ambas guardem objetivos comuns para contribuir com melhores níveis de saúde, a educação em saúde, na prática, constitui apenas parte das atividades técnicas voltadas para a saúde, cabendo a ela especialmente a habilidade de organizar os componentes educativos dos programas de saúde. Nesse sentido, a educação em saúde é uma atividade-meio (CANDEIAS, 1997).

Reconhecidas as diferenças conceituais entre os enfoques preventivista e da escolha informada, cabe observar que ambos baseiam-se na responsabilidade do indivíduo sobre a ação e no entendimento de que a educação ou a informação qualificada, respectivamente, podem influir decisivamente na decisão individual ou coletiva sobre a saúde. Para STOTZ, 2007, enfoques como estes acabam por contribuir para inoperância dos governos em resolver problemas cuja determinação está na própria estrutura social, pois a responsabilidade pela solução dos problemas de saúde é transferida para os indivíduos.

Uma alternativa às perspectivas anteriores é o enfoque radical que considera como causas dos problemas de saúde as condições e a estrutura social e, portanto, a educação em saúde é orientada no sentido da transformação destas condições, numa perspectiva de luta política pela saúde (STOTZ, 2007). O Estado é chamado a intervir, por meio de medidas legislativas, normativa, fiscalizadora, nas condições que produzem as doenças. Segundo essa concepção, a ação interventora do Estado conduziria as pessoas a escolhas mais saudáveis, o que do ponto de vista do princípio orientador da ação educativa, aproxima-se do enfoque preventivista pela ênfase na persuasão (STOTZ, 2007).

Este enfoque, ao desconsiderar as diferenças individuais de percepção da saúde-doença, o sofrimento que uma decisão mesmo que mais saudável possa 
causar à pessoa, limita a autonomia delas sobre sua vida. Ademais, não resolve a dicotomia indivíduo x coletividade, á medida que os problemas de saúde são de milhares de indivíduos, singulares, e, ao mesmo tempo, coletivas.

Outro enfoque, tratado mais como uma reflexão do que como teoria, é o da educação popular. Trata-se de um movimento social de profissionais, técnicos e pesquisadores, engajados no diálogo entre o conhecimento técnico-científico e o originado das experiências e lutas da população pela saúde. Esta perspectiva compartilha os princípios da educação popular proposta por Paulo Freire e apoiase na diversidade de experiências recolhidas e sistematizadas a partir de problemas de saúde específicos nos serviços de saúde, locais de moradia ou trabalho. Como prática pedagógica parte do saber popular anterior, saber este que mesmo fragmentado e pouco elaborado é a "matéria prima" do processo educativo; que reduz a passividade tradicional dos processos pedagógicos e a verticalidade das práticas educativas tradicionais ou mesmo radicais (VASCONCELOS, 2004).

A educação alimentar e nutricional, entendida como um campo da educação em saúde, comporta em sua concepção os mesmos referenciais da educação em saúde.

O conhecimento em nutrição pode gerar mudanças comportamentais específicas e positivas nos hábitos alimentares, introdução de melhores práticas higiênicas e uso mais eficiente dos recursos alimentares, constituindo esses objetivos da educação nutricional (ABREU e MARTINS, 1997).

Para BOOG (2004), a educação nutricional, assim como todos os processos educativos inerentes ao ser humano, acontece no cotidiano social, ao longo da existência das pessoas, no esforço que elas fazem para responder aos desafios cotidianos. Contudo, pode também se dar por intermédio de ações de instrução e ensino planejadas por pessoas capacitadas para tal fim.

Assim como a educação em saúde, a educação nutricional dispõem de inúmeras abordagens pedagógicas, historicamente caracterizadas de acordo com o movimento político-social vigente. No Brasil, segundo SANTOS (2005), uma importante contribuição para a discussão sobre novas perspectivas da educação alimentar e nutricional se consolidou em meados de 1980, com a educação 
nutricional crítica. Tal concepção determinava haver uma incapacidade da educação alimentar e nutricional e, de forma isolada, promover alterações em práticas alimentares. A educação nutricional crítica baseava-se nos princípios da pedagogia crítica dos conteúdos, de orientação marxista, considerando que a educação nutricional não é neutra e não pode seguir uma metodologia prefixada. Nessa perspectiva, essa vertente da educação nutricional pressupunha assumir o compromisso político de colocar nossa produção técnica e científica a serviço do fortalecimento das classes populares em sua luta contra a exploração, que gera a fome e a desnutrição - problemas muito prevalentes no país naquela época.

No final da década seguinte, o termo "promoção de práticas alimentares saudáveis" começa a marcar presença nos documentos oficiais brasileiros (SANTOS, 2005), reconhecendo-se a importância da alimentação saudável, completa e variada para a prevenção de doenças crônicas não transmissíveis, cuja prevalência veio aumentando significativamente (BOOG, 1999). As interfaces teórico-conceituais entre educação em saúde-educação nutricional-promoção de saúde-promoção de práticas alimentares saudáveis são evidenciadas passam, então a ser presenciadas na literatura da área.

Além das diferentes abordagens ideológico-conceituais que orientam as práticas de saúde e, consequentemente, as práticas educativas em saúde, inúmeras formulações teóricas sob o aspecto didático-pedagógico da educação em saúde encontram-se disponíveis na literatura especializada. Em relação à educação nutricional, por exemplo, a literatura apresenta modelos relacionados a conhecimento-atitude-prática, motivação, aprendizado social, processamento de informação para o consumidor, planejamento de comunicações, ação social e comunitária, difusão de informações e modelos integrados. Todos apontam a complexidade da mudança do comportamento alimentar, a interação dinâmica entre as variáveis a ele relacionadas e a importância de um processo planejado sistematicamente, visando à elaboração de intervenções (CERVATO et al. 2004).

$\mathrm{O}$ percurso teórico realizado neste estudo foi o de tentar perceber o processo educativo no âmbito da Atenção Básica à Saúde, relativamente à assistência à saúde de pessoas com DM e HA, na perspectiva das diferentes 
abordagens teóricas que o orientam, para que a sua reflexão e crítica contribuísse para a qualificação das práticas educativa em saúde.

\subsection{JUSTIFICATIVA}

$\mathrm{O}$ atual perfil de morbimortalidade da população brasileira, caracterizado pela elevada prevalência das DCNT, constitui condição que afeta expressivamente a demanda pelos serviços de saúde. O impacto dessas doenças na saúde pública pode ser minimizado com ações que promovam mudanças nos hábitos de vida, o que, por si só, justifica os estudos que procuram entender e qualificar as ações educativas promotoras dessas mudanças. Particularmente para o DM e a HA, modificações de alguns fatores de risco modificáveis, como alimentação inadequada, sedentarismo, tabagismo e etilismo, podem ser estimuladas no âmbito da Atenção Básica à Saúde, minimizando sua progressão e complicação e reduzindo a morbimortalidade por tais doenças.

No entanto, o que, à primeira vista, parece simples constitui um dos desafios do Sistema de Saúde: promover estilos de vida mais saudáveis significa intervir na perspectiva da promoção da saúde e, portanto, requer essencialmente a reorientação do próprio modelo assistencial, que ainda se configura por uma atenção centrada na doença e na sua cura, no "saber" e no "fazer" fragmentado, o que leva à desumanização e a não integralidade das práticas assistências de saúde.

Na perspectiva da promoção da saúde, as ações educativas têm sido uma prática inerente ao projeto assistencial em todos os níveis de atenção, sendo orientada por diferentes possibilidades teóricas e metodológicas para promover a emancipação e o empoderamento dos sujeitos para responder aos problemas de saúde.

Se a educação nutricional é entendida como um dos elementos da educação em saúde, sua prática também está vinculada à orientação do modelo assistencial; portanto, faz-se necessário qualificar a intervenção educativa para transpor os obstáculos do modelo hegemônico, construindo, com os sujeitos envolvidos em seu "pensar" e em seu "fazer", os elementos motivadores para as 
mudanças de atitudes em relação à promoção de práticas alimentares saudáveis e à adoção de condutas dietéticas adequadas.

Constitui, então, um desafio para os profissionais de saúde a apropriação de estratégias educacionais que concretamente possam auxiliar as pessoas, para que, de forma autônoma e consciente, realizem escolhas que as conduzam a uma vida mais saudável e plena.

A despeito do reconhecimento do alcance da educação em saúde/educação nutricional como medida coletiva para a promoção de hábitos de vida e alimentares saudáveis, são pouco numerosas as experiências documentadas sobre os programas e as atividades de educação nutricional no Brasil, principalmente as desenvolvidas na rede básica de saúde, envolvendo usuários. Configura-se, assim, o locus da Saúde da Família como um campo fértil para os estudos dessa natureza.

Questões complexas, ainda ao nível exploratório, precisam ser investigadas e respondidas, para que seja possível subsidiar programas e políticas sobre o caráter teórico-metodológico e pedagógico das ações educativas. Nesse contexto, o estudo contribui para a qualificação do processo e das práticas educativas focalizados nas ações de educação nutricional e empreendidas no âmbito da Atenção Básica à Saúde, particularmente na atenção à saúde de pessoas com DM e/ou HA.

Como o estudo foi realizado com base na percepção/representação social dos sujeitos envolvidos no processo de educação em saúde: profissionais de saúde e usuários, num processo participativo e dialógico, seus resultados oferecem uma compreensão das práticas educativas pelo prisma de quem as vivencia, o que confere um caráter de humanização e de participação ao processo de qualificação delas.

Qualificar ações de educação em saúde na perspectiva da integralidade e da participação social pode representar maior resolubilidade, eficácia e legitimação de políticas e programas de promoção da saúde em todos os níveis de atenção, o que torna o estudo relevante para a saúde pública. 


\section{OBJETIVOS}

\subsection{GERAL}

Analisar o processo educativo com ênfase na educação nutricional para pessoas com DM e HA no âmbito da Atenção Básica à Saúde.

\subsection{ESPECÍFICOS}

Reconhecer os espaços, os sujeitos e os resultados das ações de educação em saúde, com ênfase na educação nutricional, destinadas a pessoas com DM e/ou HA, no âmbito da Atenção Básica à Saúde, mediante a representação social dos profissionais de saúde sobre essas ações.

Compreender, pela ótica dos profissionais da Atenção Básica à Saúde, as dificuldades e os desafios da ação educativa para a promoção de práticas alimentares saudáveis e adequadas para pessoas com DM e/ou HA.

Caracterizar a percepção dos usuários-pacientes cadastrados e acompanhados na Atenção Básica à Saúde sobre as atividades educativas das quais participam e sobre as dificuldades que encontram para aderir e dar seguimento às orientações que recebem para o controle de sua doença e promoção de sua saúde.

Qualificar as ações educativas para promover a alimentação saudável e adequada entre pessoas com DM e/ou HA, em atividade compartilhada com os profissionais de saúde da Atenção Básica. 


\section{MÉTODOS}

\subsection{CARACTERIZAÇÃO DA PESQUISA}

Realizou-se um estudo de orientação analítico-descritiva e natureza qualitativa, com profissionais de saúde e usuários da ESF do município de Vitória-ES.

\subsection{O CENÁRIO DO ESTUDO}

O estudo foi desenvolvido em uma das 20 unidades de saúde de ESF do município de Vitória-ES, considerada referência no desenvolvimento de ações de promoção de saúde e na oferta de serviços de acompanhamento e controle para pessoas com DM e HA.

O município de Vitória está administrativamente organizado em termos da Atenção Básica à Saúde em seis regiões territoriais, onde se distribui um total de 28 unidades básicas de saúde (UBS), dessas, 20 são de ESF com 72 equipes e quatro de Programa de Agentes Comunitários de Saúde (PACS) com cinco equipes, para uma população de 297.489 habitantes (IBGE, 2010). Quanto aos equipamentos de saúde, o município conta ainda com 11 módulos e uma unidade móvel do Serviço de Orientação ao Exercício (SOE).

Complementam a rede ambulatorial e integram a Atenção Secundária do município um Laboratório Central (com posto de coletas em algumas unidades), seis Centros de Referência: o das Doenças Não Transmissíveis (DST/AIDS), o de Saúde do Trabalhador (CRST), o de Atenção ao Idoso (CRAI), o de Prevenção e Tratamento de Toxicômanos (CPTT), o de Atenção Psicossocial (CAPS) e o de Controle de Zoonoses (CCZ); um Centro de Especialidades e uma Policlínica.

A Figura 1 ilustra uma visão espacial do município de Vitória, com as delimitações das Regiões Administrativas de Saúde e a Figura 2 a distribuição 
geográfica dos equipamentos de saúde do município. A UBS escolhida para o estudo pertence à região de Maruípe.

Figura 1 - Regiões Territoriais de Saúde de Vitória-ES.

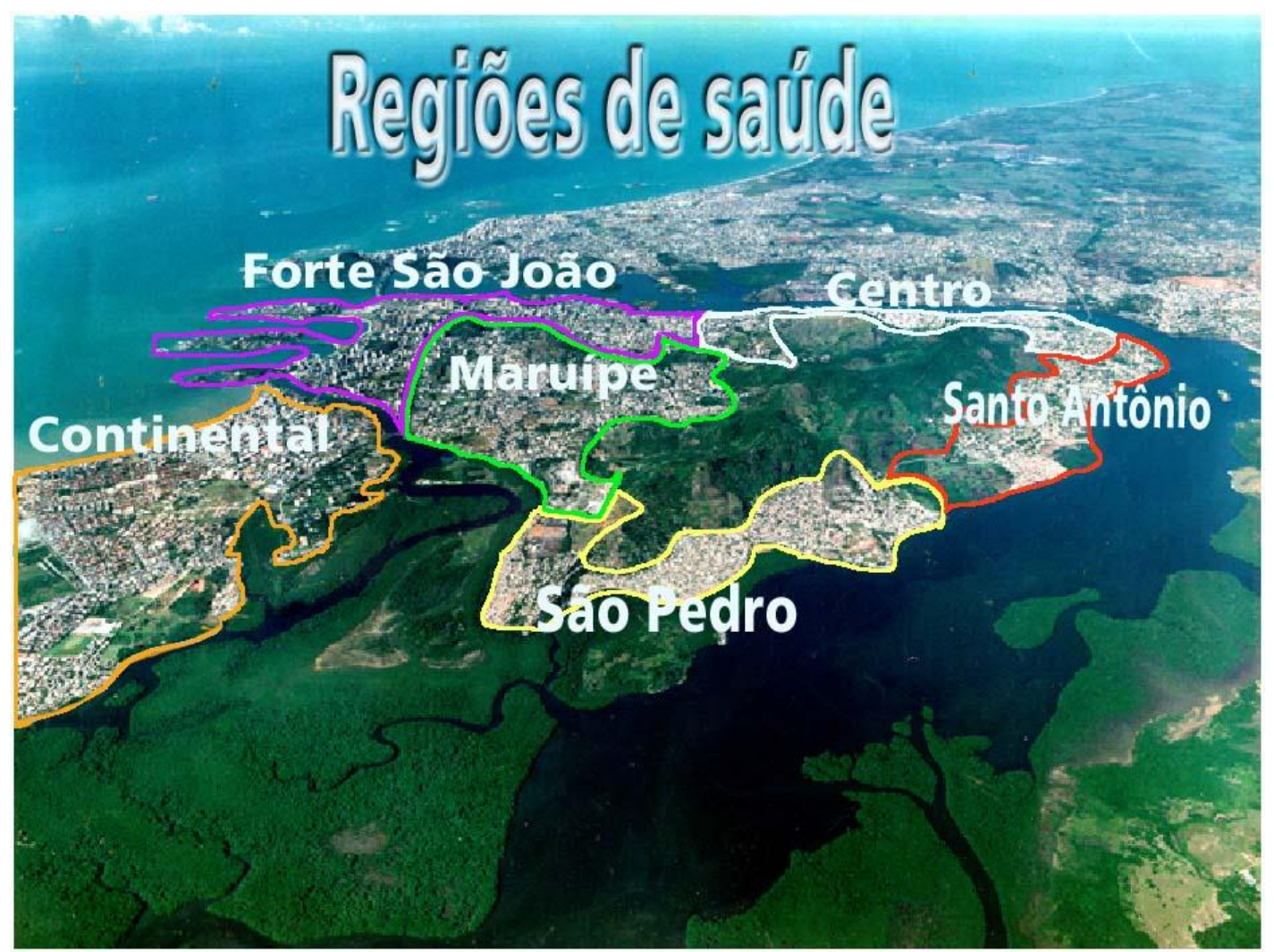

Extraído de: PMV/SEMUS - Seminário Macrorregional em Saúde da População Idosa, 2006. 
Figura 2 - Equipamentos de Saúde por Região Territorial de Saúde, Vitória-ES.

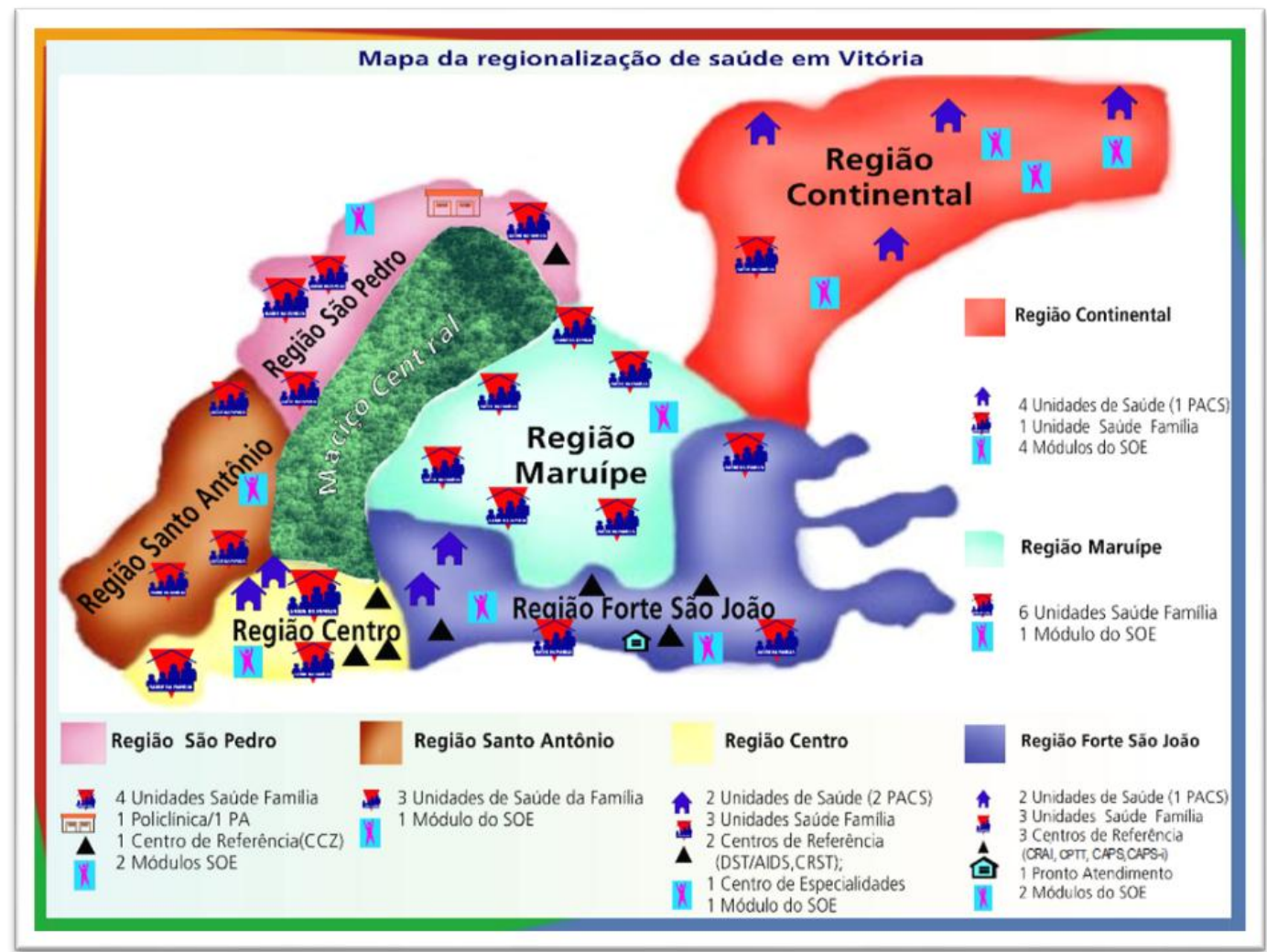

As equipes básicas de ESF são integradas por um médico generalista, um enfermeiro, três auxiliares de enfermagem e cinco a seis agentes comunitários de saúde (ACS). Todas as UBS dispõem, pelo menos, de um assistente social, um psicólogo, uma equipe de saúde bucal, formada por um cirurgião-dentista, um auxiliar de cirurgião-dentista por equipe e um técnico de higiene bucal, além de médicos especialistas, na maioria pediatras e ginecologistas.

A rede da Atenção Básica conta ainda com cerca de 80 orientadores físicos do SOE e atualmente com quatro nutricionistas que atuam diretamente nas ações da Atenção Básica à Saúde. Todavia, o município está implantando as equipes matriciais de ESF para as quais está prevista a lotação de nutricionistas em todas as Regiões de Saúde.

O município está integrado às diretrizes da Política Nacional de Atenção à Saúde (PNAS) no que concerne à vigilância, à prevenção e ao controle das DANT, e as informações sobre elas, geradas na Atenção Básica pelas equipes de PACS/PSF, alimentam os bancos de dados do SISHiperdia e do Sistema de 
Informação da Atenção Básica (SIAB). Além disso, ele participa de Estudos Multicêntricos, como o de Vigilância de Fatores de Risco e Proteção para Doenças Crônicas por Inquérito Telefônico (VIGITEL) e o Estudo Longitudinal de Saúde do Adulto (ELSA), que também geram informações sobre DCNT no município.

Segundo os dados de setembro de 2007, consolidados pelo município e disponíveis no DATASUS/SIAB, naquele ano foram cadastrados, em Vitória, 3.378 diabéticos (dos quais 2.622 acompanhados) e 14.333 hipertensos (dos quais 11.284 acompanhados). Deste total mais de $80 \%$ eram usuários cadastrados e assistidos pelas equipes de ESF (MINISTÉRIO, 2007). Essa data corresponde ao momento em que o delineamento desta pesquisa foi realizado, por isso foi mantida como referência, sem atualização.

As ações de educação em saúde são coordenadas em nível central pela Gerência de Educação em Saúde (GES) e desenvolvidas, nas microrregiões de saúde, pelas equipes de PACS/PSF principalmente.

\subsubsection{A Escolha da UBS do Estudo}

A definição da UBS do estudo foi realizada por meio de entrevistas com informantes-chave da Secretaria Municipal de Saúde, a saber: gestores e coordenadores de equipes de ESF de seis diferentes UBS, bem como as referências técnicas das coordenações da Atenção Básica, da Vigilância das Doenças e Agravos não Transmissíveis, do Controle e Avaliação, do Desenvolvimento de Recursos Humanos e da Educação Permanente, além do secretário e da vice-secretária de saúde do município.

Os critérios de seleção foram estes: ser uma UBS de ESF, referência no desenvolvimento de ações de promoção de saúde e na oferta de serviços de acompanhamento e controle para pessoas com DM e HA, preferencialmente localizada em território com extratos sociais variados, cujo gestor e coordenadores das equipes de ESF demonstrassem receptividade à proposta do estudo.

A UBS elegida para o estudo foi a Unidade de Saúde da Família (USF) do território de Maruípe, localizada na região administrativa de mesmo nome. 
A região administrativa de Maruípe é a segunda mais populosa do município, perdendo apenas para a região Continental. Compreende um conjunto de 12 bairros (unidades censitárias ou territórios), numa área aproximada de $5.671 .517 \mathrm{~m}^{2}$, e uma população estimada de 53.312 habitantes. A ocupação territorial da região é uma das mais antigas da cidade de Vitória. Nela estão o Hospital Universitário da Universidade Federal do Espírito Santo (UFES) e o maior parque-horto do município.

Os indicadores sociodemográficos colocam Maruípe entre as três regiões mais pobres de Vitória, mas com heterogeneidade entre seus territórios. Dos 14.512 domicílios, 99,5\%, 94,2\% e 99,5\% são atendidos por abastecimento de água tratada, tratamento de esgoto e coleta de lixo, respectivamente. No entanto, possui o terceiro menor rendimento médio entre as regiões do município ( $R \$$ 1.202,00, valor corrigido pelo INPC em setembro de 2008), com 44,3\% da população vivendo com dois salários mínimos, bem como a terceira menor escolaridade (média de 6,76 anos de estudo).

Em relação aos equipamentos públicos saúde, educação e assistência social, a região de Maruípe conta com seis UBS; um módulo do SOE; duas academias populares, uma exclusiva para idosos; três Centros de Referência de Assistência Social (CRAS) e quatro Projetos Caminhando Juntos (CAJUN). A rede de educação é composta de 10 Centros Municipais de Ensino Infantil (CEMEI's), uma creche de horário integral; 12 Escolas Municipais de Ensino Fundamental (EMEF's) e 18 Laboratórios de Informática.

Os dados demográficos e socioeconômicos apresentados são do Instituto Brasileiro de Geografia e Estatística (IBGE) - CENSO 2002, com ajustes realizados pela Gerência de Informação Municipal da Secretaria de Gestão Estratégica da Prefeitura de Vitória em 2003 (PREFEITURA DE VITÓRIA, 2011).

\subsubsection{A USF do território de Maruípe}

É a maior e mais complexa das seis USF da macrorregião administrativa de Maruípe. Sua área de abrangência integra a população de sete bairros (São 
Cristóvão, Maruípe, Santa Cecília, Tabuazeiro, Bairro de Lourdes, Santos Dumont e Engenharia), com 23 mil habitantes, que corresponde a 35\% da população total da região administrativa aproximadamente. Assim como a macrorregião, o território de abrangência dessa UBS caracteriza-se pela heterogeneidade entre seus bairros: por exemplo, Tabuazeiro apresenta a maior taxa de analfabetismo $(5,6 \%)$ e o menor índice de qualidade urbana $(0,5)$, enquanto Santa Cecília é o bairro com menor taxa de analfabetismo $(1,5 \%)$ e o índice de qualidade urbana é de 0,75 .

Percebe-se um grande número de famílias em vulnerabilidade social (600 famílias cadastradas no Programa Bolsa Família) e os problemas de saúde são indissociáveis desse quadro: idosos em situação de fragilidade social, transtorno mental, violência doméstica, uso e tráfico de drogas.

Entre as doenças e agravos mais relatados e assistidos pela US estão as do aparelho circulatório e as endocrinometabólicas, com relevância para a HA e o DM respectivamente, as do aparelho digestivo (saúde bucal/cárie dentária), os cuidados pós-operatórios de câncer, a violência influenciada pelo tráfico, além dos agravos sazonais: dengue e as infecções de vias aéreas inferiores.

A unidade atende a um total de 4.720 famílias, no horário de 07:00 às 22:00 horas, com atividades de acolhimento do usuário, prevenção com educação em saúde, busca ativa, tratamento e acompanhamento ambulatorial. Atende a consultas eletivas (pré-agendadas) e demanda espontânea, de acordo com sua capacidade e segundo avaliação da necessidade do usuário. Oferta diversificados serviços e realiza diferentes atividades de saúde pública: curativos; marcação e coleta e entrega de exames laboratoriais; verificação de pressão arterial; eletrocardiograma; vacinação; farmácia; agendamento de especialidades; atendimento odontológico; consultas médicas, de enfermagem, psicologia, serviço social e educação física; serviço de profilaxia da raiva; coleta de material biológico para análise de influenza sazonal (unidade sentinela).

Desenvolve, também, atividades dos Programas de Tuberculose, Hanseníase, Grupo de Apoio Terapêutico ao Tabagismo (GATT), Projeto Peso (apoio a atividades físicas a pessoas acima do peso), Programa Sorria Vitória (atendimento odontológico das crianças em idade escolar matriculadas nas 
instituições públicas do município) e realiza vigilância à saúde (ambiental, sanitária e epidemiológica) e matriciamento em saúde mental, saúde do idoso e ginecoobstetrícia. Os principais projetos intersetoriais em que a unidade está envolvida são o de Atenção à Vítimas de Violência (crianças s adolescente), o Programa Saúde na Escola e o Programa Bolsa Família.

No território de abrangência da USF de Maruípe localizam-se os seguintes equipamentos públicos de interface com a saúde pública: um CRAS; um CAJUN; um Centro de Vivência para terceira idade; três CEMEI's; quatro EMEF's; um Parque Municipal, o Campus Biomédico da UFES; um Hemocentro; a Delegacia de Proteção ao Menor em Conflito com a Lei e o Destacamento de Policia Militar. No seu entorno estão ainda: o Horto de Maruípe, academia popular, módulo do SOE, Quartel do Comando da Polícia Militar; Bancos, unidade escolar e recreativa do Serviço Social da Indústria (SESI), organizações sociais e comunitárias diversas (abrigos, associações de moradores e igrejas).

São espaços coletivos de discussão a reunião geral da unidade, o Colegiado Gestor e o Conselho Local de Saúde, este último com atribuições deliberativas e de fiscalização das ações de saúde do território.

O planejamento das atividades da ESF é realizado por cada uma das sete equipes composta por: um médico; um enfermeiro; dois ou três auxiliares de enfermagem; cinco a seis agentes comunitários de saúde; um atendente de consultório odontológico e um odontólogo para cada duas equipes.

A fonte de dados sociodemográficos referente ao território da USF do estudo é o IBGE - CENSO 2002, com ajustes realizados pela Gerência de Informação Municipal da Secretaria de Gestão Estratégica da Prefeitura de Vitória em 2003 (PREFEITURA DE VITÓRIA, 2011) e os dados de serviço foram cedidos pela coordenação da USF do território de Maruípe.

\subsection{A POPULAÇÃO E OS SUJEITOS}

A população do estudo foi composta por:

- Profissionais de saúde universitários, técnicos ou auxiliares da UBS de ESF selecionada para o estudo, que atenderam aos seguintes 
critérios de inclusão: ser profissional de saúde da UBS de estudo há, pelo menos, seis meses; participar nas ações de promoção de saúde, prevenção e controle do DM e HA realizadas pelas equipes de ESF; estar sensibilizado para a participação no estudo.

- Usuários do Sistema Municipal de Saúde, diabéticos e/ou hipertensos de ambos os sexos, cadastrados no SISHiperdia e/ou no SIAB no município de Vitória-ES, e acompanhados pelas equipes de ESF da US selecionada para o estudo, que atenderam aos critérios de inclusão: ter idade entre 30 e 80 anos; ser portador de DM e/ou HA, acompanhado há, pelo menos, seis meses, anteriormente à data da entrevista; ser assíduo nas ações realizadas pelas equipes de ESF; não ter complicações que o impedissem de participar do estudo, respondendo à entrevista; manifestar consentimento livre e ser esclarecido em participar do estudo.

\subsubsection{A escolha dos sujeitos}

A escolha dos sujeitos da pesquisa, profissionais de saúde ou usuários, foi do tipo não aleatório e intencional (FONTANELLA et al., 2008; MINAYO, 1993).

Para os primeiros, em reunião com o gestor da unidade e coordenadores das equipes de ESF, em que os objetivos e a metodologia do estudo foram apresentados e discutidos, solicitou-se que cada coordenador das sete equipes de ESF indicasse o nome de profissionais que atuassem naquela unidade, pelo menos, a seis meses do início do estudo em ações especialmente relacionadas ao acompanhamento de pessoas com DM e HA. Essa indicação resultou em uma lista de 30 nomes, composta por três a quatro profissionais de cada equipe e por três profissionais da UBS não vinculados estritamente às equipes de ESF, mas com ações articuladas a elas.

Para a definição dos usuários, solicitou-se aos integrantes de cada uma das sete equipes de ESF que indicassem de quatro a cinco pessoas acompanhadas por sua equipe e que atendessem aos critérios de inclusão citados anteriormente. 
O caráter intencional dessa seleção foi no sentido de garantir que o usuário selecionado fosse pessoa que frequentasse as atividades educativas promovidas pela UBS para que, assim, pudesse expressar sua opinião sobre elas.

A participação voluntária de cada participante da pesquisa foi precedida de convite individual mediante apresentação e esclarecimentos sobre o caráter, os objetivos e procedimentos metodológicos da pesquisa e sobre a garantia do anonimato e o sigilo das informações. A concordância em participar foi registrada mediante assinatura do Termo de Consentimento Livre e Esclarecido (Anexo 1), conforme estabelecido na Resolução CONEP 196/96 e suas complementares.

Aceitaram participar do estudo 27 profissionais de saúde, dos quais sete enfermeiros, três médicos, um educador físico, 14 agentes de saúde e dois auxiliares de enfermagem, e 25 usuários.

\subsection{AS ETAPAS DE CAMPO E A COLETA DOS DEPOIMENTOS}

O estudo foi realizado em três etapas, a saber:

3.4.1 Primeira etapa: Identificação das estratégias de intervenção educativa, implementadas no âmbito da ESF, para pessoas com DM e HA, na percepção dos profissionais de saúde.

Os dados desta etapa foram coletados no período de fevereiro a setembro de 2009, após o pré-teste da técnica e do instrumento, por meio de entrevistas semiestruturadas, abertas (PATTON, 2002; FONTANA e FREY, 2000). Utilizouse um roteiro composto de questões que abordavam a percepção dos sujeitos sobre: 1) ações de caráter educativo realizadas na UBS, com o objetivo de capacitar pessoas com DM e/ou HA para os cuidados com a sua saúde e alimentação; 2) profissionais envolvidos nessas ações; 3) contribuição, resolutividade, eficácia destas para mudanças relativas às práticas conducentes à saúde, principalmente às alimentares; 4) dificuldades percebidas para a realização das ações educativas e para a adesão ou continuação dos diabéticos e/ou 
hipertensos às orientações para o controle de sua doença e a promoção de sua saúde, principalmente aquelas relacionadas à alimentação e nutrição.

As entrevistas foram previamente agendadas com cada participante e geralmente realizadas em um consultório ou no auditório da US, com duração de quinze a trinta minutos.

Mediante autorização do entrevistado, o depoimento foi registrado em gravador digital para sua transcrição literal posterior.

3.4.2 Segunda etapa: Identificação das estratégias de intervenção educativa, implementadas no âmbito da ESF, para pessoas com DM e HA, na percepção dos usuários.

De forma similar à dos profissionais de saúde, ou seja, por meio de entrevistas semiestruturadas abertas, coletaram-se os depoimentos dos usuários. Para essa coleta, utilizou-se um roteiro composto por questões que tratavam da percepção desses sujeitos, a saber: 1) como é realizado o acompanhamento das pessoas com diabetes e/ou hipertensão e de quais atividades participam e recebem orientações sobre sua saúde e alimentação; 2) profissionais que geralmente realizam esse acompanhamento e as orientações; 3) mudanças que ocorreram em suas vidas e em sua alimentação após a participação no acompanhamento; 4) dificuldades percebidas para seguir as orientações para mudanças de hábitos de vida, especialmente alimentares.

Essa fase ocorreu no período de janeiro a agosto de 2010. As entrevistas foram agendadas pelos ACS e realizadas na residência do entrevistado ou, quando mais conveniente para a pessoa, em um consultório ou no auditório da UBS, aproveitando um dia de comparecimento para a consulta médica.

Os instrumentos e a técnica da entrevista passaram por pré-teste com população similar à do estudo, porém em UBS de outro município. As entrevistas foram realizadas individualmente por um único entrevistador e, quando autorizadas pelo entrevistado, registradas em gravador digital para posterior transcrição literal. Variou de 10min a 30min a duração das entrevistas. 


\subsubsection{Terceira etapa: Qualificação das estratégias de intervenção nutricional educativa}

Nesta etapa, foram realizados debates com os profissionais de saúde participantes do estudo. A eles foram apresentados os resultados da primeira etapa da pesquisa relativamente às ideias centrais por eles formuladas sobre espaços, sujeitos, resolubilidade, eficácia e limites das ações educativas, para que, num novo diálogo, suas concepções fossem reelaboradas e novos elementos surgissem para o processo de qualificação das práticas educativas.

Os debates foram realizados em três reuniões, no auditório da UBS de estudo em dezembro de 2010 e janeiro de 2011.

Os profissionais de saúde que participaram da primeira etapa do estudo foram preliminarmente distribuídos em três grupos de sete a dez integrantes e convidados a participar das reuniões.

Nessas reuniões, adotou-se a técnica de grupo focal como um recurso metodológico que permitisse compreender o processo de construção de percepções, atitudes e representações sociais de grupos humanos (Veiga e Gondim, apud GONDIM, 2003, p.151). Trata-se de uma técnica de pesquisa de abordagem qualitativa, não diretiva, em que se pretende o controle da discussão de um grupo de pessoas. Sua aplicação permite a coleta de dados por meio de interações grupais ao discutir um tema especial sugerido pelo pesquisador (TANAKA e MELO, 2001; MORGAN, 1997).

A técnica foi conduzida por um pesquisador facilitador e três pesquisadores auxiliares, e cada reunião teve duração de duas horas.

Para a consecução do debate, utilizou-se um roteiro com os seguintes passos: 1) apresentação dos objetivos do grupo, da forma como conduzi-lo, da duração e do tema central de discussão; 2) apresentação por meio de recurso de multimídia, de resultados parciais da primeira etapa do estudo (IC processadas com base nos depoimentos dos profissionais de saúde sobre resultados, eficácia, dificuldades e limites das ações educativas para a capacitação de pessoas com DM e HA); 3) apresentação da questão foco: como vocês acham que podemos driblar 
as dificuldades e os limites percebidos e tornar as ações educativas mais resolutivas e eficazes? 4) debate.

Mediante a concordância dos presentes, o debate foi registrado em dois gravadores, um eletrônico e outro digital. Aspectos importantes da discussão e intercorrências durante a realização dos grupos foram registrados à parte, por escrito, por um dos pesquisadores auxiliares.

\subsection{A ORGANIZAÇÃO DOS DADOS E O PROCESSAMENTO DOS DISCURSOS}

\subsubsection{Os dados das entrevistas com profissionais e usuários}

Para a transcrição e primeira editoração das entrevistas realizadas na primeira e segunda etapas do estudo, foram tomados alguns cuidados referentes à fidelidade do que foi afirmado e ao anonimato delas, como a manutenção das palavras repetidas e dos vícios de linguagem e a omissão dos nomes próprios dos sujeitos. Sempre que possível, optou-se por fazer o registro ortograficamente correto das falas, exceto para as situações que fugiam ao léxico da língua-padrão ou suprimiam sílabas e/ou fonemas iniciais e finais das palavras, conforme recomendado por ARAUJO (2001) para a transcrição e editoração de entrevistas em pesquisa de abordagem qualitativa.

Os depoimentos orais resultantes das entrevistas, após transcrição, passaram por leitura flutuante, uma das etapas preliminares do processo de análise do material empírico na pesquisa qualitativa, quando, num contato mais próximo com o material de análise, o pesquisador se permite "invadir" pelas primeiras impressões e orientações (BARDIN, 1977). A leitura flutuante permitiu delimitar as respostas para cada uma das questões formuladas, independentemente do momento exato em que os pensamentos e as percepções dos sujeitos foram expressos durante a entrevista. Isso porque, quando essas são do tipo aberto, dão margem a manifestações e sentimentos menos organizados, o que requer um esforço de organização dos dados discursivos, preliminar ao processamento e análise deles. 
Os depoimentos foram, então, tabulados e organizados segundo a técnica de análise do Discurso do Sujeito Coletivo (DSC), que consiste em uma sequência de operações metodologicamente definidas: 1) seleção de expressões-chave $(\mathrm{ECH})$ de cada depoimento ou resposta dada a uma questão; 2) identificação da ideia central (IC) de cada uma dessas expressões-chave; 3) reunião das ECH, referente às ideias centrais semelhantes ou complementares, resulta em um conjunto nuclear do discurso ou discurso-síntese, redigido na primeira pessoa do discurso, que é o próprio DSC (SALES et al., 2007; LEFÈVRE e LEFÈVRE, 2003).

A escolha do DSC como recurso metodológico se deve à propriedade dessa técnica. Ao reunir fragmentos de discursos individuais em um ou mais discursos-síntese, proferidos por um grupo social (profissionais de saúde ou usuários), propicia a expressão de pensamentos, percepções ou representações sociais sobre o objeto do estudo (ações educativas na Atenção Básica à Saúde) de forma mais densa, complexa e enriquecida. Assim, requer a pesquisa de base qualitativa, que tem nos depoimentos a matéria-prima para a descrição e a tentativa de compreender fenômenos sociais complexos. Com o DSC, evita-se reduzir os discursos individuais a uma categoria comum unificadora; ao contrário, realçam-se as expressões individuais quando o conteúdo dos depoimentos é reunido em ideias centrais de sentidos semelhantes ou complementares e estas são usadas para reconstruir o discurso de uma coletividade. Redigido na primeira pessoa do singular, o DSC produz no leitor o efeito não de um sujeito, mas de uma "coletividade falando", o que acrescenta densidade semântica às representações sociais, pois à ideia de um depoente são acrescidas e incorporadas ideias semelhantes ou complementares de outros (LEFÈVRE et al., 2009; TEIXEIRA e LEFÈVRE, 2008; LEFÈVRE et al., 2003).

Para a análise e discussão do material discursivo, recorreu-se a leituras bibliográficas, norteadas pelas possibilidades de análise e interpretação de textos (SEVERINO, 1996), recorrendo-se à literatura científica de estrutura conceitual abrangente, como encontrado no campo da sociologia do conhecimento e no das ciências sociais aplicadas à saúde coletiva. 


\subsubsection{Os depoimentos nos grupos focais}

As falas da discussão dos grupos focais foram ouvidas repetidas vezes para que se procedesse ao registro dos fragmentos de discurso que fossem mais relevantes e respondessem ao tema central da discussão.

Esses fragmentos de discurso foram então agrupados segundo as seguintes categorias de análise sobre: 1) o fortalecimento das ações educativas no plano terapêutico de pessoas com DM e HA; 2) as práticas prescritivas e as dietas restritivas; 3) o espaço de planejamento das ações educativas; 4) a ausência de profissionais especialistas para apoiar as ações e educação alimentar; 5) a falta de espaço físico para realização das ações.

Para analisar os resultados, utilizou-se como recurso o destaque de tendências e as conexões entre as falas (TANAKA e MELO, 2001) resultantes dos grupos focais e as falas resultantes das entrevistas semiestruturadas da primeira etapa da pesquisa.

Neste estudo a proposta de qualificação tem o sentido de indicar e reelaborar as qualidades do objeto do estudo, ou seja, o processo de educação em saúde com foco na educação nutricional, na perspectiva de que os sujeitos envolvidos nesse processo podem fazê-lo com mais propriedade. Ao pesquisador cabe, nesse caso, de forma pretensiosa, mas respaldada em referencial teóricometodológico das ciências sociais aplicado à Saúde Pública, tentar compreender e significar os pensamentos, sentimentos e representações desses sujeitos.

\subsection{CONSIDERAÇÕES ÉTICAS}

Este estudo está em consonância com o estabelecido na Resolução CONEP 196/96 e suas complementares. A participação na pesquisa foi condicionada à expressa autorização dos sujeitos no Termo de Consentimento Livre e Esclarecido (Anexo I). A coleta de dados só teve início após a aprovação do estudo pelo Comitê de Ética na Pesquisa da Universidade de São Paulo-USP.

A pesquisa não ofereceu riscos à saúde dos participantes. As entrevistas incluíram questões relacionadas a opiniões, sentimentos, percepções dos 
profissionais de saúde e usuários sobre o objeto do estudo, e, por isso, todas as medidas foram tomadas para deixá-los confortáveis na participação, preservando o princípio da participação voluntária. Todas as informações foram confidenciais, sem identificação pessoal, garantindo-se o anonimato e o sigilo das respostas às entrevistas.

A realização do estudo foi precedida do contato com a Secretaria de Saúde e com as coordenações e gerências envolvidas: Gerência de Atenção Básica à Saúde; Gerência de Educação em Saúde; Gerência de Recursos Humanos; Gerência da UBS (a selecionada), para apresentação dos objetivos e procedimentos metodológicos do estudo.

O pesquisador visitou a UBS selecionada em datas e horários previamente agendados e apresentou, em reuniões com as equipes de ESF e demais profissionais de saúde envolvidos, todos os esclarecimentos necessários sobre a relevância do estudo, sua finalidade, planejamento, etapas, entre outros. A mesma exposição de motivo e os esclarecimentos foram prestados inicialmente aos usuários selecionados para a participação.

As atividades em grupo com profissionais de saúde foram realizadas nas dependências das unidades de saúde, em ambientes, horários e condições que ofereceram conforto e segurança. Em nenhuma circunstância, foi conferido ônus material ou financeiro aos participantes. 


\section{RESULTADOS E DISCUSSÃO}

Os resultados e a discussão da primeira e da segunda etapa da pesquisa são apresentados e discutidos em três manuscritos, apresentados no formato prévio para posterior submissão em periódico científico.

- Manuscrito 1: Ação educativa para pessoas com diabetes mellitus e hipertensão arterial: reflexões sobre a educação em saúde na Estratégia de Saúde da Família.

- Manuscrito 2: Dificuldades e desafios da ação educativa com foco na educação nutricional de pessoas com diabetes mellitus e hipertensão arterial: a visão dos profissionais da Estratégia de Saúde da Família.

- Manuscrito 3: Ação educativa na Atenção Básica à Saúde para pessoas com diabetes mellitus e hipertensão arterial: escutando os sujeitospacientes.

Os resultados da terceira etapa são apresentados em formato tradicional, com o subtítulo Caminhos para a qualificação do processo educativo. 


\section{1 - MANUSCRITO 1}

Ação educativa para pessoas com diabetes mellitus e hipertensão arterial: reflexões sobre a educação em saúde na Estratégia de Saúde da Família.

Ana Maria Bartels Rezende

Ana Maria Cervato Mancuso

\section{INTRODUÇÃO}

Nas últimas quatro décadas, o Brasil transitou de um perfil de morbimortalidade típico de população jovem para um quadro caracterizado por enfermidades próprias das faixas etárias mais avançadas, representadas principalmente pelas doenças crônicas não transmissíveis (DCNT), entre as quais as coronarianas, constituem importante problema de saúde pública e, segundo registros oficiais, a primeira causa de morte no país (Brasil, 2005; Lessa, 2004; Gordilho et al., 2000).

A hipertensão arterial (HA) e o diabetes mellitus (DM) são as principais condições de risco para essas doenças e encontram-se entre as dez primeiras causas de morte em vários países. Suas complicações mais frequentes elevam o custo médico-social e atingem diretamente o Sistema de Saúde (Brasil, 2005; Yach et al., 2004; Garantini et al., 2004).

Há muito se considera que a modificação do estilo de vida para o controle de fatores de risco modificáveis, como alimentação, sedentarismo, tabagismo, dislipidemias, obesidade, pressão arterial, entre outros, é a base do tratamento e controle das doenças cardiovasculares. Especialmente em relação à dieta, vários estudos têm enfatizado sua associação com o controle de fatores de risco para as DAC e, portanto, com a prevenção e controle delas (Dansinger et al., 2005; Hajjar e Kotchen, 2003, Ministério da Saúde, 2001).

Para tanto, os processos educativos são tidos como a chave nas intervenções preventivas no âmbito coletivo, particularmente aqueles que têm evoluído de uma relação emissor-receptor para uma comunicação em que o 
profissional de saúde compartilha seus conhecimentos e o receptor passa de uma atitude passiva para outra ativa e responsável (Aráuz et al., 2001; Lima et al. 2000).

Para Alves, 2005, p.43, a educação em saúde é um recurso por meio do qual o conhecimento cientificamente produzido “(...) intermediado pelos profissionais de saúde, atinge a vida das pessoas (...) para adoção de novos hábitos e condutas de saúde".

A educação em saúde ganha uma perspectiva conceitual ampliada quando associada à proposta de promoção de saúde. Weare, 2002, situa a educação em saúde como elemento essencial para a sua realização.

Há os que discordam da propriedade da educação como estratégia para a promoção da saúde. Lefèvre e Lefèvre propõem que a aproximação entre conceitos não deva ser da educação com a promoção de saúde, mas da informação para a saúde com a promoção de saúde. Os autores relacionam a dimensão socializadora da promoção de saúde com a noção de empowerment, ou seja, de fortalecimento das pessoas pelo municiamento de informações significativas que confiram autonomia na tomada de decisão. A educação em saúde, por outro lado, com a proposta conducente, normativa e autoritária, que deve ser substituída por uma informativa, baseada no diálogo e na autonomia de decisão das pessoas (Lefèvre, Lefèvre, 2004).

A educação alimentar e nutricional entendida como um campo da educação em saúde comporta em sua concepção os mesmos referenciais da educação em saúde. Para Boog (2004), a educação nutricional, assim como todos os processos educativos inerentes ao ser humano, ocorre no cotidiano social, ao longo da existência das pessoas, no esforço que elas fazem para responder aos desafios cotidianos. Mas pode também se dar por intermédio de ações de instrução e ensino planejadas por pessoas capacitadas para tal fim.

Sob o aspecto didático-pedagógico dos processos educativos encontram-se disponíveis na literatura especializada formulações teóricas relacionadas aos modelos do conhecimento-atitude-prática; da motivação; do aprendizado social; do processamento de informação para o consumidor; do planejamento de comunicações; da ação social e comunitária; da difusão de informações e modelos 
integrados. Todos apontam a complexidade da mudança do comportamento alimentar, a interação dinâmica entre as variáveis relacionadas e a importância de um processo planejado sistematicamente, visando à elaboração de intervenções eficazes (Cervato et al. 2004).

Reflexões críticas sobre concepção e abordagens da educação em saúde estão registradas em ensaios sobre o tema (Alves, 2005; Valla, 1999; Vasconcelos, 1998.) e num campo mais restrito de publicações encontram-se aqueles que investigam os resultados da intervenção educativa entre diabéticos e hipertensos, avaliando o resultado da educação em saúde (Silva TR et al., 2006; Maia, Araujo, 2002; Santos, Baracho, 1995) e/ou particularizando a questão da educação alimentar e nutricional para esse grupo (Almeida-Pititto, 2009; Silva, 2005; Sartorelli et al., 2004).

No âmbito das políticas públicas, o impacto da morbimortalidade cardiovascular na população brasileira impõe que o Sistema de Saúde garanta, no espaço político-operacional, o acompanhamento e a assistência sistemática dos indivíduos identificados como portadores desses agravos. Isso nos remete ao que tem sido considerado o grande desafio do SUS: reorientar as práticas de atenção à saúde, garantindo às pessoas o acesso universal, integral e equânime a uma rede de serviços resolutivos. (Barreto, Carmo, 2007; Scherer, 2005).

Em relação ao DM e à HA, o Ministério da Saúde, em 2001, estabeleceu diretrizes e metas para reorganizar a assistência de seus portadores no Plano de Reorientação da Atenção à Hipertensão Arterial e ao Diabetes Mellitus, que incorpora o cadastro e acompanhamento de Hipertensos e Diabéticos na rede pública de saúde em um sistema informatizado (SISHiperdia) (Boing e Boing, 2007). A questão educativa nesse plano foi estruturada, num primeiro momento, para a capacitação de multiplicadores dos estados e dos municípios que, posteriormente desenvolveriam uma estratégia de ação dirigida aos serviços de saúde da rede básica dos grandes centros urbanos, por meio da realização de uma proposta de educação permanente para os profissionais (médicos e enfermeiros) das unidades básicas de saúde dessas localidades (Brasil, 2001).

Nos instrumentos normativos que encaminham diretrizes e ações das políticas públicas de saúde e nutrição no país, estão explícitas a necessidade e a 
importância das práticas educativas, que, principalmente na Atenção Básica, temse constituído como instrumento de transformação das práticas inadequadas de saúde (Lima et. al., 2000). Alves, 2005, considera que é nos serviços, pela ação de sujeitos em sua prática cotidiana, que as ações da política de saúde se materializam.

Nesse contexto, propôs-se este estudo, cujo objetivo foi descrever e analisar as percepções de profissionais da ESF sobre os espaços, os sujeitos e os resultados das ações educativas para pessoas com DM e HA, a fim de contribuir com a qualificação das ações educativas no âmbito da Atenção Básica à Saúde.

Ele constitui uma das etapas da pesquisa de doutoramento do Programa de Pós-Graduação em Nutrição em Saúde Pública da Faculdade de Saúde Pública da Universidade de São Paulo, intitulada “Ação educativa na Atenção Básica à Saúde de pessoas com diabetes mellitus e hipertensão arterial: avaliação e qualificação de estratégias com ênfase na educação nutricional.”.

\section{METODOLOGIA}

Realizou-se um estudo de orientação analítico-descritiva e natureza qualitativa, com profissionais de saúde da ESF do município de Vitória-ES.

O cenário proposto foi uma das 20 unidades básicas de saúde (UBS) do município em que a Estratégia de Saúde da Família está implantada.

A definição da UBS do estudo foi realizada por meio de entrevistas com informantes-chave da Secretaria Municipal de Saúde e os critérios de seleção foram estes: ser uma UBS de ESF, referência no desenvolvimento de ações de promoção de saúde e na oferta de serviços de acompanhamento e controle para pessoas com DM e HA, preferencialmente localizada em território com extratos sociais variados, cujo gestor e coordenadores das equipes de ESF demonstrassem receptividade à proposta do estudo.

A escolha dos sujeitos da pesquisa foi do tipo não aleatório e intencional (Fontanella, et al, 2008; Minayo, 1993). Solicitou-se que cada coordenador de equipes indicasse profissionais que atuassem naquela unidade, pelo menos, a seis meses do início do estudo em ações especialmente relacionadas ao 
acompanhamento de pessoas com DM e HA. Essa indicação resultou em uma lista de 30 nomes, composta de três a quatro profissionais de cada equipe e três profissionais da UBS não vinculados estritamente às equipes de ESF, mas com ações articuladas a elas.

A participação voluntária de cada profissional de saúde foi precedida de esclarecimentos sobre a pesquisa e a concordância em participar foi registrada no Termo de Consentimento Livre e Esclarecido, conforme estabelecido na Resolução CONEP 196/96 e suas complementares.

Procedeu-se a coleta dos dados após o pré-teste da técnica e do instrumento, por meio de entrevistas semiestruturadas, abertas (Patton, 2002; Fontana, Frey, 2000). Utilizou-se um roteiro composto de questões que abordavam a percepção dos sujeitos sobre: 1) ações de caráter educativo realizadas na UBS, com o objetivo de capacitar pessoas com DM e/ou HA para os cuidados com a sua saúde e alimentação; 2) profissionais inseridos/envolvidos nessas ações; 3) contribuição, resolubilidade, eficácia destas para mudanças relativas às práticas conducentes à saúde, principalmente às alimentares.

As entrevistas foram realizadas individualmente por um único entrevistador e gravadas para posterior transcrição literal. Para a transcrição e primeira editoração das entrevistas, foram tomados alguns cuidados referentes à fidelidade do que foi afirmado e ao anonimato delas, como a manutenção das palavras repetidas e dos vícios de linguagem e a omissão dos nomes próprios dos sujeitos. Sempre que possível, optou-se por fazer o registro ortograficamente correto das falas, exceto para as situações que fugiam ao léxico da língua-padrão ou suprimiam sílabas e/ou fonemas iniciais e finais das palavras, conforme recomendado por Araujo, 2001.

Os depoimentos orais resultantes das entrevistas, após a transcrição, passaram por leitura flutuante, em que, num contato mais próximo com o material de análise, o pesquisador se permite "invadir" pelas primeiras impressões e orientações (Bardin, 1977). Os depoimentos foram tabulados e organizados segundo a técnica de análise do Discurso do Sujeito Coletivo (DSC), conforme concebida por Lefèvre, Lefèvre, 2003. 
Para a análise e discussão do material discursivo, recorreu-se a leituras bibliográficas, norteadas pelas possibilidades de análise e interpretação de textos (Severino, 1996), valendo-se da literatura científica de estrutura conceitual abrangente, como encontrado no campo da sociologia do conhecimento e no das ciências sociais aplicadas à saúde pública.

\section{RESULTADOS E DISCUSSÃO}

Concordaram em participar do estudo 27 dos 30 profissionais selecionados, quais 26 (sete enfermeiros, três médicos, 14 agentes de saúde e dois auxiliares de enfermagem) estavam vinculados diretamente a uma das sete equipes de ESF e um (educador físico) atendia à demanda de toda a UBS no seu campo de atuação.

Do total de entrevistados, oito $(29,63 \%)$ são do sexo masculino e 19 (70,37\%), do feminino. A média de idade era de 35,89 anos, com amplitude de 27 a 60 anos e a média de tempo em que trabalhavam na UBS de 4,24 de anos completos.

A apresentação dos resultados está organizada da seguinte forma: para cada uma das três questões centrais do estudo, que constituem as categorias de análise dos discursos, serão apresentadas as IC identificadas nos depoimentos e, na sequência, os DSC correspondentes. Como o material discursivo é bastante extenso, na intenção de dar maior fluidez e harmonia ao texto, optou-se por realizar a discussão logo após a apresentação de cada IC ou de um conjunto de IC complementares e dos respectivos DSC.

\section{Primeira questão: Sobre os espaços educativos}

Os depoimentos sobre essa questão trazem a ótica dos profissionais de saúde sobre os espaços educativos da Atenção Básica, particularmente aqueles que acontecem no cotidiano da ESF e são destinados a capacitar as pessoas com DM e/ou HA. 
Do processamento das respostas resultaram três ideias centrais, apresentadas no Quadro 1, cujo material discursivo permitiu elaborar os DSC equivalentes: DSC 1.1; DSC 1.2 e DSC 1.3.

Quadro 1. Ideias centrais de profissionais de saúde de uma unidade básica de estratégia de Saúde da Família sobre os espaços educativos de atenção à saúde para pessoas com diabetes mellitus e/ou hipertensão arterial. Vitória- ES, 20092010 .

Questão1: Nesta UBS, que atividades ou ações são realizadas para orientar (educar) as pessoas com diabetes e/ou hipertensão, especialmente sobre os cuidados em relação a sua saúde e alimentação?

\begin{tabular}{|l|c|}
\hline \multicolumn{1}{|c|}{ Ideia Central (IC) } & $\begin{array}{c}\text { Frequência } \\
(\mathbf{\%})\end{array}$ \\
\hline $\begin{array}{l}\text { IC (1.1) - As orientações são realizadas principalmente nas } \\
\text { reuniões de grupos do Hiperdia. }\end{array}$ & $12(44,44)$ \\
\hline $\begin{array}{l}\text { IC (1.2) - Em geral em todos os atendimentos a gente faz } \\
\text { educação em saúde. }\end{array}$ & $8(29,63)$ \\
\hline $\begin{array}{l}\text { IC (1.3) - Além dos grupos, as orientações são realizadas nas } \\
\text { visitas domiciliares. }\end{array}$ & $7(25,93)$ \\
\hline \multicolumn{1}{|c|}{ Total } & $27(100,00)$ \\
\hline
\end{tabular}

A IC1. foi referida em 44,44\% dos depoimentos (Quadro 1). Ela associa as atividades educativas principalmente ao espaço das reuniões dos grupos promovidas periodicamente para pessoas cadastradas nos grupos do Hiperdia, destacando-se que, nesse espaço, além da abordagem coletiva, ocorre a consulta médica e de enfermagem, representada no discurso coletivo como uma abordagem individual em contraposição à abordagem considerada coletiva, realizada, de uma só vez, com todas as pessoas do grupo, geralmente por meio de palestras ou de exposições dialogadas.

No DSC 1.1 merecem destaque, inicialmente, duas visões sobre os grupos do Hiperdia como espaços educativos. A primeira refere-se à preocupação por parte dos profissionais de saúde na formação de grupos distintos, para os quais a abordagem educativa seja diferenciada em função das diferentes "realidades" de seus integrantes:

"[...] O acompanhamento que a gente faz aqui são os grupos de Hiperdia mesmo, né? Uma das principais formas que a gente utiliza é a reunião de 
grupo. Aonde nós reunimos todos os diabéticos, todos os hipertensos [...] a gente separa os grupos de diabéticos tipo 1, tipo 2 e os hipertensos leve, moderado e grave [...] a gente conhece a realidade de cada um. E pra cada grupo a gente faz uma orientação específica. Porque não é igual pra todo mundo [...]" (DSC 1.1).

A segunda refere-se à distinção de duas abordagens no espaço dos grupos do Hiperdia: uma coletiva e outra individual. As expressões iluminadas no DSC 1.1 sugerem que os profissionais de saúde diferenciem, nas ações do grupo, as práticas de caráter "educativo", associando-as ao momento coletivo desta ação, das práticas cujo objetivo é "orientar", associando-as ao momento de aferição dos sinais vitais e ao das consultas médicas e de enfermagem.

"[...] Nos grupos o primeiro momento nosso é uma conversa. É sobre assuntos diversos. [...] São feitas através de ações educativas mesmo [...]" (DSC 1.1).

“[...] Ao aferir os sinais vitais já fazemos a orientação individual [...] A consulta de enfermagem ela é uma consulta total de orientação. E a gente foca muito sobre a questão da alimentação até de uma forma individualizada mesmo [...] no momento seguinte é a consulta com o médico [...]" (DSC 1.1).

A ação educativa é tida como um dos componentes fundamentais das ações básicas de saúde e é inerente a toda e qualquer atividade de atenção em que ocorra contato entre pessoas: profissionais de saúde e usuários do Sistema. O objetivo de levá-las a refletir sobre a saúde, adotar práticas para sua melhoria ou manutenção e modificar hábitos de vida que possam comprometer a sua saúde e a saúde de outras pessoas. No entanto, os espaços em que essas ações se concretizam precisam ser primeiramente reconhecidos como tais pelos sujeitos da ação, para que estes possam dele apropriar-se e, assim, contribuir com o seu aprimoramento. $\mathrm{O}$ espaço, nesse caso, não é apenas o físico, mas o conjunto de condições em que as relações do processo educativo acontecem.

Há dez anos, o Plano de Reorientação da Atenção à Hipertensão Arterial e ao Diabetes Mellitus vem sendo implementado para orientar as ações que visam a minimizar os impactos da HA e do DM sobre a saúde pública (Ministério da Saúde, 2001). Em razão disso, nas unidades de saúde, emergiu um espaço 
estratégico para organizar a atenção a essas pessoas e desenvolver ações de caráter educativo, para municiá-las com informações em relação ao autocuidado para o controle de sua enfermidade e atuar na prevenção de comorbidades e complicações associadas. Esse espaço, chamado de "grupos do Hiperdia", em alusão à vinculação das pessoas que dele participam ao cadastro no SISHiperdia, de uma forma subliminar, assumiu uma dimensão de "condicionalidade" para que diabéticos e hipertensos cadastrados no Sistema, ao serem inseridos nos grupos, garantissem um acesso mais rápido e organizado aos procedimentos médicos e de outras especialidades e à assistência farmacêutica para os medicamentos de uso contínuo disponibilizados pelo programa.

Em uma sociedade, é comum que as pessoas se organizam para fins específicos, como forma de enfrentar as dificuldades decorrentes do Sistema social em que vivem. A utilização de espaços e estratégias grupais para abordagens educativas em saúde é uma prática assistencial secular, bastante difundida na atualidade, principalmente na Atenção Básica, na lida com pessoas portadoras de doenças crônicas. Esses espaços podem-se constituir pela iniciativa dos próprios integrantes do grupo, contando, às vezes, com o apoio de profissionais e voluntários, como é o caso de grupos como Alcoólicos e Narcóticos Anônimos, associações e movimentos ligados à igreja ou às comunidades (Gusmão, 2003). Ademais, surgem da necessidade de implementar práticas assistenciais e educativas, como é o caso dos grupos que se formam em diferentes programas e ações de saúde da Atenção Básica.

Numa dimensão pragmática, costuma-se designar os grupos como conjuntos de pessoas unidas, que assim se reconhecem por objetivos, ideais e/ou interesses comuns. Sendo assim, um grupo não é formado apenas pelo somatório de indivíduos, mas por uma identidade em torno de seus objetivos, ideais e/ou interesses (Osório, 2000; Zimerman, 2000).

No campo da atenção à saúde, Silva MA et al., 2006, propõem uma compreensão para o grupo como um espaço em que se articulem, pelo menos, três dimensões da vida humana: a social, pois no grupo as pessoas agregam, compartilham e/ou dividem expectativas e, assim, o grupo “constrói pessoas (sujeitos históricos) que constroem comunidades e estas constroem sujeitos"; a 
subjetiva, em que se manifestam as emoções, os afetos, o intelecto e a cognição, moldados pelas experiências individuais e coletivas das pessoas; a biológica, dimensão que sintetiza, no processo saúde-doença, múltiplas determinações, como a expressão genética, a do ambiente e a da atitude de cada pessoa na forma com que ela interage com o meio interno (físico e psíquico) e externo.

Conforme a finalidade e fundamentação teórica, múltiplas modalidades de grupos podem ser identificadas. Os procedimentos e as ferramentas técnicas empregadas nesse espaço também variam e combinam-se de acordo com o objetivo do trabalho grupal (Silveira, Ribeiro, 2005).

Uma das concepções mais citadas na bibliografia pertinente é a de Enrique Pichon-Riviere, que concebe o grupo como "um conjunto limitado de pessoas ligadas por constante de tempo e espaço, articuladas por sua mútua representação interna, que propõe [...] uma tarefa, que é a sua finalidade [...]" (Pichon-Rivière, 1988, p. 142).

Enrique-Pichon criou o conceito de grupo operativo, que, segundo Zimerman e Ozório (1997), pode ser definido como um conjunto de pessoas que tentam operar como equipe para realizar uma determinada tarefa.

Pode-se considerar que grupos, como os do Hiperdia, constituídos por pacientes somáticos, com as finalidades já enunciadas, apresentem características similares à de um grupo do tipo operativo, que, segundo Silveira e Ribeiro (2005, p.95), "mescla terapêutica e ensino-aprendizagem e cuja finalidade é promover a adesão ao tratamento". A prática assistencial desses grupos é, portanto, tanto terapêutica como pedagógica e tem como objetivos ampliar a consciência das pessoas sobre a doença, potencializar a capacidade em superar dificuldades, promover mudança de atitude e propiciar aprendizagem mútua (Silveira, Ribeiro, 2005).

No DSC 1.1 sobre como acontece o momento dos grupos de Hiperdia, identifica-se uma dicotomia entre as atividades clínico-terapêuticas, representadas no discurso pelas consultas médicas e de enfermagem, e as educativas ou pedagógicas, representadas pela "conversa", pelas "orientações" realizadas com todos os integrantes do grupo de uma só vez. 
Outra visão dual encontrada na fala dos profissionais de saúde é que, nos grupos do Hiperdia, acontecem práticas consideradas "coletivas", que expressariam o objetivo da equipe de saúde em organizar a atenção e promover a educação em saúde, e outras "individuais", que representariam os objetivos do usuário em garantir a consulta médica e a medicação gratuita. $\mathrm{Na}$ visão desses sujeitos, a coexistência dessas práticas, que seria estratégia apreciável para a integralidade das ações de saúde, é suplantada pela dicotomia: coletivo versus individual, e essa visão vai permear outros depoimentos e se manifestar em outros discursos apresentados neste estudo.

Gusmão (2003) identificou situação semelhante nas atividades grupais por ele desenvolvidas no atendimento em saúde mental. Para ele, essa concepção das práticas grupais se fundamenta nos modelos tradicionais de grupo, cujas propostas têm por princípio uma visão do grupo como um sistema fechado, previamente formado, que mascara as relações emanadas da prática grupal, tais como necessidades e interesses dos sujeitos, tensões, conflitos e relações de poder e não permite uma concepção de grupo como espaço dinâmico de construção e transformação (Gusmão 2003).

Para L'Abbatte (2003, p.270), as relações entre o coletivo e o individual “constituem-se em analisadores históricos [...] para toda constituição da saúde coletiva e a compreensão de seu campo de saberes e práticas". Ao ilustrar a variedade e a imprecisão de sentidos sobre o que seja "coletivo", ela utiliza algumas conotações do termo no âmbito das ciências sociais, tais como: "coletivo" como conjunto de indivíduos; "coletivo" como interação entre elementos; "coletivo" como conjunto de efeitos ou consequências da vida social; "coletivo transformado em social como campo específico e estruturado de práticas" (L'Abbatte, 2003, p.268). Os sentidos de "coletivo" enunciados por L'Abbatte têm uma dimensão semelhante aos conceitos de grupo, anteriormente apresentados, ou seja, transitam de uma condição agregada de indivíduos a um espaço de interação e transformação de sujeitos e práticas.

Nessa perspectiva, pode-se considerar que as representações sobre espaço coletivo e espaço individual dos grupos de Hiperdia, destacadas no DSC 1.1, 
parecem aproximar-se mais do conceito de coletivo como mero conjunto de indivíduos do que das demais significações do termo sugeridas por L'Abbatte.

Escóssia (2009), ao refletir sobre as definições do "coletivo" apresentadas por L'Abbatte, afirma que se percebe em todas elas uma oposição entre a dimensão coletiva e a individual, que, segundo ela, resulta de uma visão fragmentária da realidade, hierárquica e baseada numa relação de oposição, que é típica e hegemônica na sociedade moderna.

A despeito da importância deste debate no plano conceitual, o que se verifica na prática é que a milenar dicotomia entre o coletivo e o individual na história da saúde pública sobrevive e manifesta-se no discurso dos profissionais de saúde como um dilema shakespeariano: ação coletiva ou individual? Preventiva ou curativa? Educativa ou informativa? Na percepção desses sujeitos, embora no PSF predomine a ação coletiva (preventiva), entre os usuários a demanda preferencial é pela atenção individual, centrada se não no médico, ao menos nas práticas que historicamente o caracteriza: a consulta, a prescrição, a solicitação de exames, entre outras:

“[...] No PSF não tem outra coisa a fazer, a maioria das coisas é a ação preventiva [...] A cultura deles é para a consulta médica. [...] É o dia que ele vai renovar a receita [...] vai fazer um exame [...]" (DSC 1.1).

Essas ideias, por um lado, mostram que um dos problemas recorrentes no modelo assistencial é o processo de trabalho medicocentrado, que acaba operando centralmente na produção do cuidado e da cura, e não na produção da saúde, apesar de ser a ESF uma possibilidade concreta na reorientação do modelo de saúde; por outro, demonstram que persiste uma visão dicotômica entre as práticas de promoção e prevenção e as de recuperação e proteção à saúde. Essa visão não coincide com o discurso oficial sobre os preceitos da ESF, que, apesar de priorizar as ações preventivas e promocionais, numa dimensão de integralidade do Sistema, busca realizar também as ações de recuperação e proteção à saúde no âmbito da Atenção Básica. Assim, reorienta as práticas setoriais isoladas e reafirma a inclusão na prática em saúde de todos os profissionais, com ações coletivas e individuais de melhoria e manutenção da qualidade de vida (Brasil, 2000). 
As representações emanadas do DSC 1.1 suscitam refletir sobre as potencialidades e contradições da ESF no processo de mudança do modelo assistencial, particularmente quanto à proposta de transformação do modelo centrado no médico e em práticas terapêuticos individuais para um modelo centrado no usuário (família) e na equipe multiprofissional de saúde.

Nesse sentido, quase como num contraponto à visão anterior, evidencia-se ainda, no DSC 1.1, o fato de os grupos do Hiperdia serem considerados pelos profissionais de saúde como espaços para abordagem interdisciplinar e multiprofissional:

"[...] A gente não fala só de hipertensão e diabetes. A gente orienta sobre alimentação, sobre medicação, sobre exercício [...] Eles recebem orientações do educador físico, de orientações nutricionais pelo médico e enfermeiro e os encaminhamentos [...]" (DSC 1.1).

Essa visão parece ser consonante com a intenção conceptual da ESF em redirecionar a participação dos diversos profissionais de saúde, visando à construção de uma equipe articulada, multiprofissional e interdisciplinar, cujas ações estejam pautadas na Atenção Básica (Brasil 2000), e com a diretriz do Plano de Reorientação da Atenção à Hipertensão Arterial e ao Diabetes Mellitus, que privilegia a abordagem conjunta e integrada da equipe multiprofissional da ESF, tornando imperativo que esses desenvolvam conjuntamente ações multidisciplinares para a recuperação e manutenção da saúde dos usuários portadores dessas doenças (Brasil, 2001).

A IC 1.2: "Em geral, em todos os atendimentos, a gente faz educação em saúde" foi destacada em oito $(29,63 \%)$ das 27 respostas à primeira questão (Quadro 1). Ela sugere que todos os espaços de atenção à saúde são espaços potencialmente educativos.

Observa-se, no DSC 1.2 subjacente, que uma rede de atividades sequenciadas logo após o cadastro da pessoa com DM e HA no SISHiperdia condiciona o acompanhamento delas pela equipe de ESF da UBS, o recebimento das orientações diversas e o acesso à medicação para o controle de sua doença. 
"Eu acho que a gente faz educação em saúde de uma forma geral. Em todos os atendimentos, visitas, consultas é feito esta orientação. A pessoa quando chega [...] vai primeiramente para o médico. [...] elas recebem uma prescrição médica, e, até mesmo para que a medicação seja liberada, elas têm que fazer um cadastro no programa Hiperdia, [...]. O paciente vai com a receita na farmácia, eles liberam o medicamento só para 10 dias, e pedem para agendar a consulta com o enfermeiro para a gente fazer o cadastro. [...] a gente aborda o conhecimento da pessoa [...]. Dá toda a orientação do que é a doença, quais são as consequências que estas doenças podem estar trazendo, quais são os fatores que levam a pessoa estar desenvolvendo e também como que é o tratamento que ele vai ter que fazer sempre, né? Faz todas as orientações de hábitos de vida e hábitos alimentares também, todas que a gente acha cabivel para $E$ inclui esta pessoa num grupo de atendimento, de orientação [...] que é esse grupo do Hiperdia [...] ”. (DSC 1.2).

Nesse discurso, identificamos elementos convergentes para a primeira das sete teses sobre educação sanitária, enunciadas por Briceño-León: “A educação não é só o que é ensinado em programas educacionais, mas em toda a ação de saúde.” (Briceño-León, 1996, p.11). Portanto, fazem parte da educação em saúde tanto as ações educativas formais, que são aquelas a que primeiramente nos reportamos quando se fala em educação, como a educação informal, que acontece no cotidiano das ações de um programa de saúde.

O DSC 1.2 mostra que os profissionais de saúde percebem que haverá um processo educativo acontecendo em todos os espaços: nos grupos do Hiperdia, em que são realizadas palestras e oficinas para informar e orientar os diversos temas que se relacionam à prevenção e ao controle da HA e do DM; no cadastro da pessoa; no Hiperdia realizado pelo enfermeiro; na busca ativa realizada nas famílias para identificação dos casos de HA e DM e das situações de risco; nas consultas com o médico, enfermeiro ou orientador físico; nas visitas domiciliares realizadas pelos ACS; nas ações de verificação para controle da pressão arterial, da glicemia, do peso, realizado pelos auxiliares de enfermagem; enfim, em todos os espaços em que houver relacionamento humano, em que experiências e sentimentos estiverem fluindo, independentemente de a informação formal ser veiculada.

Por ser assim, ainda segundo Briceño-León, há de ter dois cuidados: o primeiro diz respeito à necessidade de refletir sobre as formas de aplicação das políticas ou programas de saúde em geral e tentar apreender qual é o tipo de 
mensagem, qual é o tipo de ação educativa que dali emana. Trata-se de uma investigação operacional sobre os efeitos e os resultados comunicacionais e educativos das ações não intencionalmente comunicacionais ou educativas (informais); o segundo deve ser quanto ao preparo de todos os profissionais envolvidos nas ações de saúde, sob o aspecto educacional (pedagógico), e não exclusivamente daqueles a quem formalmente se delega a ação educativa. $\mathrm{Na}$ análise de discursos posteriores, teremos a oportunidade de voltar a essa discussão.

Embora com nuance diferente, aparece também, no DSC 1.2, a visão dual entre práticas que são realizadas com todas as pessoas do grupo de uma só vez (coletivas) e as de cunho individual, que é preferida por algumas pessoas que não querem participar dos grupos do Hiperdia:

"[...] quando ele vai para o grupo, primeiro a gente faz uma reuniãozinha onde aborda vários temas relacionados à alimentação, atividade física, não só isto, mas outras coisas. A gente faz o atendimento individual e faz orientação aos grupos também. [...] Nem todos aceitam participar dos grupos, alguns preferem estar agendando as consultas, aqui no posto [...]" (DSC 1.2).

Outros espaços educativos que emergiram no DSC 1.2 são as visitas domiciliares e algumas atividades esporádicas, tipificadas no discurso como “coletivas", a exemplo das realizadas por acadêmicos de nutrição no pátio da US.

Pela IC 1.3, iluminada em cerca de um quarto dos depoimentos analisados, os profissionais de saúde consideram que, "além dos grupos as orientações são realizadas nas visitas domiciliares" (Quadro 1), de tal modo que o DSC 1.3 realça o espaço privilegiado dessa prática para a realização de ações educativas pela equipe da ESF, reflete a representação desses sujeitos acerca dessa prática e da sua inserção no espaço das visitas domiciliares. A visita domiciliar é entendida como espaço de verificação e de orientação da rotina alimentar, do uso correto da medicação e da prática de atividade física, as quais são prescritas pelo médico. Nesse espaço, o profissional atua numa perspectiva da prevenção: eles tão fazendo a medicação certo, entendeu? [...] Olha como ta a 
alimentação dele, o remédio também, a gente confere se ta tomando o remédio correto [...] E a gente trabalha com essa prevenção, orientação, muita, muita prevenção [...]" (DSC1.3).

$\mathrm{Na}$ esfera da Atenção Básica, a visita domiciliar constitui importante espaço de atuação das equipes de ESF, sendo a atividade externa à unidade mais realizada pelas equipes. Embora, em princípio, dela participem todos os integrantes da equipe de ESF, é uma atividade primariamente atribuída ao agente comunitário de saúde (ACS), visto fazer parte de suas competências a integração entre a equipe de saúde e a população adstrita à unidade. Segundo diretrizes do Ministério da Saúde, para este tema é atribuição específica do ACS, por meio de visitas domiciliares, o desenvolvimento de atividades de promoção da saúde, de prevenção das doenças e agravos e vigilância à saúde (Brasil, 2006). Isso talvez explique o fato de que, neste estudo, embora outros componentes da equipe de ESF participem das visitas domiciliares, todos aqueles que as destacaram como espaço educativo, de orientação e prevenção eram ACS.

Sakata et al. (2007) entendem a visita domiciliar como uma das tecnologias dos cuidados à saúde capaz de produzir relações de interação que acontecem nos espaços de intercessão entre profissionais e usuários, a exemplo do acolhimento e do vínculo. A visita domiciliar é por ele classificada como tecnologia leve, imprescindível nas práticas de saúde por favorecer uma comunicação dialógica e a integralidade do cuidado.

Assim como no estudo realizado por este autor, percebe-se, no DSC 1.3, certa ambiguidade na compreensão do significado das visitas domiciliares, que é identificada ora como espaço que promove o acompanhamento das pessoas, ora como espaço de fiscalização e vistorias (Sakata et al., 2007). Para Vasconcelos apud Sakata et al., 2007, o acompanhamento se faz presente tal qual uma prática para reorganizar o trabalho em saúde, considerando a realidade, as necessidades locais e a participação popular. Em contrapartida, entendida como vistoria ou fiscalização, a visita domiciliar pode tanto significar intromissão na vida das pessoas, limite da privacidade e autonomia quanto resultar em distanciamento dos profissionais de saúde e usuários (Craco, 2006), o que não é uma condição desejada ou esperada para essa prática assistencial. Pelo contrário, por meio das 
visitas domiciliares, espera-se que importantes vínculos assistenciais e sociais sejam estabelecidos entre os sujeitos, para facilitar o processo de adesão às práticas conducentes à saúde.

Outra reflexão que se tem feito acerca das visitas domiciliares como prática assistencial da ESF é que a atenção prestada às famílias é geralmente direcionada pelos programas governamentais de saúde pública, planejados e padronizados nas instâncias burocráticas do setor. Como exemplos, podem-se apontar o programa de incentivo ao aleitamento materno, os de prevenção e controle de doenças endêmicas da região, os de controle de hipertensão e diabetes, foco deste estudo, entre outros. Assim, a percepção e a intervenção dos profissionais locais tendem a se restringir às práticas assistenciais preestabelecidas por esses programas. Se a padronização facilita a expansão do programa em questão, pode também simplificar e empobrecer o seu alcance ao não considerar as diferentes manifestações locais dos problemas de saúde (Rosa e Labate, 2005; Vasconcelos, 1999). Nesse contexto, Rosa e Labate (2003) consideram que a execução de tarefas preestabelecidas no âmbito familiar, sem o estabelecimento de vínculos mais amplos com a comunidade, descaracteriza o enfoque família/comunidade e pode implicar intervenções desvinculadas das reais necessidades de saúde de uma população, sem impactos na humanização da assistência e na mudança da qualidade de vida dela.

\section{Segunda questão: Sobre os sujeitos da ação educativa}

A segunda questão de investigação deste estudo refere-se à percepção dos profissionais de saúde da ESF sobre a sua inserção nas atividades educativas para pessoas com DM e HÁ.

No Quadro 2, registram-se as três IC que foram destacadas nos depoimentos e possibilitaram a construção do material discursivo sobre essa questão. 
Quadro 2. Ideias centrais de profissionais de saúde de uma unidade básica de estratégia de Saúde da Família sobre os sujeitos da ação educativa para pessoas com diabetes mellitus e/ou hipertensão arterial. Vitória-ES, 2009- 2010.

Questão 2: Que pessoas geralmente estão envolvidas ou colaboram nas ações educativas para as pessoas com diabetes e/ou hipertensão? Como cada um colabora nessas ações?

\begin{tabular}{|c|c|}
\hline Ideia Central (IC) & $\begin{array}{l}\text { Frequência } \\
\quad(\%)\end{array}$ \\
\hline $\begin{array}{l}\text { IC (2.1) - Da equipe (de ESF), todo mundo se envolve: } \\
\text { enfermeiro, médico, auxiliares de enfermagem e agentes de } \\
\text { saúde. }\end{array}$ & \multirow{4}{*}{$20(76,92)$} \\
\hline $\begin{array}{l}\text { IC complementar (a) - Dependendo da demanda da Unidade } \\
\text { conta com a ajuda de outros profissionais que não são da } \\
\text { equipe. ( } 7 / 20 \text { depoimentos) }\end{array}$ & \\
\hline $\begin{array}{l}\text { IC complementar (b) - Específico de hipertensão e diabetes } \\
\text { tem também o professor de educação. ( } 15 / 20 \text { depoimentos) }\end{array}$ & \\
\hline $\begin{array}{l}\text { IC complementar (c) - Às vezes a gente conta também com a } \\
\text { ajuda de acadêmicos de nutrição. (4/20 depoimentos) }\end{array}$ & \\
\hline $\begin{array}{l}\text { IC (2.2) - Quem está mais envolvido é o enfermeiro e o agente } \\
\text { de saúde. }\end{array}$ & $3(11,54)$ \\
\hline $\begin{array}{l}\text { IC (2.3) - O básico que o paciente tem é na consulta médica e } \\
\text { de enfermagem. }\end{array}$ & $3(11,54)$ \\
\hline Total & $26(100,00)$ \\
\hline
\end{tabular}

A primeira, IC 2.1: "Da equipe (de ESF), todo mundo se envolve: enfermeiro, médico, auxiliares de enfermagem e agentes de saúde" (Quadro 2), foi verificada em $20(76,92 \%)$ dos 26 depoimentos. A ela foram associadas ideias centrais complementares relativas à ajuda de outros profissionais que não são exclusivos de cada equipe de ESF, mas que colaboram na medida da demanda das equipes. A ênfase coube à participação específica do orientador físico nas ações realizadas para pessoas com DM e/ou HA, destacada em 15 dos 20 depoimentos. Acadêmicos de nutrição em práticas de ensino também foram citados como sujeitos que colaboram nas ações educativas. O DSC 2.1 realça o envolvimento de todos os componentes da equipe e, complementarmente, a de outros profissionais da US nas ações educativas:

"[...] Da equipe, todo mundo se envolve. [...] enfermeiro, médico, auxiliar de enfermagem e agente comunitário de saúde [...]Às vezes a gente conta também com a ajuda de outros profissionais [...] tem a assistente social, a psicóloga e tem o educador físico. E o dentista, [...] 
com a orientação que eles tem em relação aos cuidados com a boca [...] Excepcionalmente o farmacêutico [...] é uma peça fundamental [...] Nós tamos querendo agora retornar com outros colaboradores: a fisioterapeuta, que ela já faz um trabalho interessante também [...] Específico de hipertensão e diabetes é mais o educador físico. [...] Quando não tinha o professor a atividade física era muito difícil [...] recebe também o acadêmico de nutrição [...] pra passar em oficinas as orientações nutricionais. A gente sai muito com eles, nas visitas [...]" (DSC2.1).

A segunda, IC 2.2: "Quem está mais envolvido é o enfermeiro e o agente de saúde" (Quadro 2), foi manifestada por três $(11,54 \%)$ dos 26 profissionais de saúde que responderam à questão. No discurso resultante dessa IC, nota-se uma valorização da "fala" no processo educativo, principalmente quando este ocorre no espaço dos grupos, em que o enfermeiro e o agente de saúde são os principais sujeitos da ação, o que sugere um caráter expositivo e informativo das ações realizadas:

"Todos os da equipe participam de alguma forma, mas nas ações educativas, na verdade, quem está mais envolvido é o enfermeiro e o agente de saúde. [...] no grupo ele vai passar também pelo médico, enfermeiro, professor de educação física, os agentes de saúde e auxiliares de enfermagem. [...] Mas quem fala mais é o enfermeiro [...]" (DSC 2.2).

No âmbito da Atenção Básica, a educação em saúde figura como prática atribuída a todos os profissionais que compõem a equipe de Saúde da Família. A expectativa é que todos estejam capacitados para, entre outras atribuições, desenvolver processos educativos para a saúde, voltados à melhoria do autocuidado dos indivíduos (Brasil, 1997).

No entanto, o DSC 2.2 sugere que alguns membros da equipe de ESF ainda não se reconhecem plenamente competentes para realizar ações educativas que demandem aprofundamento no conteúdo e exposição pública oral, como palestra ou execução de uma oficina, ficando estas a cargo do enfermeiro e/ou do médico da equipe:

"[...] quem fala mais é o enfermeiro. $O$ agente de saúde fica junto, às vezes ele dá algumas orientações. A gente estava até querendo organizar que cada um falasse um dia, porque quando você fala você aprende, né? 
Até para você estudar, para você falar com eles. Só que eles estavam receosos, recatados em fazer isto [...]" (DSC2.2).

A representação do processo educativo como um momento em que a fala é o recurso educativo mais frequente e importante é recorrente nos discursos construídos em outras questões do estudo. É compreensível, portanto, que aquele que "mais fala" seja percebido como o sujeito que "mais se envolve" na ação educativa.

A terceira, IC 2.3: "O básico que o paciente tem (de orientação/educação) é na consulta médica e de enfermagem", identificada em 11,54\% dos depoimentos (Quadro 2), posiciona o médico e o enfermeiro como os sujeitos centrais das ações educativas.

No DSC 2.3, a representação do papel do médico e do enfermeiro na ação educativa se dá, essencialmente, no momento da consulta, que, como sabemos, é um ato eminente e privativo deles e de outros profissionais de formação universitária da saúde:

"[...] É mais a enfermeira e eu que oriento na consulta médica [...] Em todos os grupos e individualmente ele vai passar primeiro pela consulta de enfermagem e depois pela consulta médica. [...] é uma consulta total de orientação [...]” (DSC 2.3).

Não há dúvidas de que uma consulta tenha cunho educativo, quando visa ao preparo da pessoa ou família para o autocuidado e é dirigida à promoção, proteção, recuperação e reabilitação da saúde. No entanto, a preocupação recai na representação que parece persistir nesse ato como um momento meramente prescritivo de formas de cuidado e atenção à saúde, restrito à assistência curativa, que não pauta os fatores de risco a saúde, não valoriza a educação em saúde e é impermeável às dimensões psicossociais e culturais das concepções de saúde, doença e cuidado (Alves, 2005).

Poucos estudos existem sobre a natureza da consulta como espaço educativo. Alves, 2006, ao estudar o desenvolvimento da ação educativa em consultas médicas com pessoas hipertensas, no âmbito do PSF, encontrou três circunstâncias: consultas em que prevalecia a ênfase nos aspectos curativos, nas quais o profissional se restringia a reiterar a prescrição quanto ao uso da 
medicação; consultas em que a ação educativa era assimilada secundariamente no projeto terapêutico, que abordavam outros cuidados de saúde, principalmente os relativos à redução de fatores de risco para a hipertensão; consultas em que se observou um equilíbrio entre a medicalização, o controle da pressão arterial e o desenvolvimento da ação educativa. Entre as três circunstâncias, a segunda prevaleceu. Em apenas três das 50 consultas analisadas, a terceira, ou seja, a de equilíbrio no plano terapêutico, embora este não constituísse uma rotina do profissional na atenção ao paciente hipertenso. No referente à orientação da dieta, embora a alimentação tivesse sido o fator de risco à hipertensão mais referido pelos profissionais, a orientação médica frequentemente não partia da realidade do paciente e restringia-se a recomendar a redução de consumo de sal e de gorduras (Alves, 2006).

Confrontando-se os DSC 2.3 e DSC 2.1, percebe-se que, para parte dos profissionais de saúde, a ação educativa está centralizada na atuação de médicos e enfermeiros, o que sugere a persistência do modelo hegemônico médico centrado. Em contrapartida, o fato de ser o discurso coletivo mais prevalente aquele que reconhece o envolvimento e participação de todos os profissionais da equipe e da US nas ações educativas sugere uma reação ao modelo tradicional, coincidente com a intenção de ser a ESF uma possibilidade concreta de reorientação do modelo no sentido da interdisciplinaridade e da integralidade das práticas promocionais, preventivas e curativas.

\section{Terceira questão - Sobre a contribuição, resolubilidade e eficácia das ações educativas.}

As IC destacadas nos depoimentos relativas a esta questão foram organizadas no Quadro 3 e 4. 
Quadro 3. Ideias centrais de profissionais de saúde de uma unidade básica de estratégia de Saúde da Família sobre a contribuição das ações educativas para a promoção da saúde e o controle da doença entre pessoas com diabetes mellitus e/ou hipertensão arterial. Vitória-ES, 2009-2010.

Questão 3: Em sua opinião, as ações educativas contribuem para a mudança dos diabéticos e hipertensos? Em que medida? Que mudanças ou resultados você observa?

\begin{tabular}{|c|c|}
\hline Ideia Central (IC) & Frequência $(\%)$ \\
\hline IC (3.1) - As ações educativas contribuem muito para mudanças & \multirow{4}{*}{$8(29,63)$} \\
\hline IC complementar (a) - no conhecimento. (5/8 depoimentos) & \\
\hline IC complementar (b) - de comportamento. (2/8 depoimentos) & \\
\hline IC complementar (c) - de atitude (motivação). (2/8 dos depoimentos) & \\
\hline IC (3.2) - Colaboram para alguns, para outros não. & \multirow{3}{*}{$11(40,74)$} \\
\hline $\begin{array}{l}\text { IC complementar (a) - Uns têm dificuldade de mudar, são resistentes } \\
\text { ou rebeldes. (6/11 dos depoimentos) }\end{array}$ & \\
\hline $\begin{array}{l}\text { IC complementar (b) - Tem uns que não sabem as consequências } \\
\text { que aquela doença pode trazer para ela no futuro. Negligencia sua } \\
\text { saúde e só muda caindo. ( } 3 / 11 \text { dos depoimentos) }\end{array}$ & \\
\hline $\begin{array}{l}\text { IC (3.3) - São poucas as mudanças observadas e os resultados não } \\
\text { são tão significativos. }\end{array}$ & \multirow[t]{3}{*}{$8(29,63)$} \\
\hline $\begin{array}{l}\text { IC complementar (a) - A maioria está interessada na consulta e na } \\
\text { medicação. ( } 3 / 8 \text { depoimentos) }\end{array}$ & \\
\hline $\begin{array}{l}\text { IC complementar (b) - Tem paciente que é muito rebelde. ( } 3 / 8 \\
\text { depoimentos) }\end{array}$ & \\
\hline Total & $27(100,00)$ \\
\hline
\end{tabular}

A IC 3.1 corresponde à percepção dos profissionais de que as ações educativas "contribuem muito para mudanças no conhecimento, de atitude e/ou de comportamento" foram manifestadas por oito (29,63\%) dos 27 entrevistados (Quadro 3).

No DSC 3.1, os profissionais consideram que as mudanças podem ser observadas no cotidiano daqueles que frequentam os grupos de Hiperdia e aprendem os cuidados sobre sua saúde e por esse motivo mudam o seu comportamento ou são motivados a fazê-lo:

"Com certeza, contribui muito. A gente vê a mudança, os efeitos, no dia a dia, no cuidado que eles têm na saúde deles [...] quando começa a participar dos grupos, eles são bem orientados e acaba tendo conhecimento de fatores que eles não tinham antes [...] ela mudou a alimentação, [...] abriu a geladeira para mostrar [...] ela tem verdura, tem folhas [...]" (DSC 3.1). 
No entanto, a percepção mais frequente, compartilhada por $11(40,74 \%)$ dos 27 respondentes, refere-se à IC 3.2, segundo a qual as ações educativas “colaboram para alguns, para outros não" (Quadro 3). Para os profissionais que assim se manifestaram, embora algumas pessoas melhorem o autocuidado, $\mathrm{o}$ conhecimento e mudem os hábitos de vida, outros têm dificuldade de mudar, são resistentes, rebeldes ou não sabem das consequências que aquela doença pode trazer no futuro; negligenciam sua saúde até que a doença se agrave e as consequências sejam sentidas, como se observa no DSC 3.2:

“[...] Muitas pessoas mudam mesmo os hábitos de vida [...] Para alguns melhora o autocuidado, o conhecimento. Só que nem todos conseguem. Uns têm dificuldades [...] eles são resistentes, tem uns que são teimosos. Tem os rebeldes [...] Tem muitas que não seguem, porque [...] não sabem as consequências que aquela doença pode trazer para ela no futuro [...] teve uma [...], que teve um derrame [...] E teve sequela [...] Ela negligenciou sua saúde também. [...] num tinha que ser dessa forma né? Mas às vezes a gente só conserta caindo [...]” (DSC 3.2).

A tônica do DSC 3.2 parece ser a da importância que os profissionais de saúde atribuem à tomada de consciência pelos pacientes das implicações ou do agravamento de sua doença, como uma condição que os motiva a participar das atividades educativas e a aderir ao tratamento:

“[...] Tem muitas que não seguem, porque não tem a informação, não sabem as consequências que aquela doença pode trazer para ela no futuro. [...] nós descobrimos uma que tem diabetes, é hipertensa [...] A enfermeira já fez as recomendações. [...] O marido dela [...] é um acamado, ficou acamado há pouco tempo e a doutora descobriu que ele é hipertenso, é diabético [...] ele teve sequela. E agora apareceu nela. A família todinha. Tem um irmão dele que é hipertenso, a [...], então a maioria da família. Eles agora, infelizmente, tão seguindo esta regra, e ai os que não vinha na reunião procuraram a gente aqui essa semana [...]" (DSC 3.2).

Quando nos reportamos a mudanças de comportamento em saúde, geralmente encontramos, na base dos programas educativos mais recentes, a Teoria Social Cognitiva (TSC), enunciada por Bandura, segundo a qual o comportamento humano é reciprocamente determinado por fatores pessoais internos (cognitivos) e por eventos ambientais. Na evolução de sua teoria, 
Bandura coloca como ideia central a perspectiva da agência, ou seja, a perspectiva de o sujeito influenciar o próprio comportamento e as circunstâncias de vida de modo intencional (Bandura et al., 2008). Pode-se considerar que a TSC foi construída na insatisfação e na pouca efetividade das teorias behavioristas e tem sido usada, mais recentemente, no âmbito da psicologia cognitiva, cujos métodos são dirigidos para modificar sentimentos e ações, influenciando um padrão de comportamento social que diverge da psicologia comportamental (Assis e Nahas, 1999).

Entre as abordagens associadas à TSC, encontramos o Health Belief Model (HBM) - Modelo de Crenças em Saúde desenvolvido nos Estados Unidos por estudiosos da psicologia social. Sua premissa básica é que o mundo do percebedor determinará o que ele fará a despeito do significativo papel que o ambiente físico tem na maneira como é configurado na mente do indivíduo (Sailer, 2004). Considera-se que atualmente seja a abordagem motivacional mais frequentemente aplicada nos programas de saúde (Williams apud Assis e Nahas, 1999, p. 38).

Na sua essência, o HBM propõe que um conjunto de crenças contribua para motivar e engajar um comportamento particular relacionado à saúde. Segundo Rosenstock (1974), apud Pontiere e Bachion (2010, p.153), as características iniciais do HBM procuram prever/entender ações e atitudes dos indivíduos em relação às doenças, tendo em vista quatro variáveis (percepções) que são interdependentes entre si, de tal forma que, para adotar um comportamento preventivo, o indivíduo deverá: considerar-se suscetível a um problema de saúde, ou seja, acreditar que esse problema pode afetá-lo (percepção de susceptibilidade ou percepção de risco); perceber que o problema pode ter consequências sérias (percepção de severidade); acreditar que o problema de saúde pode ser prevenido com ações (percepção de benefícios). Esses benefícios superam os aspectos negativos, tais como impedimentos financeiros, desconforto, vergonha (percepção de barreiras). Os benefícios da ação são avaliados em razão das barreiras para realizá-la. Além disso, a presença de estímulos para a ação é importante para desencadear as percepções de susceptibilidade e severidade e motivar o indivíduo a agir. 
Assim, nos pressupostos teóricos do HBM, encontramos elementos para compreender a percepção dos profissionais de saúde sobre a motivação que leva a pessoa com DM e HA a mudar sua atitude e comportamento: quando percebe a gravidade e as consequências de sua doença e/ou quando percebem a susceptibilidade ou o risco que têm diante dela, como foi enfatizado no DSC 3.2.

A terceira visão que os profissionais de saúde têm sobre a contribuição e eficácia das ações educativas refere-se à IC 3.3: "são poucas as mudanças observadas e os resultados não são tão significativos" (Quadro 3). A ocorrência dessa IC foi de oito $(29,63 \%)$ dos 27 depoimentos. No DSC 3.3, destaca-se, novamente, a representação que os profissionais de saúde têm sobre a preferência das pessoas por abordagens individuais (consultas) e pelas práticas curativas (medicação), em relação a abordagens de caráter educativo e preventivo:

\begin{abstract}
"Eu não vejo resultado tão significativo assim, entendeu? Num vejo as pessoas mudando muito as rotinas delas, [...] A maioria dos pacientes não faz uma dieta adequada. [...] a maioria só vem interessado mesmo [...] na consulta e na medicação [...] Então o mais importante é pegar o remédio, o exame, do que ele mesmo se responsabilizar pela saúde dele, mudando hábitos de vida [...]” (DSC 3.3).
\end{abstract}

Outra representação reincidente na fala dos profissionais de saúde no DSC 3.3 é a que associa a rebeldia, principalmente das pessoas com diabetes, à dificuldade de adesão ao tratamento e à mudança de hábitos, a despeito dos todos os esforços empreendidos pela equipe para a orientação delas. Parece haver, nesse discurso, a necessidade de justificar a pouca resolubilidade da ação educativa, de certa forma atribuindo aos indivíduos a responsabilidade pela não adesão ao tratamento.

"[...] Por mais que você fale, vai atrás dele, busca, trás tudo de novo [...] Tem paciente, assim, que é muito "relutivo" [...] O diabético então é o mais rebelde de todos [...] Você orienta, orienta, mostra, senta explica e é assim. Não sei o que passa pela cabeça deles. É um paciente muito dificil de aderir a tratamento novo" (DSC 3.3).

Se somarmos a frequência das IC de ambos os discursos, DSC 3.2 e DSC 3.3 , teremos cerca de $70 \%$ dos profissionais de saúde que consideram as ações educativas pouco resolutivas para promover mudanças nos hábitos de diabéticos e 
hipertensos. Mais: ambos os discursos apontam uma representação que não é inédita entre aqueles que buscam avaliar a eficácia da educação em saúde pela ótica dos profissionais de saúde: a culpabilização do paciente pela não adesão ao tratamento é explicada pela dificuldade ou resistência (rebeldia) em mudar hábitos e também pela falta de informação ou conhecimento dele.

"[...] Uns têm dificuldades mesmo de mudar o hábito. Eles mesmo fala: não consigo. Tem os rebeldes, né? Que não aderem, que a gente não consegue, apesar da gente falar, falar, mas eles não seguem. [...] que querem viver desregradamente, querem aproveitar, querem comer, querem fazer de tudo, não segue a alimentação. Tem muitas que não seguem, porque não tem a informação, não sabem as consequências que aquela doença pode trazer para ela no futuro. Não sabe porque não pode comer sal. Como é que ele vai agir no organismo? [...] A gente faz a parte da gente, mas depende do usurário [...] " (DSC 3.2)

Essa mesma percepção por parte dos profissionais de saúde foi encontrada por Reiners et al., 2008, ao realizarem um estudo de revisão da produção bibliográfica latino-americana da última década sobre a adesão/não adesão ao tratamento de pessoas com doenças crônicas, entre as quais a HA e o DM. Reiners observou que a maioria dos fatores apontados pelos autores dos artigos para a adesão/não adesão dos pacientes estava relacionada aos próprios pacientes, ou seja, a estes era atribuída a responsabilidade maior pelo sucesso/insucesso da ação (Reiners et al., 2008). Outra visão recorrente dos profissionais de saúde foi a de que o papel do paciente é de se submeter às recomendações dos profissionais de saúde, particularmente a prescrições médicas; ele, porém, tem autonomia para não fazê-lo, o que exime o profissional de saúde da responsabilidade sobre as consequências da decisão (Reiners et al., 2008).

A culpabilização do paciente pelos problemas de saúde tem origem numa visão do discurso biologicista do processo saúde-doença, segundo o qual os problemas de saúde são decorrentes da não observância das normas de higiene pelas pessoas. Assim, garantir mudanças de atitudes e de comportamento individuais seria a chave para resolver os problemas de saúde. Ao processo educativo atribui-se a forma de produzir as mudanças; para isso, as pessoas, desprovidas de conhecimentos, deveriam convencer-se da necessidade delas a começar da assimilação passiva de prescrições normativas, cientificamente 
respaldadas. Essa competência é dos profissionais de saúde. Decorre que, se o indivíduo não muda, a responsabilidade pela produção da doença recai sobre si, ou seja, ele é culpabilizado pelos problemas de saúde (Alves, 2005).

Esse modelo, em tese, pela própria evolução histórica da saúde pública, já deveria estar superado. Na prática pode ser constantemente identificado nas ações educativas da saúde e continua influenciando programas de intervenção no campo da alimentação e nutrição, principalmente aqueles aplicados à clínica nutricional, que têm a finalidade de ampliar a adesão das pessoas ao tratamento dietético (Santos, 2010). O próprio termo "adesão", que assume uso variado em boa parte dos estudos em que é empregado, está relacionado a uma compreensão dos profissionais: a de que são os pacientes os maiores responsáveis pelos problemas de saúde e que eles, profissionais de saúde, falham ao tentar atingir uma compreensão mais profunda e promover as mudanças de comportamento desejadas.

O entendimento de que o culpado pelo insucesso da ação educativa é o sujeito sobre o qual ela recai, coincide com os projetos concretos de educação para a saúde. Estes partem de práticas educativas conteudistas, normativas e baseadas na transmissão de informações respaldadas no poder científico e consideram o público da ação educativa como alvo, como objeto de transformação, desconsiderando o seu saber e sua vivência. Nessa perspectiva, não são as situações de desigualdades no modo de organização social da doença que têm de mudar, mas os sujeitos (Meyer, 2006; Gazzinelli et al., 2005; Smeke e Oliveira, 2001; Freire, 1996).

Portanto, como aparece nos DSCs apresentados, a despeito dos esforços empreendidos pelos programas de saúde, haverá sempre aqueles que, por resistência, rebeldia, falta de informação, entendimento, consciência, entre outros, não conseguirão implementar mudanças. Pensando dessa forma, os profissionais de saúde podem estar legitimando uma abordagem educativa normativa, prescritiva, centrada no saber científico que não lhes permite conhecer os saberes, as crenças, as experiências, enfim, as razões das pessoas para mudar ou não seu comportamento. 
Ainda relativamente à resolubilidade e eficácia das ações educativas, procurou-se saber, entre os espaços educativos destacados pelos profissionais de saúde, quais os que lhes pareciam mais eficazes para educação em saúde e particularmente para a educação alimentar das pessoas com DM e HA. No Quadro 4, apresentam-se as seis IC destacadas no processamento das respostas a esta questão. Visto que cada pessoa poderia expressar uma ou mais ideias em seu depoimento, a totalização da frequência das IC não corresponde a 100\%.

Quadro 4. Ideias centrais de profissionais de saúde de uma unidade básica de estratégia de Saúde da Família sobre a eficácia dos espaços educativos para a promoção da saúde e o controle da doença entre pessoas com diabetes mellitus e/ou hipertensão arterial. Vitória-ES, 2009-2010.

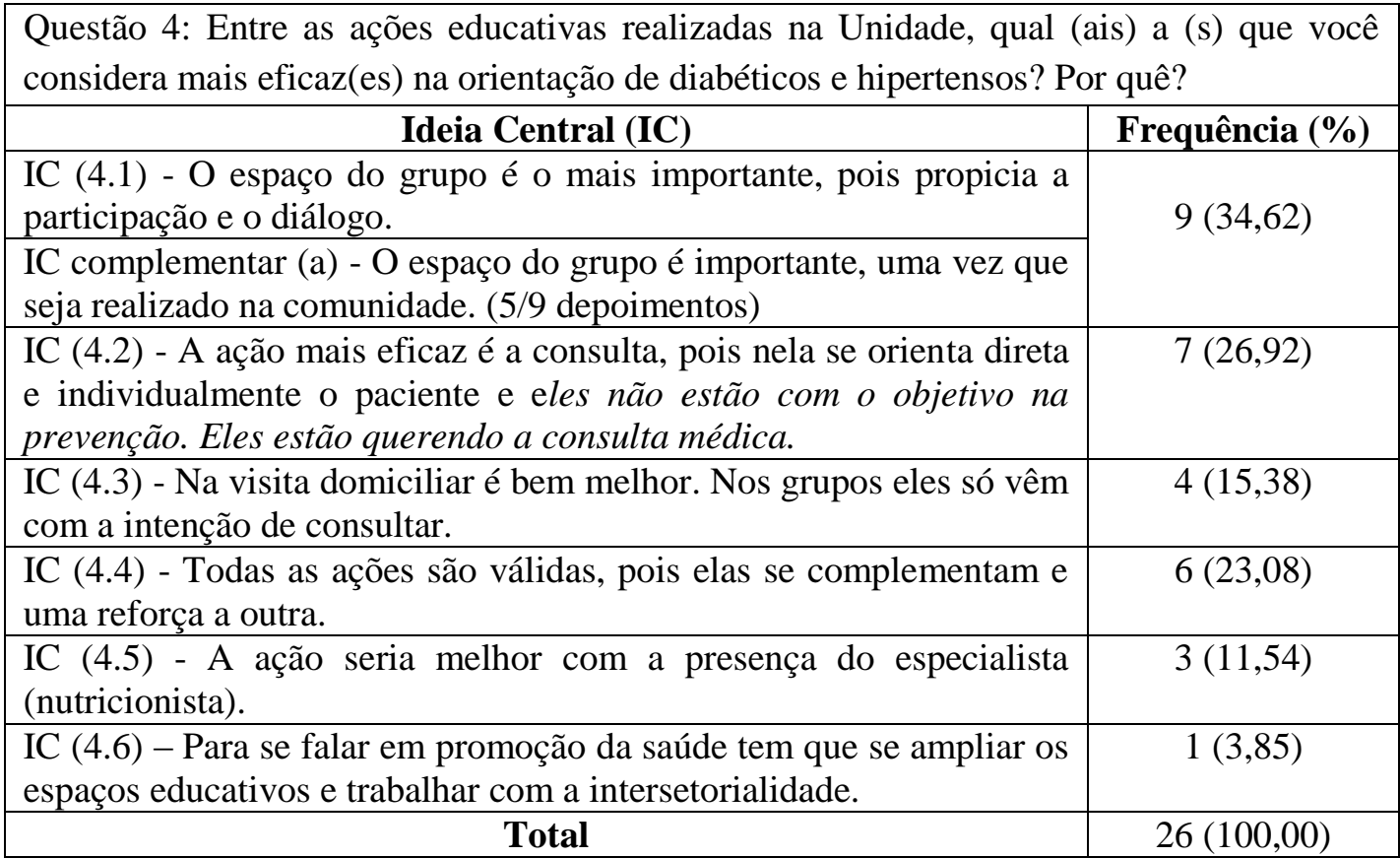

*Um mesmo depoimento pode apresentar mais de uma IC.

A IC mais frequente apareceu em nove (34,62\%) dos 26 depoimentos: "O Espaço do grupo é o mais importante, pois propicia a participação e o diálogo" (IC 4.1, Quadro 4). No DSC correspondente, destaca-se que os grupos de Hiperdia representam uma alternativa para diminuir a demanda na unidade pelo atendimento individual (consultas). Os grupos são vistos como o espaço de 
diálogo, interação e troca de experiência entre as pessoas, o que propicia a adoção de práticas mais adequadas e uma atenção humanizada:

"[...] o principal acompanhamento que a gente faz aqui são os grupos de Hiperdia mesmo, né? [...] A Unidade é um espaço que tem uma demanda muito grande, [...] focado [...] na consulta médica, então o espaço do grupo proporciona um pouco mais de diálogo. [...] na experiência do outro a pessoa vai se ver, vai perceber uma prática que ela pode estar adotando também e que vai ser boa [...]" (DSC 4.1).

Algumas expressões do DSC 4.1 denotam uma maior eficácia dos grupos em favorecer práticas que conduzam a um processo de comunicação e uma abordagem centrada no sujeito:

"[...] numa consulta individual a gente tem dificuldade de ouvir mais o usuário [...] Num espaço como este, [...] o outro falando, acho que eles se fazem entender [...] sai um pouco do técnico e ai a gente compreende mais aquilo que ele precisa [...]" (DSC 4.1).

Para Silva MA et al., 2006, os grupos de educação em saúde constituem espaços potencialmente privilegiados de empoderamento individual e coletivo, à medida que são locus de articulação das dimensões da vida humana: a dimensão social, a subjetiva e a biológica.

Torres, et al., 2003, ao descreverem e discutirem uma estratégia educativa que adotou perspectiva de promoção, prevenção e controle, realizada entre indivíduos com DM, em um ambulatório de especialidades, observaram duas circunstâncias importantes que foram coincidentes com as falas iluminadas no DSC 4.1: a primeira, porque os profissionais participantes da dinâmica dos grupos perceberam que essa experiência lhes proporcionou um aprendizado sobre como falar com as pessoas, valendo-se do conhecimento e da linguagem delas, e transmitir informações de forma que todos se envolvessem no processo educativo; a segunda, porque a dinâmica de grupo estimulou a relação interpessoal e facilitou a discussão e troca de informação entre pessoas com os mesmos objetivos, promovendo o compartilhamento de experiências comuns e o apoio mútuo.

Sobre processos comunicativos em saúde, Valla, 2000, considera que, para que o profissional de saúde exerça uma prática educativa melhor, deva fazer uso 
de uma linguagem compreensível e simples, adequada à realidade e centrada no sujeito que busque conhecer suas necessidades em relação à sua saúde e doença. Pelo que se nota, tanto no estudo de Torres, et al., 2003, quanto no material discursivo que gerou o DSC 4.1, essa postura pode ser propiciada quando a ação educativa é realizada nos grupos.

Apesar das críticas em relação às práticas educativas preestabelecidas, realizadas nos grupos formados de programas governamentais para pessoas com necessidades especiais, como é o caso dos grupos do Hiperdia, atividades grupais, quando realizadas de modo a favorecer a expressão dos participantes, permitindo a valorização de suas experiências de vida e o diálogo com o saber técnicocientífico que promovam relações interpessoais convergentes com o estabelecimento de confiança e autodeterminação e que propiciem espaços de troca de experiências e compartilhamento de saberes podem resultar em ações educativas bem sucedidas na formação de hábitos saudáveis e na adesão a tratamentos e ainda ser passíveis de promover o desenvolvimento de competências comunicativas e de trabalho no campo da educação em saúde (Francioni, Silva, 2007; Maffacciolli, Lopes, 2005; Silveira, Ribeiro, 2005; Torres, et al., 2003; Assis et al., 2002, Briceño-Leon, 1996).

Complementarmente à IC 4.1, os profissionais de saúde consideram que as ações do grupo são ainda melhores quando realizadas em espaços da comunidade e não na US. Além de ser mais cômodo e confortável para os usuários, já que a maioria deles é idosa e o deslocamento até a unidade pode ser um fator de não participação nas reuniões, agiliza as ações de acompanhamento clínico, como a aferição da pressão, dosagem da glicemia, monitoramento do peso, aviamento das receitas, entre outros procedimentos.

Em sete (26.92\%) dos 26 depoimentos, iluminou-se a IC 4.2, pela qual os profissionais de saúde consideram: “A ação mais eficaz é a consulta, pois nela se orienta direta e individualmente os pacientes que não estão com o objetivo na prevenção. Eles estão querendo a consulta médica" (Quadro 4). Para os que expressaram essa opinião, os resultados alcançados com a consulta são melhores, justamente pelo caráter de individualização dessa prática, o que possibilita uma orientação direta e baseada nas características e necessidades de cada pessoa: 
"Para mim, de todas as ações a que eu considero a mais eficaz é quando a gente está com o paciente, na consulta. A orientação mais individualizada, baseada na pessoa mesmo, que a gente orienta diretamente, vê quais são as questões de cada um, individualmente [...] Então você sabe o que você tem que reforçar de orientação [...]" (DSC 4.2).

Ilumina-se, ainda, no DSC 4.2, a fala sobre a necessidade de médico ou enfermeiro, durante a consulta, assumir o papel de outros profissionais, aconselhando o paciente sobre questões de alimentação e atividade física:

"[...] Você sabe que tem que questionar para ele: - E aí? Você iniciou aquela atividade que a gente tinha combinado? Como é que ta a alimentação? E a dieta, você tem dificuldade? [...] Damos até uma de nutricionista: falamos da alimentação, da caminhada, que não adianta seguir a prescrição médica, medicamento, é preciso lazer, exercitar o cérebro [...]" (DSC 4.2).

Conforme pode ser apreendido nos documentos oficiais, uma condição inerente aos profissionais que compõem a equipe de ESF é que esses tenham uma visão e uma atuação generalista. Especificamente em relação aos médicos, preconiza-se que eles não tenham formação de um especialista:

“... o médico da equipe preconizada pelo PSF deve ser um generalista: portanto deve atender a todos os componentes das famílias, independente de sexo e idade. [...] Sua atuação não deve estar restrita a problemas de saúde rigorosamente definida. Seu compromisso envolve ações que serão realizadas enquanto os indivíduos ainda estão saudáveis" (Brasil, 2006a, p.15).

Nota-se que são dois conceitos distintos: abordagem generalista e médico generalista, que podem ser apropriados equivocadamente para justificar a ausência de outros profissionais na equipe e assim respaldar a representação de que o médico generalista deve coadunar diferentes saberes, dando conta de exercer o aconselhamento de questões distintas e específicas, como a terapia nutricional.

Ao refletir sobre as práticas de educação em saúde no contexto da ESF, Alves (2005) ilustra essa expectativa em torno da atuação médica, exemplificando o atendimento a um paciente com crise hipertensiva. Além de administrar a 
medicação necessária, durante a consulta o médico orienta a importância da alimentação hipossódica e de exercícios regulares. Para essa autora, assistência e educação em saúde durante a consulta ambulatorial, sem que o paciente tenha que esperar o momento oficial das práticas educativas (reunião do grupo de Hiperdia), expressam integralidade da assistência.

Uma terceira IC foi identificada em quatro $(15,38 \%)$ dos 26 respondentes, que, entre os espaços educativos, percebem: "A visita domiciliar é bem melhor. Nos grupos eles só vêm com a intenção de consultar" (IC 4.3, Quadro 4). O discurso coletivo correspondente (DSC 4.3) realça a visão já expressa em outros depoimentos de que as pessoas vêm aos grupos mais com a intenção da consulta. Já na visita domiciliar, o profissional de saúde pode checar in loco se as orientações estão sendo seguidas, se a conduta com a alimentação, por exemplo, está correta; além disso, monitorar a pressão e a glicemia das pessoas, realçando novamente os aspectos de verificação e acompanhamento que caracterizam a atuação dos profissionais de saúde na visita domiciliar.

Manifesta-se novamente, nesse discurso, a dualidade entre ações coletivas e individuais. No entanto, na percepção desses profissionais, embora as pessoas prefiram as consultas (espaço individual) que acontecem no momento dos grupos (espaço coletivo), as visitas domiciliares (espaço coletivo) são mais eficazes como espaço educativo:

"Eu acho assim, que no grupo eles só vêm com a intenção de consultar, [...] têm resultado bom, mas na visita também. Quando chega na casa e estava tudo errado na alimentação, por exemplo: batata, arroz, etc. Aí a gente orienta. Quando a gente retorna a pessoa fala: Oh, eu não to comendo mais isso, eu cortei isso [...] Então eu acho que as visitas domiciliares, [...] é bem melhor pra você ta orientando." (DSC 4.3).

Uma visão mais integrada dos espaços e processos educativos foi captada em seis $(23,08 \%)$ dos 26 depoimentos analisados. Trata-se da IC 4.4, segundo a qual "todas as ações são válidas, pois elas se complementam e uma reforça a outra".

No discurso dos que compartilham essa ideia, não há destaque para um ou outro espaço educativo, mas para o fato de que uma orientação repetida, nos diversos espaços, por diferentes profissionais reforça o aprendizado e pode 
produzir resultados, desde que haja coerência por parte dos profissionais em fazer as mesmas orientações.

"Não acho que tem uma que é mais importante. [...] elas vão se
complementando. [...] A equipe faz reunião educativa com os grupos de
hipertensão e diabetes, [...] passa o sistema de nutrição, alimentação
saudável, os cuidados de nutrição. [...] Tem a visita domiciliar [...] Tem
o orientador físico [...] que vai ser questionado sobre as mesmas coisas
[...] recebem aqui, [...] na consulta médica, recebem de novo. [...] muitas
vezes o médico fala o paciente num ouve, muitas vezes a gente fala e os
outros reforçam. Quando a gente é coerente [...] faz uma mesma
orientação. Tudo é válido para eles. Todos os momentos são
produtivos." (DSC 4.4).

Outra percepção que merece destaque no DSC 4.4 é que a orientação por si só, por mais repetida e insistente, pode não ser suficiente para atingir os resultados da ação, ficando a critério do paciente acatar ou não as orientações e mudar seus hábitos:

“[...] Eles recebem aqui, passam na consulta médica, recebem de novo. A gente fica batendo sempre na mesma tecla até entrar na cabeça deles. [...] Vai agora do paciente pegar o habito, entendeu? Porque a parte mais difícil é mudar o habito da pessoa." (DSC 4.4).

A expressão desse discurso que coloca a assimilação de uma informação, norma ou conhecimento como forma de garantir a mudança de comportamento ou a adesão a uma recomendação precisa ser questionada. Os profissionais reconhecem em seu discurso a insuficiência dessa intervenção, visto que o mais difícil é a pessoa mudar o hábito.

Essa ideia foi enunciada por Briceño-Leon como um dos princípios que sedimentam suas teses sobre a educação em saúde e a participação comunitária: "Ninguém pode cuidar da saúde do outro, se este não quer fazê-lo por si mesmo" (Briceño-Leon, 1996, p. 9), ou seja, as pessoas devem ser ativas na garantia da própria saúde. Os programas não podem ser impostos; é preciso contar com a participação das pessoas, da comunidade, sendo esse um princípio ético que confere eficácia e sustentabilidade às ações de saúde.

Briceño-Leon busca, nas teorias das ciências sociais, elementos para explicar por que, mesmo diante da informação, do conhecimento, as pessoas podem decidir não mudar o comportamento, não seguir orientações que, ao 
menos, na visão daqueles que as propagam, são importantes para a saúde. Ele distingue diversas abordagens sobre as chamadas teorias da ação, que, em resumo, podem ser diferenciadas em duas grandes correntes teóricas: as que consideram que são as circunstâncias externas que envolvem a vida das pessoas, que as levam a reagir ou a escolher seu comportamento e as que sustentam que as pessoas agem em razão de seus valores e suas crenças. Sendo assim, a situação teria pouca importância diante do que as pessoas pensam, daquilo em que elas acreditam e dos seus hábitos. Se assumirmos a segunda posição, ou seja, que o comportamento está centrado em circunstâncias internas das pessoas, a via mais provável para mudá-lo, seria a da educação (Bricenõ-Leon, 1996).

Com prevalência menor, em relação às anteriormente analisadas, duas outras IC foram destacadas nas respostas à questão sobre a eficácia dos espaços e ações educativas. Elas não versam propriamente sobre qual dos espaços é considerado mais eficaz, mas realçam dois importantes aspectos para qualificação das ações educativas: a IC 4.5, segundo a qual "a ação seria melhor com a presença do especialista (nutricionista)", e a IC 4.6 - "Para se falar em promoção da saúde tem que se ampliar os espaços educativos e trabalhar com a intersetorialidade" (Quadro 4).

O DSC 4.5 evidencia a percepção de alguns profissionais de saúde de que o especialista, fundamentado em suas competências e habilidades específicas, poderia tornar a ação educativa mais eficaz:

“[...] É aquele profissional específico, no caso, o nutricionista, ta procurando ensinar com detalhes [...] Mostrando talvez receitas, opções de alimentação, de dieta. A gente fala, mas não aprofunda [...] orienta, mas às vezes eles nem leva muito em consideração [...] acho que seria mais eficaz [...]" (DSC 4.5).

Para responder a demandas como essa e melhorar a qualidade e resolutividade da Atenção Básica, o Ministério da Saúde propôs, em 2007, a criação do Núcleo de Apoio à Saúde da Família (NASF), constituídos por equipes de profissionais de diferentes áreas do conhecimento, que atuarão em parceria com os profissionais das equipes de Saúde da Família, no apoio às mesmas na unidade em que o NASF estiver cadastrado (CONASS, 2007). 
A composição de cada núcleo deverá ser definida pelos gestores municipais em conjunto com as equipes de Saúde da Família, conforme critérios de prioridades locais e de disponibilidade de profissionais de cada ocupação. O NASF deverá fundamentar-se nos princípios norteadores da Atenção Primária à Saúde (APS), tais como: ação interdisciplinar e intersetorial, educação permanente em saúde dos profissionais e da população, territorialidade, integralidade, participação social, educação popular, promoção da saúde e humanização (Brasil, 2009).

A atuação do profissional do NASF na área da nutrição deverá estruturarse em conformidade com os seguintes eixos estratégicos: 1) promoção de práticas alimentares saudáveis; 2) contribuição na construção de estratégias que respondam às principais demandas assistenciais quanto aos distúrbios alimentares, às deficiências nutricionais, à desnutrição e obesidade; 3) desenvolvimento de projetos terapêuticos, especialmente nas doenças e agravos não transmissíveis; 4) realização de diagnóstico alimentar e nutricional da população e identificação de hábitos alimentares; 5) promoção da segurança alimentar e nutricional, com vistas ao direito humano à alimentação adequada (Brasil, 2009).

A atuação do nutricionista, como a de qualquer outro profissional que integre o NASF, pode ser operacionalizada no apoio matricial a diversas ações, entre as quais a de atendimento compartilhado, projetos terapêuticos singulares, atendimento em conjunto e ações educativas.

Por fim, o DSC 4.6 traz à tona uma das construções mais imperiosas na atualidade para a qualificação das práticas da Atenção Básica à Saúde: a intersetorialidade das ações:

"[...] Prá falar em promoção da saúde você teria que trabalhar [...] a intersetorialidade [...] com a cultura, [...] com a educação, [...] com a saúde, com o ambiente [...]" (DSC 4.6).

A intersetorialidade está colocada como um eixo estruturante da da APS. É capaz de conferir aos profissionais possibilidades de prestar uma assistência mais integral e resolutiva, numa perspectiva de promoção da saúde pautada na qualidade de vida, com centralidade no usuário e no seu envolvimento ativo no processo de educação em saúde para o autocuidado (Paula et al., 2004). 
Esses autores perceberam uma confusão conceitual sobre o tema assim que analisaram o DSC de enfermeiros de um núcleo de Saúde da Família de Ribeirão Preto-SP. Tentaram apreender como eles compreendiam a intersetorialidade e como buscavam a articulação com os equipamentos sociais da população de sua área adstrita, pois os entrevistados tomavam-na por responsabilidade individual nas demandas individualizadas dos usuários, identificando a intersetorialidade como um processo de trabalho árduo e solitário. Isso sugeria que esse princípio era um desafio a ser conquistado, pois os profissionais de setores ainda trabalhavam de forma fragmentada.

De forma semelhante, o material discursivo da IC 4.6 revela um sentimento de que a intersetorialidade, embora fundamental para trabalhar a educação em saúde numa perspectiva de promoção, articulada com outros setores da sociedade, ainda é um princípio a ser conquistado:

"[...] Prá falar em promoção da saúde você teria que trabalhar com essas ações (educativas) muito ampliadas e também com vários segmentos da população, trabalhar a intersetorialidade, né? Tem que trabalhar com a cultura, tem que trabalhar com a educação, juntamente com a saúde, com o ambiente, então a gente não chegou a este ponto não [...]" (DSC 4.6).

A intersetorialidade é um dos princípios fundamentais da promoção da saúde, que requer a atuação de múltiplos setores quando se tem o foco nos determinantes da saúde e nas ações necessárias à redução das desigualdades sociais. Constitui um dos desafios das políticas públicas pela persistência de uma lógica setorial fragmentada e desarticulada no modelo administrativo tradicional de tais políticas (Sicoli, Nascimento, 2003).

Esses autores, ao analisarem cinco experiências bem sucedidas das políticas públicas municipais com interface na promoção da saúde (Santo-SP; Vitória-ES; Belo Horizonte-MG, Ipatinga-MG e Icapui-CE), observaram dificuldade de operacionalização da intersetorialidade em razão da resistência dos diversos setores envolvidos, mesmo nos casos de Ipatinga e Vitória, onde a intersetorialidade era uma meta explícita a ser atingida.

Em sua tese de doutoramento, Andrade, 2004, elabora a intersetorialidade como um dilema para a saúde e para as políticas públicas. Fundamentado num 
extenso estudo sobre esse tema, comparou a aplicação de políticas públicas setoriais nos municípios de Fortaleza-CE e Curitiba-PR, no período de 1997 a 2001. Valendo-se de ferramentas metodológicas, como análise documental, entrevistas, grupos focais e DSC, seu estudo encontrou similaridades e diferenças entre as duas experiências, mas, fundamentalmente em ambas, evidenciou um consenso discursivo e um dissenso prático sobre a intersetorialidade. Este último, relacionado à contradição entre a necessidade de integração de práticas e saberes e uma setorialização do Estado, organizada com base em poderes disciplinares hegemônicos e em poderes advindos de composições político-partidárias (Andrade, 2004).

A despeito do reconhecimento da intersetorialidade como um importante componente para mudança do modelo assistencial e de reorientação da atenção à saúde, os estudos relatados nos dão evidências da complexidade de fatores que condicionam a sua implantação na prática em qualquer esfera e níveis de aplicação das políticas públicas.

\section{CONSIDERAÇÕES FINAIS}

A análise dos depoimentos dos profissionais de saúde permitiu identificar a representação social desses sujeitos sobre as ações educativas no âmbito da ESF, destinadas à capacitação das pessoas com DM e HA para o autocuidado e a promoção da saúde.

Foram destacados, como principais espaços das ações educativas, os grupos do Hiperdia, as consultas médicas e de enfermagem e as visitas domiciliares.

O primeiro é percebido como espaço em que a dicotomia entre práticas coletivas e individuais se manifesta e se materializa em ações de caráter tanto preventivo (atividades em que as orientações são realizadas coletivamente, como palestras e oficinas) quanto curativo (relacionadas às orientações individualizadas do médico e enfermeiro em suas consultas). Já as visitas domiciliares são reconhecidas como espaço coletivo privilegiado pelos ACS, pela possibilidade de 
verificar, in loco, no dia a dia das pessoas, o seguimento das orientações realizadas sobre a alimentação, medicação, atividade física, entre outras.

Embora a maioria dos profissionais de saúde tenha elegido os grupos de Hiperdia como o espaço mais resolutivo para o desenvolvimento das ações educativas, principalmente quando são realizados nos equipamentos comunitários e não na US, parte expressiva realçou, em seu depoimento, a maior eficácia das consultas realizadas quer na unidade, quer nos grupos. Na visão dos profissionais, a prática preferida pelos sujeitos-pacientes. Evidenciam-se, nesses dois discursos, contrapontos entre as práticas entendidas como coletivas, que favorecem o diálogo e a troca de experiências entre as pessoas e privilegiam os aspectos preventivos da assistência, e as práticas entendidas como individuais, que privilegiam a atenção clínico-prescritiva, individualizada e os aspectos curativos do plano terapêutico.

Essa ênfase na dualidade entre as ações que são representadas pelos sujeitos como práticas coletivas/preventivas e aquelas que são representadas como individuais/curativas foi recorrente tanto nos discursos em que se apreendeu a dinâmica dos espaços educativos quanto nos que versaram sobre os seus resultados.

Por um lado, essa visão dicotômica das ações educativas pode ser explicada pela incorporação na linguagem dos sujeitos-profissionais de categorias analíticas historicamente usadas no discurso da saúde pública, para classificar modelos e abordagens distintas das práticas assistenciais em saúde. Supõe-se que esses profissionais, embora sem muita clareza, estejam se apropriando de expressões do discurso oficial. Esse discurso preconiza a necessidade de reorientação das práticas vigentes, que privilegiam os aspectos curativos e fragmentários da assistência, para um modelo que preze a integralidade da assistência e priorize os aspectos preventivos e promocionais da saúde. Nessa perspectiva, seria a ESF um locus, e a educação em saúde um meio para promover a reorientação desejada; por outro lado, é possível que esse discurso esteja refletindo uma concepção fragmentária da saúde e, por extensão da assistência, coincidente com o modelo hegemônico vigente. 
A respeito da participação dos profissionais de saúde nas ações educativas, a percepção predominante é que todos os integrantes da equipe da ESF se envolvem nessas ações de alguma forma, além de outros profissionais da unidade que não são exclusivos de uma equipe. Alguns depoimentos expressaram certa insegurança do ACS em assumir atividades educativas para as quais não se sentem plenamente preparados, a exemplo das palestras e oficinas, que geralmente são realizadas pelos enfermeiros, médicos ou outro profissional convidado. Outra parte dos profissionais de saúde considera que a ação educativa efetiva é aquela realizada pelo médico ou pelo enfermeiro, o que sugere a persistência do modelo centrado no médico ou no saber científico que ele representa.

Nota-se que, especialmente no âmbito da ESF, a centralidade dos médicos nas ações de saúde parece expandir-se para outros profissionais, especialmente o enfermeiro, talvez pelo status conferido a esse profissional na coordenação das ações da ESF. A preocupação aqui não reside nos aspectos coorporativos dessa centralização, mas na identificação desses profissionais com uma postura clínica idealizada na abordagem terapêutica curativa, individualizada e, muitas vezes, não integral, que se distancia da concepção oficialmente idealizada para os profissionais da ESF.

Outro aspecto importante a comentar diz respeito à necessidade de distinguir as ações educativas de caráter geral, relacionadas à promoção de hábitos saudáveis, que são da competência de qualquer profissional de saúde, das atividades educativas que compõem conteúdos e processos comunicacionais mais complexos e requerem, portanto, o desenvolvimento de competências e habilidades em áreas específicas do conhecimento. Para atingir esse discernimento e qualificar as ações educativas, os profissionais de saúde, em especial aqueles que são responsáveis pelas instâncias de planejamento e coordenação das ações de saúde, precisam apropriar-se das bases teórico-metodológicas e pedagógicas que regem a educação em saúde. Esta é uma questão imperiosa a ser estimulada durante a formação profissional, bem como pelas políticas de educação permanente em saúde.

A representação das ações educativas como fundamentais para preparar o indivíduo para o autocuidado e a promoção de sua saúde não foi tão relevante nos 
depoimentos como era de esperar, pelo menos ao nível do discurso. A maior parte dos profissionais de saúde considera que essas ações colaboram apenas para algumas pessoas que se dispõem a mudar; para outras que são resistentes, rebeldes ou desconhecem as implicações do agravamento da enfermidade, os resultados positivos são relativos e/ou pouco significativos.

Os discursos coletivos são enfáticos e recorrentes em relação à rebeldia e relutância dos diabéticos em aderir às orientações prescritas pelos profissionais, trazendo à tona um elemento perverso do modelo assistencial hegemônico: a culpabilização dos sujeitos por sua doença, pelo agravamento dela, pela falta adesão ao tratamento e, em última instância, pelo insucesso da ação educativa.

Atribuir a responsabilidade do sucesso das ações educativas aos sujeitos, para os quais a ação educativa é direcionada, é uma visão que geralmente está associada às propostas de educação para a saúde, que privilegiam os conteúdos e a transmissão passiva de informações e têm o público da ação educativa por alvo; consideram-no como objetos e não como sujeitos de transformação, desprezando o seu saber e sua vivência. Pensando dessa forma, é provável que os profissionais de saúde estejam legitimando uma abordagem educativa normativa, prescritiva, centrada no saber científico que não lhes permite conhecer os saberes, as crenças, as experiências, enfim, as razões por que as pessoas optam por esta ou aquela conduta em relação à sua saúde.

Nos depoimentos não foram encontrados elementos consistentes que pudessem ser associados a uma preocupação de envolvimento da comunidade no processo educativo; ao contrário, os discursos trazem evidências de que a elaboração, o pensar e o planejamento dessas atividades ocorrem "entre os muros" da unidade, na maioria das vezes numa informalidade técnica, metodológica e pedagógica, o que pode comprometer os resultados do processo educativo. Recomenda-se que mesmo as práticas oriundas de programas de saúde preestabelecidos, como o de acompanhamento e controle do diabetes e da hipertensão, sejam alvo de reflexão e insiram a participação da comunidade como um de seus preceitos.

A qualificação das ações educativas na abordagem de pessoas com HA e/ou DM é fundamental para o tratamento da doença, para a prevenção de 
complicações crônicas, a promoção de saúde e a melhoria da qualidade de vida. No entanto, para impactarem positivamente, elas requerem um conjunto de condições que incluam a adoção de abordagens pedagógicas participativas e os processos comunicacionais humanizados, centralizados nos sujeitos e na percepção deles sobre o processo saúde-doença.

\section{REFERÊNCIAS}

ALMEIDA-PITITTO B. Impacto de um programa de intervenção no estilo de vida sobre o perfil de risco cardiometabólico da população nipo-brasileira de alto risco. [Tese de Doutorado]. São Paulo. Faculdade de Saúde Publica, Universidade de São Paulo, 2009.

ALVES, V.S.; NUNES, M.O. Educação em saúde na atenção médica ao paciente com hipertensão arterial no Programa Saúde da Família. Interface- Comunic. Saúde Educ. v.10, n.19, p.131-147, 2006.

ALVES, V.S. Um modelo de educação em saúde para o programa de saúde da família: pela integralidade da atenção e reorientação do modelo assistencial. Interface- Comunic. Saúde Educ., v.9, n.16, p.39-52, 2005.

ANDRADE, L.O.M. A saúde e o dilema da intersetorialidade. Tese (Doutorado). Universidade Estadual de Campinas. Faculdade de Ciências Médicas. Campinas, 2004.

ARAÚJO, D.R.D. Como transcrever sua entrevista: técnica de editoração da transcrição de entrevista em pesquisa de abordagem compreensivista. Psico, v. 32, n.1, p. 147-157, 2001.

ARAUZ, A.G. et al. Intervención educativa comunitaria sobre la diabetes comunitária en el ámbito de la atención primaria. Rev Panam Salud Publica, Washington, v.9, n.3, p.145-153, 2001.

ASSIS, M.A.A.; NAHAS, M.V. Aspectos motivacionais em programas de mudança de comportamento alimentar. Rev. Nutr., v.12, n.1, p. 33-41, 1999.

ASSIS, M. et al. Repercussões de uma experiência de promoção da saúde no envelhecimento: análise preliminar a partir das percepções dos idosos. Textos Envelhecimento. V.4, n.7, 2002. Disponível em:

$<$ http://revista.unati.uerj.br/scielo.php?script=sci_arttext\&pid=S1517-

59282002000100005\&lng=pt\&nrm=iso > Acesso em: 10 jan. 2011.

BANDURA, A. et al. Teoria Social Cognitiva: conceitos básicos. Porto Alegre: ArtMed, 2008. 
BARDIN, L. Análise de conteúdo. Lisboa: Edições 70, 1977.

BARRETO, M.L.; CARMO, E.H. Padrões de adoecimento e de morte da população brasileira: os renovados desafios para o Sistema Único de Saúde. Ciênc. saúde coletiva, vol.12, suppl., p.1179-1790, 2007.

BOING, A.C; BOING, A.F. Hipertensão arterial sistêmica: o que nos dizem os sistemas brasileiros de cadastramento e informações em saúde. Rev Bras Hipertens, vol. 14, n. 2 , p. 84-88, 2007.

BOOG, M.C.F. Educação nutricional: por que e para quê? Artigo. Jornal Unicamp. Universidade Estadual de Campinas. 2 a 8 de agosto de 2004, p.2; 2004. Disponível em:

$\langle$ http://www.unicamp.br/unicamp/unicamp_hoje/jornalPDF/ju260pag02.pdf $>$. Acesso em: 25 set. 2010.

BRASIL. Ministério da Saúde. Secretaria de Atenção Básica. Departamento de Ações Programáticas Estratégicas. Diretrizes do NASF - Núcleos de Apoio a Saúde da Família. Série A. Normas e Manuais Técnicos. Cadernos de Atenção Básica, n.27. Brasília, 2009.

Ministério da Saúde. Política Nacional de Atenção Básica e revisão das diretrizes e normas para a organização da atenção básica para o programa de saúde da família e programa de agentes comunitários de saúde. Portaria n. 648, de 28 de março de 2006. Brasília, 2006.

Ministério da Saúde. A vigilância, o controlo e a prevenção das doenças crônicas não-transmissíveis: DCNT no contexto do Sistema Único de Saúde brasileiro. Brasília: Organização Pan-Americana da Saúde, 2005.

Ministério da Saúde. Plano de Reorientação da Atenção à Hipertensão Arterial e ao Diabetes Mellitus: manual de hipertensão arterial e diabetes mellitus. Brasília, 2001.

. Ministério da Saúde. Secretaria de Políticas de Saúde. Departamento de Atenção Básica. A Implantação da US da família. Cadernos de Atenção Básica 1. Brasília, 2000.

Ministério da Saúde. Secretaria de Assistência à Saúde. Coordenação de Saúde da Comunidade. Saúde da família: uma estratégia para a reorientação do modelo assistencial. Brasília, 1997.

BRICEÑO-LEON, R. Siete tesis sobre la educación sanitária para la participación comunitária. Cadernos de Saúde Pública, v.12, n.1, p.7-30, 1996.

CERVATO, M.A. et al. Bases teóricas para a prática da educação nutricional. Rev Nutrição em Pauta. 2004. Disponível em:

<http://www.nutricaoempauta.com.br/lista_artigo.php?cod=45>. Acesso em 11 out. 2010.

CONASS. Núcleo de Apoio à Saúde da Família (NASF). Nota Técnica n.20. Brasília, 2007. Disponível em:<http://www.conass.org.br/admin/arquivos/NT20-07.pdf > . Acesso em 11 jan. 2011. 
CRACO, P.F. Ação comunicativa no cuidado à saúde da família: encontros e desencontros entre profissionais de saúde e usuários. Tese (Doutorado). Escola de Enfermagem de Ribeirão Preto. Universidade de São Paulo, São Paulo, 2006.

DANSINGER, M.L. et al. Comparison of the Atkins, Ornish, Weight Watchers and Zone Diets for Weight Loss and Heart Disease Risk Reduction. A Randomized Trial. Journal of American Medical Association, v.293, n.1, p.43-53, 2005.

ESCOSSIA, L. da. O coletivo como plano de ação na Saúde Coletiva. InterfaceComunic. Saúde Educ. vol.13, s.1, p 689-694, 2009.

FONTANA, A.; FREY, J.H. The interview - from structured questions to negociated text. In: DENZIN, N.; LINCOLN, Y. Handbook of qualitative research. $2^{\text {nd }}$ ed. Thousand Oaks, CA: Sage Publications, 2000. p.645-671.

FONTANELLA et al. Amostragem por saturação em pesquisas qualitativas em saúde. Cad. saúde publica, v.24, n.1, p.17-27, 2008.

FRANCIONI, F.F.; SILVA, D.G.V. O processo de viver saudável de pessoas com Diabetes Mellitus através de um grupo de convivência. Texto contexto - enferm., vol.16, n.1, p.105-111, 2007.

FREIRE, P. Pedagogia da autonomia: saberes necessários à prática educativa. São Paulo: Paz e Terra, 1996.

GARATTINI, L. et al. Direct medical costs unequivocally related to diabetes in Italian specialized centers. Eur J Health Econ., v.5, n.1, p.15-21, 2004.

GAZZINELLI, M.F.et al. Educação em saúde: conhecimentos, representações sociais e experiências da doença. Cad. Saúde Pública, v.21, n.1, p.200-206, 2005.

GORDILHO, A. et al. Desafios a serem Enfrentados no Terceiro Milênio pelo Setor Saúde na Atenção ao Idoso. Rio de Janeiro: Universidade Aberta da Terceira Idade. Universidade do Estado do Rio de Janeiro, 2000.

GUSMÃO, C.M.V. Processo grupal: reflexões de uma prática com jovens em saúde mental. Cogitare Enferm., v.8, n.2, p.9-17, 2003.

HAJJAR, I., KOTCHEN, T. Regional variations of blood pressure in the United States are associated with regional variations in dietary intakes: the NHANES-III data. Journal of Nutrition, v.133, n.1, p. 211-214, 2003.

L'ABBATE, S. A análise institucional e a saúde coletiva. Cienc. Saude Coletiva, v.8, n.1, p.265-74, 2003.

LEFÈVRE, F.; LEFÈVRE, A.M.C. O discurso de sujeito coletivo: um novo enfoque em pesquisa qualitativa (desdobramentos). Caxias do Sul: Educ, 2003.

$\overline{2004 .}$

Promoção de saúde: a negação da negação. Rio de Janeiro: Vieira e Lente,

LESSA, I. Doenças crônicas não-transmissíveis no Brasil: um desafio para a complexa tarefa da vigilância. Ciênc. saúde coletiva, vol.9, n.4, p.931-943, 2004. 
LIMA, R. T. et al. Educação em saúde e nutrição em João Pessoa, Paraíba. Revista de Nutrição, Campinas, v.13, n.1, p.29-36, 2000.

MAIA, F.F.R.; ARAÚJO, L.R. Projeto 'Diabetes Weekend': Proposta de Educação em Diabetes Mellitus tipo I. Arq Bras de Endocrinol e Metab, v.46, n.5, p.566-573, 2002.

MAFFACCIOLLI, R.; LOPES, M.J.M. Educação em saúde: a orientação alimentar através de atividades de grupo. Acta Paul Enferm, v.18, n.4, p.438-445, 2005.

MEYER, D.E.E. et al. "Você aprende. A gente ensina?" Interrogando relações entre educação e saúde desde a perspectiva da vulnerabilidade. Cad. Saúde Pública, v.22, n.6, p.1335-1342, 2006.

MINAYO, M.C.S. O desafio do conhecimento: pesquisa qualitativa em saúde. São Paulo:Ed. Hucitec, 1993.

MINISTÉRIO DA SAÚDE. Secretaria de Políticas Públicas. Plano de Reorientação da Atenção à Hipertensão Arterial e ao Diabetes Mellitus. Rev. Saúde Pública, v.35, n.6, p.585-588, 2001. Informes Técnicos Institucionais.

OSÓRIO, L.C. Grupos teorias e práticas: acessando a era da grupalidade. Porto Alegre: Artes Médicas Sul, 2000.

PATTON, M.Q. The nature of quality inquiry. In: Qualitative research $\mathbf{e}$ evaluation methods. $3^{\text {nd }}$ ed. Thousand Oaks, CA: Sage Publications, 2002. p.3-29.

PAULA et al. Intersetorialidade: uma vivência prática ou um desafio a ser conquistado? O discurso do sujeito coletivo dos enfermeiros nos Núcleos de saúde da família do Distrito Oeste - Ribeirão Preto. Interface - Comunic., Saúde, Educ., v.8, n.15, p.331348, 2004.

PICHON-RIVIÈRE, E. El processo grupal. Del psicanálisis a la psicología social. Buenos Aires: Nueva Vision, 1988.

PONTIERE, F.M.; BACHION, M.M. Crenças de pacientes diabéticos acerca da terapia nutricional e sua influência na adesão ao tratamento. Rev. Ciên Saúde Coletiva, v.15, n.1, p.151-160, 2010.

REINERS, A.A.O. et al. Produção bibliográfica sobre adesão/não-adesão de pessoas ao tratamento de saúde. Ciênc. Saúde Coletiva (online), v.13, s.2, p.2299-2306, 2008. ISSN 1413-8123. Disponível em:

http://www.scielosp.org/pdf/csc/v13s2/v13s2a34.pdf . Acesso em: 20 jan. 2011.

ROSA, W.A.G.; LABATE, R.C. Programa de saúde da família: a construção de um modelo de assistência. Rev Latino-am Enfermagem, v.13, n.6, p.1027-1034, 2005.

SAILER, G.C. Adesão de trabalhadores de enfermagem ao tratamento com antiretrovirais pós-exposição ocupacional a material biológico. Dissertação (Mestrado) - Escola de Enfermagem de Ribeirão Preto. Universidade de São Paulo. São Paulo. 2004. 
SALES et al. O emprego da abordagem DSC (discurso do sujeito coletivo) na pesquisa em educação. Linhas, v.8, n.1, p.124-145, 2007. Disponível em:

<http://www.periodicos.udesc.br/index.php/linhas/article/view/1361/1167>. Acesso em: 10 de out. 2010.

SAKATA, K.N. Concepções da equipe de saúde da família sobre as visitas domiciliares. Rev Bras Enferm, v.60, n.6, p.659-664, 2007.

SANTOS, L.A.S. O fazer educação alimentar e nutricional: algumas contribuições para reflexão. Ciênc Saude Colet, 2010. Em prelo. Disponível em: $<$ http://www.cienciaesaudecoletiva.com.br/artigos/artigo_int.php?id_artigo=6615>Acess o em: 5 jan. 2011.

SANTOS, M.G.N.; BARACHO, M.F.P. Educação em diabetes: uma experiência no Hospital do CRUTAC, UFRN, Sto. Antônio, RN. Rev Bras de Anal Clin, v.27, n.2, p.57-60, 1995.

SARTORELLI, D.S. et al. Beneficial effects of short term nutritional conselling at the primary health-care level among Brasilian adults. Public Health Nutrition, v.8, n.7, p.820-825, 2004.

SCHERER, M.D.A. et al. Rupturas e resoluções no modelo de atenção à saúde reflexões sobre a estratégia de saúde da família com base nas categorias Kuhnianas. Interface Comunic., Saúde, Educ., v.9, n.16, p.53-66, 2005.

SEVERINO, A. J. Metodologia do trabalho científico. São Paulo: Cortez, 1996.

SICOLI, J. L.; NASCIMENTO, P. R. Promoção de saúde: concepções, princípios e operacionalização. Interface - Comunic., Saúde, Educ. (online), v.7, n.12, p. 101-122. 2003. ISSN 1414-3283. Disponível em:

<http://www.scielo.br/pdf/icse/v7n12/v7n12a07.pdf>. Acesso em: 26 jan. 2011.

SILVA, M.A. et al. Enfermeiros e grupos em PSF: possibilidade para participação social. Cogitare Enferm., v.11, n.2, p.143-149, 2006.

SILVA, M.V.L. Efeitos do aconselhamento dietético no tratamento da Hipertensão Arterial em hipertensos da US de Andorinhas, Vitória, ES. [Dissertação de Mestrado]. Vitória: Centro Biomédico da Universidade Federal do Espírito Santo, 2005.

SILVA, T.R. et al. Controle de diabetes mellitus e hipertensão arterial com grupos de intervenção educacional e terapêutica em seguimento ambulatorial de uma unidade básica de saúde. Saúde Soc., vol.15, n.3, p.180-189, 2006.

SILVEIRA, L.M.C; RIBEIRO, V.M.B. Grupo de adesão ao tratamento: espaço de "ensinagem" para profissionais de saúde e pacientes. Interface - Comunic., Saúde, Educ. [online], vol.9, n.16, p.91-104, 2005. ISSN 1414-3283.

SMEKE, E.L.M.; OLIVEIRA, N.L.S. Educação em saúde e concepções do sujeito. In: VASCONCELOS, E.M. (Org.). A saúde nas palavras e nos gestos: reflexões da rede popular e saúde. São Paulo: Hucitec, 2001. 
TORRES, H.C.; HORTALE, V.A.; SCHALL, V. A experiência de jogos em grupos operativos na educação em saúde para diabéticos. Cad. Saúde Pública, v.19, n.4, p.10391047, 2003.

VALLA, V.V. Saúde e educação. Rio de Janeiro: DP\&A Editora, 2000.

Educação popular, saúde comunitária e apoio social numa conjuntura de globalização. Cad Saúde Pública, v.15, n.2, p.7-14, 1999.

VASCONCELOS, E.M. Educação popular e a atenção à saúde da família. São Paulo: Hucitec, 1999.

Educação popular como instrumento de reorientação das estratégias de controle das doenças infecciosas e parasitárias. Cad Saúde Pública, v.14, n.2, p.39-57, 1998.

WEARE, K. The contribution of education health promotion. In: BUNTON, R.; MACDONALD, G. (Eds). Health promotion: disciplines, diversity and developments, $2^{\mathrm{a}}$ e. London: Routledge, 2002, p.102-125.

YACH, D. et al. Global burden of chronic diseases. Overcoming impediments to prevention and control. Journal of the American Medical Association, v.291, n.21, p.2616-2622, 2004.

ZIMERMAN, D.E.; OZÓRIO, L.C. Como trabalhamos com grupos. Porto Alegre: Artes Médicas Sul, 1997.

ZIMERMAN, G.I. Velhice: aspectos biopsicossociais. Porto Alegre: Artes Médicas Sul, 2000. 


\section{Dificuldades e desafios da ação educativa com foco na educação nutricional de pessoas com diabetes mellitus e hipertensão arterial: a visão dos profissionais da Estratégia de Saúde da Família.}

Ana Maria Bartels Rezende

Ana Maria Cervato-Mancuso

\section{INTRODUÇÃO}

O impacto da morbimortalidade cardiovascular na população brasileira, num contexto epidemiológico de transição em que as doenças crônicas não transmissíveis (DCNT) se sobrepõem às infecciosas e carenciais, impõe ao Sistema de Saúde garantir, no espaço político-operacional, o acompanhamento e a assistência sistemática dos portadores desses agravos e desenvolver ações de promoção da saúde e prevenção dessas doenças.

Entre as DCNT, as doenças do aparelho circulatório (DAC), em especial as coronarianas, constituem importante problema de saúde pública e, segundo registros oficiais, a primeira causa de morte no país (Brasil, 2005; Lessa, 2004; Gordilho et al., 2000). A hipertensão arterial (HA) e o diabetes mellitus (DM), principais condições de risco para essas doenças, encontram-se entre as dez primeiras causas de morte em vários países e suas complicações elevam o custo médico-social e atingem diretamente o Sistema de Saúde (Yach et al., 2004; Garantini et al., 2004; Flack et al., 2002; Mion et al., 2002).

As modificações no estilo de vida e o controle de fatores de risco modificáveis, como dislipidemias, obesidade, HA, DM, tabagismo, sedentarismo, alimentação, entre outros, são a base do tratamento e controle dessas doenças. 
Relativamente à dieta, estudos enfatizam o seu papel na prevenção e controle das doenças, especialmente a sua associação com a redução e o controle dos fatores de risco para as DAC (Dansinger et al., 2005; Appel et al., 1997; Hajjar e Kotchen, 2003). No entanto, estilo de vida relacionado à dieta, à prática da atividade física, à abstenção de álcool e fumo, entre outras, que envolvam o comportamento social das pessoas, são difíceis de modificar.

A baixa adesão ou continuação ao tratamento de diabéticos e hipertensos está relatada em alguns estudos, em que pese à diversidade de metodologias e critérios empregados.

Lessa e Fonseca, 1997, em estudo sobre raça, aderência ao tratamento e/ou consulta e controle da hipertensão obtiveram, entre 200 pacientes entrevistados, um índice de adesão ao tratamento de 41,5\%, frequência que foi considerada pelas autoras mais elevada ou similar às observadas na literatura (Lessa, Fonseca, 1997).

Ao estudarem a situação do cuidado dos pacientes diabéticos assistidos em uma unidade de atenção primária, Araújo et al., 1999, constataram: apenas 28,4\% relataram fazer uso de dieta hipocalórica (tomada no estudo como critério para seguimento de dieta adequada ao diabético) e somente 20,9\% faziam algum tipo de atividade física como forma de tratamento.

Estudo abrangendo 378 pacientes diabéticos assistidos na Atenção Primária à Saúde (APS) encontrou resultados que também apontam a baixa adesão à dieta e à atividade física: dos 284 participantes que receberam a prescrição de dieta, 53\% relataram tê-la feito nos 15 dias posteriores à consulta, $10 \%$ não estavam seguindo nenhum tipo de tratamento e $26 \%$ disseram usar apenas medicamentos no tratamento da doença. Concomitantemente, apenas 6,3\% e $10,9 \%$ dos pacientes do estudo apresentaram controle aceitável do índice de massa corporal, glicemia e pressão arterial (Assunção et al., 2001.).

Paiva et al., 2006, ao descreverem o perfil de população diabética e hipertensa, acompanhada pelo PSF do município de Francisco Morato, SP, e avaliar a assistência prestada a essa população, verificou que apenas 32,8\% da população estudada relatou uma dieta considerada adequada, segundo parâmetros 
da pesquisa. Em contrapartida, $75 \%$ relataram não ter o hábito de praticar atividade física.

Se a baixa adesão ao tratamento é um desafio na abordagem de pessoas com diabetes e hipertensão, ela motiva estudos desenvolvidos nas últimas décadas e em diferentes países que buscam demonstrar a importância das ações educativas para promover mudança no estilo de vida, maior adesão ao tratamento, resultando em melhor controle da hipertensão arterial e/ou diabetes (Almeida-Pititto, 2009; Jones et al., 2007; Miller et al., 2002; Arauz et al., 2001; Cabrera-Pivaral et al., 2001).

No Brasil, o interesse em avaliar a importância da educação em saúde e apontar as concepções teóricas que a ela se vinculam está registrado em alguns ensaios como o de Alves, 2005; Valla, 1999; Vasconcelos, 1998. Embora ainda em pequeno número de publicações e geralmente de estudos com acompanhamento de curto prazo, também se têm demonstrado resultados favoráveis dessa prática sobre o controle do DM e da HA (Silva et al., 2006; Silva, 2005; Sartorelli et al., 2004; Maia, Araujo, 2002).

Entendida como um processo, a educação em saúde visa a capacitar os indivíduos a agir conscientemente diante da realidade cotidiana, mediante o aproveitamento de experiências formais e informais, com vistas à integração, continuidade, democratização do conhecimento e ao progresso no âmbito social. Visa, ainda, à autocapacitação dos grupos sociais para lidar com problemas fundamentais da vida, tais como a nutrição. Os processos educativos são tidos como a chave nas intervenções preventivas no âmbito coletivo, particularmente aqueles que têm evoluído de uma relação emissor-receptor para uma comunicação em que o profissional de saúde compartilha seus conhecimentos e o receptor passa de uma atitude passiva para outra ativa e responsável (Aráuz et al., 2001; Lima, 2000).

A educação em saúde ganha uma perspectiva conceitual ampliada quando associada à proposta recente de promoção de saúde, ou seja, na perspectiva conceitual da promoção, e não apenas como estratégia prevencionista, a educação em saúde toma dimensão mais completa, complexa e integral. 
Porém, uma perspectiva crítica sobre a aproximação dos conceitos de educação em saúde e promoção da saúde é proposta por Lefevre e Lefevre, 2004. Os autores consideram que a aproximação entre conceitos não deva ser da educação com a promoção de saúde, mas da informação para a saúde com a promoção de saúde. Os autores identificam a dimensão conceitual socializadora da promoção de saúde com a noção de empowerment, ou seja, de fortalecimento das pessoas pelo municiamento de informações significativas que confiram autonomia na tomada de decisão. Nessa visão, a educação em saúde se aproxima de uma proposta conducente, normativa e autoritária, que deve ser substituída por outra informativa, baseada no diálogo e na autonomia de decisão (Lefevre, Lefevre, 2004).

A educação nutricional insere-se na educação em saúde, enquanto um subconjunto de práticas educativas para a promoção da alimentação saudável e adequada. Para Boog, 2004, a educação nutricional, assim como todos os processos educativos inerentes ao ser humano, acontece no cotidiano social, ao longo da existência das pessoas, no esforço que elas fazem para responder aos desafios cotidianos. Mas pode também se dar por intermédio de ações de instrução e ensino planejadas por pessoas capacitadas para tal fim.

Inúmeras formulações teóricas sob o aspecto didático-pedagógico e conceitual sobre educação em saúde encontram-se disponíveis na literatura especializada. Em relação à educação nutricional, a literatura apresenta modelos relacionados a conhecimento-atitude-prática, motivação, aprendizado social, processamento de informação para o consumidor, planejamento de comunicações, ação social e comunitária, difusão de informações e modelos integrados. Todos apontam a complexidade da mudança do comportamento alimentar, a interação dinâmica entre as variáveis a ele relacionadas e a importância de um processo planejado sistematicamente, visando à elaboração de intervenções (Cervato et al. 2004).

Intervenções com o objetivo de reduzir as cargas das DCNT são propostas, há alguns anos, pelo Ministério da Saúde (MS). Especialmente em relação ao DM e à HA, o MS, em 2000, procedeu à implantação do Plano de Reorientação da Atenção à Hipertensão Arterial e ao Diabetes Mellitus, a fim de estabelecer 
diretrizes e metas para reorganizar a assistência das pessoas com HA e DM no SUS (Boing e Boing, 2007; Brasil, 2001a).

Nos instrumentos normativos que encaminham diretrizes e ações das políticas públicas de saúde e nutrição, estão explícitas a necessidade e importância das práticas de educação em saúde e educação nutricional, de tal modo que, principalmente na Atenção Básica, têm sido consideradas como instrumento de transformação das práticas inadequadas de saúde (Lima, et.al., 2000). Todavia, a despeito do reconhecimento científico e da retórica política sobre o alcance da educação em saúde/educação nutricional como medida coletiva para a promoção de práticas de vida saudáveis e adequadas, são pouco numerosas as experiências documentadas sobre os programas e atividades de educação em saúde/nutricional no Brasil e, ainda mais raras, as desenvolvidas no âmbito da rede básica de saúde na ESF.

Nesse contexto, propôs-se analisar as percepções de profissionais da ESF sobre as dificuldades e os desafios das ações educativas na promoção de práticas alimentares saudáveis e adequadas para pessoas com DM e/ou HÁ, particularmente as indicadas no plano terapêutico.

O estudo constitui uma das etapas da pesquisa de doutoramento do Programa de Pós-Graduação em Nutrição em Saúde Pública da Faculdade de Saúde Pública da Universidade de São Paulo, intitulada "Ação educativa na Atenção Básica à Saúde de pessoas com diabetes mellitus e hipertensão arterial: avaliação e qualificação de estratégias com ênfase na educação nutricional”, que pretende contribuir com a qualificação das ações educativas no âmbito da Atenção Básica à Saúde.

\section{METODOLOGIA}

Estudo de orientação analítico-descritiva e natureza qualitativa, realizado entre profissionais de saúde da ESF de uma unidade básica de saúde (UBS) do município de Vitória-ES.

O cenário proposto foi uma das 20 unidades básicas de saúde (UBS) do município em que a Estratégia de Saúde da Família está implantada. 
A definição da UBS do estudo foi realizada por meio de entrevistas com informantes-chave da Secretaria Municipal de Saúde e os critérios de seleção foram estes: ser uma UBS de ESF, referência no desenvolvimento de ações de promoção de saúde e na oferta de serviços de acompanhamento e controle para pessoas com DM e HA, preferencialmente localizada em território com extratos sociais variados, cujo gestor e coordenadores das equipes de ESF demonstrassem receptividade à proposta do estudo.

A escolha dos sujeitos da pesquisa foi do tipo não aleatório e intencional (Fontanella, et al, 2008; Minayo, 1993). Solicitou-se que cada coordenador de equipes indicasse profissionais que atuassem naquela unidade, pelo menos, a seis meses do início do estudo em ações especialmente relacionadas ao acompanhamento de pessoas com DM e HA. Essa indicação resultou em uma lista de 30 nomes, composta de três a quatro profissionais de cada equipe e três profissionais da UBS não vinculados estritamente às equipes de ESF, mas com ações articuladas a elas.

Os depoimentos dos profissionais de saúde foram coletados no período de fevereiro a setembro de 2009, por meio de entrevistas semiestruturadas, abertas (Patton, 2002; Fontana, Frey, 2000), utilizando-se um roteiro composto por questões que abordavam a percepção desses sujeitos sobre as dificuldades percebidas para a realização das ações educativas e para a adesão dos diabéticos e/ou hipertensos às orientações realizadas para o controle de sua doença e a promoção de sua saúde, principalmente aquelas relacionadas à alimentação e nutrição.

As entrevistas foram realizadas individualmente por um único entrevistador e gravadas para posterior transcrição literal. Para a transcrição e primeira editoração das entrevistas, foram tomados alguns cuidados referentes à fidelidade do que foi afirmado e ao anonimato delas, como a manutenção das palavras repetidas e dos vícios de linguagem e a omissão dos nomes próprios dos sujeitos. Sempre que possível, optou-se por fazer o registro ortograficamente correto das falas, exceto para as situações que fugiam ao léxico da língua-padrão ou suprimiam sílabas e/ou fonemas iniciais e finais das palavras, conforme recomendado por Araujo, 2001. 
Os depoimentos orais resultantes das entrevistas, após a transcrição, passaram por leitura flutuante, em que, num contato mais próximo com o material de análise, o pesquisador se permite "invadir" pelas primeiras impressões e orientações (Bardin, 1977). Os depoimentos foram tabulados e organizados segundo a técnica de análise do Discurso do Sujeito Coletivo (DSC), conforme concebida por Lefèvre, Lefèvre, 2003.

No processo de leitura exaustiva dos depoimentos, percebeu-se que as IC iluminadas tomavam o sentido de duas categorias ou grupos distintos de análise: uma correspondente às IC que atribuíam os limites e desafios das ações educativas às circunstâncias intrínsecas e extrínsecas das pessoas com DM e/ou HA; outra correspondente àquelas IC que os atribuíam à estrutura, aos processos e/ou aos resultados das ações educativas na US.

Assunção et al., 2001, utilizaram as categorias estrutura, processos e resultados para avaliar o cuidado ao paciente diabético em nível primário de atenção à saúde. Elas se referem respectivamente: aos recursos materiais e humanos disponíveis no serviço e à própria estrutura organizacional; ao que está sendo feito, de fato, quanto ao manejo dos problemas apresentados pelos pacientes e ao efeito dos cuidados no estado de saúde do paciente. A apropriação dessas categorias por este estudo tem o sentido apenas de classificar as IC iluminadas em dois grupos, distinguindo-os para efeito de organização da análise dos discursos.

Para a discussão e análise do material discursivo, recorreu-se a leituras bibliográficas norteadas pelas possibilidades de análise e interpretação de textos (Severino, 1996), valendo-se da literatura científica de estrutura conceitual abrangente, como encontrado no campo da sociologia do conhecimento e no das ciências sociais aplicadas à saúde coletiva.

A pesquisa que originou os dados desse estudo foi aprovada pelo Comitê de Ética em Pesquisa da Faculdade de Saúde Pública da Universidade de São Paulo. 


\section{RESULTADOS E DISCUSSÃO}

Os resultados apresentados são referentes aos depoimentos de 27 profissionais de saúde que aceitaram participar do estudo, entre os quais sete enfermeiros, três médicos, 14 agentes de saúde e dois auxiliares de enfermagem, vinculados diretamente a uma das sete equipes de ESF, e um educador físico que atendia a todas as equipes.

Do total de entrevistados, oito $(29,63 \%)$ são do sexo masculino e 19 (70,37\%), do feminino. A média de idade foi de 35,89 anos, com amplitude de 27 a 60 anos e a média de tempo em que trabalhavam na UBS foi de 4,24, de anos completos.

A questão dirigida aos profissionais de saúde tinha a intenção de verificar e entender por que é difícil mudar hábitos, promover práticas de vida saudável e conveniente a pessoas com DM e HÁ e focalizar, particularmente, aquelas referentes à promoção da alimentação saudável e adequada a essas pessoas.

Como o material discursivo é bastante extenso, na intenção de dar maior fluidez e harmonia ao texto, optou-se por organizar a discussão logo após a apresentação de cada IC ou de um conjunto de IC complementares e dos respectivos DSC.

Nos depoimentos foram iluminadas IC classificadas em dois grupos ou categorias de análise, apresentadas no Quadro 1 e discutidas a seguir. 
Quadro 1. Ideias centrais de profissionais de saúde de uma unidade básica de estratégia de saúde da família sobre as dificuldades e os limites das ações educativas para a promoção da saúde e a adesão a práticas alimentares adequadas por pessoas com diabetes mellitus e/ou hipertensão arterial. Vitória-ES, 20092010.

Questão: Fale um pouco das dificuldades e/ou dos limites que você percebe nas ações educativas em mudar as práticas de vida e de alimentação das pessoas com diabetes e hipertensão.

\begin{tabular}{|l|c|}
\hline \multicolumn{1}{|c|}{ Ideias Centrais* } & $\begin{array}{c}\text { Frequência } \\
\text { (\%) }\end{array}$ \\
\hline $\begin{array}{l}\text { Os limites e dificuldades são relativos a circunstâncias extrínsecas } \\
\text { e intrínsecas próprias das pessoas com DM e/ou HA. (25/27 } \\
\text { depoimentos) }\end{array}$ & 92,59 \\
\hline
\end{tabular}

IC 1.1a - Os fatores culturais, econômicos e sociais dificultam a mudança de hábitos, particularmente dos alimentares. (11/25 dos depoimentos)

IC 1.2a - Eles são muito rebeldes, principalmente o diabético não consegue mudar os hábitos e controlar a dieta. Tem paciente, assim, que é muito "relutivo". (7/25 dos depoimentos)

IC $1.3 \mathrm{a}$ - O paciente gosta muito do médico. É mais no curativo que no preventivo. Isto é uma cultura. (5/25 depoimentos)

IC 1.4a - Um problema é o fato da maioria ser idoso, virem de uma cultura e precisarem de uma atenção diferenciada. (6/25 dos depoimentos)

IC 1.5a - Fazer dieta, se abster daquilo de que se gosta, ter disciplina é difícil para qualquer pessoa. (6/25 dos depoimentos)

IC 1.6a - Às vezes é questão de desconhecimento sobre o risco e gravidade das complicações, mas o principal é a falta de consciência. (4/25 depoimentos)

\begin{tabular}{|c|c|}
\hline Ideias Centrais* & Frequência
\end{tabular}

Os limites e dificuldades são relativos à estrutura, processos e $\quad 25,93$ resultados das ações educativas próprios do modelo de assistência. (7/27 depoimentos)

IC 1.1b - A educação em saúde não está sedimentada, fortalecida como parte do tratamento da hipertensão e do diabetes. Ela é impositiva e não reflexiva. (3/7 depoimentos)

IC $1.2 \mathrm{~b}$ - O mais difícil é o espaço para planejar, para programar as ações. (2/7 depoimentos)

IC 1.3b - A dificuldade maior está na falta de espaço físico adequado para realizar as ações, principalmente depois da "lei do CFM". (2/7 depoimentos)

IC $1.4 b$ - Seria importante ter o nutricionista para ajudar a planejar, atuar nas situações específicas e organizar a educação na comunidade. (2/7 depoimentos)

*Um mesmo depoimento pode apresentar mais de uma IC 


\section{Limites e desafios relativos a circunstâncias extrínsecas e intrínsecas inerentes às pessoas com DM e/ou HA.}

Classificou-se nesse grupo um conjunto de seis ICs, manifestadas em 25 $(92,59 \%)$ dos 27 depoimentos sobre a questão (Quadro 1).

A IC 1.1a: "Os fatores culturais, econômicos e sociais dificultam a mudança de hábitos, particularmente dos alimentares" foi a mais frequente e norteou um dos DSC mais enfáticos do estudo, com base no qual os profissionais de saúde expressaram percepções sobre diferenças e desigualdades socioeconômicas e culturais que marcam a (in) segurança alimentar e nutricional (SAN) e a alimentação adequada. No DSC $1.1^{\text {a }}$, evidenciam-se elementos de (in) SAN, tanto nos aspectos relacionados ao acesso quantitativo e qualitativo aos alimentos, quanto nos relativos à falta de informação e escolaridade, que interferem nas escolhas que as pessoas fazem por uma alimentação saudável e adequada.

\footnotetext{
"Logo de cara eu aponto dois fatores: o cultural, que é questão de como comeu a vida inteira, e agora alguém vai dizer [...] que ele não pode mais comer sal e que ele vai ter que se adaptar a isso, [...] tenho dois grupos bem distintos: um grupo em que eu percebo que é assim, de uma cultura interiorana, [...] e que trás estas características culturais da alimentação. E tem um outro grupo que tem uma condição social ruim [...] e as comidas que ele tem acesso são comidas de uma qualidade ruim, também. [...] Têm pessoas que hoje eles não têm o que comer, entendeu? [...] É família que tem diabético e hipertenso, uma criança de um ano. Às vezes não tem condições de ta comprando aquela alimentação adequada. Comer bem é caro, é muito caro.[...] Outro ponto da questão social é educacional mesmo. Eu vejo que a pessoa que geralmente tem uma informação maior, mais escolaridade, tem mais facilidade de se adaptar aquela situação. Então, se ela for um diabético ela aceita mais fácil ter que cortar alguma coisa, começar uma dieta [...] Que aqueles que têm menos escolaridade [...] Mais pobre menos recurso. Isso que acarreta mais essas doenças." (DSC 1.1a)
}

A alimentação adequada, mediante a promulgação da Atenção Primária à Saúde (APS), é direito de todos os brasileiros, cabendo ao Estado assegurá-lo por meio de políticas públicas dirigidas a todos os cidadãos, particularmente àqueles 
que se encontram em circunstâncias de maior vulnerabilidade social (Brasil, 2006a).

Atualmente, as medidas públicas para garantir o direito à alimentação adequada enfrentam o desafio da transição nutricional: a coexistência, em uma mesma comunidade e até em uma mesma família, da desnutrição, da deficiência de micronutrientes com o excesso de peso e das comorbidades não transmissíveis, resultantes do perfil alimentar das famílias brasileiras, caracterizado devido ao aumento no consumo de gorduras em geral e de origem animal; aos alimentos industrializados concentrados em açúcares, com alto teor de sódio; à diminuição no consumo de cereais e leguminosas; à inadequação do consumo de frutas, verduras e legumes (Coutinho et al., 2008; IBGE, 2004; Bermudes, Tucker, 2003).

Para enfrentar o que consideram um "dilema da saúde pública contemporânea", Coutinho et al., 2008, propõem que se dê prioridade a uma agenda única de nutrição que enfoque o curso da vida, desde o período intrauterino, conforme modelo proposto por Darnton-Hill et al., apud Coutinho et al., 2008, p. 335), compatível com práticas integrais do cuidado nutricional. Trabalhar na perspectiva da integralidade já é um princípio perseguido pela ESF; portanto, concretizar as ações de alimentação e nutrição em agenda única que foque o curso da vida pode ser uma alternativa viável. A APS é um espaço privilegiado para ações educativas de incentivo e apoio à adoção de hábitos alimentares saudáveis, desde que o processo educativo seja capaz de promover a reflexão coletiva e a criticidade das pessoas acerca dos fatores determinantes das práticas alimentares e da saúde (Coutinho et al., 2008).

Mas (in) SAN está longe de representar apenas aspectos concretos da falta de acesso a recursos e meios para saciar a fome e/ou prover uma alimentação adequada. Ela vai além e se entrelaça no emaranhado dos significados culturais sobre a fome e a alimentação adequada, como se pode observar nas seguintes expressões de DSC 1.1a:

"[...] eu aponto dois fatores: o cultural, que é questão de como comeu a vida inteira [...] e que trás estas características culturais da alimentação. E tem um outro grupo que tem uma condição social ruim [...] e as 
comidas que ele tem acesso são comidas de uma qualidade ruim, também [...]." (DSC 1.1a)

Desse modo, modelos explicativos pautados na abordagem antropológica precisam também ser incorporados na tentativa de uma compreensão dos significados culturais que regem o pensar e o fazer humano, contrapondo-se às abordagens explicativas e normativas do modelo biomédico e, em certa medida, enriquecendo as abordagens explicativas pelo modelo econômico. É o que nos propõe Freitas (2007), em ensaio sobre a SAN, no qual enfatiza a importância dos aspectos culturais para avaliar políticas de alimentação e nutrição.

Pertinente ao locus de análise deste estudo, isto é, a ESF, a autora considera que o PSF, que funciona centrado nas ações básicas de saúde, entre as quais as ações educativas, normalmente o faz sem observar os aspectos culturais sobre a comensalidade e a nutrição. Atribui isso à hegemonia do modelo biomédico, que "não consegue dar conta dos temas específicos da cultura que envolvem a nutrição (hábitos, crenças, etc.), necessários a combinação de ações básicas de saúde" (Heiman e Mendonça, 2005, apud Freitas, 2007).

Entre as questões relevantes para a abordagem cultural da SAN, a autora destaca que a produção e a reprodução de crenças alimentares são fundamentais para a formação da identidade sociocultural e, na atualidade, interagem com os valores contemporâneos da urbanização e da modernidade e afetam a nutrição humana. Assim, as ações de educação nutricional devem ter uma nova orientação pedagógica. Devem-se colocar

“[...] como ação social que versa sobre a saúde, que contemple e interprete os significados das escolhas alimentares dos sujeitos, respeitando suas próprias organizações sociais, as quais, inevitavelmente, produzem e reproduzem valores sobre o corpo e a vida." (Freitas, 2007, p.79).

É necessário, então, conhecer como os sujeitos, em seu cotidiano, dão significado as suas necessidades alimentares, a sua comida, à comensalidade. Para isso eles precisam ser ouvidos. Ainda segundo Freitas, 2007, a escuta assegura a compreensão dos problemas, aprofunda a análise na dimensão da cultura, dos sentidos e dos significados. Afinal, não é à toa que a escuta é tida por um 
elemento humanizador do cuidado em saúde. E, ao menos em concepção, a ESF favoreceria tal abordagem, pautada na humanização da assistência, dada a proximidade que se pode estabelecer entre os sujeitos: profissionais-usuários, entre os espaços: unidade-comunidade e entre as práticas: individuais-coletivas. Restaria, então, subtraída da análise de discursos anteriores, a reorientação das práticas educativas nesse sentido e a capacitação dos sujeitos nessa perspectiva de ação.

A segunda percepção sobre as dificuldades que explicam a não adesão dos sujeitos às práticas alimentares adequadas foi a manifestada na IC 1.2a: "Eles são muito rebeldes, principalmente o diabético não consegue mudar os hábitos e controlar a dieta" (Quadro 1).

O discurso recorrente sobre a rebeldia, principalmente do diabético, a relutância deste em acatar orientações sobre mudanças de hábitos e a dificuldade dos profissionais de saúde em "convencê-los" são o tom desse DSC:

"[...] nós temos muitos pacientes rebeldes, que nós estamos batendo naquela tecla, estamos sempre orientando, conversando. A maioria dos pacientes não faz uma dieta adequada. Por mais que você fale. O diabético então é o mais rebelde de todos. Você orienta, orienta, mostra, senta, explica [...] É um paciente muito difícil de aderir a tratamento novo. [...] Não consegue controlar a dieta, não consegue controlar o sal, a diabetes. [...] É muito difícil mexer com esse pessoal. Eles são teimosos." (DSC 1.2a)

Essa forma de pensar origina-se no discurso biologicista, que, se em tese, pela própria evolução histórica da saúde pública, estivesse superado, na prática seus principais elementos seriam empregados como orientadores das ações educativas na saúde. Segundo essa concepção, os problemas de saúde são decorrentes da não observância das normas de higiene pelas pessoas. Sendo assim, na garantia de mudanças de atitudes e comportamento individuais residiria a chave para resolver os problemas de saúde e ao processo educativo se atribuiria a forma de produzir as mudanças. Para tanto, basta que as pessoas, desprovidas de conhecimentos, sejam convencidas da necessidade dessas mudanças pela assimilação passiva de prescrições normativas, cientificamente respaldadas, competência essa dos profissionais de saúde. Decorre que, se o indivíduo não 
muda, a responsabilidade pela produção da doença lhe é atribuída, e ele é culpabilizado individualmente pelos problemas de saúde (Alves, 2005).

Para (Stotz, 2007), é justamente a redução dos problemas de saúde a uma dimensão biológica que possibilita culpabilizar os indivíduos por sua doença, possibilidade tanto maior quanto maiores forem as evidências da medicina baseada em estudos epidemiológicos de que os problemas de saúde têm causa nos chamados tratamentos individuais de risco: dieta inadequada, sedentarismo, tabagismo, etilismo, entre outros.

O modelo biologicista influenciou e influencia programas de intervenção educativa no campo da alimentação e nutrição, principalmente aqueles aplicados à clínica nutricional, que têm a finalidade de ampliar a adesão das pessoas ao tratamento dietético (Santos, 2010). O próprio termo "adesão" assume utilização variada em boa parte dos estudos em que é empregado e está relacionado a uma compreensão dos profissionais: são os pacientes os maiores responsáveis pelos problemas de saúde e os profissionais de saúde falham ao tentar atingir uma compreensão mais profunda e promover as mudanças de comportamento desejadas.

Entendimento similar por parte dos profissionais de saúde foi encontrado por Reiners et al., ao realizarem um estudo de revisão da produção bibliográfica latino-americana da última década sobre a adesão/não adesão ao tratamento por pessoas com doenças crônicas, entre as quais a HA e o DM. Nesse estudo se constatou que a maioria dos fatores apontados pelos autores dos artigos para a adesão/não adesão dos pacientes estava relacionada aos últimos, ou seja, a responsabilidade maior pelo sucesso/insucesso da ação foi atribuída ao paciente (Reiners et al., 2008). Outra visão recorrente dos profissionais de saúde foi a de que o papel do paciente é de se submeter às recomendações dos profissionais de saúde, particularmente a prescrições médicas, embora ele tenha autonomia para não fazê-lo, o que exime o profissional de saúde da responsabilidade sobre as consequências da decisão (Reiners et al., 2008).

Pensando dessa forma, os profissionais de saúde podem estar legitimando uma abordagem educativa normativa, prescritiva, centrada no saber científico que 
não lhes permite conhecer os saberes, as crenças, as experiências, enfim, as razões das pessoas para mudar ou não seu comportamento.

Para Lefevre e Lefevre, 2004, o profissional de saúde que atua na educação em saúde dessa maneira, geralmente acredita que o conhecimento verdadeiro e legítimo sobre a saúde e a doença é seu monopólio. Ademais, considera-se investido de autoridade sanitária para impor um padrão de comportamento aos indivíduos, por ser ele um técnico especialista.

A terceira visão identificada nos depoimentos sobre dificuldades para mudanças de práticas de vida e alimentares refere-se à IC 1.3a, na qual os profissionais de saúde expressam que a dificuldade reside no fato de que "o paciente gosta muito do médico. É mais no curativo que no preventivo. Isto é uma cultura" (Quadro 1).

No DSC referente a essa IC, os profissionais de saúde manifestam sua preocupação com a persistência de uma cultura "curativista" e medicalocêntrica entre usuários/pacientes. Isso os faz ansiar pela intervenção médica de caráter curativo, como a prescrição de medicamentos, em detrimento de condutas que os estimulem a modificar seus hábitos de vida.

\begin{abstract}
"Existe muito o paciente que gosta muito do médico, é centrado no médico. Se têm que ir para lá (para o grupo), eles só vão porque tem uma consulta junto. Ficam esperando acabar a conversa, para depois ir pro médico. Eles não estão com o objetivo na prevenção [...] Só vem mesmo no dia da consulta, pega o remédio e vai embora [...] acha que está tudo bem, não tem necessidade de ficar ouvindo ninguém falando. É a questão da medicação que ele incorpora na vida dele: - [...] Eu tomo remédio já pra isso [...] Eu não preciso me privar, deixar de comer isso ou aquilo. [...] É mais no curativo que no preventivo [...] Então eu acho que o grande desafio que a gente tem é lidar com esta cultura que eles têm e que é nossa. É uma grande dificuldade!” (DSC 1.3a)
\end{abstract}

O DSC 1.3a revela que os profissionais de saúde percebem um dos problemas recorrentes no modelo assistencial dominante, que é a centralidade no processo de trabalho do médico, que funciona com a centralidade na produção do cuidado e da cura e não na promoção da saúde e prevenção das doenças. Revela também que persiste uma visão dicotômica entre as práticas preventivas e curativas. Mais: certo sentido de culpabilização do usuário/paciente por sua conduta. No entanto, em determinado momento do discurso, a "cultura curativa" é 
reconhecida como universal, ou seja, de todos, por isso parece constituir um desfio ainda maior para o profissional de saúde a sua transformação.

Para intervir no processo saúde-doença, os profissionais de saúde, especialmente os médicos, em um modelo que o privilegia, têm a sua disposição diferentes condutas: a diagnóstica, a preventiva, a terapêutica e a de reabilitação, que formam no conjunto uma unidade e que, em tese, não deveriam ser diferenciadas em relação à importância maior de uma ou outra (Arouca, 2003). Essa noção está presente à definição legal e institucional de integralidade: "um conjunto articulado de ações e serviços de saúde, preventivos e curativos, individuais e coletivos, em cada caso, nos níveis de complexidade do sistema" (Brasil, 1990). Portanto, a fragmentação da assistência ou a priorização de uma ou outra prática em detrimento das demais comprometem a perspectiva de integralidade das ações de saúde, princípio fundamental na reorientação de um novo modelo assistencial.

O DSC 1.3a reitera o enfoque educativo predominante nos serviços de saúde: o preventivo, que tem como pressuposto básico o fato de o comportamento dos indivíduos estar estritamente relacionado à origem das doenças. $\mathrm{O}$ comportamento dietético, a falta de atividade, o hábito de fumar, entre outros, são tidos, então, como fatores de risco. Nessa perspectiva, as pessoas são estimuladas ou persuadidas a modificar esses padrões de vida, substituindo-os por estilos de vida mais saudáveis. Para tanto se elabora uma série de programas cujo conteúdo é extraído da clínica médica e/ou da epidemiologia. Na educação sanitária preventivista, o repasse de informação normalmente é realizado por meio da consulta ou em grupos, de palestras seguidas ou não de perguntas e respostas, ou seja, por técnicas geralmente expositivas. Apesar de se colocar criticamente à ineficiência do modelo curativo, esse enfoque também é orientado pelo "modelo médico" (Stotz, 2007).

Outra dificuldade percebida pelos profissionais de saúde para a mudança de práticas alimentares foi apreendida na IC 1.4a: "Um problema é o fato da maioria ser idoso, virem de uma cultura e precisarem de uma atenção diferenciada”. (Quadro 1). O DSC 1.4a associa a dificuldade à resistência que os 
idosos têm a mudanças, principalmente porque, nesses casos, se lida com elementos culturais já bastante sedimentados ao longo da vida dessas pessoas:

"[...] A maioria dos nossos pacientes são pessoas idosas, entendeu? E eles já têm aquele habito de muito tempo. Tem toda uma vida com aqueles mesmo hábitos, as mesmas coisas. Acho que é a principal dificuldade do lado deles: essa resistência em mudar os hábitos. Porque já vem de uma cultura [...].” (DSC 1.4a)

A dificuldade do idoso é também associada à dificuldade de entendimento sobre as orientações, consequência do processo de senilidade, sendo esta uma circunstância que se agrava e pode dificultar ainda mais o seguimento do tratamento naqueles casos em que as pessoas precisam ser assistidas por um cuidador. Isso parece ocorrer mais em relação às mulheres:

"[...] A dificuldade de adesão tem um pouco da questão da dificuldade de entender certas coisas, assimilar sobre a medicação, tá absorvendo essas coisas, os horários, as quantidades [...] Alguns, às vezes, sem acompanhamento familiar [...] pra ta do lado orientando ou ajudando [...] Muitas pessoas na área da gente precisam de cuidador. Para as mulheres, e as pacientes são mais idosas, elas não tem cuidador [...]."

(DSC 1.4a)

Nessas circunstâncias, a atuação dos agentes durante a visita domiciliar torna-se fundamental e já é, inclusive, esperada pela família:

"[...] A familia às vezes deixa assim: ah, o agente vem ai e te orienta da forma que ele achar melhor. Então a gente vai mais vezes nestas casas [...]." (DSC 1.4a)

$\mathrm{Na}$ percepção dos profissionais, alguns idosos se sentem desmotivados para frequentar as atividades de acompanhamento, ou mesmo para mudar seus hábitos de vida, em razão de problemas de saúde que causam desconforto e diminuem sua mobilidade:

"[...] eles são idosos, tem o calor, tem artrite, tem artrose. [...] Eles acham que eles envelheceram, então, numa certa idade ele perde a motivação. É um dos fatores também. E pra mudar isso em uma pessoa idosa, até por questão assim de teimosia deles mesmo, é muito difícil [...]." (DSC 1.4a) 
O envelhecimento da população brasileira é um fenômeno que segue tendência temporal do mundo desenvolvido e em desenvolvimento e que traz grandes desafios em políticas públicas, principalmente no campo da saúde e da assistência social. É considerado como a alteração demográfica que mais impactará a demanda por serviços de saúde, principalmente para o grupo com mais de 85 anos, em que a carga de doenças crônicas e limitações funcionais é muito grande (Caldas, 2003) e, consequentemente, o envelhecimento com dependência é maior.

O crescimento da proporção daqueles que moram sozinhos também é uma tendência, alcançando uma proporção de $13,2 \%$ da população total de idosos em 2006, com uma prevalência maior entre as mulheres, explicada pela maior longevidade feminina, que implica a maior probabilidade de a mulher idosa vir a ficar sozinha; muitas vezes, dependente de cuidados e de novos arranjos domésticos e institucionais (Camargos et al., 2007).

A família, independentemente de residir com o idoso, sempre teve um importante papel no apoio, bem-estar e qualidade de vida dele; as condições de cuidados da família, entretanto, têm sido comprometidas, principalmente em virtude da entrada da mulher no mercado de trabalho, alterando suas funções perante a família, e do surgimento de novos arranjos familiares, decorrentes de novas formas de união conjugal.

Camargos e Rodrigues, 2008, estudaram as condições de saúde de idosos que moravam sozinhos em Belo Horizonte-MG. Com base nas entrevistas em profundidade, realizadas com 40 pessoas acima de 60 anos, concluíram que, nas falas desses idosos, a preocupação com a saúde era evidente, mas a maioria deles não cuidava adequadamente da saúde como pensavam e relatavam. Os exemplos mais importantes recaíram sobre cuidados inadequados em relação aos hábitos alimentares, monitoramento inadequado da saúde, falta de prática de atividade física, utilização da medicação em desacordo com a prescrição médica (Camargos, Rodrigues, 2008).

Como a família é o principal locus de cuidados com o idoso, a ESF passa a representar o vínculo principal dele com o Sistema de Saúde (Silvestre, 2003). Porém, Caldas, 2003 adverte que, para a ESF constituir-se como estratégia 
eficiente, ela terá de incorporar o cuidado também ao idoso dependente, o que exigirá recursos financeiros especiais e uma rede de suporte institucional para essas ações.

Do material discursivo do DSC 1.4a podemos ainda inferir que, no âmbito das ações educativas em saúde, as dificuldades que surgem em razão da idade avançada parecem residir naqueles casos em que os idosos precisam dos seus familiares para acompanhar ou monitorar os cuidados e orientações prescritos pelos profissionais de saúde. Além disso, em virtude da ausência destes nos horários de trabalho, tais cuidados não são realizados da forma esperada. Preparar a própria alimentação, tomar os remédios corretamente, locomover-se até a US para monitoramento de sua saúde, entre outras, são atividades que a pessoa não consegue desenvolver com independência; portanto, é legítima a preocupação dos profissionais de saúde.

Em relação às práticas educativas dirigidas para esse grupo, há que desenvolver competências, habilidades e muita sensibilidade, o que deverá balizar a decisão sobre a abordagem, a forma e o conteúdo das ações. De qualquer forma, modelos dialógicos e humanísticos serão sempre a direção acertada.

Outra dificuldade revelada na fala dos profissionais de saúde refere-se à IC 1.5a: "Fazer dieta, se abster daquilo de que se gosta, ter disciplina é difícil para qualquer pessoa" (Quadro 1). No DSC, destacam-se as visões de que se privar de um alimento ou de um sabor de que se gosta, doce ou sagado, não é uma dificuldade específica para as pessoas com DM e HA:

"[...] Eu acho que é difícil para qualquer um, né? Imagina [...]: você adora doce e aí descobre que é diabético, não pode mais comer doce [...] $E u$, se fosse diabético, ia ter uma grande dificuldade de fazer uma alimentação restrita de açúcar, de doce. É aquilo sobre a dieta, [...] que eles até falam: - Ah! Eu estou diminuindo o sal! Mas se a gente for investigar os motivos da carne-seca que eles gostam muito [...]." (DSC 1.5a)

Merece destaque nesse discurso a percepção da relação de "dependência" com o alimento ou com práticas não saudáveis que os profissionais atribuem às pessoas que precisam mudar seus hábitos ou deles abster-se. Essa percepção parece ser usada para dimensionar a dificuldade de adesão ao tratamento, que 
impõe situações de abstenção, assim como o são no combate ao tabagismo e ao etilismo.

"[...] É como se fosse uma droga. [...] Para os homens dieta, bebida e abstinência de alguns alimentos, do cigarro, é o mais difícil. Eu acho que são dificuldades bem comuns, de uma forma geral do hipertenso e do diabético, a dificuldade da dieta, da disciplina da atividade física."

(DSC 1.5a)

Assim como as drogas, há circunstâncias que podem levar a pessoa a desvirtuar-se do tratamento. Com o alimento também as situações se colocam para desvirtuar a dieta:

"[...] tem aquele temperozinho com que ele cozinha, tem os restaurantes de fast food logo ali [...]." (DSC 1.5a)

Sob o aspecto biológico, gosto e olfato são sensibilidades químicas complexas, intermediadas pelos sistemas neurais que trabalham interligados e são fundamentais à formação das preferências e rejeições alimentares e à seleção dos alimentos para uma dieta adequada às necessidades metabólicas. E os sinais do paladar são capazes de regular a quantidade de alimento ingerida e o tamanho das refeições, ou seja, a saciedade, que é reforçada tanto nas refeições com alto teor de gordura quanto nas de alto teor de carboidratos (açúcares) (Schiffman, 1999, Guyton, Hall, 1997). No entanto, a civilização, a urbanização e recentemente a industrialização dos alimentos levaram a mudanças radicais das estratégias alimentares e à sofisticação do preparo dos alimentos, resultando na evolução do paladar do nível rudimentar (informar sensorialmente a respeito da qualidade do alimento e regular a saciedade) para o atual (Faber, 2006). Diante dessa realidade, para compreender a formação do paladar e, por extensão, as preferências e os hábitos alimentares, uma complexidade de fatores psicossociais relativos às experiências alimentares, desde os primeiros anos de vida, deve ser considerada (Ramos, Stein, 2000; Birch, 1999; Birch, 1998; Freitas, 1997).

A relação do açúcar com o DM e abordagem dietética dele variou ao longo do tempo, conforme a evolução dos conhecimentos sobre a doença e sua interação com a dieta de um modo geral. Atualmente, o tratamento do DM tem por objetivo 
manter a glicemia próxima dos valores normais, considerando, entre outras, a atividade física, a dieta e a medicação (Castro, Franco, 2002). Portanto, a dieta nem sempre prescindirá da exclusão do açúcar (sacarose). Para o paciente monitorado, que mantém a glicemia segundo as expectativas do plano terapêutico, é possível ajustar individualmente a dieta mediante o uso do açúcar nos níveis de uma alimentação considerada normal, ou seja, em que a ingestão da sacarose corresponda de 5\% a 10\% das calorias diárias (ADA, 2005).

Todavia, o mais usual é um plano terapêutico não individualizado, em que a exclusão do açúcar, fonte de sabor, prazer e saciedade, e a restrição de uma série de alimentos habituais são prescritas com impactos importantes nos aspectos psicossociais dessas pessoas.

Há que entender, portanto, quão penosa é a mudança de hábitos nessas circunstâncias, como entendido e manifestado pelos profissionais de saúde no DSC 1.5a. O processo educativo é lento e difícil, justamente porque envolve, pelo menos, três dimensões complexas: a cultural, a social e a econômica (Péres et al., 2007), como anteriormente discutido com base na IC e no DSC 1.1a.

Em estudo recente realizado por Pontiere e Bachion, 2010, observou-se, nas crenças dos pacientes diabéticos acerca da terapia nutricional, que as recomendações a eles prestadas pelos profissionais tinham caráter restritivo, impositivo e proibitivo. Essas observações sugeriram aos autores que, para conseguir a adesão do paciente ao tratamento, o profissional reduzia a tônica de suas orientações à proibição de alguns alimentos. Além disso, as recomendações acerca da dieta pareciam provir de processo unilateral, não dialógico, sem considerar as circunstâncias de vida das pessoas. Esses resultados, nas considerações das autoras, apontam a necessidade de redimensionamento da formação profissional e a utilização de abordagens holísticas, interdisciplinares e multiprofissionais na atenção aos diabéticos (Pontiere, Bachion, 2010).

No mesmo sentido, resultados de dois estudos realizados para entender as dificuldades de pacientes diabéticos no controle de sua doença mostraram que, entre aquelas relacionadas ao seguimento do tratamento, estavam o sofrimento e a revolta devido às restrições impostas pela alimentação, o que fez com que os autores inferissem que a abordagem educativa pode não apenas favorecer o 
âmbito da transmissão de conhecimentos, mas também privilegiar os aspectos emocionais, sociais e psicológicos que farão diferença no seguimento do tratamento (Péres et al., 2007).

$\mathrm{O}$ ato de comer envolve um sistema de valores, símbolos e significados que, particularmente no caso das pessoas submetidas a restrições alimentares, necessitam ser compreendidos pelos profissionais de saúde (Peres, et al, 2006), sob pena de deslocar os motivos da não adesão ao tratamento dietético da eficácia da ação educativa para a resistência ou desobediência do paciente à prescrição restritiva que lhe é dirigida. O termo prescrição é aqui empregado para registrar os moldes em que a prática educativa parece ser realizada de acordo com os discursos aqui apresentados.

No estudo de Peres et al., 2006, as mulheres demonstraram incapacidade de realizar a dieta devido ao caráter restritivo e proibitivo das prescrições, indicando um distanciamento da dieta prescrita e aquilo que consideram possível de realizar. Entre as restrições dietéticas referidas, a dos doces parece repercutir em dificuldades mais intensas.

A proibição dos alimentos doces parece acirrar o desejo de consumi-los. Santana, 2002, p. 54, diz: “[...] Da proibição surge o desejo e desse desejo surge a transgressão [...]". Para a autora, a transgressão e o desejo são fatos comuns na vida da pessoa com diabetes, aguçados pelas prescrições proibitivas. Essa visão está implícita no DSC 1.5a, quando os profissionais de saúde associam os efeitos da proibição dos alimentos aos das drogas, para representar o sentimento de dificuldade que as pessoas demonstram em se abster daquilo de que gostam muito ou a que estão muito habituadas.

Numa perspectiva histórica e socioantropológica, em ensaio sobre "As necessidades humanas e o proibicionismo das drogas no século XX”, Carneiro, 2002, formulou a comparação de alguns alimentos, bebidas e condimentos com as drogas. Para o autor, na sociedade atual, alimentos e drogas ocupam lugares conceituais aparentemente distintos, porém questionáveis ao examinar a natureza precisa de alguns produtos, como o álcool, o açúcar, o chocolate, os chás, o café, presentes no cotidiano alimentar do século vinte. Da mesma forma, o tabaco e o ópio foram tornando-se cada vez mais abundantes, disponíveis e necessários, 
principalmente a partir do século dezenove (Carneiro, 2002). O julgamento da legitimidade ou não dessas necessidades segue uma lógica muito mais econômica e cultural do que daquela pautada nos pretextos médicos e da saúde pública.

Os elementos propostos por Carneiro nos ajudam a ampliar a reflexão sobre a formação de hábitos alimentares na complexa rede de fatores psicossociais (incluídos aqui os econômicos e os culturais) que, no intenso e dinâmico processo de construção e desconstrução de pensamentos, sentimentos e crenças, engendram o comportamento humano. Eles precisam, portanto, ser apropriados por todos os sujeitos envolvidos no processo de qualificação das ações tanto de educação em saúde quanto de educação alimentar e nutricional.

Finalmente, segundo a IC 1.6a, os profissionais de saúde acreditam que a dificuldade dos diabéticos e hipertensos para mudar seu comportamento ou dar continuidade ao tratamento às vezes é questão de desconhecimento sobre o risco e gravidade das complicações, mas o principal é a falta de consciência de algumas pessoas (Quadro 1).

No DSC correspondente, eles manifestam um pensamento dual sobre a questão: ao mesmo tempo que avaliam a falta de informação como motivo ou dificuldade para adotar práticas adequadas e para seguir o tratamento, pensam que o maior problema não é esse, pois a informação "chega", inclusive, por meio dos próprios profissionais, mas as pessoas não mudam porque não têm consciência do resultado de suas atitudes.

"[...] eu penso que às vezes é questão de desconhecimento mesmo. De não ter noção do risco, [...] Talvez eles desconheçam também um pouco do que pode acarretar para eles as doenças, a gravidade, as consequências das ações deles. Mas eu acho que o principal é a falta de consciência deles mesmo.[...] Não acho que é falta da gente, profissional de saúde, chegar não. Porque a informação chega. Eu acho que é falta de consciência mesmo [...]." (DSC 1.6a)

Essa dualidade pode representar uma incerteza do profissional de saúde sobre a eficácia do processo educativo. Se ele acredita que a informação "chega", inclusive, por seu intermédio, como podem as pessoas não mudar? Para esse profissional, então, o problema passa a não residir no acesso à informação, na forma como ela é construída e difundida, mas na falta de consciência do indivíduo 
para a mudança. Há, portanto, um deslocamento de responsabilidades da qualidade da intervenção educativa para o sujeito, culpabilizando-o novamente.

É questionável a visão de que a informação e o conhecimento sejam suficientes para gerar comportamentos conducentes à saúde e que, consequentemente, os indivíduos se comportam desta ou daquela maneira por serem desprovidos de informações que os orientem. As informações transmitidas ou difundidas no processo educativo não darão conta, por si sós, de gerar ou mudar comportamentos. Mesmo considerando a importância do conhecimento, dos fatos ou das informações para municiar as pessoas no sentido de prepará-las para a ação, por mais qualificadas que sejam sob o aspecto teórico e metodológico, pode-se incorrer no risco de reduzir a prática educativa a um processo mecanicista de transmissão das informações, colocando o sabre técnico e científico como verdades absolutas. Nessa perspectiva, os profissionais da comunicação, isto é, os profissionais de saúde, seriam prepostos exclusivos do processo educativo, e o educando, usuário, paciente, seja o nome que se queira dar, o receptáculo aberto e virgem para recebê-las e acatá-las.

Para Briceño-Leon, 1996, esse tipo de pensamento tem bases explicativas no modelo Conhecimentos, Atitudes e Práticas, que sustenta uma relação linear de determinação entre esses três elementos: conhecimento leva a atitudes que conduzem as práticas, ou seja, bastaria proporcionar a informação para que as pessoas mudassem sua atitude e, em momento posterior, passassem a se comportar de maneira diferente.

No cotidiano da saúde, observam-se inúmeros exemplos da inconsistência desse modelo, mas a maior deles talvez resida no fato de ele desconsiderar os conhecimentos, os sentimentos, as experiências e as crenças que toda pessoa traz consigo - fruto de suas experiências individuais e coletivas. Portanto, gerar novas práticas e mudar hábitos é muito mais complexo, envolve compartilhamento de experiências, reelaboração de saberes e modificação de crenças. Nisso reside uma das sete teses de Briceño-Leon: “a ignorância não é um vazio a ser preenchido, mas uma plenitude a ser transformada" (Briceño-Leon, 1996). 
Limites e desafios relativos à estrutura, aos processos e aos resultados das ações educativas próprios do modelo assistencial.

Classificaram-se, nesse grupo ou categoria de análise, quatro IC, identificadas em sete $(25,93 \%)$ dos 27 depoimentos (Quadro 1).

A primeira, IC 1.1b: a educação em saúde não está sedimentada fortalecida como parte do tratamento da hipertensão e do diabetes. Ela é impositiva e não reflexiva, denota a percepção sobre a insipiência das ações educativas no plano terapêutico, mesmo reconhecida a sua importância.

"Eu penso assim: a gente não tem este retorno porque a educação não está ali sedimentada, não está fortalecida. A gente sabe que a educação de saúde é parte do tratamento da hipertensão e diabetes, não é opcional. O profissional não tem essa apropriação nem essa cultura, não reconhece isso como tratamento. Isso eu acho muito complicado. [...] tem que ter algo mais, [...] a formação mesmo. Senão fica impositivo. Processo de educação é a longo prazo, deve ser feito a todo momento, em todo contexto, a qualquer momento. Tem que levar à reflexão, ao questionamento [...]." (DSC 1.1b)

As expressões capturadas no DSC $1.1 \mathrm{~b}$ demonstram o distanciamento entre o discurso oficial que localiza a educação em saúde como eixo fundamental da ESF para a orientação de práticas de promoção de saúde e o que vem ocorrendo na "ponta", no dia a dia do "fazer" educação em saúde. O material discursivo aponta uma educação em saúde ainda insipiente, em que prevalece um modelo educativo normativo, não reflexivo, não dialógico. Interessante é que, no DSC 1.1b, esses atributos são reconhecidos como dificultadores da ação educativa, mas parecem permanecer ali, paradigmaticamente incorporados no fazer dos profissionais de saúde, que julgam não estar suficientemente "apropriados" para fazer de outra forma.

Essa visão remete à necessidade de capacitação dos sujeitos em relação ao discurso teórico-metodológico que vem opor-se ao modelo hegemônico, tanto no âmbito da formação profissional quanto no processo permanente de educação em saúde. Investimentos nesse sentido são ainda pontuais e acontecem à luz das Diretrizes Curriculares para cursos da área da saúde. Estas indicam uma formação profissional generalista, humanista, crítica e reflexiva cujo egresso seja capaz de 
atuar no processo saúde-doença nos níveis de promoção, prevenção, recuperação e reabilitação, numa perspectiva de integralidade de objetivos e ação (Brasil, 2001b).

No entanto, na prática, os currículos tradicionais seguem ainda uma lógica positivista, consoante com uma visão mecanicista da formação e, portanto, do homem. Na matriz curricular, as ciências são inseridas como disciplinas isoladas, os conteúdos são fragmentados, tornando pouco provável o desenvolvimento de uma visão de integralidade do ser humano (Batista, Batista, 2005). Para ele, no ensino superior em saúde, a formação humanística configura mais do que um campo de planejamento de desenvolvimento profissional. Subtende o exercício intencional e constante de sensibilidade, um compromisso das instituições de ensino e de todos os envolvidos no processo educativo.

Complementar ou até mesmo reformular a formação da graduação para os profissionais que vão atuar na Atenção Básica ficará a cargo dos programas de especialização em Atenção Primária à Saúde (APS), geralmente fomentados pelo Estado e pelo processo de educação continuada e/ou permanente.

Essa forma de pensar a formação de pessoas no campo da saúde, embora não seja recente, como todo processo em transformação, encontra resistências que impactam a reorientação do modelo assistencial de saúde, produzindo uma condição de morosidade do processo. Aos profissionais de saúde, na ponta, resta a sensação de que, por mais que façam, ou melhor, por mais que "falem", os resultados não são evidentes:

"[...] a gente não tem este retorno porque a educação não está ali sedimentada, não está fortalecida. A gente fala, fala, e tem a impressão que na prática pouca coisa fica. [...] Então, [...] tem que ter algo mais, de outra forma, a formação mesmo [...]." (DSC 1.1b)

Na segunda, IC 1.2b: “O mais difícil é o espaço para planejar, para programar as ações”, os profissionais de saúde externalizam uma das dificuldades vivenciadas na gestão cotidiana de seu trabalho. O DSC correspondente aponta a necessidade de planejamento integrado entre as equipes das ações educativas, para garantir a qualificação delas e, consequentemente, resultados mais efetivos. 
"[...] O mais difícil é este espaço para sentar e planejar [...] A gente precisaria é fazer essa programação junto, com o grupo todo, pra ver como organizar essas oficinas [...]." (DSC 1.2b)

As representações dos profissionais de saúde nesse discurso motivam a discussão a respeito da dificuldade de planejamento das ações educativas e, por conseguinte, das ações de educação alimentar e nutricional. Para tanto, pode-se partir da perspectiva conceitual de educação em saúde proposta por Candeias, que a define como:

“(...) quaisquer combinações de experiências de aprendizagem delineadas com vistas a facilitar ações voluntárias conducentes à saúde. A palavra combinação enfatiza a importância de combinar múltiplos determinantes do comportamento humano com múltiplas experiências de aprendizagem e de intervenções educativas. A palavra delineada distingue o processo de educação de saúde de quaisquer outros processos que contenham experiências acidentais de aprendizagem, apresentando-o como uma atividade sistematicamente planejada. (...)" (Candeias, 1997, p. 210).

Nessa perspectiva, a educação em saúde, entre outras ações técnicas destinadas à promoção da saúde, é atividade-meio, cuja finalidade é organizar logicamente o componente educativo de programas de saúde (Candeias, 1997). Como tal prescinde de planejamento racional e estratégico e de recursos, o que parece constituir um desafio operacional para a implantação das políticas de promoção da saúde, a despeito da produção teórico-metodológica considerável que se tem disponível nos diversos campos do conhecimento.

O DSC 1.2b, sugere que os espaços para o planejamento das ações educativas são reduzidos e, quando ocorrem, são realizados isoladamente por cada equipe, o que não possibilita um planejamento integrado, voltado para as necessidades globais do território, mesmo com a utilização mais racional de recursos. Mais importante, longe da lógica do planejamento participativo.

"[...] poderia organizar essas oficinas juntas. Que que a gente vai falar? Que recursos a gente vai usar pra abordar a educação nutricional? [...] Planejamento mais participativo. Porque são várias equipes, [...] muitas vezes a equipe não sabe o que a outra tá fazendo [...] [...] Deveria ter mais tempo para fazer, para você ver mudanças. Deveria ser mais elaborado." (DSC 1.2b) 
Alguns estudos concentrados na avaliação de ações educativas em saúde sugerem semelhanças na percepção dos profissionais de saúde a respeito do planejamento dessas ações. Em um survey realizado por Canesqui e Spinelli, 2006, entre médicos e enfermeiros da Saúde da Família do Estado de Mato Grosso, cujo objetivo, entre outros, foi ter acesso aos julgamentos avaliativos desses profissionais sobre a implantação das ações da Atenção Básica, concluiu-se que estes julgavam ser elevado o grau de implantação de várias ações dos programas de atenção à saúde da criança, do adolescente, da mulher e do idoso; contudo, eles julgavam, em menor grau, a implantação das ações educativas desses programas, quando comparadas com a implantação de procedimentos, como consultas médicas e de enfermagem. Especificamente em relação à implantação das ações de controle da hipertensão e diabetes, enquanto as consultas médicas foram referidas com um "bom” grau de implantação por mais de $95 \%$ dos entrevistados, para as atividades educativas de controle tanto da hipertensão quanto do diabetes, o percentual foi, aproximadamente, de $84 \%$ e $79 \%$ respectivamente (Canesqui, Spinelli, 2006).

No mesmo estudo, ao perguntarem sobre a utilização pelas equipes das atividades e dos meios de planejamento para intervenção, os profissionais consideraram que somente as reuniões gerais de equipes e as atividades de elaboração das linhas de conduta estavam, respectivamente, no grau ótimo e bom; porém a utilização das reuniões para análise dos indicadores de saúde, discussão de casos clínicos, oficinas de planejamento e reuniões intersetoriais e/ou com a comunidade foi considerada como baixo grau (Canequi, Spinelli, 2006). Vale afirmar que, também para aqueles profissionais, a implantação de ações educativas e a operacionalização das ações de saúde por meio do planejamento participativo parecem constituir um problema no âmbito da Saúde da Família.

Crevelim e Peduzzi, 2005, fundamentados num estudo qualitativo, com análise de conteúdo de entrevistas com trabalhadores e conselheiros de saúde de uma unidade da Zona Leste de São Paulo, procuraram conhecer quanto o trabalho em equipe de Saúde da Família favorece a participação da comunidade na construção de um projeto assistencial. Os resultados mostraram que os trabalhadores destacaram o trabalho em equipe, mas não incluíram os usuários no 
planejamento das ações. Isso levou o autor a concluir que, mesmo diante dos avanços, o trabalho de equipe ainda não garante um projeto assistencial comum, o que fortaleceria as relações entre usuários e trabalhadores de saúde (Crevelim, Peduzzi, 2005).

Um aspecto a levantar nas representações do DSC $1.2 b$ é que a menção do planejamento participativo é relativa à participação de outras equipes e outros profissionais da US; no entanto, sem aludir à participação da comunidade no planejamento das ações de saúde, pelo menos no que tange às ações educativas para a promoção da alimentação saudável e adequada para pessoas com DM e HA, foco deste estudo.

Outra percepção dos profissionais de saúde comprovada nos depoimentos, relativa à IC $1.3 \mathrm{~b}$, foi a de que "a dificuldade maior está na falta de espaço físico adequado para realizar as ações (principalmente depois da "lei do CFM")".

"[...] eu acho que mais pesa é o espaço físico. [...] Quando a gente faz aqui, não é adequado. Tivemos a ideia de fazer na comunidade. Agora tá tendo uma lei aí, que não podemos atender fora da US. [...] Só que a unidade não comporta essa galera toda. Com sete equipes, mais as especialidades, nós não vamos ter condição de atender e fazer revisão com esse pessoal. Se a gente quiser a gente vai fazer apenas a reunião de Hiperdia, mas não pode fazer a consulta. E os pacientes disseram: se não tiver a consulta ele não vai. [...] E eu, inclusive não quero nem ir. [...] eu tenho todo um vínculo com eles [...] E eu tá lá e não posso nem olhar uma ferida, não posso nada, é proibido. $O$ ato tem que ser simplesmente educativo. É lei do CFM [...]." (DSC 1.3b)

Essa visão difere um pouco das dificuldades atribuídas às ações educativas nas três primeiras IC, que envolviam aspectos mais de cunho teóricometodológico e concepcional do modelo de assistência. Ela destaca a dificuldade em termos da disponibilidade de recursos físicos para a realização das atividades educativas, particularmente a indisponibilidade de espaço físico adequado à realização das atividades dos grupos de Hiperdia, que não seriam mais realizadas fora das dependências da US.

O argumento principal para essa decisão foi “[...] a lei do CFN [...]”, que, no entendimento dos profissionais de saúde, limita a participação dos médicos naquelas ações que são realizadas fora das dependências de um consultório, a exemplo dos grupos de Hiperdia, que aconteciam em equipamentos da 
comunidade, como igrejas e centros comunitários, em condições estruturais que não atenderiam à Resolução do Conselho Regional de Medicina do Espírito santo (CRM-ES) 218/2009, de 27 de janeiro de 2009, que estabelece em seu artigo $2^{\circ}$ :

"Fica proibido, sob qualquer hipótese, o atendimento médico fora das dependências do consultório médico, definido na Resolução do CFM ${ }^{\circ}$. 1886/2008, com área física e instalações normatizadas pela Vigilância Sanitária, com devido alvará da mesma, salvo em caso de urgência/emergência e impossibilidade comprovada de realizá-lo, devendo, nesse caso, fazê-lo imediatamente cessado o impedimento." (CRMES, 2009).

Por outro lado, a Portaria Ministerial n. 648, de 28 de março de 2006, diz que, entre as atribuições do médico, está a de "realizar consultas clínicas e procedimentos na USF e, quando indicado e necessário, no domicílio e/ou nos demais espaços comunitários (escolas, associações, etc.)” (Brasil, 2006b). Observa-se que parece um impasse entre o órgão regulador do exercício profissional e o determinado pela portaria do Ministério da Saúde.

$\mathrm{O}$ acatamento dessa resolução resultou no redimensionamento das ações dos grupos do Hiperdia, antes desenvolvidas em espaços da comunidade, com uma aprovação tanto das equipes quanto da própria comunidade, resultando numa outra lógica de assistência, que acaba por se resumir, na maioria das oportunidades, no atendimento realizado nas consultas médicas.

Cabe, portanto, indagar: no discurso dos profissionais que consideram que, sem consultas médicas, as pessoas não participariam das demais atividades educativas dos grupos e não haveria elementos reforçadores das práticas centradas no médico, na doença e num plano terapêutico que privilegia os aspectos curativos em relação aos preventivos e promocionais? Não estaríamos, mais uma vez, diante de um discurso que se distancia da proposta de reorientação das práticas assistenciais no âmbito da Atenção Básica à Saúde?

Finalmente, no conjunto de IC que atribuíram dificuldades e limites das ações educativas a estrutura, processos e resultados da prática assistencial, resta comentar a IC $1.4 \mathrm{~b}$, segundo a qual seria importante ter o nutricionista para ajudar a planejar, atuar nas situações específicas e organizar a educação na comunidade. 
A reunião das ECH iluminadas acerca dessa IC resultou no seguinte discursosíntese:

"[...] Eu acho muito importante ter um profissional na equipe, um nutricionista, porque, muitos dos nossos pacientes, ou tão com sobrepeso ou tão com um grau de obesidade. [...] tem pacientes diabéticos, tem renal também. Tem alguns assuntos que não é muito fácil. Por exemplo, a questão da avaliação nutricional [...] Eles poderiam estar também organizando essa educação lá na comunidade [...] se não tiver condição de ter por equipe, que ao menos trabalhássemos juntos na construção de oficinas, para formular estes instrumentos, para que a gente tomasse conta de estar orientando de uma forma adequada." (DSC 1.4b)

Deduz-se desse discurso que a presença do nutricionista na esfera da ESF contribui para a qualificação das práticas assistenciais, tanto em virtude de algumas competências e habilidades especificamente atribuídas a esse profissional, como no caso de condutas que envolvem a avaliação nutricional e a elaboração de planos terapêuticos especiais, quanto do planejamento de atividades educativas e da organização da educação em saúde na comunidade.

Vale destacar, no DSC 1.4b, algumas expressões relativas à necessidade de apoio do nutricionista para preencher lacunas sentidas pelos profissionais da ESF na orientação daquelas pessoas que, em razão de algumas doenças e agravos, como o diabetes e a doença renal, exemplificados no discurso coletivo, demandam orientações específicas que fogem à competência dos profissionais que hoje integram as equipes básicas da ESF.

"Porque a gente tem várias situações, tem pacientes diabéticos, tem
renal também. Tem alguns assuntos que não é muito fácil. [...] Questão
de apropriação mesmo. Não tem essa apropriação por parte do
profissional. O que a gente faz são orientaçóes básicas, ok? Mas, então a
gente fica a desejar, carente por não ter profissionais específicos,
entendeu? [...]" (DSC 1.4b)

A expectativa da atuação do nutricionista na ESF está presente também no movimento da categoria para promover a sua inserção na esfera da Atenção Básica à Saúde, particularmente na ESF. Em documento técnico elaborado pelo Sistema de Segurança Alimentar e Nutricional (SISAN), encontra-se o referendo para a integração das ações de alimentação e nutrição nas ações primárias de 
saúde. Ele está respaldado no contexto epidemiológico brasileiro e nos instrumentos institucionais e legais de formulação e implantação das políticas públicas de promoção da saúde, alimentação e nutrição. Essa integração fortaleceria o compromisso do setor saúde com o Sistema de Segurança Alimentar e Nutricional (SISAN), com vistas ao Direito Humano à Alimentação Adequada (DHAA). A incorporação das ações de alimentação e nutrição responderia às principais demandas assistenciais da Atenção Básica à Saúde, "ampliando os planos terapêuticos tanto na ESF quanto nas unidades convencionais" (Sistema..., 2008).

Entre as ações estratégicas da competência do nutricionista pautadas pelo CFN/CRN's estão justamente algumas que aparecem no DSC 1.4b como expectativa dos profissionais de saúde sobre a contribuição do nutricionista para as equipes de saúde:

\footnotetext{
"Elaborar, em conjunto com a equipe de saúde, rotinas de atenção nutricional e atendimento para doenças relacionadas à alimentação e nutrição [...]; atuar na formação e educação continuada das equipes de saúde e participar das ações dos programas de controle dos distúrbios nutricionais como [...] sobrepeso, obesidade, doenças crônicas não transmissíveis e desnutrição; elaborar planos terapêuticos [...] que permitam a apropriação coletiva pela equipe de saúde [...]; desenvolver ações de distintas naturezas para a promoção de práticas alimentares saudáveis [...] estabelecendo estratégias conjuntas com diferentes setores e atuando nos espaços sociais da comunidade; [...] realizar o diagnóstico da situação alimentar e nutricional da população [...]" (Sistemas..., 2008, p. 28-31).
}

A importância da área de alimentação e nutrição em todas as esferas da Atenção Básica, especialmente na ESF, e a presença do nutricionista nesse âmbito parecem estar bastante argumentadas. No entanto, observa-se um distanciamento entre o discurso político oficial, que ainda está localizado nas esferas centrais do poder, mais propriamente nas instâncias da Educação, Saúde, e Desenvolvimento Social, e a realidade da maioria dos municípios brasileiros. Neles, a ausência desse profissional é um indício da necessidade de maior mobilização e articulação na implantação das políticas públicas. 
Nesse contexto, uma perspectiva importante seria a implantação dos Núcleos de Apoio à Saúde da Família (NASF), instituídos pela Portaria GM 154, de 24 de janeiro de 2008. Segundo essa portaria, a presença do nutricionista e de outros profissionais de saúde não integrantes das equipes básicas da ESF viria ao encontro da necessidade de fortalecimento dos princípios norteadores da Atenção Básica à Saúde, tais como: ação interdisciplinar e intersetorial, educação permanente em saúde, territorialidade, integralidade, participação social, educação popular, promoção da saúde e humanização (Brasil, 2009). Conceptualmente, o NASF integra-se aos esforços da ESF de reorientar práticas de saúde no sentido da integralidade e da humanização do Sistema.

A atuação do nutricionista, como a de qualquer outro profissional que integre um NASF, deverá ser operacionalizada numa lógica de apoio matricial a diversas ações, entre as quais a de atendimento compartilhado, projetos terapêuticos singulares, atendimento em conjunto e ações educativas. Os sujeitos da abordagem do cuidado nutricional serão o indivíduo, a família e a comunidade.

Em contrapartida, há muito que investir ainda no processo de formação do nutricionista e na produção de conhecimento, principalmente na esfera em que se concentra saúde coletiva ou saúde pública, na qual se localiza o campo da educação alimentar e nutricional (Santos, 2010).

\section{CONSIDERAÇÕES FINAIS}

A análise do discurso de profissionais de saúde empreendida neste estudo propiciou construir uma perspectiva sobre as ações educativas com foco na mudança de práticas alimentares de pessoas com diabetes e hipertensão, destacando as dificuldades e os limites dessas ações no âmbito da ESF.

As representações mais expressivas obtidas mediante os depoimentos foram discutidas em relação a duas categorias de análise: na primeira, os limites e dificuldades das ações educativas foram atribuídos a circunstâncias extrínsecas e intrínsecas inerentes às pessoas com DM e/ou HA; na segunda, eles foram 
relacionados à estrutura, aos processos e/ou aos resultados do modelo educativo e, portanto, do modelo assistencial.

No conjunto dos discursos coletivos referente à primeira, as visões mais frequentes foram as que relacionaram as dificuldades das ações educativas em promover práticas alimentares adequadas à condição socioeconômica e cultural das famílias; as que atribuíram o não seguimento das orientações/prescrições educativas à relutância ou rebeldia própria das pessoas com diabetes e/ou hipertensão; as que consideraram que essas pessoas não estão interessadas na prevenção, mas antes nas intervenções de caráter meramente curativo.

As expressões mais recorrentes nos DSC apontam uma prática educativa impregnada de significados inerentes ao modelo assistencial tradicional, em que o enfoque preventivista, que parece predominar entre os profissionais de saúde, se contrapõe às práticas "curativas", na impressão desses sujeitos, as que são mais demandadas pelos usuários/pacientes. Sobre isso, cabe indagar se o julgamento dos profissionais de saúde não é uma representação de preconceitos e de divergência de visões que estão permeando as relações entre profissionais de saúde e usuários/pacientes. Não seria essa uma forma de os profissionais de saúde justificarem a permanência de práticas orientadas pelo modelo biologicista, pela sobrepujança da autoridade médica e do saber técnico-científico em desconsideração ao saber e as crenças populares e pelo emprego de técnicas educativas normativas, verticalizadas, orientadas pelo princípio da persuasão e da culpabilização dos indivíduos por seu comportamento de risco?

Por outro lado, o discurso que traz a reflexão dos profissionais de saúde sobre a implicação das questões sociais e culturais (como dificuldades reais para a promoção de práticas alimentares adequadas e promotoras de saúde) aponta a necessidade de considerar a realidade de (in) SAN das famílias como elemento essencial na orientação das ações educativas. Para tanto, a proposta teóricometodológica e pedagógica da educação alimentar e nutricional deve ser alinhavada em abordagens participativas, dialógicas e problematizadoras que permitam desvelar realidades e sentimentos de (in) SAN no âmbito individual e coletivo. Nessa perspectiva, as ações educativas prescindem do conhecimento do sistema de crenças e valores individuais e coletivos para a construção de 
processos comunicacionais que municiem o indivíduo para a ação ativa e consciente em prol de sua saúde.

Não se pode perder de vista, que o fato da abordagem preventivista da educação em saúde/educação nutricional se pautar em uma lógica na qual o indivíduo é o responsável pela reversão dos problemas de saúde pode resultar em uma inoperância do Estado em atuar nos problemas relativos à estrutura social, que determina a possibilidade de ação das pessoas. No âmbito da educação nutricional, portanto, há que incorporar, na agenda do educador em saúde, a problematização sobre a acessibilidade à SAN e ao DHAA, aproximando as ações das políticas de alimentação e nutrição às de promoção da saúde.

Outro dificultador do processo educativo na percepção dos profissionais de saúde seria a idade avançada de boa parte dos usuários/pacientes. Isso se observa principalmente naquelas situações em que o envelhecimento é dependente de cuidados, geralmente provido por familiares que não dispõem de tempo e condições para acompanhar, mais sistematicamente, o comportamento das pessoas em relação ao controle de sua vida.

Essa é uma questão que exige tanto um urgente enfrentamento macropolítico quanto um de ações concretas que acontecem na relação direta dos serviços com os usuários.

A respeito da prática educativa per si, encontra-se diante de uma circunstância em que o sujeito para o qual a ação educativa é destinada não é propriamente o usuário/paciente, visto que está comprometido o estabelecimento de um processo comunicacional, até mesmo os de enfoque prescritivo, que prescindem da autonomia e consciência das pessoas. A educação em saúde, nesse caso, deve-se deslocar da atenção estritamente individual e se colocar como ação estratégica de articulação entre as necessidades da família e as instâncias em que as políticas sociais e de saúde são executadas, numa perspectiva que muito se aproxima da educação popular em saúde.

Conceptualmente, a educação popular é uma proposta de transformação das práticas tradicionais de educação em saúde em práticas pedagógicas que mobilizem a participação social e contribuam com a superação de limites que permeiam o cotidiano das pessoas em prol de uma vida digna e saudável. Como 
prática essencialmente dialógica, propicia o entendimento dos profissionais de saúde sobre as dificuldades que as pessoas têm em lidar com seus problemas cotidianos, em evidência os problemas de saúde, como as pessoas experimentam o enfrentamento de doenças, como o diabetes e a hipertensão, que implicam a modificação, às vezes radical, de seu modo de vida. Em seu âmbito de atuação, a ESF, apesar do distanciamento entre o discurso oficial e as ações empreendidas no local, seria alternativa política e metodológica para orientação das práticas educativas segundo esta concepção.

No bojo dos discursos coletivos que localizaram, na estrutura, nos processos e/ou nos resultados do modelo assistencial vigente, as dificuldades e os limites para as ações educativas com foco na educação alimentar e nutricional, foram destacadas a falta de sedimentação das atividades educativas no plano terapêutico para as pessoas com diabetes e hipertensão, a ausência de planejamento integrado e participativo dessas ações e a indisponibilidade de recursos físicos (local) e humanos específicos (presença do nutricionista na Atenção Básica à Saúde) necessários à qualificação delas.

Apreende-se desses discursos que, a despeito do atual estágio em que se encontra a reflexão sobre os modelos e abordagens mais significativas para a educação e a promoção em saúde, em termos concretos, ainda se depara com impedimentos relativos à estruturação, organização e operacionalização do Sistema para uma oferta mais qualificada dos serviços de saúde. Isso se manifesta com maior expressão quando se trata das ações educativas empreendidas numa perspectiva hegemônica que tradicionalmente fragmenta os saberes e práticas de saúde.

Os investimentos nesse campo devem contemplar a aproximação do discurso das políticas nacionais de saúde e nutrição com as esferas estaduais e, principalmente, com as municipais, em que as ações educativas se concretizam. Para tal, a estruturação dos serviços com recursos humanos capacitados sob o aspecto teórico-metodológico e pedagógico é uma condição. Em termos das particularidades da ESF, tem-se, nos NASFs, uma possibilidade concreta para apoiar as equipes locais no planejamento e na execução de ações educativas que 
percorram os caminhos da interdisciplinaridade e da integralidade das práticas assistenciais.

As representações sociais emanadas do DSC dos profissionais de saúde não apenas suscitaram a reflexão sobre as práticas educativas na atenção à saúde das pessoas com diabetes e hipertensão, mas também a ampliaram para as potencialidades e contradições da ESF no processo de mudança do modelo assistencial.

\section{REFERÊNCIAS}

ADA - American Diabetes Association. Standards of medical care in diabetes. Diabetes Care, v.28, s.1, p.54-536, 2005.

ALMEIDA-PITITTO B. Impacto de um programa de intervenção no estilo de vida sobre o perfil de risco cardiometabólico da população nipo-brasileira de alto risco. [Tese de Doutorado]. São Paulo. Faculdade de Saúde Publica, Universidade de São Paulo, 2009

ALVES, V.S. Um modelo de educação em saúde para o programa de saúde da família: pela integralidade da atenção e reorientação do modelo assistencial. Interface- Comunic. Saúde Educ., v.9, n.16, p.39-52, 2005.

APPEL, L.J. et al. A clinical trial of dietary patterns on blood pressure. New England Journal of Medicine, v.336, n.16, p.1117-1124, 1997.

ARAÚJO, D.R.D. Como transcrever sua entrevista: técnica de editoração da transcrição de entrevista em pesquisa de abordagem compreensivista. Psico, v. 32, n.1, p. 147-157, 2001.

ARAUJO, R. B. et al. Avaliação do cuidado prestado a pacientes diabéticos em nível primário. Rev. Saúde Pública [online], v.33, n.1, p. 24-32, 1999. ISSN 0034-8910. Disponível em: <http://www.scielo.br/pdf/rsp/v33n1/0020.pdf〉. Acesso em: 310 jan. 2011.

ARAUZ, A.G. et al. Intervención educativa comunitaria sobre la diabetes comunitária en el ámbito de la atención primaria. Rev Panam Salud Publica, Washington, v.9, n.3, p.145-153, 2001.

AROUCA, S. O dilema preventivista: contribuição para a compreensão e crítica da medicina preventiva. São Paulo: Editora UNESP, Rio de Janeiro: Editora FIOCRUZ, 2003.

ASSUNCAO et al. Atenção primária em diabetes no Sul do Brasil: estrutura, processo e resultado. Rev. Saúde Pública [online], v.35, n.1, p. 88-95, 2001. ISSN 0034-8910. Disponível em: <http://www.scielo.br/pdf/rsp/v35n1/4141.pdf> Acesso em 23 jan. 2011. 
BARDIN, L. Análise de conteúdo. Lisboa: Edições 70, 1977.

BATISTA, S.H.; BATISTA, N.A. Docência universitária em saúde, formação e interdisciplinaridade. In: Batista, N.A.; Batista, S.H.; Abdalla, I.G. (Org.) Ensino em saúde: visitando conceitos e práticas. São Paulo: Arte e Ciência, 2005.

BIRCH, L.L. Os padrões de aceitação do alimento pelas crianças. In: Sabor e saciedade. Anais Nestle, v.57, p.12-20, 1999.

Psychological influences on the childhood diet. J. Nutr., v.128, p, 407-410s, 1998. Disponível em:

<http://jn.nutrition.org/content/128/2/407S.full.pdf+html>. Acesso em: 22 jan. 2011.

BOING, A.C; BOING, A.F. Hipertensão arterial sistêmica: o que nos dizem os sistemas brasileiros de cadastramento e informações em saúde. Rev Bras Hipertens, vol. 14, n. 2 , p. 84-88, 2007.

BOOG, M.C.F. Educação nutricional: por que e para quê? Artigo. Jornal Unicamp. Universidade Estadual de Campinas. 2 a 8 de agosto de 2004, p.2; 2004. Disponível em: 〈http://www.unicamp.br/unicamp/unicamp_hoje/jornalPDF/ju260pag02.pdf>. Acesso em: 25 set. 2010.

BRASIL. Ministério da Saúde. Secretaria de Atenção Básica. Departamento de Ações Programáticas Estratégicas. Diretrizes do NASF - Núcleos de Apoio a Saúde da Família. Série A. Normas e Manuais Técnicos. Cadernos de Atenção Básica, n.27. Brasília, 2009.

Presidência da República. Casa Civil. Subchefia para Assuntos Jurídicos. Lei 11.346, de 15 de setembro de 2006. Cria o Sistema Nacional de Segurança Alimentar e Nutricional - SISAN com vistas em assegurar o direito humano à alimentação adequada e dá outras providências. Brasília, 2006a. Disponível em: <https://www.planalto.gov.br/ccivil_03/_Ato2004-2006/2006/Lei/L11346.htm〉. Acesso em 20 jan. 2011.

Ministério da Saúde. Política Nacional de Atenção Básica e revisão das diretrizes e normas para a organização da atenção básica para o programa de saúde da família e programa de agentes comunitários de saúde. Portaria n. 648, de 28 de março de 2006. Brasília, 2006b.

Ministério da Saúde. A vigilância, o controlo e a prevenção das doenças crônicas não-transmissíveis: DCNT no contexto do Sistema Único de Saúde brasileiro. Brasília: Organização Pan-Americana da Saúde, 2005.

Ministério da Saúde. Plano de Reorientação da Atenção à Hipertensão Arterial e ao Diabetes Mellitus: manual de hipertensão arterial e diabetes mellitus. Brasília, 2001a.

. Ministério da Educação. Secretaria de Educação Superior. Diretrizes curriculares para os cursos de graduação. Brasília, 2001b. Disponível em: <www.mec.gov.br/sesu/diretriz.shtm>. Acesso em 15 jan. 2011.

Lei $\mathrm{n}^{\circ}$ 8080, de 19 de setembro de 1990. Dispõem sobre as condições para a promoção, proteção e recuperação da saúde, a organização e funcionamento dos serviços 
correspondentes e dá outras providências. Diário Oficial da União, Brasília, DF, 20 set 1990. p. 018055.

BRICEÑO-LEON, R. Siete tesis sobre la educación sanitária para la participación comunitária. Cadernos de Saúde Pública, v.12, n.1, p.7-30, 1996.

CABRERA-PIVARAL, C.E. et al. Efectos de una intervención educativa sobre los niveles plasmáticos de LDL-colesterol en diabéticos tipo 2. Salud Pública de México, v.43, n.6, p.556-3562, 2001.

CALDAS, C.P. Envelhecimento com dependência: responsabilidades e demandas da família. Cad. Saúde Pública (online), v.19, n.3, p.733-781, 2003. ISSN 0102-311X. Disponível em:

<http://www.scielosp.org/pdf/csp/v19n3/15880.pdf>. Acesso em 21 jan. 2011.

CAMARGOS, M.C.S., RODRIGUES, R.N. Idosos que vivem sozinhos: como eles enfrentam dificuldades de saúde. Trabalho apresentado no XVI Encontro Nacional de Estudos Populacionais, realizado em Caxambu- MG, Brasil, de 29 de setembro a 03 de outubro de 2008. Disponível em:

http://www.abep.nepo.unicamp.br/encontro2008/docsPDF/ABEP2008_1605.pdf. Acesso em: 21 jan. 2011.

CAMARGOS, M.C.S. et al.. A relação entre renda e morar sozinho para idosos paulistanos: 2000. Rev. bras. estud. popul. (online), v.24, n.1, p. 37-51, 2007. ISSN 0102-3098. Disponível em:

<http://www.scielo.br/pdf/rbepop/v24n1/03.pdf>. Acesso em 21 jan. 2011.

CANDEIAS, N.M.F. Conceitos de educação e de promoção em saúde: mudanças individuais e mudanças organizacionais. Rev. Saúde Pública [online], v.31, n.2, p.209213, 1997. ISSN 0034-8910. Disponível em:

<http://www.scielosp.org/pdf/rsp/v31n2/2249.pdf> Acesso em 13 jan. 2011.

CANESQUI, A.M.; SPINELLI, M.A.S. Saúde da família no Estado do Mato Grosso, Brasil: perfis e julgamento dos médicos e enfermeiros. Cad. Saúde Pública [online], v.22, n.9, 2006, p.1881-1892. ISSN 0102-311X. Disponível em:

<http://www.scielo.br/pdf/csp/v22n9/12.pdf > Acesso em 15 jan. 2011.

CARNEIRO, H.. As necessidades humanas e o proibicionismo das drogas no século XX. Outubro (São Paulo), v.6, p.115-128, 2002. Disponível em:

http://www.revistaoutubro.com.br/edicoes/06/out6_10.pdf. Acesso em 21 jan. 2011.

CASTRO, A.G.P.; FRANCO, L.J. Caracterização do consumo de adoçantes alternativos e produtos dietéticos por indivíduos diabéticos. Arq Bras Endocrinol Metab (online), v.46, n.3, p.280-287, 2002. ISSN 0004-2730. Disponível em: <http://www.scielo.br/pdf/abem/v46n3/10899.pdf>. Acesso em 23 jan. 2011.

CERVATO, M.A. et al. Bases teóricas para a prática da educação nutricional. Rev Nutrição em Pauta. 2004. Disponível em:

<http://www.nutricaoempauta.com.br/lista_artigo.php?cod=45.> Acesso em 11 out. 2010.

CREVELIM, M.A; PEDUZZI, M. Participação da comunidade na equipe de saúde da família é possível de estabelecer um projeto comum entre trabalhadores e usuários? Ciênc. saúde coletiva [online], v.10, n.2. p.323-331, 2005. ISSN 1413-8123. Disponível 
em: <http://www.scielosp.org/pdf/csc/v10n2/a10v10n2.pdf>. Disponível em: 15 jan. 2011 .

CRMES - Conselho Regional de Medicina do Espírito Santo. Resolução no 218/2009, de 27 de janeiro de 2009. Regulamenta sobre como os estabelecimentos públicos, privados, filantrópicos ou de qualquer natureza, que se proponham a prestar atendimento médico devem estar estruturados. Disponível em: <http://www.crmes.org.br/conteudo.php?incConteudo=VER_RESOLUCOES\&ID_RESOLUCAO=79\&C OD_BLOCO $=\& C O D \_C O N T=>$. Acesso em 02 de jan. de 2010.

DANSINGER, M.L. et al. Comparison of the Atkins, Ornish, Weight Watchers and Zone Diets for Weight Loss and Heart Disease Risk Reduction. A Randomized Trial. Journal of American Medical Association, v.293, n.1, p.43-53, 2005.

FABER, J. Avanços na compreensão do paladar. Rev. Dent. Press Ortodon. Ortop. Facial (online), v.11, n.1, p.14-14, 2006. ISNN 1415-5419. Disponível em: <http://www.scielo.br/pdf/dpress/v11n1/28242.pdf>. Acesso em 22 jan. 2011.

FLACK, J.M. et al. Cardiovascular disease costs associated with uncontrolled hypertension. Manage Care Interface, New York, v.15, n.11, p.28-36, 2002.

FONTANA, A.; FREY, J.H. The interview - from structured questions to negociated text. In: DENZIN, N.; LINCOLN, Y. Handbook of qualitative research. $2^{\text {nd }}$ ed. Thousand Oaks, CA: Sage Publications, 2000. p.645-671.

FONTANELLA et al. Amostragem por saturação em pesquisas qualitativas em saúde. Cad. saúde pública, v.24, n.1, p.17-27, 2008.

FREITAS, M.C.S.; PENA, P.G.L. Segurança alimentar e nutricional: a produção do conhecimento com ênfase nos aspectos da cultura. Rev. Nutr. (online), v.20, n.1, p.6981, 2007. ISSN 1415-5273. Disponível em:

<http://www.scielo.br/pdf/rn/v20n1/a08v20n1.pdf>. Acesso em 20 jan. 2011.

FREITAS, M.C.S. Educação nutricional: aspectos socioculturais. Rev Nutr PUCCamp, v.10, p.45-49, 1997.

GARANTTINI, L. et al. Direct medical costs unequivocally related to diabetes in Italian specialized centers. Eur J Health Econ., v.5, n.1, p.15-21, 2004.

GORDILHO, A. et al. Desafios a serem Enfrentados no Terceiro Milênio pelo Setor Saúde na Atenção ao Idoso. Rio de Janeiro: Universidade Aberta da Terceira Idade. Universidade do Estado do Rio de Janeiro, 2000.

GUYTON AC, HALL JE. Os sentidos químicos: gustação e olfação. In: Guyton AC, Hall JE. Tratado de fisiologia médica. 9. ed. Rio de Janeiro: Guanabara Koogan; p. 611-617, 1997.

HAJJAR, I., KOTCHEN, T. Regional variations of blood pressure in the United States are associated with regional variations in dietary intakes: the NHANES-III data. Journal of Nutrition, v.133, n.1, p. 211-214, 2003. 
IBGE - Instituto Brasileiro de Geografia e Estatística.. Pesquisa de Orçamentos Familiares (POF) 2002-2003: análise da disponibilidade domiciliar de alimentos e do estado nutricional no Brasil. Rio de Janeiro: IBGE, 2004. Disponível em:

<http://www.ibge.gov.br/home/estatistica/populacao/condicaodevida/pof/2002analise/pof 2002analise.pdf>. Acesso em 23 jan. 2011.

JONES, N. et al. An investigation of adult's views of the outcomes of dietary treatment. Journal of Human Nutrition \& Dietetics, v.20, n.5, p. 486-494, 2007.

LEFÈVRE, F.; LEFÈVRE, A.M.C. O discurso de sujeito coletivo: um novo enfoque em pesquisa qualitativa (desdobramentos). Caxias do Sul: Educ, 2003.

$\overline{2004 .}$

Promoção de saúde: a negação da negação. Rio de Janeiro: Vieira e Lente,

LESSA, I. Doenças crônicas não-transmissíveis no Brasil: um desafio para a complexa tarefa da vigilância. Ciênc. saúde coletiva, vol.9, n.4, p.931-943, 2004.

LESSA, I. FONSECA, J. Raça, aderência ao tratamento e/ou consultas e controle da hipertensão arterial. Arq Bras Cardiol, v.68, n. 6, p.443-449, 1997.

LIMA, R. T.et al. Educação em saúde e nutrição em João Pessoa, Paraíba. Revista de Nutrição, Campinas, v.13, n.1, p.29-36, 2000.

MAIA, F.F.R.; ARAÚJO, L.R. Projeto 'Diabetes Weekend': Proposta de Educação em Diabetes Mellitus tipo I. Arq Bras de Endocrinol e Metab, v.46, n.5, p.566-573, 2002.

MILLER, C. K. et al. Evaluation of a theory-based nutrition intervention for older adults with diabetes mellitus. J Am Diet Assoc. v.102, n.8, p.1069-81, 2002.

MINAYO, M.C.S. O desafio do conhecimento: pesquisa qualitativa em saúde. São Paulo:Ed. Hucitec, 1993.

MION Jr, D. et al. Hipertensão Arterial: abordagem geral. Projeto Diretrizes AMB/CFM, 2002. Disponível em:

<http://www.projetodiretrizes.org.br/projeto_diretrizes/059.pdf>. Acesso em: 11 out. 2010 .

PAIVA et al.. Avaliação da assistência com diabetes e/ou hipertensão pelo Programa de Saúde da Família do Município de Francisco Morato, São Paulo, Brasil. Cad. Saúde Pública, v.22, n.2, p. 377-385, 2006.

PATTON, M.Q. The nature of quality inquiry. In: Qualitative research e evaluation methods. $3^{\text {nd }}$ ed. Thousand Oaks, CA: Sage Publications, 2002. p.3-29.

PÉRES, D.S. et al. Dificuldades dos pacientes diabéticos para o controle da doença: sentimentos e comportamentos. Rev. Latino-am Enfermagem (online), v.15, n.6, 2007. Disponível em: <http://www.scielo.br/pdf/rlae/v15n6/pt_07.pdf>. Acesso em 21 jan. 2011.

PERES, D.S. et al. Comportamento alimentar em mulheres portadoras de diabetes tipo 2. Rev. Saúde Pública [online]. 2006, v.40, n.2, p.310-317. ISSN 0034-8910. Disponível em: 
<http://www.scielosp.org/pdf/rsp/v40n2/28537.pdf>. Acesso em 21 jan. 2011.

PONTIERE, F.M.; BACHION, M.M. Crenças de pacientes diabéticos acerca da terapia nutricional e sua influência na adesão ao tratamento. Ciênc. saúde coletiva, v.15, n.1, p.151-160, 2010.

RAMOS, M.; STEIN, L.M. J Pediatr, v.76, s.3, p.229-237, 2000. Disponível em: $<$ http://www.fag.edu.br/professores/fabiana/Est\%E1 gio\%20ESCOLA/Desenvolvimento \%20do\%20comportamneto\%20alimentar\%20infantil.pdf>. Acesso em: 22 jan. 2011.

REINERS, A.A.O. et al. Produção bibliográfica sobre adesão/não-adesão de pessoas ao tratamento de saúde. Ciênc. saúde coletiva (online), v.13, s.2, p.2299-2306, 2008. ISSN 1413-8123. Disponível em: http://www.scielosp.org/pdf/csc/v13s2/v13s2a34.pdf . Acesso em: 20 jan. 2011.

SANTANA, M.G. O desejo, o controle e o limite: possíveis enfrentamentos no cotidiano diabético. In: (Org.). Rede de saberes em diabetes e saúde: um exercício de interdisciplinaridade. Pelotas: Edição Independente, 2002, p.53-72.

SANTOS, L.A.S. O fazer educação alimentar e nutricional: algumas contribuições para reflexão. Ciênc. saúde coletiva, 2010. Em prelo. Disponível em:

http://www.cienciaesaudecoletiva.com.br/artigos/artigo_int.php?id_artigo=6615>.

Acesso em: 5 jan. 2011.

SARTORELLI, D.S. et al. Beneficial effects of short term nutritional conselling at the primary health-care level among Brasilian adults. Public Health Nutrition, v.8, n.7, p.820-825, 2004.

SCHIFFMAN, S.S. Fisiologia do paladar. In: Sabor e saciedade. Anais Nestle, v.57, p.1$11,1999$.

SEVERINO, A. J. Metodologia do trabalho científico. São Paulo: Cortez, 1996.

SILVA, M.V.L. Efeitos do aconselhamento dietético no tratamento da Hipertensão Arterial em hipertensos da US de Andorinhas, Vitória, ES. [Dissertação de Mestrado]. Vitória: Centro Biomédico da Universidade Federal do Espírito Santo, 2005.

SILVA, T.R. et al. Controle de diabetes mellitus e hipertensão arterial com grupos de intervenção educacional e terapêutica em seguimento ambulatorial de uma unidade básica de saúde. Saúde Soc., vol.15, n.3, p.180-189, 2006.

SILVESTRE, J.A; COSTA NETO, M.M. Abordagens do idoso em programas de saúde da família. Cad. Saúde Pública (online), v.19, n.3, p.839-847, 2003. ISSN 0102-311X. Disponível em: <http://www.scielosp.org/pdf/csp/v19n3/15887.pdf〉. Acesso em: 21 jan. 2011.

SISTEMA CONSELHOS FEDERAL E REGIONAIS DE NUTRICIONISTAS. O papel do nutricionista na atenção primária à saúde. Documento Técnico. Brasília, 2008.

STOTZ, E. Enfoque sobre educação popular e saúde. In: Brasil. Ministério de Saúde. Secretaria de Gestão Estratégica e Participativa. Departamento de Apoio à Gestão Participativa. Caderno de educação popular e saúde. Brasília: Ministério da Saúde, 2007. Série B. Textos Básicos de Saúde. 
VALLA, V.V. Educação popular, saúde comunitária e apoio social numa conjuntura de globalização. Cad Saúde Pública, v.15, n.2, p.7-14, 1999.

VASCONCELOS, E.M. Educação popular como instrumento de reorientação das estratégias de controle das doenças infecciosas e parasitárias. Cad Saúde Pública, v.14, n.2, p.39-57, 1998.

$\mathrm{YACH}$, D. et al. Global burden of chronic diseases. Overcoming impediments to prevention and control. Journal of the American Medical Association, v.291, n.21, p.2616-2622, 2004. 


\section{Ação educativa na Atenção Básica à Saúde para pessoas com diabetes mellitus e hipertensão arterial: escutando os sujeitos- pacientes.}

Ana Maria Bartels Rezende

Ana Maria Cervato-Mancuso

\section{INTRODUÇÃO}

Num contexto epidemiológico de transição, as doenças crônicas não transmissíveis (DCNT), especialmente as coronarianas e o diabetes mellitus do tipo 2, constituem relevante problema de saúde pública e impõem ao Sistema de Saúde a garantia de acompanhamento e assistência sistemática de seus portadores, além de ações de promoção da saúde e prevenção dos riscos modificáveis para essas doenças (Barreto et al. 2005; Brasil, 2005; Lessa, 2004).

A base da prevenção e do tratamento dessas doenças parece localizar-se nas modificações do estilo de vida e no controle de fatores de risco modificáveis, sobre os quais o paciente e a equipe de saúde podem atuar, como a alimentação inadequada, o sedentarismo, o tabagismo e etilismo, entre outros (Gus, et al., 2002; Ministério da Saúde, 2001).

Especialmente para pessoas com diabetes mellitus (DM) e hipertensão arterial (HA), o controle metabólico rigoroso e a adoção de estilo de vida saudável em relação à dieta e atividade física impactam positivamente a redução da morbimortalidade cardiovascular (SBD, 2003; Kohlmann Jr. et al., 1999). No entanto, por se reportarem ao comportamento social e por terem suas bases constituídas no núcleo familiar desde a infância, essas são medidas difíceis de modificar (Motta, Boog, 1991).

A baixa adesão ou continuação ao tratamento de diabéticos e hipertensos é objeto de estudos para a saúde pública e está relatada em investigações no Brasil e 
em outros países (Paiva et al., 2006; Hernandez-Ronquillo et al., 2003; Assunção et al., 2001). Entre os fatores que dificultam a adesão ao tratamento por parte desses pacientes estão: o baixo nível socioeconômico, que resulta na menor adesão devido ao custo dos medicamentos (Botelho, Dudrak, 1992) e dos alimentos (Sherman et al., 2000); a baixa escolaridade (Moreira et al., 2003) e fatores circunstanciais, como comer em restaurantes; a oferta de alimentos inadequados por outras pessoas (Ary et al.,1986).

Se, por um lado, a baixa adesão ao tratamento é um desafio, por outro ela motiva estudos que buscam demonstrar a importância das ações educativas para promover mudanças no estilo de vida e maior adesão ao tratamento, resultando em melhor controle da HA e/ou do DM (Almeida-Pititto, 2009; Jones et al., 2007; Miller et al., 2002; Arauz et al., 2001; Cabrera-Pivaralet al., 2001; Gonzales et al., 1997; Gruesser et al.1997). No Brasil, embora ainda em pequeno número, algumas publicações relatam resultados favoráveis das práticas educativas sobre o controle dessas doenças (Silva, TR et.al., 2006; Silva, 2005; Sartorelli et al., 2004; Maia, Araujo, 2002).

Os processos educativos são tidos como a chave nas intervenções preventivas no âmbito coletivo (Arauz et al., 2001; Lima, 2000) e ganham uma perspectiva conceitual ampliada quando associados à proposta recente de promoção de saúde. Alves, 2005, considera a educação em saúde como “(...) um recurso por meio do qual o conhecimento cientificamente produzido (...) intermediado pelos profissionais de saúde, atinge a vida das pessoas (...) para adoção de novos hábitos e condutas de saúde" (Alves, 2005, p. 43).

A educação nutricional insere-se na educação em saúde com a finalidade primeira de "proporcionar os conhecimentos necessários e a motivação coletiva para formar atitudes e hábitos de uma alimentação sadia, completa, adequada e variada" (Cerqueira, apud Boog, 1999, p.140). Além disso, como elemento específico para as mudanças comportamentais relativas às práticas alimentares, para prover necessidades biológicas e socioculturais da nutrição humana para a promoção, proteção e recuperação da saúde dos indivíduos. Para Boog, 2004, a educação nutricional, assim como todos os processos educativos inerentes ao ser humano, acontece no cotidiano social, ao longo da existência das pessoas, no 
esforço que elas fazem para responder aos desafios cotidianos; acontece ainda por intermédio de ações de instrução e ensino planejadas por pessoas capacitadas para tal.

A promoção de atividades educativas, com o intuito de minimizar os impactos do diabetes mellitus e da hipertensão arterial sobre a saúde pública, encontra-se entre os objetivos do Plano de Reorientação da Atenção à Hipertensão Arterial e ao Diabetes Mellitus, proposto pelo Ministério da Saúde em 2000. A finalidade é estabelecer diretrizes e metas para reorganizar a assistência às pessoas portadoras dessas doenças, cadastradas e acompanhadas na rede básica de saúde (Boing e Boing, 2007; Brasil, 2001).

O tema da alimentação saudável e adequada figura como estratégia de intervenção nos programas e políticas que pretendem promover saúde e qualidade de vida da população e intervir nos fatores de risco para as doenças que mais a atingem. A Política Nacional de Alimentação e Nutrição (PNAN) traz, entre suas diretrizes programáticas, a promoção de práticas alimentares e estilos de vida saudáveis, "com ênfase particular a orientação quanto à prevenção de doenças crônicas não transmissíveis, tais como as cardiovasculares e a diabetes mellitus (...)” (Brasil, 2008a, p.22).

O entendimento de Pinheiro e Luz, 2003, de que as políticas de saúde se materializam na base do Sistema, no fazer cotidiano dos sujeitos que nele e por ele estão envolvidos, permite reconhecer a Estratégia de Saúde da Família (ESF) como locus fundamental para as ações educativas em saúde. Concebida como estratégia estruturante dos sistemas municipais de saúde, a ESF tem sido uma alternativa para a reorientação das práticas de saúde para o fortalecimento dos princípios de universalidade, equidade e integralidade do SUS (Barreto, Carmo, 2007; Alves, 2005; Scherer, 2005; Lima et al., 2000)

Uma das prerrogativas do trabalho das equipes de ESF é que este favoreça a integração entre a comunidade e as equipes de saúde da família e fortaleça a relação profisssional de saúde e usuário (Crevelim, Peduzzi, 2005), para que os processos comunicativos e/ou informacionais em saúde sejam mais eficazes e resolutivos. No entanto, na realidade dos serviços de saúde, a população ainda é alijada das decisões sobre o que lhe diz respeito. O usuário não é tido como 
protagonista do próprio viver nem participa da produção do próprio cuidado (Matumoto, 2003).

Resultados da pesquisa de Crevelim e Peduzzi, 2005, evidenciaram que os trabalhadores de saúde não incluem os usuários na dinâmica do grupo de trabalho e no planejamento das ações. Essa prática precisa ser reorientada na perspectiva da interação entre trabalhador e usuário, visto que a ESF traz, em sua concepção, o fortalecimento das relações entre ambos os sujeitos.

Nesse contexto, este estudo foi proposto com o objetivo de dar voz aos sujeitos-pacientes, diabéticos e/ou hipertensos, acompanhados em uma unidade de ESF, para caracterizar a percepção desses sujeitos sobre as atividades educativas e as dificuldades que se colocam para a adesão a práticas de vida saudável, especialmente a práticas alimentares adequadas.

Acredita-se que os resultados aqui apresentados contribuam para a compreensão sobre os motivos da baixa adesão das pessoas com diabetes e/ou hipertensão às recomendações que lhes são dirigidas no processo educativo em saúde e para a qualificação das práticas de educação nutricional no âmbito da Atenção Básica à Saúde.

O estudo constitui uma das etapas da pesquisa de doutoramento do Programa de Pós-Graduação em Nutrição em Saúde Pública da Faculdade de Saúde Pública da Universidade de São Paulo, intitulada “Ação educativa na Atenção Básica à Saúde de pessoas com diabetes mellitus e hipertensão arterial: avaliação e qualificação de estratégias com ênfase na educação nutricional.”.

\section{METODOLOGIA}

Realizou-se pesquisa exploratória, de orientação analítico-descritiva e natureza qualitativa, pela qual se acessou a percepção de pessoas com DM e HA, acompanhadas em uma unidade básica de ESF do município de Vitória-ES, sobre o objeto do estudo.

A escolha dos sujeitos da pesquisa foi do tipo não aleatório e intencional (Fontanella et al., 2008; Minayo, 1993). Em reunião com os integrantes de cada 
uma das sete equipes de ESF, solicitou-se que indicassem de quatro a cinco usuários que atendessem aos seguintes critérios de inclusão: portador de DM e/ou HA, cadastrado e acompanhado pela unidade básica de saúde (UBS) do estudo há, pelo menos, seis meses, com idade entre 40 e 80 anos, em condições de prestar informações respondendo a uma entrevista.

Concordaram em participar do estudo 22 dos 30 sujeitos-pacientes indicados, dos quais foram coletados os depoimentos no período de janeiro a agosto de 2010. Para tanto, utilizou-se roteiro de entrevista semiestruturada, aberta (Patton, 2002; Fontana, Frey, 2000), composto por questões que abordavam a percepção desses sujeitos sobre: 1) as atividades de que participavam para as orientações sobre sua saúde e alimentação; 2) os profissionais que geralmente realizavam o acompanhamento e as orientações; 3) as mudanças que aconteceram em sua vida e em sua alimentação depois que iniciaram o acompanhamento; 4) as dificuldades percebidas para seguir as orientações que recebiam sobre mudanças de hábitos de vida, especialmente as alimentares.

As entrevistas foram realizadas na residência do entrevistado ou, quando mais conveniente a ele, na UBS, aproveitando um dia de comparecimento à consulta médica. Todas as entrevistas foram realizadas individualmente por único entrevistador e gravadas para posterior transcrição. A duração delas variou de 10 a 30 minutos.

Na primeira editoração dos depoimentos, cuidados referentes à fidelidade do que foi afirmado e ao anonimato dos entrevistados foram tomados, como a manutenção das palavras repetidas e dos vícios de linguagem e a omissão dos nomes próprios dos sujeitos. Sempre que possível, optou-se por fazer o registro ortograficamente correto das falas, exceto para as situações que fugiam ao léxico da língua-padrão ou suprimiam sílabas e/ou fonemas iniciais e finais das palavras, conforme recomendado por Araujo, 2001, para a transcrição e editoração de entrevistas em pesquisa de abordagem qualitativa.

Os depoimentos transcritos passaram por leitura flutuante, uma das etapas preliminares do processo de análise do material empírico na pesquisa qualitativa, em que, num contato mais próximo com o material de análise, o pesquisador se permite "invadir" pelas primeiras impressões e orientações (Bardin, 1977). Essa 
leitura permitiu delimitar respostas para cada uma das questões formuladas, independentemente do momento exato em que os pensamentos e as percepções dos sujeitos foram expressos durante a entrevista, pois, quando são do tipo aberto, dão margem a manifestações e sentimentos "menos" organizados. Isso requer um esforço de organização dos dados discursivos, preliminar ao processamento e análise deles.

Os depoimentos foram, então, tabulados e organizados segundo a técnica de análise do Discurso do Sujeito Coletivo (DSC), em que uma sequência de operações metodologicamente definidas: 1) seleção de expressões-chave (ECH) de cada depoimento ou resposta dada a uma questão; 2) identificação da ideia central (IC) de cada uma dessas expressões-chave; 3) reunião das $\mathrm{ECH}$, referente às IC semelhantes ou complementares, resulta em um conjunto nuclear do discurso ou discurso-síntese, redigido na primeira pessoa do discurso, que é o próprio DSC (Sales, et al, 2007; Lefèvre, Lefèvre, 2003).

A escolha do DSC como recurso metodológico se deve à propriedade dessa técnica. Ao reunir fragmentos de discursos individuais em um ou mais discursos-síntese, proferidos por um grupo social (profissionais de saúde ou usuários), possibilita a expressão de pensamentos, percepções ou representações sociais sobre o objeto do estudo (ações educativas na Atenção Básica à Saúde e dificuldade de adesão às orientações alimentares) de forma mais densa, complexa e enriquecida, como requer a pesquisa de base qualitativa. No DSC, realçam-se as expressões individuais ao reunir o conteúdo dos depoimentos em ideias centrais de sentidos semelhantes ou complementares, reconstruindo-se o discurso de uma coletividade. Redigido na primeira pessoa do singular, o DSC produz no leitor o efeito não de um sujeito, mas de uma "coletividade falando", o que acrescenta densidade semântica às representações sociais (Lefèvre et al., 2009; Teixeira, Lefèvre, 2008; Lefèvre et al. 2003).

Para a discussão e análise do material discursivo, recorreu-se a leituras bibliográficas norteadas pelas possibilidades de análise e interpretação de textos (Severino, 1996), valendo-se da literatura científica de estrutura conceitual abrangente, como encontrado no campo da sociologia do conhecimento e no das ciências sociais aplicada à saúde coletiva. 


\section{Aspectos Éticos}

A pesquisa que originou os dados deste estudo foi aprovada pelo Comitê de Ética em Pesquisa da Faculdade de Saúde Pública da Universidade de São Paulo.

A participação voluntária de cada pessoa foi precedida de consulta individual mediante esclarecimentos sobre o caráter, os objetivos e procedimentos metodológicos da pesquisa e sobre a garantia do anonimato e o sigilo das informações prestadas. A concordância em participar foi registrada em Termo de Consentimento Livre e Esclarecido, conforme estabelecido na Resolução CONEP 196/96 e suas complementares.

\section{RESULTADOS}

Os resultados apresentados nessa seção referem-se ao material discursivo de 22 depoimentos. Entre os sujeitos-pacientes participantes, seis $(27,3 \%)$ são do sexo masculino e $16(72,7 \%)$, do feminino. A média de idade era de 60,32 anos, com amplitude de 40 a 79 anos.

As questões propostas na entrevista tinham a intensão de verificar a percepção dos sujeitos-pacientes sobre: os espaços educativos de que participam; o envolvimento dos profissionais nas ações educativas; principalmente o motivo por que é difícil mudar hábitos e seguir condutas de vida saudável, focalizando aquelas relativas à promoção da alimentação adequada para pessoas com DM e HA.

O processamento dos depoimentos da primeira questão do estudo resultou em duas IC: uma pela qual os sujeitos-pacientes reconhecem as reuniões dos grupos como espaços de acompanhamento e orientação e outra em que esses se reportam principalmente às consultas médicas como espaços educativos: 


\section{IC 1.1: Na unidade o atendimento é no grupo, onde a gente faz a} consulta e tem as reuniões. É de primeira! IC destacada em nove (41\%) dos 22 depoimentos.

\section{DSC 1.1.}

"Quando vai na unidade, é atendido no grupo, né? É de primeira!. Mede a pressão, a glicose e peso, altura. A enfermeira chefe conversa muito com a gente, pergunta todos os detalhes. Eles como que a gente deve se alimentar, que deve fazer caminhada. E diminuir o sal, açúcar. Tem palestra, sobre o diabetes, sobre a hipertensão. Já assisti filme informando tudinho. Sempre quando tem as reuniões ela põe uma mesa de tudo quanto é coisa. $O$ que pode comer o que não pode comer. $O$ lugar vermelho é perigoso. O lugar verde, o lugar amarelo, para mostrar a alimentação balanceada para que as pessoas mais leigas, que não tem leitura, saber direitinho o que pode e o que não pode comer. $E$ uma fruta. Não é duas, três, entendeu? Ela coloca assim para as pessoas entenderem melhor. Para nós é muito legal. E depois a gente faz a consulta. A doutora pergunta como está sendo a alimentação, como é que a gente usa o óleo. A pressão, se aquele um 'mililesimosinho' ela quer que a gente diminui, não quer que a gente continue com aquele açúcar alto, com a glicose alta, ela está sempre controlando. Geralmente eles marcam as consultas de 3 em 3 meses, entendeu? A doutora. sempre avisava a gente sobre as reuniões. As meninas vem aqui em casa marcar. Quando ela era feita aqui na igreja, antes da consulta vinha um rapaz da educação física, falar com a gente e a enfermeira falava sobre a alimentação. Ela sempre frisou da gordura, do óleo, ela sempre tava, em todas as reuniões. Quando tinha aquelas campanhas de colesterol, campanha de glicose, então ela sensibilizava para a gente."

Numa expressão complementar à IC do DSC 1.1, os sujeitos-pacientes demonstram sua insatisfação com o fato de os grupos não serem mais realizados na comunidade. Ao que parece, isso tem dificultado tanto as práticas educativas coletivas quanto as individuais:

\section{DSC 1.1 complementar.}

"[...] Até um tempo atrás, nós éramos atendidos aqui perto, na igreja, mas do final do ano para cá nós somos atendidos no auditório aqui do posto. [...] Lá na mesma hora que tivesse a consulta, minutos antes tinha a palestra. Não sei por que mudou [...]. Era bem melhor antes. Agora ta bem pior, até pra gente consultar ta mais dificil." 
IC 1.2: Tem as consultas marcadas para os remédios, os exames e as orientações inclusive sobre a alimentação. IC destacada em 13 (59\%) dos 22 depoimentos.

\begin{abstract}
DSC 1.2
"Tem consultas marcadas, né? E a doutora me orienta muito bem. Meu médico passa remédio direitinho, eu tomo direitinho. A gente vai lá todo mês pegar. Às vezes falta uma medicação. Mas graças a Deus a gente não tem do que reclamar. Essa menina (agente de saúde) vem, diz o dia da consulta. Eu vou, peso, sou examinado, pego o remédio, mando fazer o exame que tiver de fazer: sangue, urina... A respeito do movimento de alimentação, a doutora estava nos orientando como faz para controlar a pressão. Me deu uma folha de papel explicando como é a dieta. É um atendimento que eu vou dizer, muito bom. Tenho o acompanhamento com o cardiologista, com o ortopedista. Eu tenho tudo isto. Nas datas tudo certinho. Prevenção da osteoporose também, então isto aí eu faço tudo direitinho. E nunca negaram nada pra mim, graças a Deus. É bom demais. Deus me livre, se sair daqui."
\end{abstract}

Para a questão do estudo relativa ao envolvimento dos profissionais de saúde no acompanhamento e na orientação dos sujeitos-pacientes, foram identificadas três IC que destacam, respectivamente, o papel da equipe multiprofissional, do médico e dos agentes de saúde.

\title{
IC 2.1: Todos os profissionais estão envolvidos nesta orientação.
}

\section{DSC 2.1}

"Os profissionais são todos estes que me orientam, né? Tem a médica, a enfermeira e os agentes de saúde. A enfermeira orienta e depois passa pelo médico. Sempre que vai fazer a palestra, tem uma equipe que vai com ela. A doutora, as enfermeiras, educação física, dentista, estagiário. Eles orientam a fazer educação física, ter uma atividade física. E são todos profissionais. Todo mundo envolvido nesta orientação. Nutricionista mesmo, num tem o acompanhamento com o nutricionista. Sempre são os meus médicos mesmo que me acompanham."

\section{IC 2.2: É só o médico mesmo!}

\section{DSC 2.2}

“[...] É a doutora mesmo, Eu tenho o médico do plano de saúde, mas não deixo de estar aqui. É só ele mesmo. Tem doutora, também, que se a pessoa tiver acamada ela visita com o agente de saúde, com o auxiliar. A 
doutora também, no dia da consulta ela faz uma palestra, né? É só ela (ele) mesmo."

\section{IC 2.3: Os profissionais agentes de saúde estão sempre acompanhando} a gente.

\section{DSC 2.3}

"Tem o agente de saúde, né? Que marca consulta pra mim todo mês. Os profissionais agentes de saúde ta sempre acompanhando a gente. Se a gente precisa fazer uma consulta rápida, ta sempre avisando a gente do dia da consulta. A gente não perde porque ela passa na porta um dia antes para dizer que é no outro dia a consulta."

Para constituir as IC e os DSC referentes à percepção dos sujeitospacientes sobre as mudanças em sua vida e a sua saúde devido às orientações que lhes são dirigidas, foram considerados apenas 18 depoimentos dos 22 coletados, pois, nos três outros, as respostas não foram suficientemente claras, fugindo ao foco da questão. Foram identificadas duas IC que podem expressar a adesão e a não adesão dos sujeitos-pacientes ao plano terapêutico no que tange à alimentação.

\section{IC 3.1: Aprendi a viver melhor, mudei radicalmente a minha}

alimentação. IC destacada em $16(89 \%)$ dos 18 depoimentos.

\section{DSC 3.1}

"Eu mudei radicalmente minha alimentação, aprendi a viver melhor, a comer esta dieta. Tenho procurado comer mais frutas, mais legumes, estas coisas assim. A palestra orientou muito mais. To comendo uma comida melhor, mais selecionada. Antes eu não tinha isto, eu comia muito embutido, muita fritura, essas coisas. Eu tava comendo só carne gordurosa. Já pensou? Hoje eu evito a gordura. Estou a base de salada e atividade física. Quando vem aqueles tira gosto...né? Muito gordura eu já tiro. Biscoito também, né? Não pode comer doce, só aquele de água e sal ou então um pão sem miolo, que eu como, um pouquinho de manteiga que as vezes eu compro até aquela que não tem muita gordura, né? Eu tava comprando mais era o queijo que eles falaram que é bom porque tem menos gordura, menos sal, né? Então eu tomo café com leite, leite desnatado, e com um pedacinho de queijo e um pão sem miolo. Nove horas eu como uma banana. Eu não comia só uma banana. Depois da palestra eles me orientaram, tem que ser só uma banana por dia. Já fui orientada que fruta também tem muito açúcar. Ai meio dia, onze e meia 
meu estomago já pede almoço. Ai almoço duas colheres de arroz, boto uma concha de feijão, faço assim um ensopado de verdura com jiló ou então uma verdura. Menos massa. Deve ser pouca massa, né? Se eu comer arroz eu não posso misturar com macarrão, eu não como polenta. Quando é batatinha eu boto um pedacinho. Verdura a gosto. Eu não sou muito chegada a verdura, mas eu como. E um bife. E a gente come mais peixe lá em casa. Faço uma salada de alface, folhas, né? Repolho cru, eu compro até do roxo. É, a minha alimentação. E o açúcar, eu não como açúcar há muito tempo, só de vez em quando, mas não exagero. Eu senti que agora tá melhorando. E a diabetes passou a melhorar também. Para mim não tem coisa melhor. Eu me sinto melhor. Valeu a pena."

\section{IC 3.2: Tentei mudar, mas não tenho jeito, porque minha família é}

toda assim. IC destacada em dois (11\%) dos 18 depoimentos.

\section{DSC 3.2}

"Eu faço tudo errado. Mas a minha família é toda desse jeito, de mamãe a nós. A gente sempre fritou torresmo, que é uma delicia o torresminho Faço meu café, pra eu poder tomar com adoçante, mas num tem jeito. Meu marido bota muito açúcar no café, aquilo é um veneno, né? Mas eu bebo porque eu quero beber, porque ele num bota na minha boca; é pra eles né? Mas eu sou assim desse jeito. Porque eu não consigo comer assim, se eu to vendo eles comerem. Eu acho que se eu vivesse sozinha num lugar eu teria minha vida melhor. Não tenho jeito, eu sou compulsiva."

A quarta questão do estudo foi fundamental para trazer à tona, pela percepção, sentimentos, crenças e vivências dos sujeitos-pacientes, os impedimentos mais significativos à adoção de práticas alimentares saudáveis e adequadas. Dos depoimentos coletados foram destacadas seis IC que resultaram nos DSC apresentados a seguir.

IC 4.1: Tirar o açúcar é triste! E a hipertensão é o sal. IC iluminada em cinco $(23 \%)$ dos 22 depoimentos.

\section{DSC 4.1}

"Maior dificuldade é deixar de comer um docinho. Tirar o açúcar. Não comer um docinho é triste, né? Eu gostava de comer um docinho. Comprava assim uma lata de doce, ai meu Deus eu comia! Quando eu soube que tinha diabetes fiquei quase doida. Porque eu acho que eu era viciada em ficar chupando bala, e tudo, né? Tomar café com adoçante não é bom. Então eu tomo o café com leite e zero cal ${ }^{\circledR}$. Ai depois me dá 
vontade de tomar outro café com açúcar. Eu vou falando assim 'não, não vou tomar, não vou tomar'. Enquanto eu num boto um pinguinho de açúcar, um pouquinho de café e num tomo, eu num fico satisfeita. Mas eu to orando pra isso. Eu to fazendo agora até doce, né? Eu faço doce de banana, que a doutora ensinou sem açúcar. Esses dias aí, por ultimo eu botei cravo, botei um pouquinho de zero cal, ficou mais gostoso, né? Ai eu vou comendo assim, depois do almoço como um pouquinho. Suco sem açúcar, ou então de caju né, eu boto um pouquinho de zero cal ${ }^{\circledR}$. Faço tudo separado: suco deles, e tem o meu, né? Diet. E a hipertensão é o sal, porque eu detesto comer sem sal. O dia que eu coloco um pouquinho de sal a mais a pressão sobe, coração começa a bater forte."

\section{IC 4.2: A dificuldade é mudar o modo que a gente tem que alimentar.}

IC iluminada em quatro (18\%) dos 22 depoimentos

\section{DSC 4.2}

"Mudança da alimentação mesmo. Porque eu acho difícil o modo que a gente tem que se alimentar, eu não me alimento. É o café da manhã, que teria que ser uma alimentação mais... né? Ampla? Eu sei que tem que se alimentar de manhã de três em três horas, ai eu acabo não fazendo. De manhã eu não consigo. Eu só tomo café com leite. Porque se eu comer mais coisas eu não me sinto bem. [...] Eu que faço a comida. Acabo de temperar o feijão, boto um pouquinho e como. Eu acho difícil isso, porque sou eu que faço a comida. Ah, o mais difícil foi o pão, de sal, que eu comia muito. Manteiga, tem muitos anos que eu não como mais manteiga. A carne gordurosa. Porque eu gosto muito. Era só costela, gorda mesmo. E a massa, a massa tem estado difícil eu abandonar. Eu não como nada. Nem pão com manteiga eu não como mais. Eu já estava pesando quase 100 quilos. Se eu continuasse comendo... O médico virou e falou: 'tá arriscado a te dá um enfarte... E eu já enfartei duas vezes."

\section{IC 4.3: O mais difícil é resistir às tentações que tem por aí. IC} iluminada em cinco (23\%) dos 22 depoimentos.

\section{DSC 4.3}

"A mais difícil foi que eu gostava de toma minha cervejinha, né? Toda sexta feira termina o serviço, meus colegas saem pra tomar uma cerveja. Eu bebia até meia noite, e agora não faço isso mais. Antigamente eu tomava uma cerveja na quarta feira, muitas vezes no sábado no domingo. Hoje não, hoje eu só tomo uma cervejinha no sábado, no domingo eu fico praticamente de molho. As vezes tem umas tentações por aí, porque a gente vai a uma festinha... Eu mesmo, no caso, evito bastante. Mas quando a gente vai a uma festinha é meio difícil de resistir. É que final 
de semana eu gosto de sair, dançar meu forró, me divertir. Só quando eu morrer, ai eu num vou mesmo não. O resto não, o resto é tranquilo."

\section{IC: 4.4: A dificuldade é porque não é todo dia que a gente tem}

disponíveis as coisas. IC iluminada em dois (9\%) dos 22 depoimentos.

\section{DSC 4.4}

"A dificuldade para gente é porque não é todo dia que a gente tem disponível as coisas, entendeu? Tem que comer um monte de coisa. Para o intestino tem que comer linhaça. Tem dia que você não pode ter. Não é todo dia que você está disponível. Só Deus tem poder para nos dar força, porque se fosse a gente viver do salário... Mas graças a Deus to vivendo. Tem que fazer economia também. Como dizia o meu colega: '- Você tem uns negócio de comer manjuba e ficar arrotando caviar, quem come manjuba tem que arrotar é manjuba mesmo!' A dificuldade é esta. Porque as outras coisas que depende da gente fazer é muito fácil".

IC 4.5: É a falta de esforço, a teimosia. IC iluminada em três (14\%) dos 22 depoimentos.

\section{DSC 4.5}

"Eu acho que é falta de esforço mesmo. Eu sou muito teimosa, sabe? Não vou dizer que eu como assim exagerado, mas é que eu como umas coisas erradas, entendeu? Eu como doce, e todas pessoas que é diabética tem fome de doce, né? Mas num é tão exagerado não. Chego na sala pego uma bala pra botar dentro da boca. Eu estando em casa eu como o dia todo. Diz que é falta de controle que eu não tenho vontade. Eu tenho vontade, quem que não tem vontade de emagrecer? Eu tenho é dificuldade, eu precisava de alguma coisa pra melhorar, eu acho que tem alguma coisa pra resolver isso."

IC 4.6: Não tive problema. Já estou acostumada. (IC iluminada em três dos 22 depoimentos).

\section{DSC 4.6}

"Eu não tive problema não. Tem tanto tempo que eu comecei com isso. Já estou acostumada. Não tenho dificuldade. Passei do açúcar para o adoçante. Acostumei. Só quando tem uma festa ou um aniversário. Se eu vou num lugar que tem uma festa, exemplo: eu vou na igreja, as vezes tem lá muita coisa para comer, dependendo do que é eu como. Como um pedacinho só. Dependendo eu não como também." 


\section{DISCUSSÃO}

$\mathrm{Na}$ percepção de parte dos sujeitos-pacientes, os grupos do Hiperdia funcionam como espaços em que são acompanhados e orientados para o autocuidado em relação ao controle de sua doença. Para Silva MA et al., 2006, os grupos de educação em saúde constituem espaços potencialmente privilegiados de empoderamento individual e coletivo, à medida que são locus de articulação das dimensões da vida humana: a dimensão social, a subjetiva e a biológica.

Pelas características desses grupos, considera-se que sejam similares aos grupos do tipo operativo, concebido por Pichon-Rivière, 1988, que, segundo Silveira e Ribeiro, "mescla terapêutica e ensino-aprendizagem e cuja finalidade é promover a adesão ao tratamento" (Silveira, Ribeiro, 2005, p.96). A prática assistencial nesses grupos é, portanto, tanto terapêutica como pedagógica e tem por objetivos ampliar a consciência das pessoas sobre a doença, potencializar a capacidade em superar dificuldades, promover mudança de atitude e propiciar aprendizagem mútua.

Pelo que se pode apreender no DSC 1.1, os sujeitos-pacientes demonstram uma avaliação positiva desse espaço, principalmente em razão de que nele, além das orientações realizadas nas "reuniões", que corresponderiam às práticas educativas coletivas, eles acessam a consulta médica e seus desdobramentos: o aviamento da receita para a retirada do medicamento, a solicitação e apreciação de exames. Para esses sujeitos, a forma como as orientações são realizadas nas atividades dos grupos parece adequada à condição de entendimento das pessoas mais leigas e valoriza situações alimentares concretas. Isso pode representar que as estratégias pedagógicas e a linguagem que é empregada nesse espaço têm propiciado eficiência no processo comunicativo.

A utilização de estratégias e recursos pedagógicos que tornem o conteúdo educativo mais concreto e significante e predisponham a pessoa a modificar suas práticas, como evidenciado no material discursivo, é consoante com as estratégias de motivação do tipo 'apelo ao raciocínio' (Esperança, Galisa, 2006). Assim, quando as pessoas são levadas a acessar conhecimentos que já possuem e a fazer 
associações no sentido de dar significado à ação para sua vida, sentem-se motivadas a aprender o conteúdo tratado.

Torres, et al., 2003, ao descreverem e discutirem uma estratégia educativa que adotou perspectiva de promoção, prevenção e controle, realizada entre indivíduos com DM, observaram que a dinâmica de grupo estimulou a relação interpessoal e facilitou a discussão e troca de informação entre pessoas com os mesmos objetivos, promovendo o compartilhamento de experiências comuns e o apoio mútuo. Nota-se que, tanto no estudo desses autores quanto no material discursivo que gerou o DSC 1.1, essa postura pode ser propiciada no processo comunicativo em saúde. Nele o profissional de saúde faz uso de uma linguagem compreensível e simples, adequada à realidade e centrada no sujeito que busca conhecer suas necessidades em relação à sua saúde e doença (Valla, 2000).

Sobre a expressão complementar à IC 1.1 - as ações dos grupos educativos são melhores quando realizadas na comunidade -, supõe-se que essa visão se relacione a maior comodidade e conforto conferido quando as ações são realizadas mais próximas a moradia das pessoas. Isso ocorre porque a maioria é idosa e o deslocamento até a unidade pode ser um fator que dificulta a participação nas reuniões.

Deve-se ressaltar, no entanto, que, em maior proporção, os depoimentos destacaram as consultas médicas como espaços educativos preferenciais (IC 1.2), resultando em um discurso em que se nota certa preferência dos sujeitos-pacientes pelas práticas assistenciais que envolvem a medicalização do cuidado (DSC 1.2). Nele, o 'doutor' é o profissional mais citado e sua competência ante a prescrição do medicamento e a realização de exames é valorizada. Quanto às orientações em relação à alimentação, ao que parece, nesse espaço é realizada de forma prescritivo-normativa, não havendo no material discursivo elementos que apontem uma adequação dessas orientações às necessidades individuais do sujeito-paciente.

Esse achado não é inédito na produção científica da Saúde Pública, que geralmente explica o fenômeno pela persistência do modelo assistencial hegemônico que, resistente à proposta atual de reorientação das práticas de saúde, continua a influenciá-las. Nesse modelo, as práticas de saúde são centradas no 
médico e no saber médico; o foco da atenção é a doença e a abordagem privilegiada é a "curativa” (Stotz, 2007, Alves, 2005).

A demasiada valorização da medicalização da assistência pelos usuários do Sistema de Saúde pode legitimar abordagens normativas, prescritivas, centradas no saber científico, que não consideram o saber, as crenças, valores e experiências, enfim, as razões subjetivas que levariam as pessoas a mudar seu comportamento em prol de sua saúde. Pensando que as soluções para seu problema de saúde provêm essencialmente do exterior (da prescrição médica, dos medicamentos, dos recursos diagnósticos, entre outros), os sujeitos passam a defender os interesses dominantes do Sistema, querendo mais medicalização e convênios de saúde e criando uma nova subordinação para a produção de sua saúde (Gazzinelli et al., 2005; Smeke, 2001).

Destaca-se, ainda, no DSC 1.2, que os sujeitos-pacientes reconhecem ter acesso mais facilitado a algumas especialidades médicas por estarem cadastrados e acompanhados na UBS, fato relevante para garantir o acesso aos níveis assistenciais de maior complexidade, que é condição para a integralidade da assistência.

Sobre a percepção dos sujeitos-pacientes em relação à segunda questão do estudo, evidencia-se o reconhecimento deles de que toda a equipe básica de ESF está envolvida nas atividades educativas. O DSC 2.1 destaca também o envolvimento de outros profissionais, a exemplo do orientador físico e do dentista.

Essa visão contempla a concepção preliminar da ESF como alternativa para mudança do modelo assistencial em que o trabalho de equipe é considerado uma prerrogativa estratégica para impulsionar essa mudança (Brasil, 2000; Ciampone, Peduzzi, 2000).

Fortuna et al., 2005, consideram que o trabalho de equipe na saúde vai além da concepção de equipe como mero conjunto de trabalhadores de um mesmo serviço. Elas enxergam o trabalho em equipe como uma possibilidade de "recomposição" (destaque das autoras) do trabalho em saúde na direção da interdisciplinaridade, contrapondo-se a uma atenção fragmentada, medicalizante e descontextualizada, como geralmente ocorre no processo tradicional de atenção à 
saúde. Nessa perspectiva, as expressões do DSC 2.1 apontam a existência de um envolvimento e interação entre os profissionais das equipes de ESF e destas com os demais profissionais da UBS, que favoreceria uma articulação de saberes e experiências necessárias a uma atenção mais integral, como preconiza o novo modelo assistencial.

No entanto, o trabalho multiprofissional para conferir qualidade ao cuidado em saúde, além de recompor os diferentes processos de trabalho, deve flexibilizar a divisão do trabalho, preservar as diferenças técnicas entre trabalhadores especializados, questionar a desigualdade na valoração dos diferentes trabalhos e seus agentes e considerar a interdependência dos trabalhos especializados e a autonomia profissional (Peduzzi, 2000). Nesse sentido, a presença de outros profissionais no apoio às equipes mínimas de saúde da família se faz necessária para a qualificação das práticas de saúde.

Quanto à ausência do nutricionista nas ações da ESF, percebida pelos sujeitos-pacientes no DSC 2.1, Assis et al., 2002, destacam a impossibilidade de transformação efetiva da Atenção Básica á Saúde, no sentido da integralidade da assistência, sem o apoio de profissionais que estudam, pesquisam e praticam cotidianamente a vigilância alimentar e nutricional e assistência dietoterápica de indivíduos e populações.

A IC 2.2 e respectivo discurso distinguem o médico como o profissional mais importante no acompanhamento e orientação das pessoas com DM e HA. Longe de encontrar no material discursivo a desvalorização de qualquer profissional de saúde, o destaque dado ao médico apenas denota uma visão de centralização do cuidado na figura desse ator, representação constituída pelo modelo tradicional de assistência à saúde, ainda muito prevalente na população.

Essa forma de perceber a saúde é, no entanto, fragmentária, centrada na doença e na sua cura. Reforça um modelo com rígida divisão de trabalho e valoração social desigual dos diversos trabalhos e trabalhadores, que atende a interesses corporativos e econômicos, também hegemônicos, que são amplamente questionados. Na reorientação das práticas assistenciais, em termos institucionais e sociais, a valoração desigual de diferentes trabalhos e de diferentes trabalhadores deve ser evitada (Almeida, Mishima, 2001). Afinal, como bem 
evocou Assis et al. 2002, p. 263, o discurso oficial sobre o Programa de Saúde da Família “(...) não é Programa do médico da família, pois não é centrado no trabalho médico, mas de uma equipe multiprofissional, na qual todos os saberes são respeitados (...)".

Ainda em relação ao envolvimento dos profissionais de saúde nas práticas educativas, na ótica de alguns sujeitos-pacientes, a participação dos ACS foi destacada. O DSC 2.3 expressa uma representação bastante objetiva dos usuários em relação ao papel dos ACS: a de resolver algumas de suas demandas em relação aos serviços da Unidade. O ACS parece funcionar como um informante das demandas dos usuários em relação à UBS e vice-versa.

No entanto, as atribuições oficiais do ACS vão além da orientação das famílias em relação à utilização dos serviços de saúde disponibilizados pela unidade. Inclui o desenvolvimento de ações de integração da equipe de saúde com a população adstrita à UBS, ações educativas individuais e coletivas, visando à promoção da saúde, à prevenção de doenças e agravos e à vigilância à saúde dessa população (Brasil, 2006a). Assim, é um elemento fundamental para o estabelecimento do vínculo entre a população e o serviço de saúde, que deve estar imbuído de competências técnicas e humanas bastante complexas.

\section{Ações educativas e adoção de práticas alimentares saudáveis e adequadas.}

A maioria dos sujeitos-pacientes reconhece mudanças significantes, particularmente em sua alimentação, pelas orientações que recebem durante seu acompanhamento e associam os efeitos da adoção de práticas alimentares adequadas ao controle de sua doença e ao impacto positivo na vida deles. Pelas expressões do DSC 3.1, demonstram um conjunto de conhecimentos sobre alimentação saudável e adequada, cujo conteúdo faz parte do discurso oficial sobre a promoção da alimentação saudável, sedimentado nas diretrizes que compõem o Guia Alimentar Para a População Brasileira (Brasil, 2008b): a regularidade e variedade das refeições; a moderação no uso de gordura, sal e açúcar; o consumo maior de hortaliças e frutas; a utilização dos laticínios (neste caso, o leite desnatado); a alternância de carnes vermelhas com o consumo de 
peixes e outras carnes brancas; a equivalência e proporcionalidade dos grupos alimentares.

Poderia ser essa percepção indicativa da eficácia das ações educativas de que essas pessoas têm participado? Ou um viés de uma prática educativa baseada na transmissão vertical de informações que, embora sejam assimiladas pelos indivíduos, não garantem, na prática, a sua adoção?

Embora a maior parte dos sujeitos-pacientes tenha relatado mudanças alimentares que consideram importantes na vida deles, o discurso coletivo daqueles para os quais essas mudanças não foram alcançadas (DSC 3.2) traz à tona o sentimento de frustração e tristeza. Elas se julgam erradas e incapazes de mudar e atribuem parte do problema ao convívio com os hábitos alimentares da família, que julgam inadequados, e parte a uma incompetência pessoal em reverter a situação. Importante destacar que o sentimento de impotência é tal, que as faz pensar que, talvez, o isolamento social seja a resposta para o problema. Nesse contexto, a doença pode representar uma ameaça à autonomia pessoal (Santos et al., 2005), constituindo fator de frustração, tristeza e ameaça à qualidade de vida dessas pessoas.

Pesquisas que investigam a mudança de hábitos de vida entre pessoas com DM e HA revelam que a frequência de mudança de hábitos alimentares é baixa e uma das mais difíceis de realizar. Perès, et al., 2003, analisaram o conteúdo de entrevistas com pacientes hipertensos acompanhados em US de Ribeirão PretoSP. Quando interrogados sobre a mudança de hábitos após o diagnóstico da hipertensão, apenas $17 \%$ se referiram mudanças alimentares, entre as quais foram citadas: evitar o sal e embutidos, evitar a gordura e evitar o álcool. Por outro lado, em relação a mudanças nos hábitos de vida, $70 \%$ se referiram à educação física e à caminhada.

Em estudo similar, realizado com mulheres portadoras de diabetes tipo 2, os mesmos autores evidenciaram dificuldade no seguimento da dieta prescrita, dificuldade que foi associada à perda do prazer de comer e beber, da autonomia $\mathrm{e}$ da liberdade para se alimentar (Perès, et al., 2006).

Hernandez-Ronquillo et al., 2003, em estudo realizado no México com pacientes diabéticos tipo 2 , verificou um nível de não adesão às recomendações 
dietéticas de $62 \%$, às recomendações de atividade física de $85 \%$, à medicação oral de $17 \%$ e à aplicação da insulina de $13 \%$.

Por outro lado, a depender da eficácia da ação educativa, mudanças no comportamento alimentar podem ser estimuladas. Rêgo et al., 2006, relatam um processo de intervenção educativa com portadores de DM, de Nova Aurora-GO, que teve como objetivo superar as abordagens convencionais de educação, utilizando a abordagem problematizadora/ libertadora de Paulo Freire. A dialogicidade do método apresentou-se como eficaz para facilitar aos portadores de DM a adesão a novos hábitos de vida para o desenvolvimento e aquisição de atitudes de autocuidado.

A maior eficácia do processo educativo ou a menor passam pelo entendimento dos educadores sobre as circunstâncias que envolvem a motivação dos indivíduos para mudanças. As abordagens educativas centradas no sujeito e problematizadoras, ao valorizarem sentimentos, crenças, percepções e representações das pessoas sobre o objeto do processo educativo, tendem ao maior sucesso.

No conjunto das IC que procuraram evidenciar as principais dificuldades que os sujeitos-pacientes têm em realizar mudanças em sua alimentação, observou-se que o aspecto de maior repercussão na vida deles diz respeito à restrição alimentar imposta nos planos terapêuticos. Particularmente para a pessoa diabética, as mudanças alimentares muitas vezes vêm impregnadas de significados restritivos ou até proibitivos que, associadas pela pessoa à diminuição do prazer de se alimentar e do convívio social, apresenta-se como a principal dificuldade em relação ao seguimento da prescrição alimentar.

O DSC 4.1 é muito ilustrativo do que parece ser uma das maiores dificuldades para essas pessoas: abster-se de dois elementos gustativos, o açúcar e o sal, que, além de conferirem sabor aos alimentos, imprimem uma carga de significados a eles.

O estudo de Peres et al., 2006, sobre o comportamento alimentar em mulheres com diabetes tipo 2 encontrou as mesmas evidências. Em vários depoimentos, as mulheres demonstraram incapacidade de realizar a dieta devido ao caráter restritivo e proibitivo das prescrições, indicando um distanciamento da 
dieta prescrita e daquilo que consideram possível de realizar. Entre as restrições dietéticas referidas, a dos doces parece repercutir em dificuldades mais intensas.

A proibição dos alimentos doces parece acirrar o desejo de consumi-los. Santana, 2002, p. 54, diz: “(...) Da proibição surge o desejo e desse desejo surge a transgressão. (...)”. Para a autora, a transgressão e o desejo são fatos comuns na vida da pessoa com diabetes, aguçados pelas prescrições proibitivas. Essa visão está nitidamente elaborada no DSC 4.1.

Quanto à relação do açúcar com o DM, a abordagem dietética variou ao longo do tempo, conforme evolução dos conhecimentos sobre a doença e sua interação com a dieta de um modo geral. Atualmente, o tratamento do DM tem por objetivo manter a glicemia próxima dos valores normais, considerando, entre outras, a atividade física, a dieta e a medicação (Castro, Franco, 2002). Portanto, a dieta nem sempre prescindirá da exclusão do açúcar (sacarose). Para o paciente monitorado, que mantém a glicemia nas expectativas do plano terapêutico, é possível ajustar individualmente a dieta mediante uso desse açúcar nos níveis de uma alimentação considerada normal, ou seja, em que a ingestão da sacarose corresponda de $5 \%$ a $10 \%$ das calorias diárias (ADA, 2005).

Porém, o mais usual é um plano terapêutico não individualizado, em que a exclusão do açúcar, fonte de sabor, prazer e saciedade, bem como a restrição de uma série de alimentos habituais, é prescrita com impactos importantes nos aspectos psicossociais dessas pessoas.

Uma questão a se destacar no DSC 4.1 diz respeito aos aspectos de apoio da família à pessoa com DM e/ou HA, pois sua adesão ao plano terapêutico tem uma estreita relação com o convívio e o apoio familiar. O fato de a família assumir uma conduta alimentar saudável, além de ser um fator de promoção da saúde para todos, contribui para a adaptação da pessoa diabética. De outra forma, o consumo de alimentos que, em princípio, não devem ser usados pelo diabético favorece a transgressão alimentar e/ou o isolamento social, como discutido no DSC 3.2. Recomenda-se, portanto, que o processo educativo propicie uma reorganização da dinâmica familiar, de forma que a alimentação saudável venha a ser uma opção de todos e não uma imposição apenas à pessoa com diabetes. 
O DSC 4.2 denota, novamente, a sensação de incompetência dos sujeitospacientes por não conseguirem realizar a alimentação da forma que acreditam ser a correta e, concomitantemente, um ressentimento por não poderem mais desfrutar o prazer da alimentação de que tanto gostam. Nesse discurso, a dificuldade para adesão à dieta adequada é atribuída não apenas às restrições alimentares variadas, mas ainda às práticas que devem ser instituídas sobre a regularidade das refeições.

Em estudo recente realizado por Pontiere e Bachion, observou-se, com base nas crenças dos pacientes diabéticos na terapia nutricional, que as recomendações que lhes eram prestadas pelos profissionais tinham caráter restritivo, impositivo e proibitivo. Tal fato sugeriu aos autores que, para conseguir a adesão do paciente ao tratamento, o profissional reduzia a tônica de suas orientações à proibição de alguns alimentos. Além disso, as recomendações acerca da dieta pareciam provir de processo unilateral, não dialógico e sem consideração às circunstâncias de vida das pessoas. Esses resultados, nas avaliações das autoras, apontam a necessidade de redimensionamento da formação profissional e a utilização de abordagens holísticas, interdisciplinar e multiprofissional na atenção aos diabéticos (Pontiere, Bachion, 2010).

A dificuldade manifestada no DSC 4.3 guarda relação com os aspectos da comensalidade e do alimento como elemento sociocultural importante nos momentos de lazer e convivência social. O consumo de bebidas alcoólicas está nitidamente relacionado neste discurso com o convívio social. Abster-se da “cervejinha" após o serviço, numa roda de amigos ou mesmo no convívio com a família no almoço de domingo, representa uma forma de isolamento social, que dificulta muito a adesão ao plano terapêutico.

A despeito de acreditar que o consumo moderado do álcool tenha efeito protetor nas doenças do coração, o consumo de mais de três doses diárias está relacionado a efeitos adversos quanto às DCV, como o aumento da pressão arterial (Kotchen, Kotchen, 1998). Quanto ao DM, o álcool pode interferir no seu controle, por interferência no metabolismo glicídico, além de possibilitar a elevação de triglicerídeos. Nesses casos, a American Heart Association sugere um consumo de álcool limitado a um drink diário para mulheres e dois para homens, 
o que corresponderia, no caso da cerveja, a uma a duas latas respectivamente (AHA, 2001).

Nesses casos, a abordagem no âmbito da educação nutricional não deve ter caráter proibitivo, mas orientador e reflexivo, para manter a autonomia do indivíduo diante de suas escolhas, evitando-se frustrações e isolamento social, que pouco ou nada contribuem para comportamentos saudáveis.

Outra dificuldade importante para a adesão ao tratamento e à mudança de hábitos alimentares, manifestada na IC 4.4, diz respeito ao acesso permanente aos recursos alimentares necessários a uma alimentação considerada adequada. Portanto diz respeito a aspectos de segurança alimentar e nutricional (SAN) e ao Direito Humano à Alimentação Adequada (DHAA).

No DSC 4.4, evidenciam-se claramente elementos que se contrapõem à SAN das pessoas que o proferiram e que repercutem tanto nos aspectos quantitativos quanto nos qualitativos de sua alimentação, principalmente.

A SAN, mediante a promulgação da Lei Orgânica de Segurança Alimentar e Nutricional (LOSAN), é direito de todos os brasileiros, cabendo ao Estado assegurá-lo por meio de políticas públicas dirigidas a todos os cidadãos, particularmente àqueles que se encontram em circunstâncias de maior vulnerabilidade social (Brasil, 2006b). Mais recentemente, após a Emenda Constitucional 064/2010, o Brasil tornou o DHAA um dos direitos sociais inscritos na Constituição Brasileira. Esse é um direito inerente a todas as pessoas e definido como

(...) o direito de ter acesso regular, permanente e irrestrito, quer diretamente ou por meio de aquisições financeiras, a alimentos seguros, saudáveis, em quantidade e qualidade adequadas e suficientes, correspondentes a tradições culturais do seu povo e que garanta uma vida livre do medo, digna e plena nas dimensões física e mental, individual e coletiva. (ONU, apud Valente et al., 2007, p.10)

Nas situações em que a (in) SAN se colocar como impeditivo para a realização do DHAA, a abordagem do serviço de saúde deve transcender a esse setor e mobilizar indivíduo, família e comunidade, para garantir o acesso aos canais e mecanismo que o permitam buscar por esse direito. Para isso, é 
fundamental que saibam quais são esses direitos e como podem exigi-los. Estamos diante de uma situação que envolve o processo educativo social mais amplo. Portanto, profissionais de saúde devem-se apropriar da linguagem e da abordagem desses direitos para inseri-la em suas práticas cotidianas. O DHAA somente se efetiva quando se coloca em prática o princípio de que cada direito humano corresponde a obrigações do Estado e à responsabilidade dos diferentes atores sociais (Valente et al., 2007).

Por outro lado, há que desmitificar algumas impressões que são socialmente constituídas muitas vezes por interesses comerciais, que alimento saudável é alimento "caro" ou de difícil acesso. O efeito midiático em torno de alguns alimentos, como a linhaça citada da no DSC 4.4, também precisa ser questionado e discutido na prática educativa em nutrição.

Outra IC que merece atenção é a que resultou no DSC 4.5, em que os sujeitos-pacientes julgam ser a sua falta de esforço e teimosia os motivos para o não seguimento das orientações alimentares. Nessa forma de pensar, podem estar envolvidos processos subjetivos intrínsecos, relacionados à autoculpabilização do paciente por sua doença e também se explica por uma prática assistencial higienista, segundo a qual os problemas de saúde são decorrentes da falta de observância de normas de higiene pelas pessoas. Nesse caso, o processo educativo é direcionado para garantir mudanças pela transmissão-assimilação passiva de prescrições normativas advindas do saber científico delegado aos profissionais de saúde. Se o indivíduo não adere às orientações, passa a ser culpabilizado individualmente pelos problemas de saúde (Alves, 2005). Embora essa seja uma concepção do processo saúde-doença bastante questionada e superada pela própria evolução histórica da saúde pública, na prática pode ser identificada nas ações educativas da saúde e continuar influenciando programas de intervenção no campo da alimentação e nutrição, principalmente aqueles aplicados à clínica nutricional, que têm a finalidade de ampliar a adesão das pessoas ao tratamento dietético (Santos, 2010).

Principalmente para as pessoas com DM, as mudanças que ocorrem em sua vida são muito significativas. Ao depararem as restrições no seu comportamento, principalmente no alimentar, é que tomam consciência de suas 
limitações. Por isso, o conflito entre o desejo de se alimentar e a necessidade de contê-lo pode estar presente à vida dessas pessoas, de forma a causar sofrimento, o que o faz "transgredir as regras alimentares" (destaque nosso) e sentir prazer ou culpa por essa transgressão (Santos et al., 2005).

Considera-se que ato de comer envolva um sistema de valores, símbolos e significados, que, particularmente no caso das pessoas submetidas a restrições alimentares, necessitam ser compreendidos pelos profissionais de saúde (Peres et al., 2006), sob pena de deslocar os motivos da não adesão ao tratamento dietético da eficácia da ação educativa para a resistência ou desobediência do paciente à prescrição restritiva que lhe é dirigida. Sabendo disso, a abordagem educativa jamais se deveria dar na perspectiva de culpabilização do sujeito-paciente.

Finalmente, o DSC 4.6 traz o sentimento de algumas pessoas, para as quais a convivência com a doença e a necessidade de mudanças em sua prática de vida parecem ser mais tranquilas. Embora as restrições alimentares se manifestam, com frequência, como aspecto de maior repercussão (Ribeiro et al., 2010), elas não fazem disso o ponto central de sua vida. Com isso vão encontrando estratégias de convívio mais tranquilo com a doença e suas limitações.

\section{CONSIDERAÇÕES FINAIS}

Os discursos coletivos de pessoas com DM e/ou HA acessados nesse estudo propiciaram a compreensão de alguns dos fatores que explicam a adesão delas ao plano terapêutico, principalmente em relação às condutas alimentares,

visto que de seus depoimentos foram extraídos sentimentos, percepções e representações que significam o convívio dessas pessoas com seu problema de saúde.

Observou-se que, embora as representações desse acompanhamento estivessem muito referenciadas nas ações nos grupos do Hiperdia, é na consulta médica, realizada concomitantemente às demais atividades do grupo, que a maioria dos sujeitos-pacientes se sente mais contemplada na assistência a sua saúde. 
Ainda que o pensamento da maioria desses sujeitos pareça ser orientado pelo modelo assistencial medicocentrado, as atividades educativas foram reconhecidas como momentos em que a equipe multiprofissional de saúde está envolvida. Essas atividades foram consideradas importantes para o esclarecimento sobre a conduta alimentar. Constatou-se o empenho da equipe de saúde em valerse de estratégias e recursos pedagógicos diversificados e adaptados à realidade cognitiva dos sujeitos-pacientes.

Ressalta-se, entretanto, que métodos e técnicas de ensino-aprendizagem podem ser empregados segundo divergentes orientações político-pedagógicas e que, a despeito de criarem melhores condições favoráveis para o processo comunicativo, podem ser inócuos ao propósito maior da ESF de reorientação das práticas de saúde ou mesmo reforçar as práticas hegemônicas. Essa consideração deve ser motivo de reflexão tanto no meio acadêmico de formação profissional quanto no processo de educação permanente da equipe de saúde.

Os DSC constituídos na primeira questão do estudo, ou seja, a percepção dos sujeitos-pacientes sobre os espaços educativos que frequentam, referendaram o potencial dos grupos de educação em saúde no sentido do empoderamento das pessoas para a produção individual e coletiva de práticas de vida mais saudável.

A ênfase no discurso coletivo, relativo às mudanças que os sujeitospacientes conseguiram empreender em sua alimentação, mostra que adesão às recomendações alimentares e o impacto positivo delas sobre a vida desses sujeitos parecem ser a realidade da maioria. Afinal, mais de $80 \%$ perceberam que aprenderam a viver melhor depois que mudaram sua alimentação. Essa percepção, somada aos principais aspectos de mudanças das práticas alimentares relacionados nos depoimentos, coincidentes com as recomendações para uma dieta saudável e adequada a essas pessoas com DM e/ou HA, parece indicar a eficácia das ações educativas em promover mudanças alimentares, ao menos a respeito do discurso.

Por outro lado, os discursos coletivos elaborados nas IC mais prevalentes sobre as dificuldades sentidas no processo de mudança das práticas alimentares revelaram que as restrições alimentares são significadas como necessárias ao seu tratamento, porém difíceis de realizar. O sentimento manifestado diante da restrição do açúcar principalmente, por um lado, é de pesar e tristeza quando 
acatam a prescrição; por outro, de culpa e remorso quando não conseguem fazêlo.

A prática prescritiva, neste caso proscritiva, com frequência, desconsidera significados, representações e sentimentos que as pessoas possuem em relação aos alimentos e são elaborados no convívio social delas. Nesse sentido, se no plano terapêutico existe a necessidade e/ou a indicação para tal restrição, abordagens educativas menos normativas e verticalizadas, mais reflexivas e de empoderamento das pessoas para a autonomia nas escolhas devem ser preferidas.

Merece ainda comentários o discurso que traz para a reflexão a questão socioeconômica como uma dificuldade real para a promoção de práticas alimentares adequadas. Embora com uma incidência pequena, a ênfase desse discurso aponta a necessidade de considerar a realidade de (in) SAN das famílias como elemento essencial na orientação das ações de educação em saúde. Para isso, a proposta teórico-metodológica e pedagógica da educação alimentar deve ser alinhavada em abordagens participativas, dialógicas e problematizadoras que permitam desvelar realidades e sentimentos de (in) SAN no âmbito individual e coletivo.

Faz-se necessário perceber e abordar a (in) SAN na perspectiva do DHAA. Para tanto, profissionais de saúde, usuários e comunidade devem apropriar-se desses conceitos, das formas de acessibilidade ao DHAA e das redes de controle social pertinentes. Isso requer, necessariamente, processos de mobilização da comunidade e de capacitação dos profissionais de saúde e usuários nesse campo.

Nos discursos coletivos não se identificou a presença ou o envolvimento dos sujeitos-pacientes, seja de forma individual ou coletiva, no controle social das ações de que participam e da assistência que lhes é prestada. Percebe-se, nos depoimentos, uma avaliação positiva da atuação das equipes de ESF, realçada a atuação dos médicos e dos agentes de saúde, e uma satisfação com os serviços que lhes são prestados; porém a participação dos sujeitos é passiva diante da atenção que lhes é provida. Recomenda-se que, mesmo as práticas oriundas de programas de saúde preestabelecidos, como o de acompanhamento e controle do diabetes e da hipertensão realizado no Hiperdia, sejam alvo de reflexão e possam inserir a participação da comunidade como um de seus preceitos. 
A qualificação das ações educativas na abordagem de pessoas com HA e/ou DM é fundamental para o tratamento da doença, para a prevenção de complicações crônicas, promoção de saúde e melhoria da qualidade de vida. Para impactarem positivamente, no entanto, elas requerem um conjunto de condições que inclua a adoção de abordagens pedagógicas participativas, processos comunicacionais humanizados, centralizados nos sujeitos e na percepção deles sobre o processo saúde-doença. O material discursivo desse estudo trouxe elementos para afirmar que ainda há muito que investir nesse sentido.

\section{REFERÊNCIAS}

ADA - American Diabetes Association. Standards of medical care in diabetes. Diabetes Care, v.28, s.1, p.54-536, 2005.

AHA - American Heart Association. Science Advisory. Wine and your heart. A science advisory for healthcare professionals from the nutrition committee, council on cardiovascular nursing of The American Heart Association. Circulation, v.103, n.3, p.472-475, 2001.

ALMEIDA, M.C.P.; MISHIMA, S.M. O desafio do trabalho em equipe na atenção à Saúde da Família: construindo "novas autonomias" no trabalho. Interface (Botucatu) [online], v.5, n.9, p.150-153. ISSN 1414-3283. Disponível em:< http://www.scielo.br/pdf/icse/v5n9/12.pdf >. Acesso em: 11 fev. 20111.

ALMEIDA-PITITTO B. Impacto de um programa de intervenção no estilo de vida sobre o perfil de risco cardiometabólico da população nipo-brasileira de alto risco. [Tese de Doutorado]. São Paulo. Faculdade de Saúde Publica, Universidade de São Paulo, 2009.

ALVES, V.S. Um modelo de educação em saúde para o programa de saúde da família: pela integralidade da atenção e reorientação do modelo assistencial. Interface- Comunic. Saúde Educ., v.9, n.16, p.39-52, 2005.

ARAÚJO, D.R.D. Como transcrever sua entrevista: técnica de editoração da transcrição de entrevista em pesquisa de abordagem compreensivista. Psico, v. 32, n.1, p. 147-157, 2001.

ARAUZ, A.G. et al. Intervención educativa comunitaria sobre la diabetes comunitária en el ámbito de la atención primaria. Rev Panam Salud Publica, Washington, v.9, n.3, p.145-153, 2001.

ARY, D. V. et al., Patient perspective on factors contributing to nonadherence to diabetes regimen. Diabetes Care, v. 9, n. 2, p. 168-172, 1986. 
ASSIS, A.M.O. et al. O Programa Saúde da Família: contribuições para uma reflexão sobre a inserção do nutricionista na equipe multidisciplinar. Rev. Nutr. [online], vol.15, n.3, p.255-266, 2002. ISSN 1415-5273. Disponível em:

<http://www.scielo.br/pdf/rn/v15n3/a01v15n3.pdf>. Acesso em 11 fev. 2011.

ASSUNCAO, M.C.F. et al. Atenção primária em diabetes no Sul do Brasil: estrutura, processo e resultado. Rev. Saúde Pública [online], v.35, n.1, p.88-95, 2001. ISSN 00348910. Disponível em: <http://www.scielo.br/pdf/rsp/v35n1/4141.pdf> Acesso em 23 jan. 2011.

BARDIN, L. Análise de conteúdo. Lisboa: Edições 70, 1977.

BARRETO, M.L.; CARMO, E.H. Padrões de adoecimento e de morte da população brasileira: os renovados desafios para o Sistema Único de Saúde. Ciênc. saúde coletiva, vol.12, supl., p.1179-1790, 2007.

BARRETO, S.M. et al. Análise da estratégia global para a alimentação atividade física e saúde, da Organização Mundial da Saúde. Epidemiol Serv Saúde, v.14, n.1, p.41-68, 2005.

BOING, A.C; BOING, A.F. Hipertensão arterial sistêmica: o que nos dizem os sistemas brasileiros de cadastramento e informações em saúde. Rev Bras Hipertens, vol. 14, n. 2, p. 84-88, 2007.

BOOG, M.C.F. Educação nutricional: por que e para quê? Artigo. Jornal Unicamp. Universidade Estadual de Campinas. 2 a 8 de agosto de 2004, p.2; 2004. Disponível em: $\langle$ http://www.unicamp.br/unicamp/unicamp_hoje/jornalPDF/ju260pag02.pdf $>$. Acesso em: 25 set. 2010.

Educação nutricional em serviços públicos de saúde. Cad. Saúde Pública, v. 15, n2, p.139-147, 1999.

BOTELHO, R.; DUDRAK, R. Home Assessment of Adherence to long-term Medication in the Eldery. The Journal of Family Pratictive, v. 35, p. 61-64, 1992.

BRASIL. Ministério da Saúde. Secretaria de Atenção Básica. Departamento de Atenção Básica. Política Nacional de Alimentação e Nutrição. 2. ed. rev. Brasília: Ministério da Saúde, 2008a. Série B. Textos Básicos de Saúde.

. Ministério da Saúde. Secretaria da Atenção à Saúde. Departamento de Atenção Básica. Guia alimentar para a população brasileira: promovendo a alimentação saudável. Serie A. Normas e Manuais Técnicos. Brasília, 2008b.

Ministério da Saúde. Política Nacional de Atenção Básica e revisão das diretrizes e normas para a organização da atenção básica para o programa de saúde da família e programa de agentes comunitários de saúde. Portaria n. 648, de 28 de março de 2006. Brasília, 2006a.

Presidência da República. Casa Civil. Subchefia para Assuntos Jurídicos. Lei 11.346, de 15 de setembro de 2006. Cria o Sistema Nacional de Segurança Alimentar e Nutricional - SISAN com vistas em assegurar o direito humano à alimentação adequada $\mathrm{e}$ dá outras providências. Brasília, 2006b. Disponível em: 
<https://www.planalto.gov.br/ccivil_03/_Ato2004-2006/2006/Lei/L11346.htm>. Acesso em 20 jan. 2011.

Ministério da Saúde. A vigilância, o controlo e a prevenção das doenças crônicas não-transmissíveis: DCNT no contexto do Sistema Único de Saúde brasileiro. Brasília: Organização Pan-Americana da Saúde, 2005.

Ministério da Saúde. Plano de Reorientação da Atenção à Hipertensão Arterial e ao Diabetes Mellitus: manual de hipertensão arterial e diabetes mellitus. Brasília, 2001.

Ministério da Saúde. Secretaria de Políticas de Saúde. Departamento de Atenção Básica. A Implantação da US da família. Cadernos de Atenção Básica 1. Brasília, 2000.

CABRERA-PIVARAL, C.E. et al. Efectos de una intervención educativa sobre los niveles plasmáticos de LDL-colesterol en diabéticos tipo 2. Salud Pública de México, v.43, n.6, p.556-3562, 2001.

CASTRO, A.G.P.; FRANCO, L.J. Caracterização do consumo de adoçantes alternativos e produtos dietéticos por indivíduos diabéticos. Arq Bras Endocrinol Metab (online), v.46, n.3, p. 280-287, 20002. ISSN 0004-2730. Disponível em: <http://www.scielo.br/pdf/abem/v46n3/10899.pdf>. Acesso em 23 jan. 2011.

CIAMPONE, M.H.T.; PEDUZZI, M. Trabalho em equipe e trabalho em grupo no Programa de Saúde da família. Rev Bras Enfermagem, v. 53 (especial), p.143-147, 2000. Disponível em:

<http://www.scielo.br/pdf/rlae/v13n2/v13n2a20.pdf>. Acesso em: 10 fev. 2011.

CREVELIM, M.A.; PEDUZZI, M. Participação da comunidade na equipe de saúde da família: é possível estabelecer um projeto comum entre trabalhadores e usuários? Ciênc. saúde coletiva [online]. v.10, n.2, p. 323-331, 2005. ISSN 1413-8123. Disponível em: <http://www.scielosp.org/pdf/csc/v10n2/a10v10n2.pdf>. Acesso em 10 de jan. 2011.

ESPERANÇA, M.B.E; GALISA, M.S. Programa de Comunicação e Reeducação Alimentar (PCRA). In: FAGIOLI, D.; NASSER, L.A. Educação nutricional na infância e na adolescência: planejamento, avaliação e dinâmicas. São Paulo: RCN Ed., 2006. Cap. 5.

FONTANA, A.; FREY, J.H. The interview - from structured questions to negociated text. In: DENZIN, N.; LINCOLN, Y. Handbook of qualitative research. $2^{\text {nd }}$ ed. Thousand Oaks, CA: Sage Publications, 2000. p.645-671.

FONTANELLA, B.J.B. et al. Amostragem por saturação em pesquisas qualitativas em saúde. Cad. saúde pública, v.24, n.1, p.17-27, 2008.

FORTUNA, C.M. et al. O trabalho de equipe no programa de saúde da família: reflexões a partir de conceitos do processo grupal e de grupos operativos. Rev. Latino-Am. Enfermagem [online], vol.13, n.2, pp. 262-268, 2005. ISSN 01041169. 〈http://www.scielo.br/pdf/rlae/v13n2/v13n2a20.pdf>. Acesso em 11 fev. 2011. 
GAZZINELLI, M.F.et al. Educação em saúde: conhecimentos, representações sociais e experiências da doença. Cad. Saúde Pública, v.21, n.1, p.200-206, 2005.

GONZÁLEZ, R.G. et al. Comunicación y educación interativa em salud y su aplicación al control del paciente diabético. Revista Panamericana de Salud Publica, Washington, DC, v.2, n.1, p.32-36, 1997.

GRUESSER, M. et al. Structured patient education for out-patients with hypertension in general practice: a model project in Germany. J Human hypertens, v.11, n.8, p.501506, 1997.

GUS, I.; FISCHMANN, A.; MEDINA, C. Prevalência dos fatores de risco da doença arterial coronariana no Estado do rio Grande do Sul. Arq Bras Cardiol, v.78, n.5, p.478483, 2002.

HERNANDES-RONQUILLO et al., Factors associated whith therapy noncompliance in type-2 diabetes patients. Salud pública de México, v. 45, n. 3, p. 191-197, 2003.

JONES, N. et al. An investigation of adult's views of the outcomes of dietary treatment. Journal of Human Nutrition \& Dietetics, v.20, n.5, p. 486-494, 2007.

Kotchen T.A., Kotchen M.J. Nutrition, diet and hypertension. In: Shils M.E. et al., editors. Modern nutrition in health and disease. $9^{\text {th }}$ ed. USA: Williams \& Wilkins, 1998, p.1217-27.

KOHLMANN JR., O. et al. III Consenso Brasileiro de Hipertensão Arterial. Arq Bras Endocrinol Metab [online], v.43, n.4, p. 257-286, 1999. ISSN 0004-2730. Disponível em: 〈http://www.scielo.br/pdf/abem/v43n4/11752.pdf〉. Acesso em: 30 jan. 2011.

LEFÈVRE, A.M.C. et al. A utilização da metodologia do discurso do sujeito coletivo na avaliação qualitativa dos cursos de especialização "capacitação e desenvolvimento de recursos humanos em saúde - CADRHU, São Paulo - 2002. Saúde e sociedade, v.12, n.2, p. $68-75,2003$.

LEFÈVRE, F.; LEFÈVRE, A.M.C. O discurso de sujeito coletivo: um novo enfoque em pesquisa qualitativa (desdobramentos). Caxias do Sul: Educ, 2003.

LEFÈVRE, F. et al.. Discurso do sujeito coletivo, complexidade e auto-organização. Ciênc. saúde coletiva, v.14, n.4, p.1193-1204, 2009.

LESSA, I. Doenças crônicas não-transmissíveis no Brasil: um desafio para a complexa tarefa da vigilância. Ciênc. saúde coletiva, vol.9, n.4, p.931-943, 2004.

LIMA, R. T. et al. Educação em saúde e nutrição em João Pessoa, Paraíba. Revista de Nutrição, Campinas, v.13, n.1, p.29-36, 2000.

MAIA, F.F.R.; ARAÚJO, L.R. Projeto 'Diabetes Weekend': Proposta de Educação em Diabetes Mellitus tipo I. Arq Bras de Endocrinol e Metab, v.46, n.5, p.566-573, 2002.

MATUMOTO, S. Encontros e desencontros entre trabalhadores e usuários na saúde em transformação: um ensaio cartográfico do acolhimento. Tese [Doutorado]. Escola de Enfermagem de Ribeirão Preto. Universidade de São Paulo, 2003. Disponível em:

<http://www.scielosp.org/pdf/csc/v10n2/a10v10n2.pdf>. Acesso em 11 jan. 2011. 
MILLER, C. K. et al. Evaluation of a theory-based nutrition intervention for older adults with diabetes mellitus. J Am Diet Assoc. v.102, n.8, p.1069-81, 2002.

MINAYO, M.C.S. O desafio do conhecimento: pesquisa qualitativa em saúde. São Paulo:Ed. Hucitec, 1993.

MINISTÉRIO DA SAÚDE. Secretaria de Políticas Públicas. Plano de Reorientação da Atenção à Hipertensão Arterial e ao Diabetes Mellitus. Rev. Saúde Pública, v.35, n.6, p.585-588, 2001. Informes Técnicos Institucionais.

MOREIRA, R.O. et al. Diabetes Mellitus e depressão: uma revisão sistemática. Arq Bras Endocrinol Metab, v. 47, n. 1, p. 19-20, 2003.

MOTTA, D.G.; BOOG, M.C.F. Fundamentos do Comportamento Alimentar. In: Educação Nutricional. 3 ed. São Paulo: Ibras, 1991. p.34-54.

PAIVA, D.C.P. et al. Avaliação da assistência com diabetes e/ou hipertensão pelo Programa de Saúde da Família do Município de Francisco Morato, São Paulo, Brasil. Cad. Saúde Pública, v.22, n.2, p. 377-385, 2006.

PATTON, M.Q. The nature of quality inquiry. In: Qualitative research e evaluation methods. $3^{\text {nd }}$ ed. Thousand Oaks, CA: Sage Publications, 2002. p.3-29.

PEDUZZI, M. A inserção do enfermeiro na equipe de saúde da família, na perspectiva da promoção da saúde. In: São Paulo. Secretaria do Estado da Saúde. Seminário: O enfermeiro no Programa de Saúde da Família. São Paulo, 2000.

PERES, D.S. et al.. Comportamento alimentar em mulheres portadoras de diabetes tipo 2. Rev. Saúde Pública [online]. 2006, v.40, n.2, p.310-317. ISSN 0034-8910. Disponível em:

<http://www.scielosp.org/pdf/rsp/v40n2/28537.pdf> Acesso em 3 jan. 20011.

PERES, D.S. et al. Portador de hipertensão arterial: atitudes, crenças, percepções, pensamentos e práticas. Rev Saúde Pública, v.37, n.5, p.635-642, 2003.

PICHON-RIVIÈRE, E. El processo grupal. Del psicanálisis a la psicología social. Buenos Aires: Nueva Vision, 1988.

PINHEIRO, R.; LUZ, M.T. Práticas eficazes x modelos ideais: ação e pensamento na construção da integralidade. In: PINHEIRO, R.; MATTOS, R.A. (Org.) Construção da integralidade: cotidiano, saberes e práticas em saúde. Rio de Janeiro: UERJ/IMS: ABRASCO, 2003. p.7-34.

PONTIERE, F.M.; BACHION, M.M. Crenças de pacientes diabéticos acerca da terapia nutricional e sua influência na adesão ao tratamento. Rev. Ciên Saúde Coletiva, v.15, n.1, p.151-160, 2010.

RÊGO, M.A.B. et al. Educação para a saúde como estratégia de intervenção de enfermagem às pessoas portadoras de diabetes. Rev Gaúcha Enferm, v.27, n.1, p.60-70, 2006. Disponível em:

< http://www.revistas.ufg.br/index.php/fen/article/view/8024/5807>. Acesso em: $11 \mathrm{fev}$. 2011. 
RIBEIRO, J.P. et al. Compreendendo o significado de qualidade de vida segundo idosos portadores de diabetes mellitus tipo II. Esc. Anna Nery [online], v.14, n.4, p. 765-771, $2010 . \quad$ ISSN 1414-8145. Disponível em: <http://www.scielo.br/pdf/ean/v14n4/v14n4a16.pdf>. Acesso em: 13 fev. 2011.

SALES, F. et al. O emprego da abordagem DSC (discurso do sujeito coletivo) na pesquisa em educação. Linhas, v.8, n.1, p.124-145, 2007. Disponível em:

<http://www.periodicos.udesc.br/index.php/linhas/article/view/1361/1167>. Acesso em: 10 de out. 2010.

SANTANA, M.G.O desejo, o controle e o limite: possíveis enfrentamentos no cotidiano diabético. In: (Org.). Rede de saberes em diabetes e saúde: um exercício de interdisciplinaridade. Pelotas: Edição Independente, 2002, p.53-72.

SANTOS, E.C.B. et al. O cuidado sob a ótica do paciente diabético e de seu principal cuidador. Rev. Latino-Am. Enfermagem [online]. v.13, n.3, p.397-406, 2005. ISSN 0104-1169. Disponível em:

<http://www.scielo.br/pdf/rlae/v13n3/v13n3a15.pdf>. Acesso em: 12 fev. 2011.

SANTOS, L.A.S. O fazer educação alimentar e nutricional: algumas contribuições para reflexão. Ciênc Saude Colet, 2010. Em prelo. Disponível em: <http://www.cienciaesaudecoletiva.com.br/artigos/artigo_int.php?id_artigo=6615>. Acesso em: 5 jan. 2011.

SARTORELLI, D.S. et al. Beneficial effects of short term nutritional conselling at the primary health-care level among Brasilian adults. Public Health Nutrition, v.8, n.7, p.820-825, 2004.

SBD - SOCIEDADE BRASILEIRA DE DIABETES. Consenso brasileiro sobre diabetes 2002: diagnóstico e classificação do diabetes melito e tratamento do diabetes melito do tipo 2. Rio de Janeiro: Diagraphic, 2003.

SCHERER, M.D.A. et al. Rupturas e resoluções no modelo de atenção à saúde reflexões sobre a estratégia de saúde da família com base nas categorias Kuhnianas. Interface Comunic., Saúde, Educ., v.9, n.16, p.53-66, 2005.

SEVERINO, A. J. Metodologia do trabalho científico. São Paulo: Cortez, 1996.

SHERMAN, A.M. et al., Adherence: characteristics and interventions: Controlled Clinical Trials, v. 21, p. 206-2011, 2000.

SILVA, M.A. et al. Enfermeiros e grupos em PSF: possibilidade para participação social. Cogitare Enferm., v.11, n.2, p.143-149, 2006.

SILVA, M.V.L. Efeitos do aconselhamento dietético no tratamento da Hipertensão Arterial em hipertensos da US de Andorinhas, Vitória, ES. [Dissertação de Mestrado]. Vitória: Centro Biomédico da Universidade Federal do Espírito Santo, 2005.

SILVA, T.R. et al. Controle de diabetes mellitus e hipertensão arterial com grupos de intervenção educacional e terapêutica em seguimento ambulatorial de uma unidade básica de saúde. Saúde Soc., vol.15, n.3, p. 1801-189, 2006. 
SILVEIRA, L.M.C; RIBEIRO, V.M.B. Grupo de adesão ao tratamento: espaço de "ensinagem" para profissionais de saúde e pacientes. Interface - Comunic., Saúde, Educ. [online], vol.9, n.16, p.91-104, 2005. ISSN 1414-3283.

SMEKE, E.L.M.; OLIVEIRA, N.L.S. Educação em saúde e concepções do sujeito. In: VASCONCELOS, E.M. (Org.). A saúde nas palavras e nos gestos: reflexões da rede popular e saúde. São Paulo: Hucitec, 2001.

STOTZ, E. Enfoque sobre educação popular e saúde. In: Brasil. Ministério de Saúde. Secretaria de Gestão Estratégica e Participativa. Departamento de Apoio à Gestão Participativa. Caderno de educação popular e saúde. Série B. Textos Básicos de Saúde Brasília: Ministério da Saúde, 2007.p.46-57.

TEIXEIRA, J.J.V; LEFÈVRE, F. Significado da intervenção médica e da fé religiosa para o paciente idoso com câncer. Ciênc. saúde coletiva, v.13, n.4, p.1247-1256, 2008.

TORRES, H.C.; HORTALE, V.A.; SCHALL, V. A experiência de jogos em grupos operativos na educação em saúde para diabéticos. Cad. Saúde Pública [online], v.19, n.4, p.1039-1047, 2003. ISSN 0102-311X. Disponível em:< http://www.scielo.br/pdf/csp/v19n4/16853.pdf >. Acesso em 3 jan. 2011.

VALENTE, F. et al. Curso de formação em Direito Humano à Alimentação Adequada. No contexto da Segurança Alimentar e Nutricional. Módulo III. Exigibilidade. ABRANDH, 2007. Apostila.

VALLA, V.V. Saúde e educação. Rio de Janeiro: DP\&A Editora, 2000. 


\subsection{RESULTADOS E DISCUSSÃO DA TERCEIRA ETAPA DO ESTUDO}

\section{Caminhos para a qualificação do processo educativo}

Qualificar significa “emitir opinião sobre, avaliar; indicar as qualidades de, classificar" (HOUAISS, 2009, p. 620). Entende-se, portanto, que a qualificação é um ato pertinente aos sujeitos que estão empenhados em compreender um dado fenômeno. Esse foi o sentido que se adotou na terceira etapa da pesquisa, relativa à qualificação das ações educativas, da qual participaram 25 dos 27 profissionais de saúde selecionados para o estudo.

O resultado dos debates nos grupos focais representa a reelaboração dos discursos desses sujeitos num novo diálogo com o pesquisador para subsidiar o processo de qualificação das ações educativas para pessoas com DM e HA, com foco na educação alimentar, empreendida no âmbito da ESF.

Nas reuniões dos grupos focais, os participantes foram conduzidos a dialogar sobre quatro categorias de análise previamente estabelecidas com base nas ideias centrais dos depoimentos da primeira etapa da pesquisa, quando se desvelaram as dificuldades e os desafios das ações educativas empreendidas para pessoas com DM e HA na ESF. Sobre o conjunto de argumentos mais significativos apresentados durante esses diálogos é que se discute a seguir.

\subsubsection{O fortalecimento das ações educativas no plano terapêutico para pessoas com DM e HA}

Tanto no plano acadêmico-científico como no discurso políticoinstitucional, o processo educativo em saúde é colocado como chave para tornar as pessoas capazes e autônomas para as decisões em prol de sua saúde. Tanto assim que esse processo é considerado inerente a todas as práticas desenvolvidas no âmbito do SUS. Nesse sentido, as ações educativas devem ser valorizadas e qualificadas para que contribuam com a afirmação do próprio Sistema e com a reorientação de suas práticas (Brasil, 2007). 
No entanto, essa dimensão não é percebida pelos sujeitos que, nos serviços, dão concretude às práticas educativas. Para os profissionais de saúde participantes do estudo

"Existem muitos obstáculos e pouco interesse dos usuários e dos profissionais diante das ações educativas.";

"Eles vem (na UBS) para tratar, não vem para prevenção".

Segundo esses profissionais, o usuário orienta a solução de seus problemas de saúde na perspectiva de um cuidado medicalizado para a cura de sua doença e não pela via da educação para a promoção de sua saúde e controle de sua doença e, por isso, valoriza menos as atividades educativas, representada no discurso como aquelas que são realizadas nos grupos do Hiperdia, que as abordagens individuais realizadas durante a consulta médica e/ou de enfermagem.

Não obstante, percebe-se, tanto nos discursos coletivos da primeira etapa do estudo como nos fragmentos de discurso dessa etapa, que essa orientação não é exclusiva do sujeito usuário; antes permeia a visão e a prática das equipes de saúde que reconhecem, na vulnerabilidade do processo educativo, muitos obstáculos e, em razão disso, justificam e legitimam as práticas tradicionais.

Se o sujeito-paciente prefere as consultas médicas às atividades realizadas nos grupos do Hiperdia, então inseri-las no espaço desses grupos atende aos interesses dos usuários e, de certa forma, à condição físico-funcional e de logística do serviço de saúde. Inserir abordagens individuais, como a consulta médica e de enfermagem no espaço dos grupos, passa a ser uma estratégia para capturar o usuário ao menos uma vez a cada três meses e realizar o que é percebido pelo profissional de saúde como atividade educativa de cunho coletivo. É exatamente a essa atividade que o profissional de saúde atribui a necessidade de reconhecimento, tanto pelo usuário quanto por ele próprio.

Quando aos participantes do grupo focal, foi lançada a questão -“como podemos, então, driblar esse desafio e aprimorar as práticas educativos no sentido de sua valorização ou fortalecimento?”, uma manifestação enfática foi: 
"Deveria ter mecanismos de avaliação das atividades educativas para que se possa saber se está tendo impacto na vida das pessoas [...]. Para isto é preciso definir indicadores."

No aprofundamento do debate sobre esse argumento, percebeu-se que a avaliação do impacto da ação educativa a que o profissional de saúde se refere mantém aparentemente a orientação hegemônica do modelo assistencial, ou seja, não se trata de avaliar o processo educativo em sua amplitude e complexidade, mas avaliar a sua repercussão (ou não) apenas sobre os aspectos biológicos que envolvem o controle da doença. Tanto assim que os indicadores sugeridos foram:

“[...] saber se os pacientes estão mesmo perdendo peso, se a sua pressão ou o seu diabetes estão controlados", ou então

“[...] se eles estão seguindo aquela alimentação, se estão tomando os remédios direitinho $[\ldots] "$

Obviamente, não se questiona aqui a importância dos recursos diagnósticos e de controle metabólico, de caráter biométrico e dietético, como indicativos do seguimento do plano terapêutico; afinal, na perspectiva da integralidade do cuidado, as doenças crônicas exigem constante apreciação desses indicadores, cujos parâmetros não forem monitorados e controlados, poderão levar a consequências não desejadas e muito mais caras às pessoas e ao Sistema de Saúde.

O que se quer considerar, no entanto, é a necessidade de ampliar a reflexão sobre o significado desses "controles" para a vida das pessoas. Significa deslocarse um pouco da avaliação de resultados das ações educativas sobre o controle metabólico para avaliar o impacto dessas ações na vida daqueles que convivem com tais doenças. Trata-se, mais devidamente, de avaliar o processo educativo mais amplo e não apenas o sujeito-biológico a que ele se destina. Afinal, esse processo, como tal se considera, deve conferir autonomia ao sujeito (BRASIL, 2007), para que este, ao fazer uma escolha em prol de sua saúde, por exemplo, uma opção alimentar mais saudável e adequada, possa fazê-lo com liberdade e sustentabilidade. 
Em contrapartida, o processo educativo conducente em que o indivíduo é convencido a acatar normas e restrições alimentares, pois acredita que, se não o fizer, será apenado com a piora de sua saúde, pode levar a sentimentos de falta de autonomia, frustração e tristeza e a comportamentos de transgressão do plano terapêutico.

Os discursos dos sujeitos-pacientes foram muito significativos para a discussão da autonomia que o processo educativo deve imprimir na escolha livre e informada dos sujeitos (LEFEVRE, LEFEVRE, 2004). Na mesma proporção que as pessoas se referiram efusivamente às mudanças "radicais" empreendidas em sua alimentação, depois que passaram a ser acompanhadas pela US, demonstraram angústia, tristeza e até revolta com as restrições alimentares a que se submetiam.

As escolhas "saudáveis" deixaram, portanto, as pessoas infelizes, infelicidade que pode constituir um fator de transgressão e de falta de manutenção do plano terapêutico, tão ou mais sério de ser considerado do que o atingimento de metas do controle metabólico padronizado.

Se o olhar do profissional de saúde fosse menos de vigilância, de fiscalização dos controles cotidianos dos fatores biomédicos, e mais de compreensão daquilo que angustia as pessoas em relação às atitudes e aos comportamentos que precisam assumir para o controle de sua doença, se qualificariam as ações educativas no sentido de uma assistência mais humanizada. De certa forma, isso implica reelaborar as falas, tais como:

"Deve se chamar a responsabilidade do paciente e de sua família para o seguimento da alimentação adequada"

Nesse fragmento de discurso, emerge novamente o modelo centrado na doença e o sujeito-paciente tido como responsável, em última instância, por sua prevenção e eliminação (perspectiva higienista). As práticas de saúde assumem caráter de vigilância e o profissional de saúde o papel de físcal dos comportamentos que são prescritos para o controle da doença ou de seus fatores de risco. 
Aqui fica resguardada a importância do conceito e das práticas de vigilância à saúde, quando essas são empreendidas na perspectiva da promoção da saúde. Para a PNPS a vigilância à saúde inclui o monitoramento, prevenção e vigilância da morbimortalidade e dos fatores de risco relativos às DANT, para qual se utiliza os sistemas de informação existentes na análise e no planejamento das ações de promoção da saúde e prevenção dessas doenças (BRASIL, 2006c).

Porém, fica registrada a diferença que deve existir entre a abordagem de vigilância (acompanhamento para intervenção) de fatores de risco em um dado contexto de saúde e a prática de fiscalização de normas de higiene que são prescritas num processo no qual se trabalha a persuasão do indivíduo e não o seu empoderamento para escolhas mais saudáveis, sedimentadas e fortalecidas.

\subsubsection{O processo educativo e as práticas prescritivo-normativas}

$\mathrm{Na}$ linha de aprimoramento do processo educativo na perspectiva da humanização da assistência, deve-se refletir sobre as falas manifestadas e debatidas nessa categoria de análise:

\footnotetext{
“A maioria dos pacientes é idosa, para mudar os hábitos é difícil.";

"[...] mas é preciso ver que cada vez eles chegam à unidade mais jovem, tem muito jovem já com pressão alta, colesterol, obesidade.";

“[...] é preciso avaliar para ver a condição financeira, econômica que para alguns é muito difícil.”;

"Falta informação para o usuário e para os profissionais com relação à lida com os alimentos.".
}

Apesar de tratarem, entre outras, de circunstâncias aparentemente diversas - o idoso, o jovem, o acesso à informação e aos recursos para alimentação adequada -, nos caminhos para a qualificação da intervenção educativa elas deverão convergir para um mesmo sentido: a singularidade individual e coletiva do processo educativo. A complexidade do processo educativo é tal que não há outra forma a fazer senão a apontada na discussão por um dos profissionais de saúde presentes: 
"A abordagem tem que ser diferenciada, o profissional tem que se colocar no lugar do paciente, sentir suas necessidades e seus problemas para ajudá-lo a planejar sua vida.”

Essa fala é representativa do discurso acadêmico e oficial sobre o processo educativo centrado no sujeito e foi manifestada no discurso dos profissionais de saúde como uma expectativa de reorientação das práticas atuais. No entanto, aparentemente está localizada apenas na esfera do discurso. Para a intervenção educativa acontecer nas bases em que essas ideias se materializam, são necessários investimentos institucionais que passam pela capacitação dos trabalhadores da saúde para uma escuta qualificada dos problemas dos usuários e a alocação multiprofissional de recursos humanos ao nível de atenção em que a intervenção se realiza. Por conseguinte, pela interação de saberes e práticas interdisciplinares, para que o Sistema efetivamente propicie intervenções com base nas peculiaridades individuais e coletivas dos sujeitos.

Particularmente para as intervenções nutricionais, um aspecto importante para o aprimoramento das ações educativas reside na possibilidade de ter o nutricionista como um profissional de apoio para as equipes de ESF, cuja formação desenvolve competências e habilidades para lidar com os problemas de nutrição e dietética de pessoas e coletividades. Diante disso, assim argumentaram os profissionais de saúde:

“[...] é preciso ensinar a utilizar os recursos que eles têm”;

“[...] é preciso ter uma organização do plano alimentar para que a pessoa aprenda a como se organizar para sua alimentação. A dieta não basta, não pode isto, não pode aquilo. Mas o que pode? O que ela vai comer na segunda, na terça, na quarta, no café da manha, no almoço?";

"Eles precisam saber sobre porções, sobre o que é que pode comer de cada alimento.".

Para responder à expectativa como essa e melhorar a qualidade e resolutividade da Atenção Básica, o Ministério da Saúde propôs, em 2007, a criação de Núcleos de Apoio à Saúde da Família (NASF), constituídos por equipes de profissionais de diferentes áreas do conhecimento que atuarão em 
parceria com os profissionais das equipes de Saúde da Família, no apoio a elas na unidade em que o NASF estiver cadastrado (BRASIL, 2009a).

A presença do especialista por si só não garantirá que as práticas de educação alimentar e nutricional se orientem por outra abordagem que não a normativo-prescritiva. Todavia, não resta dúvida de que imprime um caráter de maior propriedade na intervenção, principalmente naqueles aspectos que são muito específicos da formação desses profissionais, como a dietética, o planejamento de refeições, a economia doméstica, a composição dos alimentos, entre outros. Resulta disso ações mais qualificadas em termos das informações técnicas que fazem parte do conjunto de competências que devem ser codificadas e significadas com os sujeitos envolvidos no processo educativo.

Como bem caracterizou BOOG (1999, p.139), existe uma "contradição entre a aparente banalidade do ato da alimentação em contraposição á complexidade dos problemas alimentares" que precisa ser urgentemente avaliada pelas políticas de promoção da saúde e reelaborada ao nível do discurso dos profissionais de saúde. No âmbito da intervenção nutricional educativa orientada pela abordagem prescritivo-normativa, dizer que "[...] é preciso ter o nutricionista [...] para ensinar a utilizar os recursos que as pessoas têm" pode significar "é preciso ter o nutricionista para prescrever uma dieta com recursos parcos para aqueles que não têm acesso aos recursos alimentares, ou às informações suficientes para sua adequada utilização".

É preciso urgentemente ressignificar esse discurso, para assim reorientar as práticas educativas no sentido de uma intervenção emancipadora para as pessoas que, atualmente neste país, são sujeitos de direitos em relação à alimentação adequada e à segurança alimentar e nutricional (BRASIL, 2006a).

\subsubsection{O planejamento das ações educativas a organização do processo de trabalho e a capacitação dos profissionais de saúde}

O tom do debate travado nos grupos focais sobre a questão do planejamento das ações educativas pode ser representado pelo fragmento do discurso de um dos participantes dos grupos focais: 
"É preciso ter o planejamento para que se tenha mais motivação e assim melhor qualidade da educação em saúde."

Para os sujeitos que na ponta atuam como propulsores da reorientação do modelo assistencial no âmbito da Atenção Básica de Saúde,

"É preciso ter uma organização no trabalho para que o profissional se organize para fazer melhor suas ações."

Eles, portanto, reconhecem que a qualificação das práticas de saúde passa pela organização do seu trabalho. Como fazer isso, parece ser um grande desafio diante da

“[...] demanda que é muito grande, o profissional não dá conta [...]”;

"Como fazer um processo mais qualitativo sem ter tempo, sem ter a capacitação para a educação em saúde?”;

"Atualmente os profissionais focam mais nos doentes e não nos demais, deixando de lado a prevenção.”;

"É preciso fazer um tempo para o planejamento. Temos que ter estratégias para aproveitamento do tempo.”.

Nota-se que os fragmentos do discurso são esclarecedores da dificuldade de organização do fazer cotidiano dos profissionais de saúde. Estimulados no debate para uma atitude de enfrentamento dessas dificuldades, as principais sugestão foram:

"Poderíamos ter reuniões para o planejamento, com tempo marcado, metodologias, espaço físico, equipamentos";

"Precisaria ter a socialização dos métodos e técnicas entre as equipes. Tem equipe que faz de outra forma e a gente nem fica sabendo";

"As equipes precisam se integrar mais, mas falta espaço para o planejamento";

“As equipes precisam ser capacitadas para aprenderem a se organizar.".

No documento que institui a revisão das diretrizes e normas para a organização da Atenção Básica no âmbito da ESF, ou seja, na PNAB, está 
explícito que o conjunto de ações que a compõe, inclusive as educativas, deverá ser desenvolvido por meio do exercício de práticas gerenciais e sanitárias organizadas na forma de trabalho em equipe.

Sabe-se que o fato de um processo estar instituído oficialmente nem sempre garante a sua concretização, principalmente quando ele é formulado com objetivos de traçar as diretrizes gerais de uma política nacional, que se vai materializar na esfera e com os atores locais. No entanto, esse documento oferece subsídios que podem auxiliar as equipes de ESF no desafio de organização de suas práticas. Um deles diz respeito ao trabalho de equipe que supõe a interação entre sujeitos para a realização de objetivos comuns. No seu discurso, os profissionais de saúde reconhecem no trabalho em equipe e na interação entre elas uma possibilidade concreta de organizar seu processo de trabalho, estabelecendo atividades compartilhadas e troca de experiências. Esbarram, porém, na questão de uma demanda que é muito grande e que não lhes permite efetivar os momentos que deveriam ser garantidos para tal.

Ainda, no documento que institui a PNAB, são relacionadas entre as características do processo de trabalho da Atenção Básica, a “(...) programação e implementação das atividades, com a priorização de solução dos problemas de saúde mais frequentes, considerando a responsabilidade da assistência resolutiva à demanda espontânea (...)" (BRASIL, 2006b, p.18).

A prioridade conferida ao atendimento da demanda espontânea é, portanto, uma condição da Atenção Básica, enquanto como porta de entrada preferencial do SUS, o que constitui desafio para a qualificação do processo de trabalho como um todo e tem, segundo a percepção dos profissionais de saúde, uma repercussão importante nas atividades de planejamento e organização das ações educativas de promoção de saúde. Como essa demanda é geralmente muito grande e diversificada para a capacidade instalada das equipes, elas comprometem tempo e espaço disponíveis no seu atendimento prioritário.

O desafio deve ser abordado com responsabilidade, num movimento de integração de esforços e recursos da gestão local e municipal com as demais esferas de gestão da saúde e cuja solução requer a reorientação do modelo de gestão, com estabelecimento de prioridades para a definição e organização do 
processo de trabalho e o comprometimento dos gestores locais em prover estrutura de atendimento ágil, resolutiva e de qualidade. Investimentos em informatização das unidades de saúde, por exemplo, um recurso aparentemente inerente a agilidade de diversas atividades laborais, está longe de constituir a realidade dos serviços de saúde.

Em termos gerais, a PNAB define as responsabilidades de cada esfera de governo, para garantir a infraestrutura, os recursos necessários, as características do processo de trabalho e as regras de financiamento que incluem as especificidades da ESF (BRASIL, 2006b).

Abordar o problema da organização do processo de trabalho requer, ainda, a capacitação dos profissionais de saúde nesse campo de saber e de ação, necessidade essa revelada no debate nos grupos focais. A educação permanente dos profissionais da Atenção Básica é responsabilidade conjunta das secretarias municipais e estaduais de saúde. Ademais, os conteúdos mínimos desse processo devem priorizar as áreas estratégicas da Atenção Básica, acordadas na Comissão Intergestores Tripartite (CIT) e nas Comissões Intergestores Bipartite (CIBs), entre as quais se encontra o controle do DM e da HA, acrescidas das prioridades municipais e estaduais (BRASIL, 2006b). Sendo assim, uma articulação no sentido de encaminhar essa demanda às Comissões Intergestores poderia ser uma via efetiva de abordagem do problema.

Além da PNAB, o documento que institui e normaliza a PNPS preconiza o desenvolvimento de estratégias de qualificação em ações de promoção da saúde para profissionais inseridos no SUS e o apoio técnico e financeiro aos projetos de qualificação de profissionais da ESF e do Programa de Agentes Comunitários de Saúde para a atuação na área de informação, comunicação e educação popular em saúde (BRASIL, 2006c).

Mas a principal interlocução político-institucional para a capacitação do profissional de saúde deve ser com a Política Nacional de Educação Permanente em Saúde, que normatiza as estratégias voltadas para a adequação da formação e qualificação dos profissionais de saúde às demandas de saúde da população e ao desenvolvimento do SUS. Instituída pela Portaria MS/GM n. 1996, de 20 de 
agosto de 2007, seu objetivo é fornecer a base normativa para a organização dos processos de gestão da educação na saúde (BRASIL, 2009b).

Especialmente em relação às ações educativas para pessoas com DM e HA, o Plano de Reorganização da Atenção à Hipertensão Arterial e ao Diabetes Mellitus estabelece as diretrizes para o acompanhamento dessas pessoas, com realce para a atualização dos profissionais da rede básica, a garantia do diagnóstico e o estímulo à vinculação do paciente às unidades de saúde para tratamento e acompanhamento. Embora esteja estabelecido que as ações de educação e promoção da saúde são os alicerces desse plano, para a assistência ao DM e à HA são imprescindíveis ações de prevenção secundária contra as complicações, as quais necessariamente incluem o tratamento farmacológico e os exames oferecidos na Atenção Básica.

Para operacionalizar a atualização dos profissionais de saúde, no primeiro momento de implantação do plano foi realizada capacitação de multiplicadores que, no momento seguinte, desenvolveram uma estratégia de ação dirigida aos serviços de saúde da rede básica dos grandes centros urbanos, por meio da realização de uma proposta de educação permanente para os profissionais das unidades básicas de saúde dessas localidades.

No entanto, pelo que se pode perceber, o processo não teve continuidade e, atualmente, no cenário desse estudo a maior parte dos profissionais que atuam nas equipes de ESF, principalmente os ACS, ressentem-se da falta de capacitação sobre esse tema.

Cabe ainda realçar que a socialização do conteúdo de cada uma desses documentos contribuiria para a possibilidade de acesso por parte dos serviços aos recursos necessários à implantação e implementação dos objetos das políticas públicas de saúde, bem como para o controle social delas. Isso também é parte de um processo educativo que deve ser constituído e garantido na formação e na educação permanente dos profissionais de saúde. 


\title{
4.4.4 Sobre a falta de espaço físico para realização das ações educativas.
}

Essa é uma dificuldade muito concreta para o aprimoramento das práticas educativas, que, de certa forma, está vinculada à anterior, pois também se refere a uma demanda demasiadamente grande para a estrutura fisco-funcional instalada nas da US pública. Os fragmentos do discurso dão conta de caracterizar bem esse problema:
"A unidade não comporta, tem um limite muito grande";
"As atividades educativas (dos grupos) tiveram que ser suspensas porque o médico não pode mais fazer a consulta na comunidade e a unidade não comporta tanta gente e atividade";
"Os pacientes chegam para a consulta e sentem falta da atividade educativa".
"O horário disponibilizado para as reuniões de grupo, [...] não é apropriado para as pessoas que trabalham, mas não tem outro jeito...";

As sugestões que surgiram para contorná-lo sugerem o retorno das atividades em espaços da comunidade, pois,

\begin{abstract}
"Quando a equipe vai para a comunidade fica mais próxima e isto dá a oportunidade de interação com as pessoas. Eles se sentem mais valorizados, mais livres para falar de seus problemas e de seus avanços.”.
\end{abstract}

Embora o discurso aponte quão interessante pode ser realizar as ações educativas na comunidade, também aí os profissionais de saúde esbarram com a questão da falta de condições dos equipamentos sociais que acessam:

"Mas não tem muita facilidade de espaços comunitários no território";

"Os espaços são de difícil acesso, não têm conforto e higiene";

"O território é muito acidentado, o que dificulta, muitas vezes, o acesso, a locomoção do usuário e das equipes até os locais de realização das reuniões";

"A gente não consegue consolidar um espaço.". 
Pode-se considerar que nos documentos que institucionalizam os diferentes componentes da política de saúde do país encontram-se elementos valorativos do espaço das ações educativas para implementação dessas políticas. No entanto, o conjunto dos argumentos apresentados nos debates dos grupos focais apontou uma incongruência entre o discurso oficial apreendido nesses documentos e o que foi percebido na concretude das práticas assistenciais cotidianas, entre as quais as ações educativas, como qualquer outra atividademeio, requerem recursos adequados para ocorrer com eficácia e para serem aprimoradas. 


\section{CONCLUSÕES}

Com este estudo foi possível descrever o processo educativo com ênfase na educação nutricional empreendido no âmbito da Atenção Básica à Saúde para pessoas com DM e HA. Ele apresenta o recorte de um cenário de práticas assistenciais em uma unidade de ESF na ótica dos profissionais de saúde e dos sujeitos-pacientes por eles acompanhados, cujos principais espaços das ações educativas foram os grupos de orientação e as consultas médicas. Nesses espaços, a histórica dicotomia entre concepções e práticas coletivas/preventivas e individuais/curativas se manifesta no discurso e nas práticas cotidianas de saúde.

Embora os sujeitos-pacientes tenham nos grupos de orientação a principal referência para o seu acompanhamento, é na consulta médica que a maioria deles se sente mais contemplada na assistência a sua saúde. Apesar de esse pensamento medicocentrado prevalecer, as atividades educativas realizadas nos grupos foram consideradas importantes para o esclarecimento dos sujeitos-pacientes em relação ao seu autocuidado, particularmente, sobre as condutas alimentares adequadas e reconhecidas como momentos em que vários profissionais da equipe da US estão envolvidos.

A presença e o envolvimento de todos os integrantes da equipe nas ações educativas podem sugerir uma reação dos profissionais de saúde ao modelo tradicional medicocentrado, coincidente com a intenção de um processo educativo que valoriza a interdisciplinaridade e o compartilhamento de diferentes saberes e converge com o princípio da integralidade das ações de saúde.

Constatou-se o empenho da equipe de saúde em usar estratégias e recursos pedagógicos diversificados e adaptados à realidade cognitiva dos sujeitospacientes, embora métodos e técnicas de ensino-aprendizagem sejam empregados segundo divergentes orientações político-pedagógicas. Ademais, a despeito de criarem condições favoráveis para o processo comunicativo, podem ser inócuas ao propósito maior da ESF de reorientação das práticas de saúde ou mesmo reforçar as práticas hegemônicas.

As mudanças empreendidas pelos sujeitos-pacientes em sua alimentação foram coincidentes com as recomendações para uma dieta saudável e adequada. 
Isso pode indicar a eficácia das ações educativas em promover mudanças alimentares, ao menos relativamente ao discurso.

Em contrapartida, as dificuldades sentidas no processo de mudança das práticas alimentares evidenciaram que as restrições alimentares, principalmente para os diabéticos, são significadas como necessárias ao seu tratamento, porém muito difíceis e penosas. O sentimento manifestado diante da restrição do açúcar e dos doces principalmente é, por um lado, de pesar e tristeza quando acatam a prescrição e, por outro, de culpa e remorso quando não conseguem fazê-lo.

Esse sentimento é gerado quando a prática educativa assume caráter normativo-prescritivo, desconsidera percepções, significados, e sentimentos das pessoas em relação aos alimentos e o fato deles serem elaborados no convívio social. Todavia, se, no plano terapêutico, existe a necessidade e/ou a indicação de restrições alimentares em prol do controle da doença, abordagens educativas menos normativas e verticalizadas, mais reflexivas, dialogais e de empoderamento das pessoas para a autonomia nas escolhas devem ser preferidas.

Assume-se, portanto, que o processo educativo deva se deslocar da perspectiva conducente da educação em saúde para a perspectiva da capacitação informativa e emancipadora, que municie as pessoas para escolhas (e não para a adesão) que para ela signifiquem mais saúde e bem estar.

Semelhantemente à visão dos sujeitos-pacientes, embora a maioria dos profissionais de saúde tenha elegido os grupos como o espaço mais resolutivo para o desenvolvimento das ações educativas, principalmente quando eles são realizados nos equipamentos comunitários e não na US, parte expressiva realçou em seu depoimento a maior eficácia das consultas, que é, também, na visão dos profissionais, a prática preferida pelos sujeitos-pacientes.

No entanto, para os ACS, além dos grupos e das consultas, as visitas domiciliares foram reconhecidas como espaço educativo privilegiado pela possibilidade de verificar, in loco no dia a dia das pessoas, o seguimento das orientações realizadas sobre a alimentação, medicação, atividade física, entre outras.

A ênfase na dualidade entre as ações que são representadas pelos sujeitos como coletivo-preventivas ou como individual-curativas foi recorrente tanto nos 
discursos em que se apreendeu a dinâmica dos espaços educativos quanto nos que versaram sobre os seus resultados.

Considera-se que essa visão dicotômica pode ser indício da incorporação na linguagem dos sujeitos-profissionais de categorias analíticas próprias do discurso acadêmico da saúde pública atual e assim, ainda que sem muita clareza, esses sujeitos se apropriam de expressões do discurso oficial, que preconiza a necessidade de reorientação do modelo assistencial. Nessa perspectiva, a ESF se coloca como um locus e a educação em saúde, um meio para promover a reorientação desejada. Porém, esse discurso pode refletir ainda uma concepção fragmentária da saúde e, por extensão da assistência, coincidente com o modelo hegemônico vigente.

Em relação à atuação dos profissionais nas ações educativas, considerou-se importante distinguir as ações educativas de caráter geral, da competência de qualquer profissional de saúde, daquelas que compõem conteúdos e processos comunicacionais mais complexos e requerem, portanto, o desenvolvimento de competências e habilidades em áreas específicas do conhecimento. Ademais, para qualificar as ações educativas, os profissionais de saúde, em especial aqueles que são responsáveis pelas instâncias de planejamento e coordenação das ações de saúde, precisam apropriar-se das bases teórico-metodológicas e pedagógicas que regem o processo educativo.

Esta é uma questão imperiosa a ser estimulada na formação profissional e pelas políticas de educação permanente em saúde, que propiciará que os profissionais de saúde tenham a oportunidade de reelaborar seu discurso e sua prática à luz das concepções atuais sobre o modelo assistencial de saúde.

A representação pouco positiva do potencial das práticas educativas em preparar o indivíduo para o autocuidado e para a promoção de sua saúde, por responsabilizá-lo por sua doença, pelo agravamento dela, pela falta de adesão ao tratamento e, em última instância, pelo insucesso da ação educativa coincide com a concepção educativa hegemônica que privilegia a transmissão vertical e passiva de conteúdos e que desconsidera sentimentos, valores, conhecimentos e crenças dos sujeitos e a interação deles no processo educativo. Pensando dessa forma, é possível que os profissionais de saúde estejam legitimando uma abordagem 
educativa normativa, prescritiva, centrada no saber científico, que não lhes permite conhecer as razões por que as pessoas optam por esta ou aquela conduta em relação à sua saúde.

Nessa perspectiva, as ações educativas para impactar positivamente a abordagem de pessoas com HA e/ou DM prescindem do conhecimento do sistema de crenças e valores individuais e coletivos o que favorecerá a construção de processos comunicacionais aprimorados.

A respeito da participação social, nos discursos coletivos não se identificam a presença e o envolvimento dos sujeitos-pacientes, de forma individual ou coletiva, no controle social das ações de que participam e da assistência que lhes é prestada. Percebe-se nos depoimentos uma avaliação positiva relativamente à atuação das equipes de ESF, realçada a atuação dos médicos e dos agentes de saúde, e uma satisfação com os serviços prestados; porém a participação dos sujeitos é passiva diante da atenção que lhes é provida. Recomenda-se que mesmo as práticas oriundas de programas de saúde preestabelecidos, como o de acompanhamento e controle do DM e da HA, sejam alvo de reflexão e insiram a participação da comunidade como um de seus preceitos.

As dificuldades e desafios das ações educativas foram atribuídos a circunstâncias extrínsecas e intrínsecas inerentes às pessoas com DM e/ou HA, bem como relacionados à estrutura, aos processos e/ou aos resultados do modelo educativo.

Referentemente aos primeiros, a promoção de práticas alimentares adequadas depende da condição socioeconômica e cultural das famílias, do perfil etário e da relutância ou rebeldia própria das pessoas com DM e HA. Esse discurso aponta a necessidade de considerar a realidade de (in) SAN das famílias como elemento essencial na orientação das ações de educação alimentar e nutricional. Para isso, a proposta teórico-metodológica e pedagógica deve ser alinhavada em abordagens participativas, dialógicas e problematizadoras que permitam desvelar realidades e sentimentos de (in) SAN no âmbito individual e coletivo. 
Nos discursos coletivos que localizaram as dificuldades e os desafios para as ações educativas na estrutura, nos processos e/ou nos resultados do modelo assistencial vigente, foram destacadas a falta de sedimentação dessas atividades no plano terapêutico, a ausência de planejamento integrado e participativo dessas ações e a indisponibilidade de recursos físicos (local) e humanos específicos (presença do nutricionista na Atenção Básica à Saúde) necessários à qualificação dessas ações.

Apreendeu-se desses discursos que, a despeito do atual estágio em que se encontra a reflexão sobre os modelos e abordagens mais significativas para a educação e a promoção em saúde, em termos concretos, ainda se depara com impedimentos relativos à estruturação, organização e operacionalização do Sistema para uma oferta mais qualificada dos serviços de saúde.

Desse modo, a qualificação das ações educativas no âmbito da Atenção Básica à Saúde prescinde de um conjunto de investimentos político-institucionais e administrativos relativos tanto à reorientação teórico-conceitual do modelo de atenção à saúde, quanto aos investimentos para equipar e organizar os serviços com recursos físicos, materiais e, principalmente, de pessoas, humana e tecnicamente qualificadas, sem os quais o aprimoramento dos processos educativos e comunicacionais em saúde não se realiza.

Nesse caminho, deve-se, ainda, garantir a aproximação do discurso das políticas nacionais de saúde, alimentação e nutrição e de educação permanente em saúde, geradas no campo acadêmico e científico da saúde pública, com as esferas estaduais e, principalmente municipais-locais, em que o discurso político se concretiza e as práticas de saúde são re-significadas.

Recomenda-se, com base neste estudo, a inclusão de análises qualitativas no processo de avaliação e qualificação das ações educativas em saúde, mesmo considerando os vieses a elas inerentes, por possibilitarem maior valor explicativo aos aspectos subjetivos que envolvem os espaços e os sujeitos dessas ações. 


\section{REFERÊNCIAS}

ABREU, S.S.; MARTINS, C. Manual do Educador. Curitiba: Nutroclinica, 1997.

ALMEIDA-PITITTO B. Impacto de um programa de intervenção no estilo de vida sobre o perfil de risco cardiometabólico da população nipo-brasileira de alto risco. [Tese de Doutorado]. São Paulo. Faculdade de Saúde Publica, Universidade de São Paulo, 2009.

ALVES, V.S. Um modelo de educação em saúde para o programa de saúde da família: pela integralidade da atenção e reorientação do modelo assistencial. Interface- Comunic. Saúde Educ., v.9, n.16, p.39-52, 2005.

AMBROSIO, G.B. et al. Effects of interventions on community awareness and treatment of hypertension: results of a WHO study. Bulletin of the World Health Oraganization, Geneva, v.66, n.1, p.107-113, 1988.

ANDERSON, R., KIRK, L. Methods oj Improving Patient Compliance in Chronic Disease States. Archives of Internal. Medicine, v.142, p.1673-1675, 1982.

APPEL, L.J. et al. A clinical trial of dietary patterns on blood pressure. New England Journal of Medicine, v.336, p.1117-1124, 1997.

ARAÚJO, D.R.D. Como transcrever sua entrevista: técnica de editoração da transcrição de entrevista em pesquisa de abordagem compreensivista. Psico, v.32, n.1, p. 147-157, 2001.

ARAUJO, R.B. et al. Avaliação do cuidado prestado a pacientes diabéticos em nível primário. Rev. Saúde Pública [online], v.33, n.1, p. 24-32, 1999. ISSN 0034-8910. Disponível em:

<http://www.scielo.br/pdf/rsp/v33n1/0020.pdf>. Acesso em: 10 jan. 2011.

ARAUZ, A.G. et al. A community diabetes educational intervention at the primarycare level. Rev Panam Salud Publica, Washington, v.9, n.3, p.145-153, 2001.

ARY, D. V. et al. Patient perspective on factors contributing to nonadherence to diabetes regimen. Diabetes Care, v. 9, n. 2, p. 168-172, 1986.

ASSUNCAO, M.C.F. et al. Atenção primária em diabetes no Sul do Brasil: estrutura, processo e resultado. Rev. Saúde Pública [online], v.35, n.1, p. 88-95, 2001. ISSN 0034-8910. Disponível em: 〈http://www.scielo.br/pdf/rsp/v35n1/4141.pdf〉 Acesso em 23 jan. 2011.

BARDIN, L. Análise de conteúdo. Lisboa: Edições 70, 1977

BARRETO, M.L.; CARMO, E.H. Padrões de adoecimento e de morte da população brasileira: os renovados desafios para o Sistema Único de Saúde. Ciênc. saúde coletiva, v.12, suppl., p.1179-1790, 2007.

BOING, A.C; BOING, A.F. Hipertensão arterial sistêmica: o que nos dizem os sistemas brasileiros de cadastramento e informações em saúde. Rev Bras Hipertens, v.14, n.2, p. 84-88, 2007. 
BOOG, M.C.F. Educação nutricional em serviços públicos de saúde. Cadernos de Saúde Pública, v.15, s.2, p. 139-147, 1999.

Educação nutricional: por que é para quê? Artigo. Jornal Unicamp. Universidade Estadual de Campinas. 2 a 8 de agosto de 2004. Disponível em: <http://www.unicamp.br>. Acesso em 22 set. 2006.

Educação Nutricional: passado, presente, futuro. Revista de Nutrição da PUCCAMP, Campinas, v.10, n.1, p.5-19, 1997.

BRASIL. Ministério da Saúde. Plano de Reorientação da Atenção à Hipertensão Arterial e ao Diabetes Mellitus: manual de hipertensão arterial e diabetes mellitus. Brasília, 2001.

Ministério da Saúde. A vigilância, o controlo e a prevenção das doenças crônicas não-transmissíveis: DCNT no contexto do Sistema Único de Saúde brasileiro. Brasil. Ministério da Saúde - Brasília: Organização Pan-Americana da Saúde, 2005.

Lei 11.346, de 15 de setembro de 2006. Cria o Sistema Nacional de Segurança Alimentar e Nutricional - SISAN com vistas em assegurar o direito humano à alimentação adequada e dá outras providências. Diário Oficial da União, Brasília, DF, 10 de set. 2006a. Disponível em:

<https://www.planalto.gov.br/ccivil_03/_Ato2004-2006/2006/Lei/L11346.htm.>.

Acesso em 20 jan. 2011.

Ministério da Saúde. Secretaria de Atenção à Saúde. Departamento de Atenção Básica. Política nacional de atenção básica. Brasília, 2006b. (Série A. Normas e Manuais Técnicos) (Série Pactos pela Saúde 2006, v.4)

Ministério da Saúde. Secretaria de Vigilância em Saúde. Política nacional de promoção da saúde. Brasília: Ministério da Saúde. 2006c. (Série B. Textos Básicos de Saúde) (Série Pactos pela Saúde 2006, v.7).

Ministério da Saúde. Secretaria de Gestão Estratégica e Participativa. Departamento de Apoio à Gestão Participativa. Caderno de educação popular em saúde. (Série B - Textos Básicos em Saúde). Brasília: Ministério da Saúde, 2007.

Ministério da Saúde. Secretaria de Atenção Básica. Departamento de Atenção Básica. Política nacional de alimentação e nutrição. 2. ed. rev. (Série B Textos Básicos de Saúde). Brasília: Ministério da Saúde, 2008.

Ministério da Saúde. Secretaria de Atenção Básica. Departamento de Ações Programáticas Estratégicas. Diretrizes do NASF - Núcleos de Apoio a Saúde da Família. Série A. Normas e Manuais Técnicos. Cadernos de Atenção Básica, n.27. Brasília, 2009a.

Ministério da Saúde. Secretaria de Gestão do Trabalho e da Educação na Saúde. Departamento de Gestão da Educação em Saúde. Política nacional de educação permanente em saúde. Brasília: Ministério da Saúde, 2009b. (Série B. Textos Básicos de Saúde) (Série Pactos pela Saúde 2006, v.9). 
BOTELHO, R.; DUDRAK, R. Home Assessment of Adherence to long-term Medication in the Eldery. The Journal of Family Pratictive, v.35, p.61-64, 1992.

CABRERA-PIVARAL, C.E. et al. Efectos de una intervención educativa sobre los niveles plasmáticos de LDL-colesterol en diabéticos tipo 2. Salud Pública de México, v.43, n.6, p.556-3562, 2001.

CANDEIAS, N.M.F. Conceitos de educação e de promoção em saúde: mudanças individuais e mudanças organizacionais. Rev. Saúde Pública [online], v.31, n.2, p.209-213. ISSN 0034-8910. Disponível em: <http://www.scielosp.org/pdf/rsp/v31n2/2249.pdf> Acesso em 13 jan. 2011.

CERVATO, A.M. et al. Bases teóricas para a prática da educação nutricional. Nutrição clínica. Rev. Nutrição em Pauta, n.67, 2004. Disponível em: <http://www.nutricaoempauta.com.br/lista_artigo.php?cod=45>. Acesso em: 20 out. 2006.

CHOR, D. et al. Doenças cardiovasculares: comentários sobre a mortalidade precoce no Brasil. Arquivos Brasileiros de Cardiologia, São Paulo, v.64, n.1, p.15-19, 1995.

COLOMBO, R.C.R.; AGUILLAR, O.M. Estilo de vida e fatores de risco de pacientes com primeiro episódio de infarto agudo do miocárdio. Rev.latinoam.enfermagem, Ribeirão Preto, v. 5, n. 2, p.69-82, abril, 1997.

DANSINGER, M.L. et al. Comparison of the Atkins, Ornish, Weight Watchers and Zone Diets for Weight Loss and Heart Disease Risk Reduction. A Randomized Trial. Journal of American Medical Association, v.293, p.43-53, 2005.

EPSTEIN L.H.; PALUCH R.A.; GORDY C.C. et al. Decreasing sedentary behaviors in treating pediatric obesity. Arch Pediatr Adolesc Med, v.154, p.220-226, 2000.

FLACK, J.M. et al. Cardiovascular disease costs associated with uncontrolled hypertension. Manage Care Interface, New York, v.15, n.11, p.28-36, 2002.

FORTES, P. Ética e Saúde. São Paulo. EPU, 1998.

FONTANA, A.; FREY, J.H. The interview - from structured questions to negociated text. In: DENZIN, N.; LINCOLN, Y. Handbook of qualitative research. $2^{\text {nd }}$ ed. Thousand Oaks, CA: Sage Publications, 2000. p.645-671.

FONTANELLA, B.J.B. et al. Amostragem por saturação em pesquisas qualitativas em saúde. Cad. saúde publica, v.24, n.1, p.17-27, 2008.

FREIRE, P. Extensão ou comunicação. Rio de Janeiro: Paz e Terra, 1972.

GARATTINI, L. et al. Direct medical costs unequivocally related to diabetes in Italian specialized centers. The European Journal of Health Economics, Berlim, v.5, n.1, p.15-21, 2004.

GOLDMAN, L.; COOK, E.F. The decline in isquemic heart disease mortality rates. An analyses of the comparative effects of medical intervention and changes in lifestyle. Ann. Intern. Med., v. 101, n. 6, p.285-92, 1984. 
GONDIM, S.M.G. Grupos focais como técnica de investigação qualitativa: desafios metodológicos. Paidéia, v.12; n.24, p.149-161, 2003.

GONZÁLEZ, R.G. et al. Comunicación y educación interativa em salud y su aplicación al control del paciente diabético. Revista Panamericana de Salud Publica, Washington, DC, v.2, n.1, p.32-36, 1997.

GORDILHO, A. et al. Desafios a serem Enfrentados no Terceiro Milênio pelo Setor Saúde na Atenção ao Idoso. Rio de Janeiro: Universidade Aberta da Terceira Idade. Universidade do Estado do Rio de Janeiro, 2000.

GORTMAKER et al. Social and economic consequences of overweight in adolescence and young adulthood. N Engl J Med.; v.329, p.1008-1012, 1993.

GRUESSER, M. et al. Implementation of Structured Teaching and treatment Program for Patients with Hypertension in Ambulatory Care. Diabetes, New York, v.45, p.279A, 1996. Supplement 2.

HAJJAR, I.; KOTCHEN, T. Regional variations of blood pressure in the United States are associated with regional variations in dietary intakes: the NHANES-III data. Journal of Nutrition, v.133, n.1, p. 211-214, 2003.

HERNANDES-RONQUILLO et al., Factors associated whith therapy noncompliance n type-2 diabetes patients. Salud pública de México, v.45, n.3, p.191-197, 2003.

HILL, et al. Obesity and the environment: where do we go from here? Science, v. 299, n. 5608, p.853-855, 2003.

HILL, J.O.; PETERS J.C. Environmental contributions to the obesity epidemic. Science, v.280, p.1371-1374, 1998.

HOUAISS, A; VILLAR, M.S. Minidicionário Houaiss da língua portuguesa. 3 ed. Ver e aum. Rio de Janeiro: Objetiva, 2009.

IBGE - Instituto Brasileiro de geografia e Estatística. Dados do Censo 2010 publicados no DOU em 04/01/2010. 2010. Disponível em: $<$ http://www.ibge.gov.br/censo2010/dados_divulgados/index.php?uf=32>. Acesso em 29 jan. 2011.

JONES, N. et al. An investigation of adult's views of the outcomes of dietary treatment. Journal of Human Nutrition \& Dietetics, v. 20, n. 5, p. 486-494, 2007.

KRUMMEL, D. Nutrição na Hipertensão. In: MAHAN, L. K.; ESCOTT-STUMP, S. Alimentos, Nutrição e Dietoterapia. 9 ed. São Paulo: Roca, 1998. p. 569-582.

LABONTE, R. Health promotion and the common good: towards a politics of practice. Critical Public Health, v.8, n.2, p.107-109, 1998.

LESSA, I. FONSECA, J. Raça, aderência ao tratamento e/ou consultas e controle da hipertensão arterial. Arq Bras Cardiol, v.68, n. 6, p.443-449, 1997.

Doenças crônicas não transmissíveis no Brasil: um desafio para a complexa tarefa da vigilância. Ciênc. Saúde Coletiva, v.9, n.4, p.931-943, 2004. 
LEFEVRE, F.; LEFEVRE, A.M.C. O discurso de sujeito coletivo: um novo enfoque em pesquisa qualitativa (desdobramentos). Caxias do Sul: Educ, 2003.

Lent, 2004, p. 59-63.

Promoção de saúde - A negação da negação. Rio de Janeiro: Vieira e

LEFÈVRE, F. et al. Discurso do sujeito coletivo, complexidade e auto-organização. Ciênc. saúde coletiva, v.14, n.4, p.1193-1204, 2009.

LIMA, R. T. et al. Educação em saúde e nutrição em João Pessoa, Paraíba. Revista de Nutrição, Campinas, v.13, n.1, p.29-36, 2000.

MARTINS, I.S. et al. Doenças cardiovasculares ateroscleróticas, dislipidemias, hipertensão, obesidade e diabetes melito em população da área metropolitana da região sudeste do Brasil: I - Metodologia da pesquisa. Rev. Saúde Pública, v.27, n.4, p.250-261, 1993.

MILLER, C. K. et al. Evaluation of a theory-based nutrition intervention for older adults with diabetes mellitus. J Am Diet Assoc, v.102, n.8, p. 1069-81, 2002.

MINAYO, M.C.S. O desafio do conhecimento: pesquisa qualitativa em saúde. São Paulo:Ed. Hucitec, 1993.

MINISTÉRIO DA SAÚDE. Secretaria de Políticas Públicas. Plano de Reorientação da Atenção à Hipertensão Arterial e ao Diabetes Mellitus. Rev. Saúde Pública, v.35, n.6, p.585-588, 2001. Informes Técnicos Institucionais.

Hiperdia: Sistema de Cadastramento e Acompanhamento de Hipertensos e Diabéticos. Disponível em: <http://hiperdia.datasus.gov.br>. Acesso em: 30 abr. 2007.

MION JR, D. et al. Hipertensão Arterial: abordagem geral. Projeto Diretrizes AMB/CFM, 2002. Disponível em: http://www.amb.org.br/. Acesso em: 01 jun. 2008.

MONTEIRO, C.A. Velhos e novos males da saúde no Brasil: a evolução do país e de suas doenças. São Paulo: Hucitec, 1995.

MOREIRA, R. O. et al. Diabetes Mellitus e depressão: uma revisão sistemática. Arq Bras Endocrinol Metab, v.47, n.1, p.19-20, 2003.

MORGAN, D. Social psychology. New York: McGraw-Hill College, 1997.

OLIVEIRA, A.M A. et al. Sobrepeso e obesidade infantil: influência de fatores biológicos e ambientais em Feira de Santana, BA. Arq. Bras. Endocrinol. Metab., v. 47, n. 2, p.144-150, 2003.

PAIVA, D.C.P. et al. Avaliação da assistência com diabetes e/ou hipertensão pelo Programa de Saúde da Família do Município de Francisco Morato, São Paulo, Brasil. Cad. Saúde Pública, v.22, n.2, p. 377-385, 2006.

PATTON, M.Q. The nature of quality inquiry. In: Qualitative research e evaluation methods. $3^{\text {nd }}$ ed. Thousand Oaks, CA: Sage Publications, 2002. p.3-29. 
PREFEITURA DE VITÓRIA. Vitória em dados. Disponível em: <http://legado.vitoria.es.gov.br/regionais/home.asp>. Acesso em: 5 de jan. 2011.

Secretaria Municipal de Saúde. Seminário Macrorregional em Saúde da População Idosa, Vitória, 2006. Disponível em:

$<$ http://portal.saude.gov.br/portal/arquivos/zip/apresentacao_vitoria.ppt.>. Acesso em 15 jan. 2008.

SALES, F. et al. O emprego da abordagem DSC (discurso do sujeito coletivo) na pesquisa em educação. Linhas, v.8, n.1, p.124-145, 2007. Disponível em:

$<$ http://www.periodicos.udesc.br/index.php/linhas/article/view/1361/1167>. Acesso em: 10 de out. 2010.

SANTOS, L. A. da S. Educação alimentar e nutricional no contexto da promoção de práticas alimentares saudáveis. Revista de Nutrição, v. 18, n. 5, Campinas, 2005. Disponível em: <http://www.scielo.br〉. Acesso em 30 set 2006.

SARTORELLI, D. S. et al. Beneficial effects of short term nutritional conselling at the primary health-care level among Brasilian adults. Public Health Nutrition, v.8, n.7, p.820-825, 2005

SCHERER, M.D.A. et al. Rupturas e resoluções no modelo de atenção à saúde reflexões sobre a estratégia de saúde da família com base nas categorias Kuhnianas. Interface - Comunic., Saúde, Educ., v.9, n.16, p.53-66, 2005.

SEVERINO, A. J. Metodologia do trabalho científico. São Paulo: Cortez, 1996.

SECRETARIA DE POLÍTICAS DE SAÚDE. Política Nacional de Alimentação e Nutrição do Setor de Saúde. Rev. Saúde Pública, v.34, n.1, p.104-108, 2000. Informes Técnicos Institucionais.

SHERMAN, A.M. et al., Adherence: characteristics and interventions: Controlled Clinical Trials, v.21, p.206-2011, 2000.

SILVA, M.V.L. Efeitos do aconselhamento dietético no tratamento da Hipertensão Arterial em hipertensos da US de Andorinhas, Vitória, ES. [Dissertação de Mestrado]. Vitória: Centro Biomédico da Universidade Federal do Espírito Santo, 2005.

SILVA, T.R. et al. Controle de diabetes mellitus e hipertensão arterial com grupos de intervenção educacional e terapêutica em seguimento ambulatorial de uma unidade básica de saúde. Saúde Soc., vol.15, n.3, p. 1801-189, 2006.

STOTZ, E. Enfoque sobre educação popular e saúde. In: Brasil. Ministério de Saúde. Secretaria de Gestão Estratégica e Participativa. Departamento de Apoio à Gestão Participativa. Caderno de educação popular e saúde. Série B. Textos Básicos de Saúde Brasília: Ministério da Saúde, 2007.p.46-57.

TANAKA, O.Y.; MELO, C. Avaliação de programas de saúde do adolescente um modo de fazer. São Paulo: EDUSP, 2001. 
TEIXEIRA, J.J.V; LEFÈVRE, F. Significado da intervenção médica e da fé religiosa para o paciente idoso com câncer. Ciênc. saúde coletiva, v.13, n.4, p.1247-1256, 2008.

TURNER, R.W.D. Coronary heart disease: the size and nature of the problem. Postgrad Med., v.56, p. 538-47, 1980.

VASCONCELOS, E.M. Educação popular: de uma prática alternativa a uma estratégia de gestão participativa das políticas de saúde. Physis. v.14, n.1, p.67-83, 2004.

WEARE, K. The contribution of education health promotion. In: BUNTON, R.; MACDONALD, G. (Eds). Health promotion: disciplines, diversity and developments, $2^{\mathrm{a}}$ e. London: Routledge, 2002, p.102-125.

YACH, D. et al. Global burden of chronic diseases. Overcoming impediments to prevention and control. Journal of the American Medical Association, v.291, n.21, p.2616-2622, 2004.

ZIMMET, Z.P. et al. Obesity, hypertension, carbohydrate disorders and risk of chronic diseases. Med. J. Aust., v.145, n.6, p.256-62, 1986. 


\section{ANEXOS}




\section{ANEXO 1: TERMO DE CONSENTIMENTO LIVRE E ESCLARECIDO}

Você está sendo convidado(a) como voluntário(a) a participar da pesquisa: Intervenção Nutricional na Atenção à Saúde de Diabéticos e Hipertensos: Avaliação e Validação de Estratégias de Educação em Saúde e Educação Nutricional

\section{A JUSTIFICATIVA, OS OBJETIVOS E OS PROCEDIMENTOS:}

O motivo que nos leva a estudar as ações educativas relacionadas à alimentação é a necessidade de aprimorar a atenção à saúde desenvolvida nas Unidades de Saúde do SUS.

A pesquisa se justifica pelo fato de que para as doenças não transmissíveis, particularmente para o Diabetes Mellitus e Hipertensão Arterial, modificações no estilo de vida com adesão a comportamento alimentar adequado são práticas que podem ser estimuladas nas ações da Atenção Básica, desenvolvidas pela Estratégia de Saúde da Família, que podem evitar progressão e complicação, reduzir as internações hospitalares, bem como a mortalidade por estes agravos.

O objetivo desse projeto é estudar a sua percepção e opinião sobre as ações e estratégias de educação nutricional realizadas durante os atendimentos na unidade de saúde, visando contribuir para a promoção de práticas alimentares adequadas.

Os procedimentos de coleta de dados serão realizados por meio de entrevistas individuais e grupais e de oficinas. Você está sendo convidado para participar do procedimento de

( ) entrevista individual que acontecerá em local e data agendados em comum acordo entre você e o pesquisador. Será realizada utilizando-se um roteiro de perguntas abertas sobre as atividades educativas desenvolvidas pelo serviço de saúde. As entrevistas serão gravadas para posterior transcrição e estudo. As respostas serão anônimas.

( ) entrevista em grupo que ocorrerão em 2 momentos, com duração de duas horas e serão realizadas nas Unidades de Saúde, em data e horário previamente acordado. Será utilizado um roteiro de questões sobre as atividades educativas 
desenvolvidas pelo serviço de saúde especificamente para indivíduos diabéticos e indivíduos hipertensos. As entrevistas serão gravadas para posterior transcrição e estudo. As respostas serão anônimas.

( ) oficina de capacitação que acontecerá em local e data agendados em comum acordo entre você e o pesquisador, realizada em três momentos, com duração de duas horas.

\section{DESCONFORTOS E RISCOS E BENEFÍCIOS:}

Este tipo de Pesquisa pode lhe trazer algum desconforto, referente, por exemplo, ao seu deslocamento até o local das atividades, à disponibilidade de seu tempo para participar das mesmas, sendo que todos os esforços serão feitos para que estes desconfortos sejam mínimos. Porém isto se justifica, pois sua participação é essencial para que os objetivos do Estudo sejam atendidos. Como usuário ou profissional de saúde do SUS, você e toda a comunidade poderão se beneficiar se a atenção à sua saúde for de melhor qualidade, formulada com a sua participação e adequada a sua necessidade e realidade.

\section{GARANTIA DE ESCLARECIMENTO, LIBERDADE DE RECUSA E GARANTIA DE SIGILO:}

Você será esclarecido(a) sobre a pesquisa em qualquer aspecto que desejar. Você é livre para recusar-se a participar, retirar seu consentimento ou interromper a participação a qualquer momento. A sua participação é voluntária e a recusa em participar não irá acarretar qualquer penalidade ou perda de benefícios.

$\mathrm{O}(\mathrm{s})$ pesquisador(es) irá(ão) tratar a sua identidade com padrões profissionais de sigilo. Os resultados da pesquisa serão apresentados para você e permanecerão confidenciais. Seu nome ou o material que indique a sua participação não será liberado sem a sua permissão. Você não será identificado(a) em nenhuma publicação que possa resultar deste estudo. Uma cópia deste consentimento informado será arquivada no Programa de Pós- Graduação da Faculdade de Saúde Pública da Universidade de São Paulo e outra na Secretaria de Saúde de Vitória. Uma terceira cópia será fornecida a você. 


\section{CUSTOS DA PARTICIPAÇÃO, RESSARCIMENTO E INDENIZAÇÃO}

POR EVENTUAIS DANOS: A participação no estudo não acarretará custos para você e não será disponível nenhuma compensação financeira adicional.

\section{DECLARAÇÃO DO (A) PARTICIPANTE}

$\mathrm{Eu}$, fui informada (o) dos objetivos da pesquisa acima de maneira clara e detalhada e esclareci minhas dúvidas. Sei que em qualquer momento poderei solicitar novas informações e modificar minha decisão se assim o desejar. $\mathrm{O}$ (a) professor(a) orientador(a) certificaram-me de que todos os dados desta pesquisa serão confidenciais.

Também sei que caso existam gastos adicionais, estes serão absorvidos pelo orçamento da pesquisa. Em caso de dúvidas poderei chamar a estudante Ana Maria Bartels Rezende o(a) professor(a) orientador(a) Ana Maria Cervato Mancuso nos telefones (27) 33256764 ou (11) 3061 7701, ramal 223 ou o Comitê de Ética em Pesquisa da Faculdade de Saúde Pública da Universidade de São Paulo, sito à Av. Dr. Arnaldo, 715, Cerqueira César - São Paulo, SP.

Declaro que concordo em participar desse estudo. Recebi uma cópia deste termo de consentimento livre e esclarecido e me foi dada a oportunidade de ler e esclarecer as minhas dúvidas.

Nome Assinatura do Participante Data

Nome Assinatura do Pesquisador Data

Nome Assinatura da Testemunha Data




\section{ANEXO 2: DISCURSO DO SUJEITO COLETIVO - MANUSCRITO 1}

\section{Questão 1}

\section{Discurso do sujeito coletivo 1.1}

"O acompanhamento que a gente faz aqui são os grupos de HiperDia mesmo, né? Uma das principais formas que a gente utiliza é a reunião de grupo. Aonde nós reunimos todos os diabéticos, todos os hipertensos, em média de 3 em 3 meses. Primeiramente são formados grupos conjuntos, sem classificação de risco destes pacientes. Depois, a gente separa os grupos de diabéticos tipo 1, tipo 2 e os hipertensos leve, moderado e grave. Os de alto risco são encaminhados para o acompanhamento médico, além do grupo. São grupos que a gente conhece a realidade de cada um. E pra cada grupo a gente faz uma orientação específica. Porque não é igual pra todo mundo, né? Tudo acontece no mesmo dia. Ao aferir os sinais vitais já fazemos a orientação individual, alertando para os riscos das complicações, caso ele não mude os hábitos alimentares. Pedimos para que fale como foi a sua alimentação hoje, na semana, e aí a gente avalia se eles usaram mais carboidratos, doces... Nos grupos o primeiro momento nosso é uma conversa. É sobre assuntos diversos. A gente não fala só de hipertensão e diabetes. Eles recebem orientações do educador físico, de orientações nutricionais pelo médico e enfermeiro e os encaminhamentos. A gente orienta sobre alimentação, sobre medicação, sobre exercício. O médico também orienta da forma dele, a gente orienta da nossa forma. Não é uma palestra. É uma orientação mesmo. A gente faz ações, fala o que é cada coisa, o que as pessoas devem fazer pra tá controlando, o que pode ser utilizado no controle, no tratamento da hipertensão e do diabetes mesmo, entendeu? São feitas através de ações educativas mesmo, na comunidade ou na própria unidade de saúde, né? E logo após tem a consulta. Este paciente ele vai passar pela consulta de enfermagem e pela consulta médica. Todos eles. A consulta de enfermagem ela é uma consulta total de orientação. E a gente foca muito sobre a questão da alimentação até de uma forma individualizada mesmo, ta? A gente cobra as orientações já feitas, vê quais não foram cumpridas... Tem até um script, com a orientação de dieta, né? Eu tenho até um papel mais ou menos explicando. Uma "dietinha". Não é bem uma dieta pronta, mas o que ele deve evitar, como fazer uma refeição no almoço, comer massa, não comer massa, colocar hortaliça, a questão da carne, enfim, é uma consulta de orientação mesmo. Aí, no momento seguinte é a consulta com o médico. A cultura deles é para a consulta médica, que acontece nos grupos. É o dia que ele vai renovar a receita dele, que ele vai fazer um exame. Nas datas nacionais, estaduais, é feita uma programação especial para 
os grupos. Que é quando chega assim, a semana do hipertenso... Nós temos folder, cartaz, que é para fazer o dia D. Aí chega à vontade. No PSF não tem outra coisa a fazer, a maioria das coisas é a ação preventiva."

\section{Discurso do Sujeito Coletivo 1.2}

"Eu acho que a gente faz educação em saúde de uma forma geral. Em todos os atendimentos, visitas, consultas é feito esta orientação. A pessoa quando chega a Unidade com o diagnóstico vai primeiramente para o médico. Então elas recebem uma prescrição médica, e até mesmo para que a medicação seja liberada elas têm que fazer um cadastro no programa Hiperdia, do Ministério da Saúde. O paciente vai com a receita na farmácia, eles liberam o medicamento só para 10 dias, e pedem para agendar a consulta com o enfermeiro para a gente fazer o cadastro. Neste dia, a gente preenche toda uma ficha, faz a avaliação deles: do peso, da PA, da glicemia capilar, o índice de massa corpórea. Além de fazer o cadastro a gente aborda o conhecimento da pessoa a respeito disso. Dá toda a orientação do que é a doença, quais são as consequências que estas doenças podem estar trazendo, quais são os fatores que levam a pessoa estar desenvolvendo e também como que é o tratamento que ele vai ter que fazer sempre, né? Faz todas as orientações de hábitos de vida e hábitos alimentares também, todas que a gente acha cabivel nesta consulta de enfermagem, né? Fala do tratamento medicamentoso, da importância dele fazer o uso correto, de fazer um controle da pressão pelo mapa. Fala do tratamento não medicamentoso também. Aí a gente aborda a adequação da alimentação, a importância, a atividade física, adequar o peso corporal. Todas estas orientações são feitas no cadastro e a gente vê a possibilidade dele estar participando do grupo. E inclui esta pessoa num grupo de atendimento, de orientação, que a gente faz na comunidade, que é esse grupo do Hiperdia. Aí, quando ele vai para o grupo, primeiro a gente faz uma reuniãozinha onde aborda vários temas relacionados à alimentação, atividade física, não só isto, mas outras coisas. A gente faz o atendimento individual e faz orientação aos grupos também. Toda vez que tiver uma reunião de hipertenso e diabético existe uma palestra para a orientação deste grupo. Cada semana é um grupo diferente por área. Nem todos aceitam participar dos grupos, alguns preferem estar agendando as consultas, aqui no posto. E quando eles vêm também nós orientamos sobre esta questão da alimentação. Aí também comentamos: qual é a sua alimentação? Como é que você se alimenta? Qual é a comida que você come? Ele vai falando. Aí a gente vai falando com eles qual o melhor para eles. Na hora da visita domiciliar também nós podemos fazer orientação sobre isto e tem o professor que orienta sobre o exercício. 
A gente fala o que julga que é o melhor. Toda vez que a gente faz a visita domiciliar é claro que a gente reforça a abordagem educativa, em relação a mudança de comportamentos, né? E essa recomendação é pra todos. A alimentação, como ela ta indo, a gente mede a pressão, a glicose, a glicemia deles, né? Então, sempre que tem essa visita é uma oportunidade também. De tempos em tempos a gente tem alguma coisa aqui na unidade de ação educativa: às vezes a gente faz um cantinho da saúde. A gente estava com os acadêmicos de Nutrição que faziam atividades ali fora com os pacientes. Então assim, de tempos em tempos acontece alguma coisa de coletivo. É assim que a gente tem feito."

\section{Discurso do sujeito coletivo 1.3}

"Além do grupo a gente faz as visitas domiciliares, que acontece na casa. É para ser mensal, só que a gente não dá para cobrir todos, infelizmente não dá. A gente faz com a enfermeira, com a médica, com a auxiliar de enfermagem, pra ta acompanhando eles, vendo como é que ta, se eles tão fazendo a medicação certo, entendeu? E no momento eles também passam a orientação, aí a gente vai aprendendo um pouquinho. Eles vão aprendendo e a gente vai aprendendo também. E as orientações feitas por nós agentes de saúde, aonde nós trabalhamos com todas as orientações em termos de alimentação né? Olha como ta a alimentação dele, o remédio também, a gente confere se ta tomando o remédio correto. Orientamos em termos da física também, que é pra ta fazendo a caminhada se for necessário. Isso depende do médico também certo? E a gente trabalha com essa prevenção, orientação, muita, muita prevenção... A gente bate, bate, bate na mesma tecla. Às vezes a gente se torna chata, mas é uma coisa que a gente se torna repetitiva. Basicamente isso."

\section{Questão 2}

\section{Discurso do sujeito coletivo 2.1}

"Da equipe, todo mundo se envolve. No grupo a gente sempre tem fixo: enfermeiro, médico, auxiliar de enfermagem e agente comunitário de saúde. Todos esses fazem esse acompanhamento na comunidade. A enfermeira é quem dá a palestra. $O$ agente ta começando. Ele ainda não ta assumindo a educação, certo? Ele fica mais presente, mas ele não faz ainda a oficina, né? Sempre tem que ta ou o enfermeiro ou o médico dando orientações, e logo após tem a consulta. E tem as visitas domiciliares, que a gente faz com a enfermeira, com a médica, que a gente faz com a auxiliar de enfermagem. Às vezes a gente conta também com a ajuda de outros profissionais, que não são só da equipe, que 
atende a várias equipes. A gente tem a assistente social, a psicóloga e tem o educador físico. E o dentista, né? Agora é até um procedimento novo, com a orientação que eles tem em relação aos cuidados com a boca, com o câncer de boca, a avaliação é de seis em seis meses. Excepcionalmente o farmacêutico. Ela é uma peça fundamental, não é a mais importante, mas ela é muito importante. Não está sempre presente, porque ela é uma e a Unidade é grande, né? Sete equipes, ela tem que estar em todas. Nós tamos querendo agora retornar com outros colaboradores: a fisioterapeuta, que ela já faz um trabalho interessante também. Dependendo da dificuldade que a gente encontrar na área, a gente pode ta chamando eles também. Quando a gente tem a reunião de equipe, a gente sempre ta convidando um ou outro e eles participam. Mas depende muito da demanda da Unidade. Específico de hipertensão e diabetes é mais o educador físico. A gente referencia muito para o educador físico, que é o que a gente tem na Unidade. A gente costuma fazer isto: quando ele chega pra poder fazer o cadastro, na primeira consulta a gente orienta: faz alguma atividade física? Não? A gente orienta: olha, vai fazer o controle primeiro, e assim que o médico tiver liberando ou mesmo antes do médico liberar é só passar por um atendimento com o educador físico para fazer uma avaliação, e depois que ele tiver liberado vai ver qual a atividade mais adequada para ele. Quando não tinha o professor a atividade física era muito difícil. Agora pra nós melhorou mais, porque tem o professor também. A gente convida: ó, a gente vai ta com um grupo hoje, será que você poderia bater um papo com essas pessoas, passar algumas orientações? E ele participa também, entendeu? Ele fala qual é o serviço que ele presta diante daqueles hipertensos e diabéticos, o que que o hipertenso e diabético pode fazer pra ter qualidade de vida dentro da questão das atividades. Conversa com ele e fala sobre a atividade que tem que fazer, da caminhada, do exercício físico e qualquer coisa ele encaminha pra hidroginástica. Eles até cobram se ele não puder ir. A gente recebe também o acadêmico de nutrição, quando vem de fora. Sempre que possível, né? A gente procura fazer o contato pra esse reforço, pra passar em oficinas as orientações nutricionais. A gente sai muito com eles, nas visitas. Eles orientam também da forma como eles podem. Fala sobre a importância das dietas, medicação. Então eles também ajudam muito nosso trabalho. Há essa oportunidade também. Mas a gente não conta com eles em todas, né?"

\section{Discurso do sujeito coletivo 2.2}

"Todos os da equipe participam de alguma forma, mas nas ações educativas, na verdade, quem está mais envolvido é o enfermeiro e o agente de saúde. Na recepção eles vão fazer o primeiro acolhimento, agendar a consulta, então ele vai passar pelo médico, o médico 
vai encaminhar para a farmácia, na farmácia eles vão orientar também, então o farmacêutico, o pessoal da farmácia também está envolvido, faz a orientação da medicação. Depois que passa pela farmácia vai encaminhar para o grupo, no grupo ele vai passar também pelo médico, enfermeiro, professor de educação física, os agentes de saúde e auxiliares de enfermagem. Pelo auxiliar de enfermagem, menos, né? Mas quem fala mais é o enfermeiro. $O$ agente de saúde fica junto, às vezes ele dá algumas orientações. A gente estava até querendo organizar que cada um falasse um dia, porque quando você fala você aprende, né? Até para você estudar, para você falar com eles. Só que eles estavam receosos, recatados em fazer isto. A gente está fazendo algumas mudanças, mas a princípio é só o enfermeiro e o agente de saúde."

\section{Discurso do sujeito coletivo 2.3}

"O básico que o paciente tem é na consulta. É mais a enfermeira e eu que oriento na consulta médica. E a gente se organiza da seguinte forma: normalmente a gente faz o grupo na comunidade e o primeiro momento nosso é uma conversa. A gente não fala só de hipertensão e diabetes. No caso a dengue, a gente fala sobre a dengue. E a gente foca muito sobre a questão da alimentação até de uma forma individualizada mesmo, ta? Em todos os grupos e individualmente ele vai passar primeiro pela consulta de enfermagem e depois pela consulta médica. Todos eles. A consulta de enfermagem ela é uma consulta total de orientação. E é basicamente sobre a alimentação, do pouco sal, da gordura, o diabetes. A gente cobra as orientações já feitas, vê quais não foram cumpridas. Tudo acontece no mesmo dia."

\section{Questão 3}

\section{Discurso do sujeito coletivo 3.1}

"Com certeza, contribui muito. A gente vê a mudança, os efeitos, no dia a dia, no cuidado que eles têm na saúde deles. Melhora porque eles ficam aprendendo. Tem muita diferença, porque aquele que vem ao grupo eles parece que tem uma noção maior de como é o acompanhamento e o que eles têm que fazer pra eles se controlar. Tem coisas que eles às vezes num sabe, por exemplo, assim, o diabético, ele tem que enxugar o pé direitinho, ter cuidado com a unha, ter a toalhinha própria para enxugar o pé, então eles não sabe. Dependendo da pessoa a pessoa não teve tanta orientação, entendeu? E quando começa a participar dos grupos, eles são bem orientados e acaba tendo conhecimento de fatores que eles não tinham antes e vão tirando as dúvidas. Aí a importância da reunião é essa. Porque é uma informação passada pra todo mundo e 
discutida lá dentro, entendeu? A gente não tem um estudo formal, mas a gente vê na pratica este tipo de mudança de comportamento. Quando a gente fala, por exemplo, da dispensação do material de insulina, que a gente fala do lixeiro, tal, e aí a gente vê. Esta semana mesmo eu vi paciente trazendo nas garrafas pet para a gente dispensar. Uma paciente chegou para mim e falou que ela mudou a alimentação, mostrou que a dieta lá na casa dela, abriu a geladeira para mostrar o que ela tem na geladeira: ela tem verdura, tem folhas. Ela mostrou o prato dela, quando nós fomos lá era uma e meia, ela estava almoçando ainda, ela mostrou o que ela estava comendo. Então ela segue isto aí. Olha, quando na verdade, diretamente é quando a gente ouve assim: - Olha, se você não falasse isso para mim, eu não dava importância. Isso aconteceu comigo, com uma pessoa que ele apenas tinha hipertensão, não era diabetes. Aí tava perdendo peso. Então eu comecei a conversar com ele. Passei os sinais de diabetes, disse para ele o que acontece. E aí ele falou assim: - Mas eu tô perdendo peso porque estou fazendo atividade física, só. Aí, ele urinando várias vezes (sinais do diabetes), então ele decidiu procurar um médico. Eu penso que é importante sim. Eu penso que isto é um benefício. A própria motivação. É válido, é bom, com certeza!"

\section{Discurso do sujeito coletivo 3.2}

"Colabora, mas para uns, para outros não. Quando a gente conversa a gente tem este parecer individualizado e juntando o que a gente observa a gente sente uma mudança sim. Não de 100\%, né? A gente tem contribuído para isso. Quem participa mesmo, ele faz uma caminhada, vem a consultas. Quando a médica pede para que ele faça direito, ele faz direitinho. Tem uma senhora da minha área que tem 82 anos. Reclamava que tinha uma dor no joelho, na medida que o professor entrou no nosso grupo, ela começou a participar. Não tem aquela na água (hidroginástica)? Então, ela começou a fazer. Agora ta andando, ta indo participar da igreja, do grupo da terceira idade, entendeu? Então você vê: uma senhora de oitenta anos, fazendo isso e fazendo curso daquele negócio que enxuga prato. Muitas pessoas mudam mesmo os hábitos de vida. Tem gente que nem fazia exercício físico, passou a fazer. Tem gente que nem tomava o remédio direito agora já toma, já ta mais controlado. A dieta não fazia agora já faz. As pessoas tão pensando mais sobre a qualidade de vida que ela quer para ela no futuro. Para alguns melhora o autocuidado, o conhecimento. Só que nem todos consegue. Uns têm dificuldades mesmo de mudar o hábito. Eles mesmo fala: não consigo. Tem os rebeldes, né? Que não aderem, que a gente não consegue, apesar da gente falar, falar, mas eles não seguem. Imagine que você encontre 20\%, 25\% dos pacientes que querem viver desregradamente, querem 
aproveitar, querem comer, querem fazer de tudo, não segue a alimentação. Tem muitas que não seguem, porque não tem a informação, não sabem as consequências que aquela doença pode trazer para ela no futuro. Não sabe porque não pode comer sal. Como é que ele vai agir no organismo? Igual, agora nós descobrimos uma que tem diabetes, é hipertensa e hoje já conversou com a enfermeira. A enfermeira já fez as recomendações. Daí, como o caso dela está pouquinho, eu acho que ela descobriu agora, ela já vai seguir. O marido dela não tinha, agora tem. E ele é um acamado, ficou acamado há pouco tempo e a doutora descobriu que ele é hipertenso, é diabético. Esse paciente, ele teve sequela. E agora apareceu nela. A família todinha. Tem um irmão dele que é hipertenso, a cunhada dele é hipertensa, então a maioria da família. Eles agora, infelizmente, tão seguindo esta regra, e ai os que não vinha na reunião procuraram a gente aqui essa semana. Eu fiquei feliz por isso. Inclusive teve uma (outra pessoa) também teve AVC, que teve um derrame né? E teve sequela. Ela veio aqui, a sogra veio. Ai o enfermeiro foi pegar o prontuário dessa paciente, foi mostrar pra ela: - Ué?! Que que ta acontecendo? Então viu que ela estava sem acompanhamento. Ela negligenciou sua saúde também. Infelizmente, às vezes num tinha que ser dessa forma né? Mas às vezes a gente só conserta caindo. A gente faz a parte da gente, mas depende do usurário. Acho até interessante isso, entendeu? Porque ai que é a gente vê que o nosso trabalho funciona. Então alguns casos assim estão acontecendo. Isso ta servindo até de exemplo pra comunidade, que está assim reforçando em cuidar da sua saúde. Então eu acho que é isto mesmo: a orientação tem esta função, além de informar. Olha, eu acho que sem orientação seria muito pior."

\section{Discurso de sujeito coletivo 3.3}

"Eu não vejo resultado tão significativo assim, entendeu? Num vejo as pessoas mudando muito as rotinas delas, como nessa questão que eu oriento, nas atividades físicas, mudança de orientação nutricional. Tivemos umas poucas conquistas, pessoas que se sensibilizou, comendo mais frutas, legumes, comendo de três em três horas, etc. Não são muitas, são poucas. A maioria dos pacientes não faz uma dieta adequada. Por mais que você fale, vai atrás dele, busca, trás tudo de novo, então a gente fica é nessa luta! A gente fica até desanimada. Na verdade, a maioria só vem interessado mesmo no que? Interessado na consulta e na medicação, entendeu? Às vezes as pessoas não querem ouvir mais, entendeu? - Ah, eu já sei. Eu sei que eu tenho que comer fruta e verdura e legumes, evitar gordura, evitar sal, evitar o açúcar. Então, por esse motivo é que ele acha que já sabe, não precisa ficar vindo à reunião. Às vezes a reunião para ter a fala é 
marcado às sete horas e a consulta começa a partir das oito, aí o que acontece: - Já que a consulta é às oito horas, eu vou chegar às oito, eu não vou vir aqui ouvir as coisas que eu já sei. Então, chega às oito. Então o mais importante é pegar o remédio, o exame, do que ele mesmo se responsabilizar pela saúde dele, mudando hábitos de vida. Nós temos muitos pacientes rebeldes, que nós estamos batendo naquela tecla, estamos sempre orientando, conversando, falando mesmo que os pacientes faltam consulta, medicação chega tomando errado, num toma, esquece de tomar. O diabético então é o mais rebelde de todos. Você orienta, orienta, mostra, senta explica e é assim. Não sei o que passa pela cabeça deles. É um paciente muito dificil de aderir a tratamento novo."

\section{Questão 4}

\section{Discurso do sujeito coletivo 4.1}

"Eu acho o principal acompanhamento que a gente faz aqui são os grupos de hiperdia mesmo, né? Acredito que o grupo é um espaço que você consegue fazer um trabalho de formiguinha um pouco melhor. A Unidade é um espaço que tem uma demanda muito grande, que é focado na maioria das vezes na consulta médica, então o espaço do grupo proporciona um pouco mais de diálogo. Apesar da gente ter um bom atendimento individual, o atendimento em grupo é diferenciado por que você dá espaço para as pessoas interagirem, compartilharem experiência, então tem esta troca. Ás vezes na experiência do outro a pessoa vai se ver, vai perceber uma prática que ela pode estar adotando também e que vai ser boa. Acho que quando a gente está numa consulta individual a gente tem dificuldade de ouvir mais o usuário. Quando você está num espaço como este, que você proporciona o dialogo, o outro falando, acho que eles se fazem entender. A gente falando, a gente tem um linguajar diferenciado para este espaço, sai um pouco do técnico e ai a gente compreende mais aquilo que ele precisa. A gente profissional de saúde muitas vezes tem dificuldade de compreender aquilo que eles precisam. Quando a gente está no espaço do grupo tudo vira uma conversa, porque é um espaço menos tenso, menos formal. Os grupos de hipertensos e diabéticos é muito importante, uma vez que a gente faz o trabalho lá na comunidade. Por quê? Porque a maioria das pessoas dos grupos de hipertensos e diabéticos são pessoas idosas. Então quanto mais a gente tá próximo deles, pra eles é melhor. Facilita ainda mais. Eles nem vem na Unidade, é na comunidade mesmo. Ai vai enfermeiro, médico, auxiliar, dentista entendeu? Todos fazem esse acompanhamento na comunidade, todos esses acompanha no dia do grupo dele. Então pra eles a gente ta próximo da comunidade, é sempre bom. Quando a gente ta com o grupo lá na comunidade a frequência é bem maior que aqui na 
Unidade de Saúde. Agora, quando a gente fala pra vir pra unidade, ai já costuma ter uma falha, por quê? Porque eles acham que tem que chegar aqui, passar por recepção, passar pra aferir a pressão, depois ficar aguardando, entendeu? Aqui a espera é maior. E lá na comunidade não, lá na comunidade é mais rápido. Às vezes as pessoas, numa época dessas, ta num calor prá descer, pra vir aqui, prá subir de novo, às vezes a pessoa prefere não vir. Aí termina perdendo, falta o remédio, ele vai vir num dia que não é dia de grupo. Isso aí atrapalha o planejamento do trabalho, entendeu? Eu acho muito importante para eles ter grupo na comunidade."

\section{Discurso do sujeito coletivo 4.2}

"Para mim, de todas as ações a que eu considero a mais eficaz é quando a gente está com o paciente, na consulta. A orientação mais individualizada, baseada na pessoa mesmo, que a gente orienta diretamente, vê quais são as questões de cada um, individualmente. No início o momento de orientação ficava muito dentro da questão do grupo. E aí a gente viu que a gente tem melhores resultados se a gente individualizar esta atenção e ter este tempo para cada paciente. Porque a gente vê o paciente repetidamente durante o ano. Então você sabe o que você tem que reforçar de orientação. Você sabe que tem que questionar para ele: - E aí? Você iniciou aquela atividade que a gente tinha combinado? Como é que ta a alimentação? E a dieta, você tem dificuldade? Se a gente vê que o paciente tem duvida a gente repete tudinho pra ele. Até ele falar pra gente o que ele tem que fazer. Usamos de recurso para sensibilizar. Damos até uma de nutricionista: falamos da alimentação, da caminhada, que não adianta seguir a prescrição médica, medicamento, é preciso lazer, exercitar o cérebro. Se tem que ir lá (no grupo) eles só vão porque tem uma consulta junto. Eles ficam esperando acabar a conversa, para depois ir pro médico. Eles não estão com o objetivo na prevenção. Eles estão querendo a consulta médica. É mais no curativo que no preventivo. Então eu acho que é na consulta mesmo, de enfermagem, a consulta médica. Elas abordam as questões educativas. Eu acho que é mais eficaz.

\section{Discurso do sujeito coletivo 4.3}

Eu acho assim, que no grupo eles só vêm com a intenção de consultar, entendeu? Os grupos têm resultado bom, mas na visita também. Quando chega na casa e estava tudo errado na alimentação, por exemplo: batata, arroz, etc. Aí a gente orienta. Quando a gente retorna a pessoa fala: Oh, eu não to comendo mais isso, eu cortei isso... Em todas as visitas isso é falado, né? A alimentação, como ela ta indo, a gente mede a pressão, a 
glicose, a glicemia deles, né? Então eu acho que as visitas domiciliares, elas é bem melhor pra você ta orientando.

\section{Discurso do sujeito coletivo 4.4}

Não acho que tem uma que é mais importante. Na verdade eu acho que elas vão se complementando. Entendeu? A equipe faz reunião educativa com os grupos de hipertensão e diabetes, onde ela passa o sistema de nutrição, alimentação saudável, os cuidados de nutrição. Eles vão aprendendo e a gente vai aprendendo também. Tem a visita domiciliar, que a gente faz com a enfermeira, com a médica, com a auxiliar de enfermagem. Tem o orientador físico que também vai lá, que vai ser questionado sobre as mesmas coisas e vai ser reforçado em cada atendimento sobre a atividade que elas têm que fazer, da caminhada, do exercício físico. Eles recebem aqui, passam na consulta médica, recebem de novo. A gente fica batendo sempre na mesma tecla até entrar na cabeça deles. Tem que ser em equipe, tem que ter jogo porque muitas vezes o médico fala o paciente num ouve, muitas vezes a gente fala e os outros reforçam. Quando a gente é coerente a gente faz uma mesma orientação. Tudo é válido para eles. Todos os momentos são produtivos. Vai agora do paciente pegar o habito, entendeu? Porque a parte mais difícil é mudar o habito da pessoa.

\section{Discurso do sujeito coletivo 4.5}

"Acredito que o recurso que a gente tem de só ficar falando, e às vezes botar no papel, que nem todo mundo consegue se orientar por ali, talvez dificulte um pouco mais. Com o especialista, com o nutricionista com o indivíduo, seria melhor. É aquele profissional específico, no caso, o nutricionista, ta procurando ensinar eles com detalhes, o que acontece. Mostrando talvez receitas, opções de alimentação, de dieta. A gente fala, mas não aprofunda, entendeu? A gente orienta, mas às vezes eles nem leva muito em consideração. Não que os funcionários do PSF não são bons, são! Falo de mudança de orientação nutricional, do que a gente conhece. Essa orientação, acho que seria mais eficaz para este paciente. A gente sente falta do nutricionista. Eu acho muito importante"

\section{Discurso do sujeito coletivo 4.6}

"Prá falar em promoção da saúde você teria que trabalhar com essas ações (educativas) muito ampliadas e também com vários segmentos da população, trabalhar a intersetorialidade, né? Tem que trabalhar com a cultura, tem que trabalhar com a educação, juntamente com a saúde, com o ambiente, então a gente não chegou a este 
ponto não. Mas acho que tem que ampliar os espaços mesmo, pra sensibilizar. Então deveria de fazer um trabalho com mais intensidade e mais frequência. Isso assim, a gente tem que trabalhar isso. A questão coletiva, sabe? Em termo de mídia: o radio, televisão, né? Porque a gente sabe: a quantidade de hipertensos e diabéticos que a gente tem, a gente num sabe o que fazer com eles não. Eles vão aumentar cada vez mais. E tá aumentando a longevidade, e tá aumentando o risco da doença. Então eu acho que a gente tem que trabalhar isso. A questão coletiva mesmo. A gente deveria fazer mais campanhas durante o ano. Porque a gente faz muito pouca ação na comunidade. A participação deles às vezes é muito pouco. Alguns chegam: - ah, eu to com pressa, tem que assistir mesmo? Então não tem essa cultura do trabalho com o coletivo, da parte da educação, ele ainda não tem essa importância. Teria que ter um universo maior deste coletivo prá ter a prevenção mesmo. Então a gente acaba fazendo um pouco. A gente não tem essa apropriação ainda." 


\section{ANEXO 3: DISCURSO DO SUJEITO COLETIVO - MANUSCRITO 2}

\section{Questão 1}

\section{Discurso do sujeito coletivo 1.1a}

Logo de cara eu aponto dois fatores: o cultural, que é questão de como comeu a vida inteira, e agora alguém vai dizer para ele, aos cinquenta anos de idade, que ele não pode mais comer sal e que ele vai ter que se adaptar a isso, né? E aí é muito complicado pra ele, culturalmente. Eu tenho dois grupos bem distintos: um grupo em que eu percebo que é assim, de uma cultura interiorana, que é um pouco que veio do interior e que trás estas características culturais da alimentação. E tem um outro grupo que tem uma condição social ruim. Eu acho que o fator econômico é importante também. A questão econômica, social, também está relacionada. O cara tem uma condição financeira ruim, e as comidas que ele tem acesso são comidas de uma qualidade ruim, também, né? Já tem o de poder aquisitivo melhor, que você pode ter acesso, pode comprar. Então, só não come se não quer. Às vezes depende muito da família que nós vamos visitar, porque tem família que tem a condição social melhor, que não aceita tanto a visita do agente, entendeu? Fala que não precisa, que tem plano, essas coisas. Agora, pessoa já de baixa renda eles aceitam com mais facilidade, fica mais fácil pra passar informação. Por fatores socioeconômicos, não tem condições. Têm pessoas que hoje eles não têm o que comer, entendeu? É família que tem diabético e hipertenso, uma criança de um ano. Às vezes não tem condições de ta comprando aquela alimentação adequada. Comer bem é caro, é muito caro. Então eu sinto que a dificuldade é financeira, às vezes ele não tem condição de comprar todos os dias a verdura. Então acaba no feijão com arroz. Porque cinco quilos de arroz é sete reais. Cê vai comprar dois quilos de batatinha ou mais, uma verdura, uma folha, você compra pouco e não alimenta. Cê tem que pagar em dia e o dinheiro não dá mais. Eu vejo muitos pacientes que são bem carentesinhos e passa isto para nós. Outro ponto da questão social é educacional mesmo. Eu vejo que a pessoa que geralmente tem uma informação maior, mais escolaridade, tem mais facilidade de se adaptar aquela situação. Então, se ela for um diabético ela aceita mais fácil ter que cortar alguma coisa, começar uma dieta, começar fazer exercício, entendeu? Que aqueles que têm menos escolaridade. Uma coisa que a gente tem muita dificuldade é o hipertenso idoso, analfabeto, que não consegue tomar o remédio sozinho, e não tem ninguém da família para tomar conta. Acaba tomando o remédio de forma errada. Com pouco estudo eles se automedicam. Então eu acho que no geral, a pessoa que tem mais informação, tem mais escolaridade, fica mais fácil. Esses aí são os que conseguem 
controlar. Eu acho que isso influencia muito também, entendeu? Então isso ai vem acarretar essas doenças. Mais pobre menos recurso. Isso que acarreta mais essas doenças.

\section{Discurso do sujeito coletivo 1.2a}

O que eu penso: nós temos muitos pacientes rebeldes, que nós estamos batendo naquela tecla, estamos sempre orientando, conversando. A maioria dos pacientes não faz uma dieta adequada. Por mais que você fale. O diabético então é o mais rebelde de todos. Tem paciente, assim, que é muito "relutivo". Você orienta, orienta, mostra, senta, explica e é assim, não sei o que passa pela cabeça deles. Os pacientes rebeldes, eles não escutam a gente por mais que a gente fala. È um paciente muito difícil de aderir a tratamento novo. A gente não consegue de jeito nenhum. Não consegue controlar a dieta, não consegue controlar o sal, a diabetes. Eu vejo a dificuldade no começo, que a pessoa é difícil mudar aqueles hábitos que ela já tem. Então a pessoa está acostumada a ter um ritmo de vida e ela quando descobre que tem que mudar, entendeu? Olha, muitas vezes é a teimosia mesmo porque a minha área é uma área nobre, uma área boa e eu já cheguei na casa de paciente com a auxiliar pra verificar a glicose dele e a pressão e ele simplesmente entrou lá dentro pegou um pote de paçoca começou a comer e ofereceu a gente ainda. É muito difícil mexer com esse pessoal. Eles são teimosos.

\section{Discurso do sujeito coletivo 1.3a}

Existe muito o paciente que gosta muito do médico, é centrado no médico. Se têm que ir para lá (para o grupo), eles só vão porque tem uma consulta junto. Ficam esperando acabar a conversa, para depois ir pro médico. Eles não estão com o objetivo na prevenção. Eles estão querendo a consulta médica. Só vem mesmo no dia da consulta, pega o remédio e vai embora. Medir pressão é difícil, eles só medem quando vem à consulta. Então a gente orienta: - se pudesse estar vindo mais vezes para medir pressão, pra controlar a glicose, pra ver como que ta a taxa. Eles só vêm mesmo pegar remédio, e pronto. Só tomar os remédios, acha que está tudo bem, não tem necessidade de ficar ouvindo ninguém falando. É a questão da medicação que ele incorpora na vida dele: - Eu vou me privar de comer o que eu gosto se tem remédio pra tomar? Eu tomo remédio já pra isso, pra tratar da minha hipertensão. Eu não preciso me privar, deixar de comer isso ou aquilo. Porque diabético, a maior parte do tempo ele é assintomático. Então ele pensa assim: eu to bem, vou comê, e tomando o remédio controla. Outra situação é que eles acham que é assim, que a medicação de hipertensão é igual à medicação de dor: eu 
to sentindo dor, então agora eu tomo um remédio, mas se eu não to com dor, pra que que eu tenho que tomar mais remédio? É mais no curativo que no preventivo. É uma cultura mesmo. Então eu acho que o grande desafio que a gente tem é lidar com esta cultura que eles têm e que é nossa. É uma grande dificuldade!

\section{Discurso do sujeito coletivo 1.4a}

A maioria dos nossos pacientes são pessoas idosas, entendeu? E eles já têm aquele habito de muito tempo. Tem toda uma vida com aqueles mesmo hábitos, as mesmas coisas. Acho que é a principal dificuldade do lado deles: essa resistência em mudar os hábitos. Porque já vem de uma cultura. Então a cultura do povo é difícil de você mudar. Não é uma coisa assim duma hora para outra, tem que ser aos poucos. Na medida, devagarzinho. É um trabalho assim tipo formiguinha, até você conseguir um resultado. Então cada dia você luta um pouquinho, até a pessoa aderir. E muitos, por serem idosos, têm a questão da medicação. Em pessoas de mais idade, então que que acontece? É muita medicação! A dificuldade de adesão tem um pouco da questão da dificuldade de entender certas coisas, assimilar sobre a medicação, tá absorvendo essas coisas, os horários, as quantidades. Alguns, às vezes, sem acompanhamento familiar a gente percebe que têm dificuldades. Num tem uma pessoa pra ta do lado orientando ou ajudando a tomar essas medicações. Muitas pessoas na área da gente precisam de cuidador. Para as mulheres, e as pacientes são mais idosas, elas não tem cuidador. Às vezes tem parente, mas que trabalha um tempo,naquele tempo para ta ficando ali com eles. Esta é uma dificuldade. Então você tem que estar ali mais vezes para saber realmente se está fazendo aquilo certo, se ta tomando remédio. A família às vezes deixa assim: ah, o agente vem aí e te orienta da forma que ele achar melhor. Então a gente vai mais vezes nestas casas. A gente ta em contato pelo menos uma ou duas vezes por semana. Olha, eu vou falar uma coisa pra você, eles são idosos, tem o calor, tem artrite, tem artrose. Muitas vezes eu falo: - Dona fulana, mas a senhora pode depois do trabalho, à tardinha, colocar o pé para cima, descansar e depois ir à Unidade para medir a pressão, ver se está tudo bem. Eu falo que a Unidade fica aberta até às oito, nove horas. Mas é difícil. Não é distancia, o problema não é a distancia. Eu acho que a Unidade é muito próxima. Então eu acho que é comodismo. Eles acham que eles envelheceram, então, numa certa idade ele perde a motivação. É um dos fatores também. E pra mudar isso em uma pessoa idosa, até por questão assim de teimosia deles mesmo, é muito difícil. 


\section{Discurso do sujeito coletivo 1.5a}

Eu acho que é difícil para qualquer um, né? Imagina você descobrir: você adora doce e aí descobre que é diabético, não pode mais comer doce; eu nem sei, mas eu acho que é muito complicado. Eu, se fosse diabético, eu ia ter uma grande dificuldade de fazer uma alimentação restrita de açúcar, de doce. É aquilo sobre a dieta, que é uma coisa assim que eles até falam: - Ah! Eu estou diminuindo o sal! Mas se a gente for investigar os motivos da carne-seca que eles gostam muito... Mudar hábito alimentar é difícil, tem aquele temperozinho com que ele cozinha, tem os restaurantes de fast food logo ali. Por exemplo, tem uma mulher na nossa área que ela faz salgado, entendeu? Ela acha dificílimo por ela trabalhar nisto. É como se fosse uma droga. É igual à gente. Eu por exemplo: sou acostumada com o café. Aí eu vejo a dificuldade que é fazer diminuir. Para os homens dieta, bebida e abstinência de alguns alimentos, do cigarro, é o mais difícil. Eu acho que são dificuldades bem comuns, de uma forma geral do hipertenso e do diabético, a dificuldade da dieta, da disciplina da atividade física.

\section{Discurso do sujeito coletivo 1.6a}

Olha, eu penso que às vezes é questão de desconhecimento mesmo. De não ter noção do risco, quando não tem o controle da doença, o risco da gravidade das complicações. Por exemplo: às vezes eles acham que comer legume, verdura e fruta, tá bom. E pode comer de tudo!? Nem tudo de verdura, legume, fruta é indicado. Tem o índice glicêmico diferente entre os alimentos. Talvez eles desconheçam também um pouco do que pode acarretar para eles as doenças, a gravidade, as consequências das ações deles. Mas eu acho que o principal é a falta de consciência deles mesmo. Não acho que é falta da gente, profissional de saúde, chegar não. Porque a informação chega. Eu acho que é falta de consciência mesmo. E acho que eles são um pouco desligados. Por mais que a gente oriente todos os mitos, se a pessoa não controla o que acontece, quais as complicações, consequências, o futuro disso, como vai virar? É como eu falei: têm uns sem consciência mesmo Eu acho que isto talvez falte um pouco para estes pacientes.

\section{Questão 2}

\section{Discurso do sujeito coletivo 1.1b}

Eu penso assim: a gente não tem este retorno porque a educação não está ali sedimentada, não está fortalecida. A gente sabe que a educação de saúde é parte do tratamento da hipertensão e diabetes, não é opcional. O profissional não tem essa 
apropriação nem essa cultura, não reconhece isso como tratamento. Isso eu acho muito complicado. A gente fala, fala, e tem a impressão que na prática pouca coisa fica. Só de você falar, às vezes eu não vejo resultado tão significativo assim, entendeu? Então, na minha opinião, tem que ter algo mais, de outra forma, a formação mesmo. Senão fica impositivo. Processo de educação é a longo prazo, deve ser feito a todo momento, em todo contexto, a qualquer momento. Tem que levar à reflexão, ao questionamento. Eu acho que a gente poderia organizar isso. A gente teria que contar com a equipe toda. Tudo faz parte do tratamento.

\section{Discurso do sujeito coletivo 1.2b}

Planejamento. O mais difícil é este espaço para sentar e planejar. Eu acho que esta é a maior dificuldade. A gente precisaria é fazer essa programação junto, com o grupo todo, pra ver como organizar essas oficinas. A gente teria que contar com a equipe toda. Planejamento mais participativo. Porque são várias equipes, então assim, muitas vezes a equipe não sabe o que a outra tá fazendo, poderia organizar essas oficinas juntas. Que que a gente vai falar? Que recursos a gente vai usar pra abordar a educação nutricional? Qual recursos a gente vai usar pra abordagem da atividade física? Fulano,quer falar sobre isto? Sobre aquilo? Deveria ter mais tempo para fazer, para você ver mudanças. Deveria ser mais elaborado.

\section{Discurso do sujeito coletivo 1.3b}

Prá gente, o que eu acho que mais pesa é o espaço físico. Porque a gente tem que ficar se deslocando. Quando a gente faz aqui, não é adequado. Tivemos a ideia de fazer na comunidade. Agora tá tendo uma lei aí, que não podemos atender fora da Unidade de Saúde. Nós vamos trazer os grupos para cá. Só que não comporta. A Unidade não comporta essa galera toda. Com sete equipes, mais as especialidades, nós não vamos ter condição de atender e fazer revisão com esse pessoal. Se a gente quiser a gente vai fazer apenas a reunião de hiperdia, mas não pode fazer a consulta. E os pacientes disseram: se não tiver a consulta ele não vai. Fica acostumado sempre a ir porque tem a consulta depois. Se não tiver ele não vai. Todos os de bairro X já falaram isso. E eu, inclusive não quero nem ir. Porque olha, eu tenho todo um vínculo com eles, pessoal, profissional até, muitas vezes. E eu tá lá e não posso nem olhar uma ferida, não posso nada, é proibido. $O$ ato tem que ser simplesmente educativo. É lei do CFM. Não podemos. Porque não tem estrutura, não paga a exposição do profissional. Era cômodo para gente e para eles. Porque desafogava um pouco a Unidade, mas não vai poder fazer isso mais. Então 
realmente nós temos essa dificuldade. Então o que eu acho que mais dificulta para a gente é o espaço físico.

\section{Discurso do sujeito coletivo 1.4b}

Na minha opinião, teria que ter outros profissionais envolvidos pra planejar e mesmo pra estar atuando. Eu acho muito importante ter um profissional na equipe, um nutricionista, porque, muitos dos nossos pacientes, ou tão com sobrepeso ou tão com um grau de obesidade. Porque a gente tem várias situações, tem pacientes diabéticos, tem renal também. Tem alguns assuntos que não é muito fácil. Por exemplo, a questão da avaliação nutricional, isso não é fácil pra gente. Questão de apropriação mesmo. Não tem essa apropriação por parte do profissional. $O$ que a gente faz são orientações básicas, ok? Mas, então a gente fica a desejar, carente por não ter profissionais específicos, entendeu? Eles poderiam estar também organizando essa educação lá na comunidade, nos espaços que ele tem lá. Não vou dizer um por equipe, se não tiver condição de ter por equipe, que ao menos trabalhássemos juntos na construção de oficinas, para formular estes instrumentos, para que a gente tomasse conta de estar orientando de uma forma adequada. 


\section{CURRÍCULO LATTES}

\section{Ana Maria Bartels Rezende}

Graduada em Nutrição pela Universidade Federal de Viçosa (1984), com especialização em Administração dos Serviços de Saúde - Administração Hospitalar e Saúde Pública, pela Universidade de Ribeirão Preto (1987) e mestrado em Extensão Rural pela Universidade Federal de Viçosa (1990). Experiência na área de Nutrição Humana com ênfase em Saúde Coletiva. Doutoranda do Programa de Nutrição em Saúde Pública da USP Universidade de São Paulo. Desde 2000 é coordenadora e professora do Curso de Nutrição do Centro Universitário Vila Velha - UVV, sendo responsável por disciplinas e estágios curriculares da área de Nutrição e Dietética e Nutrição em Saúde Coletiva. Desenvolve atividades de extensão e pesquisa, principalmente sobre os temas: segurança alimentar e nutricional, saúde e nutrição de coletividades sadias e enfermas e educação nutricional. (Texto informado pelo autor)

Última atualização do currículo em 22/03/2011

Endereço para acessar este CV:

http://lattes.cnpq.br/9268900700640115

\section{Certificado}

pelo autor em

22/03/11

\section{Dados pessoais}

Nome Ana Maria Bartels Rezende

Nome em citações bibliográficas REZENDE, A. M. B.

Sexo Feminino

Endereço profissional CENTRO UNIVERSITÁRIO VILA VELHA, COORDENAÇÃO DE NUTRIÇÃO. Rua Comissário José Dantas de Melo, 21, Biomédicas Boa Vista 29102-770 - Vitoria, ES - Brasil

Telefone: (027) 33202070 Fax: (027) 33202078

URL da Homepage: $\underline{\text { www.uvv.br }}$

\section{Formação acadêmica/Titulação}

1985 - 1990 Mestrado em Extensão Rural (Conceito CAPES 4) .

Universidade Federal de Viçosa, UFV, Brasil.

Título: Mediadores da Relação entre Estado Nutricional e, Ano de Obtenção: 1991.

Orientador: José Solon Guerreiro.

Bolsista do(a): Conselho Nacional de Desenvolvimento Científico e

Tecnológico, ,

Grande área: Ciências da Saúde / Área: Saúde Coletiva.

1986 - 1987 Especialização em Administração dos Serviços de Saúde . (Carga Horária: 700h).

Universidade de Ribeirão Preto, UNAERP, Brasil. 


\section{Ana Maria Cervato-Mancuso}

Possui graduação em Nutrição pela Universidade de São Paulo (1983), mestrado em Saúde Pública pela Universidade de São Paulo (1995) e doutorado em Saúde Pública pela Universidade de São Paulo (1999) realizando estágio do doutorado na Universidade de Barcelona (Espanha). Atualmente é professor doutor da Universidade de São Paulo. Tem experiência como nutricionista em Nutrição em Saúde Pública e no ensino superior na área de Saúde Coletiva, com ênfase em Saúde Pública, atuando principalmente nos seguintes temas: educação nutricional, formação profissional, segurança alimentar e nutricional, idosos, diabetes mellitus e comportamento. (Texto informado pelo autor)

Última atualização do currículo em 23/03/2011

Endereço para acessar este CV: http://lattes.cnpq.br/0558045570548264

Certificado

pelo autor em

23/03/11

Dados pessoais

Nome Ana Maria Cervato-Mancuso

Nome em citações CERVATO, A. M.; CERVATO-MANCUSO, A.M. bibliográficas

Sexo Feminino

Endereço Universidade de São Paulo, Faculdade de Saúde Pública, Departamento profissional de Nutrição.

Av dr Arnaldo, 715

Cerqueira Cesar

01246-904 - Sao Paulo, SP - Brasil

Telefone: (11) 30617705 Fax: (11) 30617736

URL da Homepage: http://www.fsp.usp.br

\section{Formação acadêmica/Titulação}

1995 - 1999 Doutorado em Saúde Pública (Conceito CAPES 5) .

Universidade de São Paulo, USP, Brasil.

Título: Intervenção nutricional educativa: promovendo a saúde de adultos e idosos em Universidades Abertas à Terceira Idade, Ano de Obtenção: 1999.

Orientador: $\mathbf{y}$ Maria de Fátima Nunes Marucci.

Palavras-chave: educação nutricional; promoção da saúde; terceira idade.

Grande área: Ciências da Saúde / Área: Saúde Coletiva / Subárea: Saúde Pública. 
